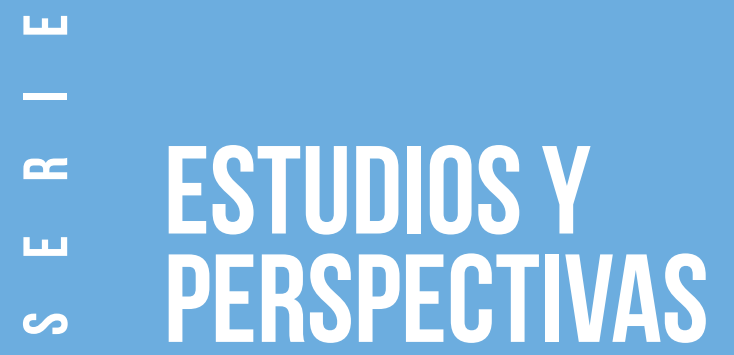

\title{
La tributación sobre las altas rentas en América Latina
}

Juan Carlos Gómez Sabaíni

Darío Rossignolo 


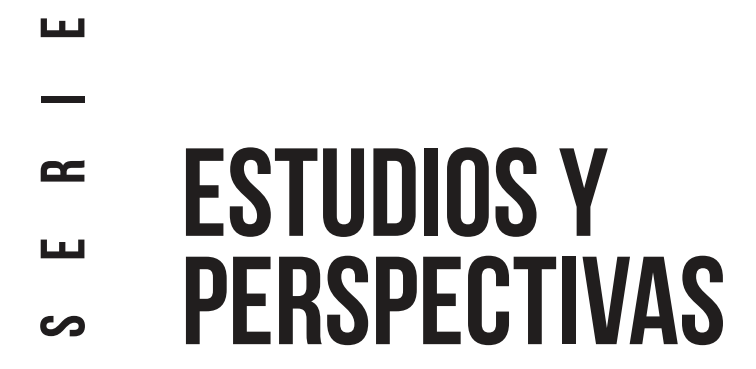

13

\section{OFICINA DE LA CEPAL EN MONTEVIDEO}

\section{La tributación sobre las altas rentas en América Latina}

Juan Carlos Gómez Sabaíni

Darío Rossignolo

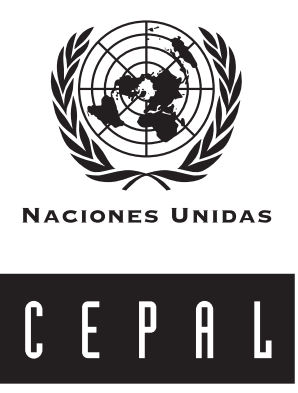


Este documento fue preparado por Juan Carlos Sabaini y Darío Rossignolo, consultores de la Comisión Económica para América Latina y el Caribe (CEPAL), en el marco del Convenio de cooperación técnica entre la CEPAL y el Gobierno de Uruguay a través del Ministerio de Economía y Finanzas.

El informe fue presentado en el taller Desigualdad y tributación a los altos ingresos, organizado en forma conjunta por la Comisión Económica para América Latina (CEPAL), el Centro de Estudios Fiscales del Uruguay (CEF) y la Agencia Española de Cooperación Internacional para el Desarrollo en Montevideo (AECID).

Las opiniones expresadas en este documento, que no ha sido sometido a revisión editorial, son de exclusiva responsabilidad de los autores y pueden no coincidir con las de la organización.

Publicación de las Naciones Unidas

ISSN 1727-8686

LC/L.3760

Copyright $@$ Naciones Unidas, enero de 2014. Todos los derechos reservados

Impreso en Naciones Unidas, Santiago de Chile

Los Estados miembros y sus instituciones gubernamentales pueden reproducir esta obra sin autorización previa. Solo se les solicita que mencionen la fuente e informen a las Naciones Unidas de tal reproducción. 


\section{Índice}

I. La tributación en América Latina y las dificultades para gravar a las altas rentas .............. 11

A. La estructura tributaria en los países de la región y las herramientas disponibles .................. 11

B. El Impuesto a la Renta y su potencialidad como instrumento de recaudación........................ 15

C. Las limitaciones que enfrenta el Impuesto a la Renta Personal en América Latina................ 18

1. El comportamiento de las tasas legales ..................................................................... 18

2. La estrechez de las bases imponibles del IRPN y sus efectos en la equidad................... 21

3. La composición de las fuentes de rentas alcanzadas por el impuesto .............................. 24

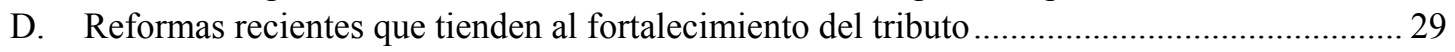

E. La tributación patrimonial y las debilidades estructurales que limitan su desarrollo.............. 30

II. La imposición a la renta y sus efectos en la distribución del ingreso

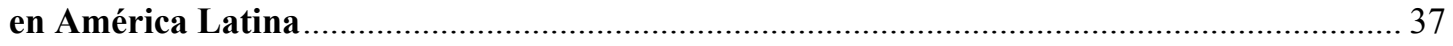

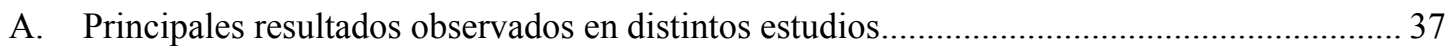

B. Las limitaciones que plantea la información de las encuestas de hogares ...............................46

C. El ajuste por subdeclaración de ingresos utilizado en distintos estudios

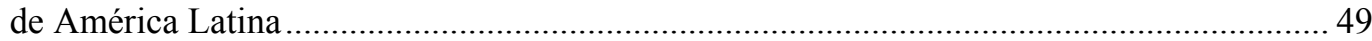

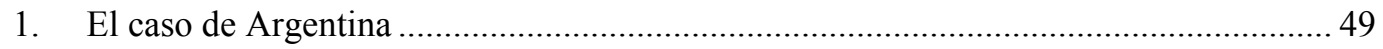

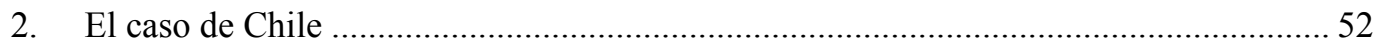

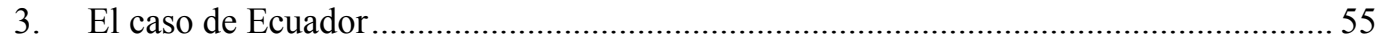

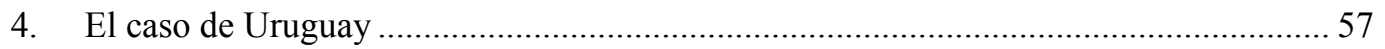

III. La importancia de las altas rentas y las posibilidades de su medición .................................. 61

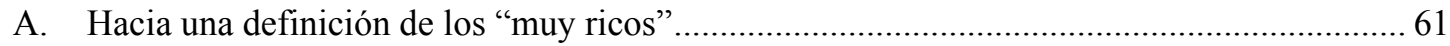

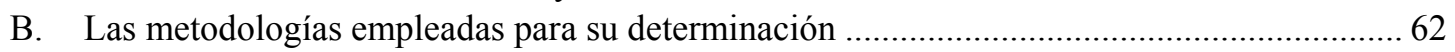

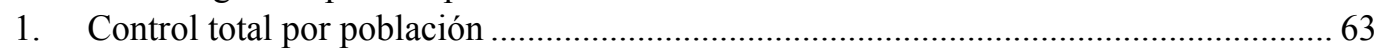

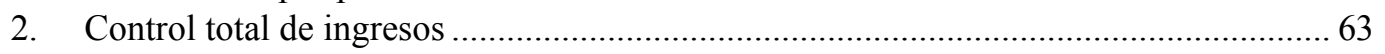

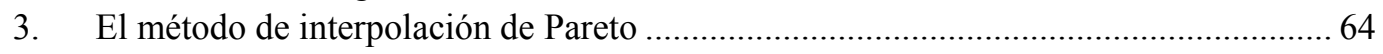


C. Las limitaciones metodológicas para la estimación de las altas rentas ...................................65

D. Los efectos de las tasas marginales máximas en la concentración de los ingresos .................66 66

IV. Principales resultados de los estudios sobre las altas rentas en la distribución del ingreso

A. El contexto internacional: grandes avances en la comprensión y cuantificación

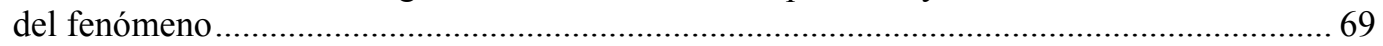

B. Las consecuencias del ajuste de los altos ingresos en la desigualdad global .......................... 77

C. La situación en América Latina: escasos análisis y limitados resultados observados............. 79

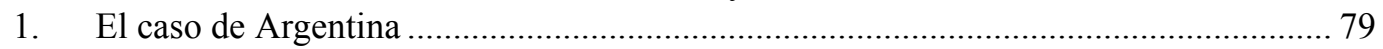

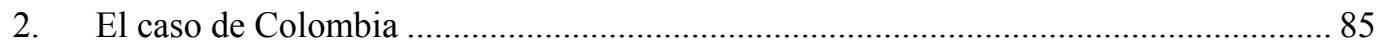

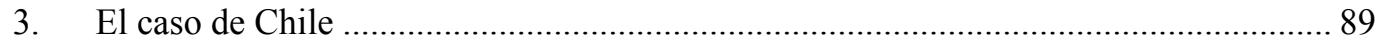

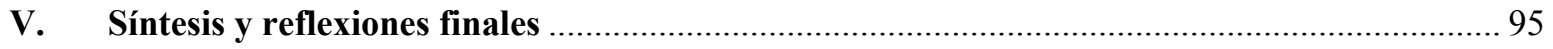

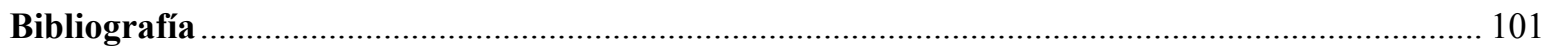

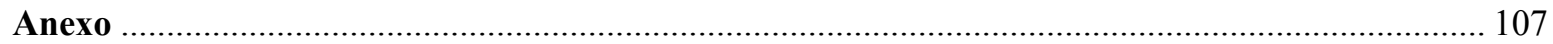

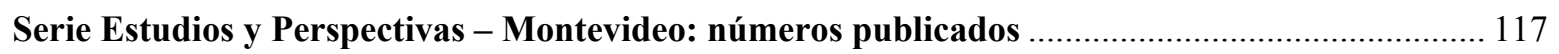

Cuadros

CUADRO 1 EVOLUCIÓN DE LA PRESIÓN TRIBUTARIA EN AMÉRICA LATINA, PROMEDIOS NO PONDERADOS ………………...................................................... 12

CUADRO 2 RESULTADOS DE ESTIMACIONES SOBRE RECAUDACIÓN EFECTIVA Y POTENCIAL DEL IMPUESTO A LA RENTA Y DEL IRPF PARA VARIOS PAÍSES DE AMÉRICA LATINA ………….................................................17

CUADRO 3 ESTRUCTURA DE LA RECAUDACIÓN DE LOS IMPUESTOS PATRIMONIALES EN PAÍSES DE AMÉRICA LATINA Y LA OECD, AÑO 2010 ………………………........31

CUADRO 4 RESULTADOS DE ESTUDIOS SOBRE INCIDENCIA DISTRIBUTIVA DEL IMPUESTO A LA RENTA DE PERSONAS NATURALES EN AMÉRICA LATINA

CUADRO 5 ARGENTINA: COMPARACIÓN DE LOS EFECTOS DISTRIBUTIVOS DEL IMPUESTO A LA RENTA PARA DIFERENTES PERÍODOS ...................................4

CUADRO 6 INGRESO INDIVIDUAL PROMEDIO DE LAS DOS PERSONAS DE MAYORES INGRESOS INDIVIDUALES Y PROPORCIÓN DE INGRESOS LABORALES ..............48

CUADRO 7 ARGENTINA: SUBDECLARACIÓN EN LA EPH, ESTIMACIONES REALIZADAS

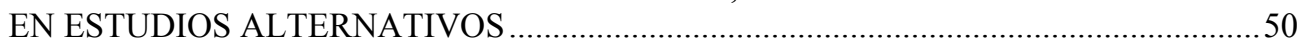

CUADRO 8 ARGENTINA: COEFICIENTES DE AJUSTE POR SUBDECLARACIÓN DE INGRESOS, FACTORES DE CORRECCIÓN ............................................................50

CUADRO 9 ARGENTINA: ESQUEMA DE LA DISTRIBUCIÓN DEL INGRESO,

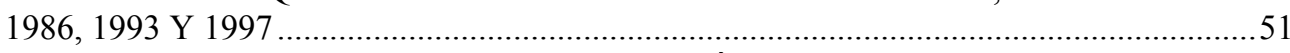

CUADRO 10 ARGENTINA: ESQUEMA DE LA DISTRIBUCIÓN DEL INGRESO, 1997 .....................52

CUADRO 11 ARGENTINA: ESQUEMA DE LA DISTRIBUCIÓN DEL INGRESO, 2008 Y 2010.

CUADRO 12 CHILE: COEFICIENTE DE AJUSTE DE LOS INGRESOS MEDIDOS EN LA ENCUESTA CASEN 1994 Y 1996.

CUADRO 13 CHILE: FACTORES DE AJUSTE DE LOS INGRESOS DE LOS HOGARES, SEGÚN DECILES DE LA DISTRIBUCIÓN DEL INGRESO PER CÁPITA AJUSTADO...............54

CUADRO 14 CHILE: ESQUEMA DE LA DISTRIBUCIÓN DEL INGRESO .......................................55

CUADRO 15 COEFICIENTES DE AJUSTE POR SUBDECLARACIÓN DIFERENCIALES POR FUENTE ......................................................................................................... 56

CUADRO 16 INGRESO CORRIENTE CON VALOR LOCATIVO EN AMBAS ENCUESTAS SEGÚN DECILES DEL INGRESO PER CÁPITA DEL HOGAR, JUNIO 1994-MAYO 1995 
CUADRO 17 RELACIÓN ENTRE LOS INGRESOS DE LA EGIH SOBRE LOS DE LA ECH POR TIPO DE INGRESO SEGÚN ÁREA GEOGRÁFICA,

MONTEVIDEO E INTERIOR .58

CUADRO 18 CONTRIBUCIÓN A LA DIFERENCIA DE LOS INGRESOS EN AMBAS ENCUESTAS, POR TIPO DE INGRESO SEGÚN ÁREA GEOGRÁFICA, MONTEVIDEO E INTERIOR

CUADRO 19 PROMEDIO DE LOS INGRESOS DE LOS PERCEPTORES POR QUINTILES, SEGÚN FUENTES DEL INGRESO PER CÁPITA DEL HOGAR, MONTEVIDEO, JUNIO 1994-MAYO 1995.

CUADRO 20

PROMEDIO DE LOS INGRESOS DE LOS PERCEPTORES POR QUINTILES, SEGÚN FUENTES DEL INGRESO PER CÁPITA DEL HOGAR, INTERIOR, JUNIO 1994-MAYO 1995.

CUADRO 21 COMPARACIÓN DE LA PARTICIPACIÓN DE LOS TRAMOS

DE INGRESOS ELEVADOS. .76

CUADRO 22 LA CONCENTRACIÓN DE INGRESOS EN EL TOP 1\% Y EL CRECIMIENTO DEL INGRESO PROMEDIO EN ESTADOS UNIDOS 77

CUADRO 23 LA EVOLUCIÓN DEL ÍNDICE DE GINI EN ESTADOS UNIDOS, COMPARACIÓN CON ENCUESTAS DE HOGARES 78

CUADRO 24 ARGENTINA: COMPARACIÓN DE LA PARTICIPACIÓN DE LOS TRAMOS DE INGRESOS ELEVADOS . .81

CUADRO 25 ARGENTINA: COMPARACIÓN POR TRAMOS DE INGRESOS GRAVADOS, AFIP Y EPH.

CUADRO 26

LA EVOLUCIÓN DEL ÍNDICE DE GINI EN COLOMBIA, COMPARACIÓN CON ENCUESTAS DE HOGARES

CUADRO 27

CHILE: PARTICIPACIONES EN EL INGRESO TOTAL.

CUADRO A.1

EVOLUCIÓN DE LAS TASAS MARGINALES MÍNIMAS, PAÍSES

Y AÑOS SELECCIONADOS DE AMÉRICA LATINA. 108

CUADRO A.2

EVOLUCIÓN DE LAS TASAS MARGINALES MÁXIMAS, PAÍSES

Y AÑOS SELECCIONADOS DE AMÉRICA LATINA. 108

CUADRO A.3 EVOLUCIÓN DE LOS NIVELES DE INGRESO GRAVABLE MÁXIMOS, AMÉRICA LATINA, PAÍSES Y PERÍODOS SELECCIONADOS 109

CUADRO A.4 EVOLUCIÓN DE LOS NIVELES DE INGRESO GRAVABLE MÍNIMOS, AMÉRICA LATINA, PAÍSES Y PERÍODOS SELECCIONADOS

CUADRO A.5

CHILE: TRATAMIENTO TRIBUTARIO DE LOS INTERESES

CHILE:TRATAMIENTO TRIBUTARIO DE LOS DIVIDENDOS 111

CUADRO A.7

CHILE:TRATAMIENTO TRIBUTARIO DE LOS RENDIMIENTOS EN VEHÍCULOS DE INVERSIÓN COLECTIVA

CUADRO A.8 ARGENTINA: TRATAMIENTO DE LOS PRINCIPALES TIPOS DE RENTAS FINANCIERAS OBTENIDAS EN EL PAÍS SEGÚN EL SUJETO QUE LAS OBTIENE

CUADRO A.9 URUGUAY: TRATAMIENTO DE LOS PRINCIPALES TIPOS DE RENTAS DEL CAPITAL .

CUADRO A.10 TRATAMIENTO DE LOS PRINCIPALES TIPOS DE RENTAS FINANCIERAS SELECCIONADAS, LOS CASOS DE ECUADOR, MÉXICO Y PERÚ.

CUADRO A.11 PRINCIPALES REFORMAS DEL IMPUESTO SOBRE LA RENTA, PAÍSES DE AMÉRICA DEL SUR

CUADRO A.12 PRINCIPALES REFORMAS DEL IMPUESTO SOBRE LA RENTA, CENTROAMÉRICA Y REPÚBLICA DOMINICANA.

\section{Gráficos}

GRÁFICO 1 EVOLUCIÓN DE LA PRESIÓN TRIBUTARIA EN AMÉRICA LATINA, Y LA OECD, PROMEDIOS NO PONDERADOS .14

GRÁFICO 2 COMPOSICIÓN DE LOS RECURSOS TRIBUTARIOS EN AMÉRICA LATINA Y LA OECD, PROMEDIOS NO PONDERADOS 
GRÁFICO 3 EVOLUCIÓN DEL “ESFUERZO TRIBUTARIO” DEL IMPUESTO

A LA RENTA Y EL IRPF.

GRÁFICO 4

LA EVOLUCIÓN DE LAS TASAS MARGINALES MÁXIMAS

Y LA RECAUDACIÓN DEL IRPN.

GRÁFICO 5

LA EVOLUCIÓN DE LAS TASAS MARGINALES MÍNIMAS

Y LA RECAUDACIÓN DEL IRPN.

GRÁFICO 6

RELACIÓN ENTRE LA RECAUDACIÓN DEL IRPN Y LAS TASAS

MARGINALES MÍNIMAS Y MÁXIMAS

GRÁFICO 7

EVOLUCIÓN DE LOS NIVELES DE INGRESO GRAVABLE MÍNIMOS

Y MÁXIMOS, AMÉRICA LATINA, PROMEDIOS PARA PAÍSES Y PERÍODOS

SELECCIONADOS EN MÚLTIPLOS DEL INGRESO PER CÁPITA....

GRÁFICO 8

ARGENTINA: DECLARACIONES JURADAS DEL IMPUESTO A LA RENTA

DE PERSONAS FÍSICAS, EVOLUCIÓN DE LA PARTICIPACIÓN DE LAS

PRESENTACIONES POR TRAMOS DE GANANCIA SUJETA A IMPUESTO

GRÁFICO 9

ARGENTINA: DECLARACIONES JURADAS DEL IMPUESTO A LA RENTA DE PERSONAS FÍSICAS, EVOLUCIÓN DE LA PARTICIPACIÓN DE LOS INGRESOS

GRAVADOS POR TRAMOS DE GANANCIA SUJETA A IMPUESTO....

GRÁFICO 10

ESTRUCTURA DEL IMPUESTO A LA RENTA PERSONAL EN PAÍSES

SELECCIONADOS DE AMÉRICA LATINA.

GRÁFICO 11

EJEMPLOS HIPOTÉTICOS DE DISTRIBUCIÓN DEL INGRESO Y NIVELES

DE MÍNIMOS.

GRÁFICO 12

EVOLUCIÓN DE LA RECAUDACIÓN DEL IRPN Y DEL INGRESO

PER CÁPITA...

GRÁFICO 13

RELACIÓN ENT

GRÁFICO 14 PER CÁPITA.

GRÁFICO 15

EVOLUCIÓN DE LA RECAUDACIÓN DEL IRPN Y LA DESIGUALDAD.....

GRÁFICO 16

RELACIÓN ENTRE LA RECAUDACIÓN DEL IRPN Y EL ÍNDICE DE GINI

GRÁFICO 17

GRÁFICO 18

A LA RENTA 1981-2012

CAMBIOS EN LAS PARTICIPACIONES DE LOS INGRESOS MÁS ELEVADOS

Y LAS TASAS MARGINALES MÁXIMAS DEL IRPN

GRÁFICO 19

PARTICIPACIÓN DE LOS TRAMOS DE INGRESOS MÁS ELEVADOS

EN PAÍSES SELECCIONADOS

GRÁFICO 20

DESCOMPOSICIÓN DE LOS TRAMOS DE INGRESOS MÁS ELEVADOS

GRÁFICO 21

PARA PAÍSES SELECCIONADOS

COMPOSICIÓN DE LOS INGRESOS DEL PERCENTIL DE INGRESOS

MÁS ELEVADOS

GRÁFICO 22

ARGENTINA: EVOLUCIÓN DE LOS TRAMOS DE INGRESOS

MÁS ELEVADOS

GRÁFICO 23

ARGENTINA: PARTICIPACIÓN EN EL INGRESO TOTAL

GRÁFICO 24

GRÁFICO 25

ARGENTINA: EVOLUCIÓN DE LA PARTICIPACIÓN EN EL INGRESO TOTAL .......82

ARGENTINA: EVOLUCIÓN DEL COEFICIENTE DE GINI EPH Y AJUSTADO CON DATOS DE DECLARACIONES JURADAS DEL IMPUESTO A LA RENTA ..................83

GRÁFICO 26 ARGENTINA: COMPOSICIÓN DEL 1\% DE INGRESOS MÁS ELEVADOS ....................8

GRÁFICO 27

GRÁFICO 28

GRÁFICO 29

ARGENTINA: COMPOSICIÓN DEL 0,1\% DE INGRESOS MÁS ELEVADOS ................85

COLOMBIA: PARTICIPACIÓN EN EL INGRESO TOTAL, 1993-2010 ……....................86

GRÁFICO 30

COLOMBIA: PARTICIPACIÓN EN EL INGRESO TOTAL, 2006-2010.

COLOMBIA: LA EVOLUCIÓN DEL ÍNDICE DE GINI DE ENCUESTAS DE

HOGARES Y AJUSTADO CON DATOS DE DECLARACIONES JURADAS

DEL IMPUESTO A LA RENTA.

GRÁFICO 31

COLOMBIA: COMPOSICIÓN DEL 1\% DE INGRESOS MÁS ELEVADOS.. 
GRÁFICO 34 CHILE: EVOLUCIÓN DE LA PARTICIPACIÓN EN EL INGRESO TOTAL...................91

GRÁFICO 35 CHILE: LA EVOLUCIÓN DEL ÍNDICE DE GINI DE ENCUESTAS DE HOGARES Y AJUSTADO CON DATOS DE DECLARACIONES JURADAS DEL IMPUESTO

A LA RENTA

\section{Recuadros}

RECUADRO 1 ESTIMACIONES DE "ESFUERZO TRIBUTARIO”..... 16

RECUADRO 2 CONCEPTOS TEÓRICOS PARA EL ANÁLISIS DE INCIDENCIA DISTRIBUTIVA DE LOS TRIBUTOS. 



\section{Introducción}

Con posterioridad a las consecuencias económicas y sociales de la debacle económica internacional de 2008-2009, en la mayoría de los países desarrollados resurgió un antiguo debate respecto a quién debe soportar el peso y los costos de la necesaria recuperación de las economías domésticas. La respuesta a esta pregunta se ha concentrado en la posibilidad concreta de exigir un mayor esfuerzo de aquellos individuos que tienen un mayor patrimonio o que obtienen regularmente muy altos ingresos, y que por diversas razones no están contribuyendo de manera acorde al nivel de los mismos. Esto permitiría la obtención de nuevos recursos para el financiamiento de programas sociales que apuntalen la recuperación económica y llevaría a una mejora en la percepción de la sociedad respecto a los efectos de la política tributaria en sus consecuencias sobre la equidad distributiva.

En los países desarrollados, y en especial en los Estados Unidos en donde este tema se configuró como uno de los debates centrales más recientes, la disponibilidad de una gran cantidad de información acerca de los ingresos y el patrimonio de los hogares e individuos más ricos y —aún más importantede los impuestos que los mismos pagan anualmente, ha permitido la realización de una serie de estudios muy detallados y precisos acerca de los potenciales efectos (recaudatorios y distributivos) de una reforma impositiva que busque gravar de manera diferencial a los sectores de altas rentas.

Por el contrario, en los países de Latinoamérica este debate aun no está incorporado en la agenda de la discusión en materia de equidad distributiva. Adicionalmente, se carece por el momento de un indispensable contenido estadístico que haga factible, por un lado, un análisis específico en aquellos países donde se intenta dotar de mayor progresividad al sistema tributario vigente y, por el otro lado, una comparación coherente entre países de la región para evaluar la calidad y efectividad de las medidas aplicadas.

En líneas generales se observa una actitud de aceptación frente a las limitaciones estructurales que enfrenta la imposición directa en la región, como pueden ser la extensión de los sectores informales y las legislaciones tributarias vigentes, lo cual obliga a investigar cuáles son los principales obstáculos que se observan para dotar a este gravamen con una mayor participación en la recaudación total, al mismo tiempo que un mayor grado de progresividad.

El objetivo de este trabajo es efectuar un análisis sobre la evolución de la recaudación del impuesto a la Renta en América Latina, procurando relacionar las variaciones experimentadas en la 
presión tributaria con las variaciones en las bases imponibles y tasas impositivas acontecidas a lo largo del período analizado. Lo anterior incluye la discusión sobre la evolución de la distribución del ingreso, y contiene la presentación de los resultados y la descripción de la metodología de abordaje de la serie de estudios que han analizado la evolución de la concentración de los ingresos en distintas economías.

Para ello, el presente documento se estructura como sigue. Luego de esta breve introducción, se presentará la evolución de la recaudación del Impuesto a la Renta en América Latina, y la relación con la participación de los tramos de altos ingresos en la generación de los ingresos tributarios referidos. Además, se hará referencia a los factores más importantes que han limitado la capacidad recaudatoria del impuesto sobre la Renta en América Latina, analizando el comportamiento de las tasas legales, la amplitud de las bases imponibles y su composición. Asimismo, se analizarán los diferentes factores que podrían haber impactado en la evolución de los ingresos del impuesto sobre la Renta. En la mencionada descripción se incluirán: la evolución del ingreso per cápita; datos sobre la evolución de las tasas impositivas, mínimas y máximas; el comportamiento de los ingresos mínimos y máximos gravables y las reformas tributarias recientes que hayan afectado la recaudación del impuesto. La sección se completará con una referencia a la imposición patrimonial en los países de la región, en virtud de su potencial incidencia sobre los individuos de altos ingresos y las posibilidades de complementar la estructura de tributación sobre los ingresos ya mencionada.

En segundo lugar se presenta el impacto distributivo del impuesto a la Renta de Personas Físicas, a partir de los resultados de los estudios realizados, las consideraciones metodológicas y las cuestiones relacionadas con la información de base generalmente utilizada, las encuestas de hogares. A partir de sus debilidades en relación con la captación de altos ingresos, se presentan los diferentes procedimientos empleados en la literatura para ajustar los datos de las encuestas mediante ajustes por subdeclaración de ingresos.

El capítulo tercero presenta con detalle los estudios realizados con fines de medir la participación de los tramos de ingresos altos en la distribución de la renta, a partir de datos provenientes de declaraciones juradas de impuestos. Allí se plantean las consideraciones metodológicas realizadas para la delimitación cuantitativa de los "ricos", los "controles" totales, el método de interpolación que se utiliza para las estimaciones y las limitaciones que estos análisis llevan de suyo.

Los resultados de los estudios se muestran en el capítulo cuarto, en donde se introducen los datos de los trabajos realizados para los países avanzados, en mayor medida, y los relacionados con los escasos estudios existentes para América Latina, presentando resultados para Argentina, Colombia y Chile. La sección sexta concluye y presenta las reflexiones finales.

A lo largo del trabajo se presentarán lineamientos orientativos e hipótesis de trabajo sobre la importancia de estos sectores y su evolución, a través de correlaciones y estimaciones econométricas forzosamente simplificadas, debidas a la ausencia de este tipo de información en Latinoamérica. Una de las recomendaciones del trabajo estriba en fortalecer el conocimiento sobre la participación de los tramos de ingresos más elevados en la distribución de la renta, lo que ha avanzado de manera sustancial en los países avanzados y es desconocido para la mayoría de los países de América Latina. 


\section{La tributación en América Latina y las dificultades para gravar a las altas rentas}

\section{A. La estructura tributaria en los países de la región y las herramientas disponibles}

En una mirada de mediano plazo, puede afirmarse que la recaudación tributaria en América Latina ha evidenciado notables incrementos en su nivel y en su composición en las últimas décadas. La presión tributaria total, incluyendo contribuciones sociales, se ha estabilizado en niveles cercanos a superiores al 19\% del PBI alcanzados a partir de 2005, partiendo de niveles cercanos a los 14 a 16 puntos de la década 1990-2001.

Este aumento en la carga tributaria en la mayoría de los países de la región ha estado vinculado a una mayor preponderancia de los impuestos generales sobre bienes y servicios (IVA principalmente) y a la expansión de las bases imponibles generada por tres factores principales ${ }^{1}$ : a) un fuerte y acelerado proceso de crecimiento económico impulsado por el auge en los precios de las exportaciones de bienes primarios. b) la introducción de iniciativas novedosas como impuestos mínimos e impuestos a las transacciones financieras junto con la introducción y perfeccionamiento de impuestos sobre recursos naturales (windfall taxes) ${ }^{2}$; y c) diversas reformas a la estructura y administración tributaria.

Adicionalmente, la recaudación del impuesto a la Renta también ha experimentado un incremento de relevancia; la presión tributaria del impuesto a la Renta de Personas Jurídicas supera el 3\% del PBI en el período 2001-2011, cuando en la década anterior la misma alcazaba los 2 puntos del PBI. El impuesto

De acuerdo con Gómez Sabaíni, Jiménez y Rossignolo (2012).

A pesar de que la mayor parte de los ingresos procedentes de los recursos naturales se consideran como ingresos no tributarios, por lo que el aumento derivado del incremento de precios se observa principalmente en el aumento de la recaudación fiscal, hay una parte significativa de carácter tributario derivado del impuesto a la renta a las empresas del sector. 
a la Renta de Personas Físicas o Naturales ${ }^{3}$ se ha estabilizado en un nivel superior al $1 \%$ del PBI, a diferencia del período anterior, en el cual los valores eran inferiores al 1\% del PBI.

En cuanto a la estructura tributaria, el diseño de las reformas en las últimas dos décadas se basó en la búsqueda de mayor solvencia fiscal, dejando de lado otros objetivos centrales de la política tributaria. El comportamiento de la recaudación muestra que, en comparación con 1990-2001, en promedio, la presión tributaria ha crecido aproximadamente 2,9 puntos porcentuales para el total de recursos tributarios (a una tasa del 18\%) y alrededor de 2,7 puntos porcentuales en el último período (un $21,1 \%$ ) si se excluyen los recursos correspondientes a la seguridad social, lo que puede apreciarse en el cuadro 1.

\section{CUADRO 1}

\section{EVOLUCIÓN DE LA PRESIÓN TRIBUTARIA EN AMÉRICA LATINA, PROMEDIOS NO PONDERADOS}

\begin{tabular}{|c|c|c|c|c|c|c|c|}
\hline \multirow[b]{2}{*}{ Clasificación impuestos } & \multicolumn{5}{|c|}{ Presión tributaria } & \multicolumn{2}{|c|}{ Composición } \\
\hline & $\begin{array}{l}\text { Promedio } \\
1990-2001\end{array}$ & $\begin{array}{l}\text { Promedio } \\
2001-2011\end{array}$ & $\begin{array}{c}\text { Tasa } \\
\text { crecimiento }\end{array}$ & $\begin{array}{l}\text { Diferencia en } \\
\text { porcentaje }\end{array}$ & Explicación & $\begin{array}{l}\text { Promedio } \\
1990-2001\end{array}$ & $\begin{array}{l}\text { Promedio } \\
2001-2011\end{array}$ \\
\hline $\begin{array}{l}\text { Total ingresos tributarios } \\
\text { Ingresos tributarios }\end{array}$ & 13,00 & 15,63 & 20,3 & 2,63 & 92,2 & 83,1 & 84,6 \\
\hline directos & 3,59 & 5,27 & 46,8 & 1,68 & 58,8 & 22,7 & 28,4 \\
\hline $\begin{array}{l}\text { Impuestos sobre } \\
\text { ingreso, utilidades y } \\
\text { ganancias de capital }\end{array}$ & 3,06 & 4,22 & 37,8 & 1,16 & 40,6 & 19,6 & 22,7 \\
\hline Personas físicas & 0,88 & 1,15 & 30,0 & 0,27 & 9,3 & 5,6 & 6,2 \\
\hline $\begin{array}{l}\text { Corporaciones y } \\
\text { empresas }\end{array}$ & 2,09 & 2,94 & 40,9 & 0,85 & 29,9 & 13,4 & 15,8 \\
\hline No clasificables & 0,09 & 0,13 & 42,4 & 0,04 & 1,4 & 0,6 & 0,7 \\
\hline $\begin{array}{l}\text { Impuestos sobre la } \\
\text { propiedad }\end{array}$ & 0,49 & 0,73 & 48,6 & 0,24 & 8,4 & 3,0 & 4,0 \\
\hline $\begin{array}{l}\text { Otros impuestos } \\
\text { directos }\end{array}$ & 0,03 & 0,31 & 909,9 & 0,28 & 9,8 & 0,0 & 1,7 \\
\hline $\begin{array}{l}\text { Ingresos tributarios } \\
\text { indirectos }\end{array}$ & 8,92 & 10,01 & 12,3 & 1,10 & 38,4 & 57,1 & 54,3 \\
\hline $\begin{array}{l}\text { Impuestos generales } \\
\text { sobre bienes y servicios }\end{array}$ & 5,19 & 6,89 & 32,7 & 1,70 & 59,4 & 32,8 & 37,3 \\
\hline $\begin{array}{l}\text { Impuestos específicos } \\
\text { sobre bienes y servicios }\end{array}$ & 2,12 & 1,88 & $-11,5$ & $-0,24$ & $-8,5$ & 13,7 & 10,3 \\
\hline $\begin{array}{l}\text { Comercio y } \\
\text { transacciones } \\
\text { internacionales }\end{array}$ & 1,60 & 1,24 & $-22,2$ & $-0,35$ & $-12,4$ & 10,6 & 6,8 \\
\hline Otros indirectos & 0,01 & 0,01 & $-24,4$ & 0,00 & $-0,1$ & 0,1 & 0,0 \\
\hline Otros impuestos & 0,49 & 0,35 & $-29,2$ & $-0,14$ & $-5,0$ & 3,3 & 1,9 \\
\hline Contribuciones sociales & 2,62 & 2,84 & 8,5 & 0,22 & 7,8 & 16,9 & 15,4 \\
\hline $\begin{array}{l}\text { Total ingresos tributarios } \\
\text { (incluyendo contribuciones } \\
\text { sociales) }\end{array}$ & 15,62 & 18,47 & 18,3 & 2,86 & 100,0 & 100,0 & 100,0 \\
\hline
\end{tabular}

Fuente: Elaboración propia en base a CEPALSTAT y Database CIAT-IDB.

Uno de los fenómenos más significativos de la política tributaria del período bajo análisis en los países latinoamericanos ha sido el considerable aumento de la importancia de los impuestos generales sobre bienes y servicios (Impuesto al Valor Agregado o similares) dentro del total de los ingresos tributarios totales en la región. En el cuadro 1 se muestra un crecimiento del 32,7\% del peso relativo de dichos tributos en la estructura tributaria promedio a nivel regional, explicando alrededor del $60 \%$ del incremento en la carga tributaria total promedio. Se observa, además, que casi todo el aumento de

En este trabajo se considerarán como sinónimos el Impuesto a la Renta de Personas Físicas (IRPF) y el Impuesto a la Renta de Personas Naturales (IRPN), por un lado, y el Impuesto a la Renta de Personas Jurídicas (IRPJ) y el Impuesto a la Renta de Sociedades, por el otro. 
la ponderación porcentual de este tipo de impuestos se dio durante la década del noventa a raíz de las reformas tributarias que ampliaron la base tributaria y aumentaron las alícuotas generales de este tipo de gravámenes.

Asimismo, se puede apreciar que el crecimiento de los impuestos sobre los ingresos y las ganancias de capital constituye el segundo factor que explica el incremento en la carga tributaria regional durante las últimas dos décadas. Estos tributos mostraron un aumento en su participación porcentual dentro del total de recursos tributarios superior al 38\%, pasando de representar un promedio del 19,6\% para el período 1990-2001 al 22,7\% promedio entre 2001 y 2011.

Entre los incrementos mencionados también se destacan los importantes aumentos en la recaudación del Impuesto a la Renta: un $41 \%$ en el caso de Corporaciones, y un $30 \%$ en el caso de Personas Naturales al comparar el período 2001-2011 con la década 1990-2001 (2,1 a 2,9 en porcentajes del PBI en el caso del IRPJ, y $0,9 \%$ a $1,15 \%$ para el IRPN). Algunas de las explicaciones a este fenómeno radican que, en este caso el mayor crecimiento se produjo principalmente durante la última década debido a la ampliación parcial de algunas bases tributarias gravando a los servicios, la aplicación de tributos o contribuciones distorsivos, impuestos mínimos o tributación sobre bases imponibles presuntas, las mejoras logradas en un mejor control del universo de contribuyentes y, en algunos países, la apropiación de mayores recursos originados en la producción y exportación de bienes.

En ese sentido, las consecuencias de las políticas implementadas durante los noventa con énfasis en la simplificación, la derogación de tributos, y la reducción de gravámenes al comercio exterior, terminaron impulsando una mayor presencia de la imposición a la renta, el que actualmente se ha constituido en el segundo gravamen en términos de participación recaudatoria en el contexto de los países de la región (Gómez Sabaíni, Jiménez y Rossignolo, 2012).

Como se ha señalado en numerosos estudios, la evolución de la estructura tributaria en los países de América Latina ha resultado, en la mayoría de los casos, en una relación muy desigual entre la imposición directa e indirecta. En ese sentido, la política tributaria no sólo ha fortalecido la imposición general al consumo a través del fortalecimiento del IVA sino que, además, la imposición a la renta se orientó a gravar básicamente los ingresos de las personas jurídicas $\mathrm{y}$, en mucha menor medida, a las rentas obtenidas por las personas naturales. Todos estos resultados contrastan drásticamente con los que muestran los países desarrollados.

Por un lado, como puede apreciarse en el Gráfico 1, los niveles de presión tributaria de la región se encuentran muy por debajo de los países de la OECD. En promedio para el período 1990-2001, la carga tributaria de la región se elevó, en promedio, a 15,5\% del PBI, mientras que en los países de la OECD la misma alcanzó 35 puntos del producto. En 2001-2001, en América Latina la carga tributaria creció a 18,5\% del PBI, aún lejos de los 34,3\% del PBI de la OECD. La comparación con los 15 países iniciales de la Unión Europea (EU 15) arroja contrastes aún más marcados: la presión tributaria en 1990-2001 fue del 39,2\% del PBI, disminuyendo ligeramente a 38,3\% en 2001-2011.

Para los países de la OECD, la presión tributaria promedio de los ingresos tributarios indirectos alcanzó los 11 puntos del PBI en 1990-2001, los que se mantuvieron prácticamente constantes en el período subsiguiente. En América Latina, entretanto, los mencionados tributos alcanzaron 8,8\% del PBI en 2001-2011, con un ligero crecimiento en relación con los 7,2 puntos del PBI de 1990-2001.

En relación con los ingresos tributarios directos, la importancia relativa de los mismos en los países de la OECD es significativamente mayor que en Latinoamérica. En efecto, estos impuestos representaron en promedio para la década 2001-2011, un 14,4\% del PBI, con una leve disminución considerando los 15 puntos del PBI del período 1990-2001; para los países de Latinoamérica, la recaudación de los ingresos tributarios directos creció de 3,5\% del PBI en 1990-2001 a 5,3\% en 2001-2011, en consecuencia, tal como se puede apreciar en el grafico 1, el Impuesto a la Renta (y los impuestos directos) recauda, en promedio, más del doble de recursos en los países de la OECD que en América Latina. 


\section{GRÁFICO 1}

\section{EVOLUCIÓN DE LA PRESIÓN TRIBUTARIA EN AMÉRICA LATINA Y LA OECD, PROMEDIOS NO PONDERADOS}

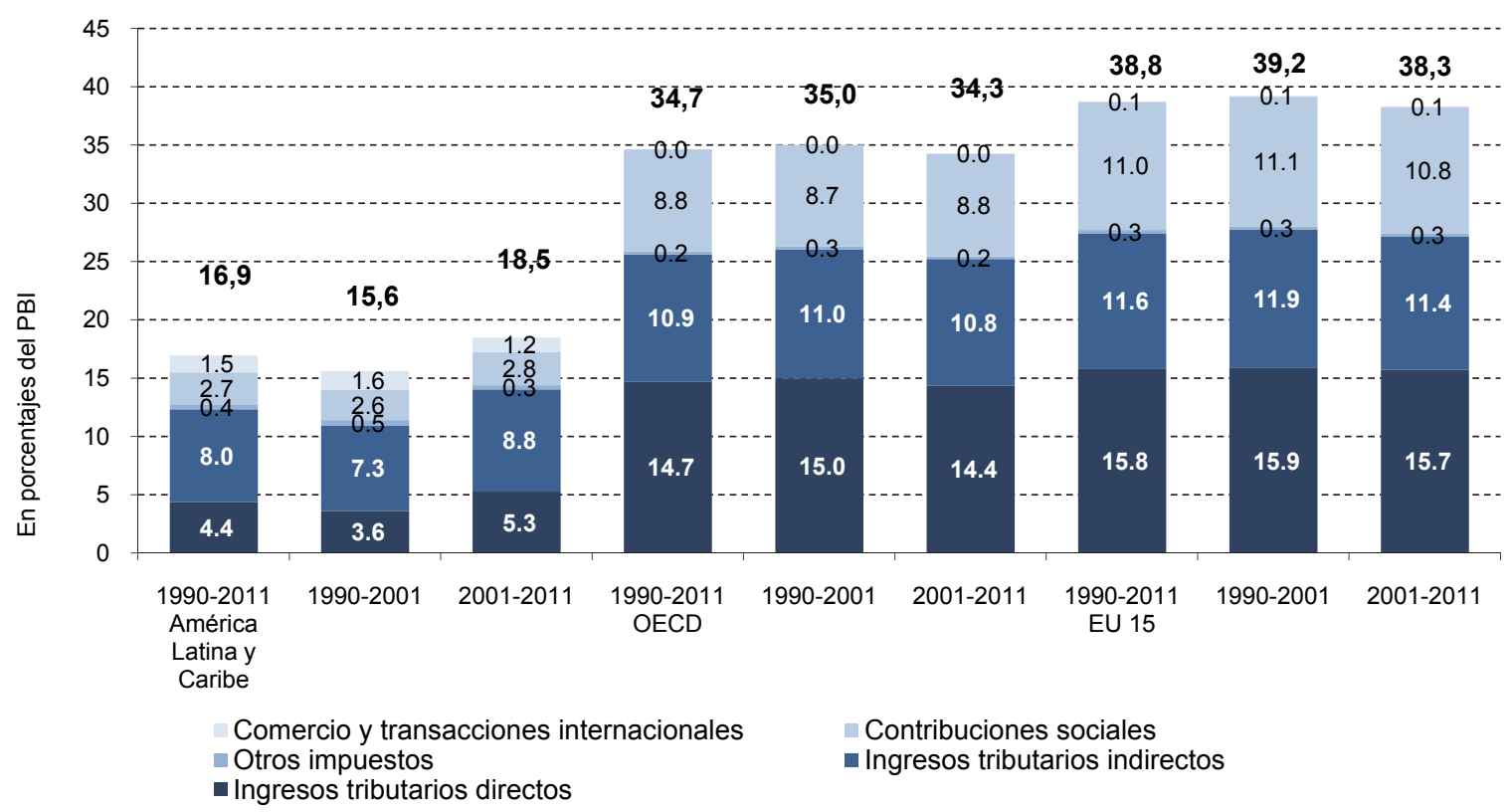

Fuente: Elaboración propia en base a CEPALSTAT, OECD y Database CIAT-IDB.

La composición de los recursos tributarios continúa siendo divergente de la de los países de la OECD aunque en los últimos años se ha evidenciado un notable acercamiento. Para los países de la OECD (y para el EU 15) los impuestos directos representaron alrededor del $42 \%$ del total para la década 2001-2011, mientras que los impuestos indirectos significaron el 31,6\% para idéntico período, valores ambos que se mantuvieron invariantes al comparar entre los períodos analizados (véase el gráfico 2).

\section{GRÁFICO 2}

COMPOSICIÓN DE LOS RECURSOS TRIBUTARIOS EN AMÉRICA LATINA Y LA OECD, PROMEDIOS NO PONDERADOS

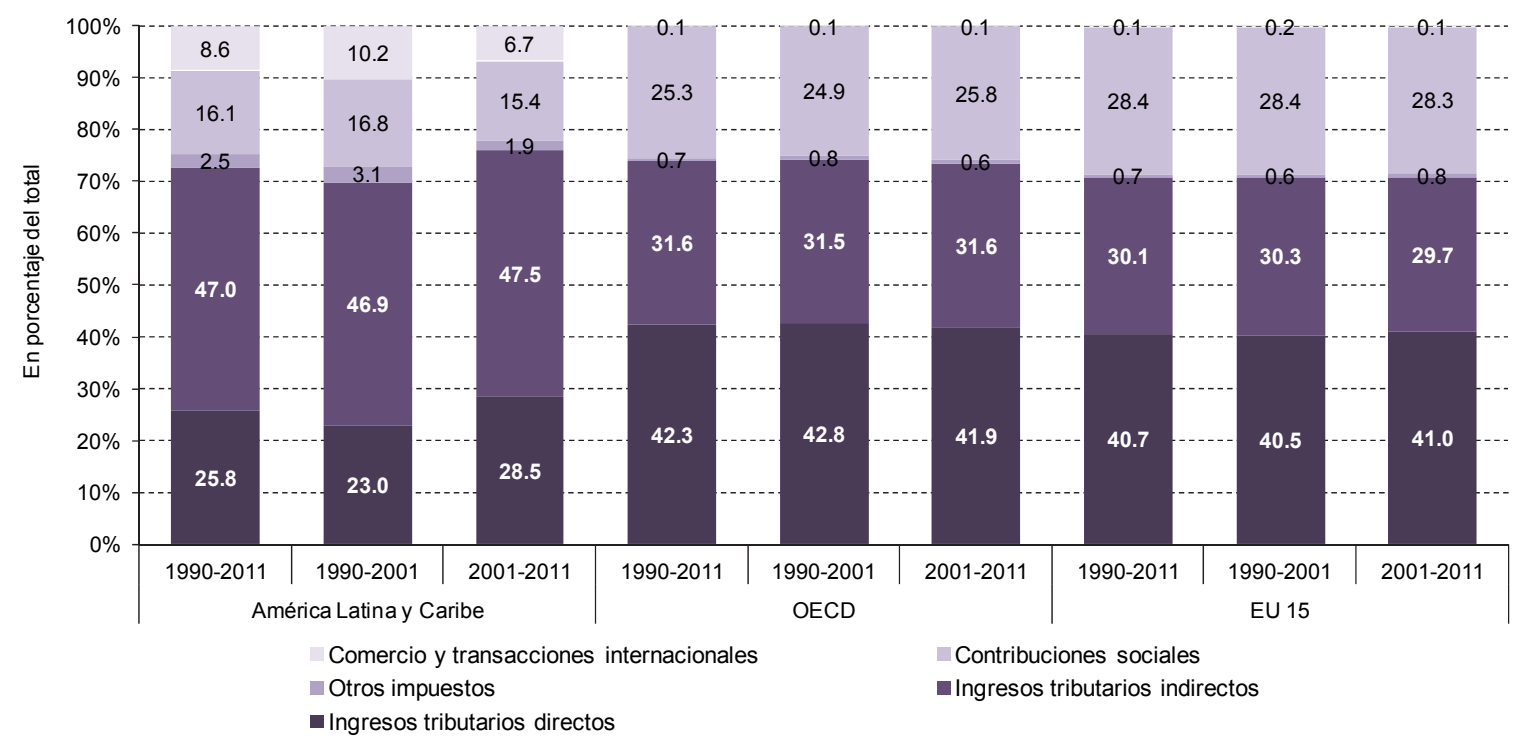

Fuente: Elaboración propia en base a CEPALSTAT, OECD y Database CIAT-IDB. 
En América Latina, por su parte, la mayor proporción de recursos tributarios corresponde a los impuestos indirectos, los cuales han concentrado un $47,5 \%$ del total de recursos para el período 2001-2011, con un leve aumento porcentual respecto de la década anterior. En cambio, la participación de los impuestos directos es sensiblemente menor para el período 2001-2011 (28,5\%) aunque muestra un destacable incremento relativo respecto de los valores promedio del período 1990-2001, donde la imposición directa sólo aportaba el $22,8 \%$ de la recaudación y la brecha respecto de los tributos indirectos era mucho mayor.

Más allá de los valiosos avances logrados en estos aspectos, el mayor énfasis puesto en la tributación directa radica en sus ventajas relativas que la misma posee en cuanto al efecto distributivo de los impuestos y, en relación con ello, en la posibilidad de gravar a los contribuyentes directamente en función de su capacidad contributiva. Impuestos aplicados sobre los ingresos, sobre el patrimonio, o bien sobre las transferencias de bienes patrimoniales (lo que incluye tanto herencias y legados como operaciones periódicas con bienes inmuebles) constituyen todos elementos válidos y útiles a la hora de intentar "gravar más a los que más tienen", lo que redunda en un sistema tributario más equitativo.

Por lo tanto, en los próximos párrafos se procederá a analizar los principales aspectos que definen y caracterizan a este grupo de gravámenes -donde el Impuesto sobre la Renta Personal ocupa un lugar preponderante-, sin dejar de enfatizar cuáles son las principales limitaciones y obstáculos que los mismos han debido y deben enfrentar actualmente en los sistemas tributarios de la región.

\section{B. El Impuesto a la Renta y su potencialidad como instrumento de recaudación}

Más allá de los notables incrementos que la recaudación de los impuestos sobre los ingresos ha experimentado en Latinoamérica, no puede decirse que no exista espacio para aumentar aún más los ingresos tributarios generados por dicho tributo - aprovechando sus ventajas relativas en materia de eficiencia y equidad distributiva. El argumento central de esta afirmación radica en la estructura desbalanceada que muestra el Impuesto sobre la Renta en su composición a favor de la imposición sobre personas jurídicas, la cual se ha mantenido a lo largo de los años y contrasta fuertemente con lo observado en los países desarrollados.

Una estimación de la base imponible potencial del Impuesto a la Renta debería incluir tanto a los gastos tributarios como las mediciones de evasión del impuesto. Sin embargo, las dificultades metodológicas en relación con definición de la base del impuesto, su administración y las deficiencias en el sistema de estadísticas de cada país ${ }^{4}$ y las divergencias entre países, además de los requerimientos informativos que esto demandaría en función de operar con metodologías homogéneas, ponen esta tarea cerca de lo inabordable 5 .

Para llevar a cabo esta tarea, entonces, se recurre a realizar una estimación de recaudación potencial mediante la metodología de "esfuerzo tributario". Desafortunadamente, existen pocos trabajos que se focalizan en particular en el Impuesto a la Renta, sino que realizan sus estimaciones para el sistema tributario en general (véase el recuadro 1).

Dos referencias que se focalizan en los países de América Latina merecen ser citadas al respecto. Por un lado, Perry (2006) ${ }^{6}$ analiza el caso de América Latina y, en un enfoque cross section, establece una relación entre la presión tributaria de cada país y el logaritmo del PBI per cápita, concluyendo en consecuencia que los países recaudan por debajo de su potencial para todas las categorías tributarias. Para el caso del Impuesto a la Renta personal, por ejemplo, Argentina recauda 4,4 puntos del PBI menos que lo que debería, mientras que para Brasil el mismo coeficiente arroja un valor inferior en 3,7 puntos del PBI.

\footnotetext{
Cetrángolo, O. y Gómez Sabaíni, J. C. (2009).

Esta sección sigue a Rossignolo (2012).

Perry, G., O. Arias, H. López, W. Maloney y L. Servén (2006).
} 


\section{RECUADRO 1 \\ ESTIMACIONES DE "ESFUERZO TRIBUTARIO"}

Si bien no están exentas de críticas, las comparaciones internacionales de "esfuerzo tributario" buscan como objetivo principal revelar si un país se encuentra limitado en la recaudación impositiva por una baja capacidad de generar recursos o por un bajo esfuerzo en la explotación de la capacidad tributaria existente para financiar el gasto público. Otro de los objetivos es el de proporcionar una guía sobre cuál es la combinación de políticas fiscales adecuadas al momento de enfrentar un desbalance presupuestario; si el país en cuestión estuviere recaudando cerca de su nivel potencial, esto implicaría que la corrección del déficit debería llevarse a cabo vía reducción del gasto, y no aumento de los impuestos. A continuación se hará referencia a algunos de los antecedentes en la temática.

Stotsky y Woldemariam (1997) aproximan a la medición de la capacidad tributaria a partir de estimar mediante un modelo de datos de panel. Utilizando una muestra de 46 países del África Subsahariana, investigan los determinantes del esfuerzo tributario. El estudio arroja como resultado el hecho de que la participación de la agricultura y de la minería en el PBI resultan ser variables negativas y significativas en la determinación de la capacidad tributaria, mientras que tanto el grado de exportaciones a PBI como el ingreso per cápita, son también significativas pero afectan positivamente la capacidad tributaria.

El índice de esfuerzo tributario, medido a partir del cociente entre la recaudación actual y la predicha, arroja como resultado que la mayoría de los países del sur de África presenta una relación superior a 1, indicando exceso de tributación. Los países con índices bajos deberían enfatizar el incremento en la recaudación antes que una reducción de los gastos ante la eventualidad de un desequilibrio presupuestario.

Pessino y Fenocchietto (2010) utilizan un modelo de frontera impositiva, en analogía a una función de producción estocástica, a diferencia de una regresión convencional, dado que representa el máximo nivel de imposición alcanzable considerando un set de variables explicativas. En este modelo, un esfuerzo tributario bajo implica que el esfuerzo es reducido en relación al de otros países, no implicando necesariamente que el país sea ineficiente en recaudar impuestos. Los autores corroboran la relación positiva y significativa entre la presión tributaria y el grado de desarrollo económico, apertura económica y educación, mientras que es negativa par la participación de la agricultura, la desigualdad en la distribución del ingreso y la ineficiencia en la recaudación. Los países europeos de elevado ingreso per cápita, abiertos al comercio internacional, baja inflación y elevado nivel de educación se encuentran cerca de su potencial tributario.

Artana y Templado (2010) analizan, para una muestra de 118 países, en un enfoque cross section, si existe evidencia de que los países estén recaudando en exceso de su potencial. Utilizando como variable dependiente al cociente entre recaudación tributaria y $\mathrm{PBI}$, a través de un modelo lineal generalizado, para estos autores, Argentina, por ejemplo, recauda una magnitud mucho mayor que el valor predicho por el modelo en todos los rubros: $13 \%$ del PBI en exceso en el caso del total de recursos, mientras que para el caso de impuestos sobre ingresos y propiedad, el exceso es del orden de 6 puntos del PBI. Este resultado es el más alto para los países de Latinoamérica y uno de los más elevados a nivel internacional.

Fuente: Rossignolo (2012) y Gómez Sabaíni, Jiménez y Rossignolo (2011).

Por otro lado, Rossignolo (2012) y y Gómez Sabaíni, Jiménez y Rossignolo (2011) llevan a cabo una estimación a través de un modelo de datos de panel para América Latina para el período 1990-2008 para predecir el "esfuerzo tributario" de los diferentes países en relación con el impuesto a la Renta total y del impuesto a la Renta de Personas Físicas, utilizando una muestra de 15 países ${ }^{7}$. De acuerdo a los antecedentes en la materia, se realizaron estimaciones de recaudación potencial mediante la metodología de "esfuerzo tributario". Los resultados arrojados por las mismas están de acuerdo con la literatura: relación positiva de la recaudación tanto del impuesto a la Renta como del IRPF con el nivel de desarrollo, como también la recaudación crece a mayor desigualdad en la distribución del ingreso, educación y grado de institucionalidad.

Al momento de llevar a cabo la comparación de la recaudación determinada en los modelos con la efectiva se revela la importancia de las heterogeneidades entre los distintos países. Existen casos de países con elevada presión tributaria, como es el caso de Brasil, México, y Perú, en donde se está muy cerca o aún superando el nivel de recaudación potencial.

Sin embargo, en otros casos (Argentina, Chile), en donde, si bien en el caso del total del impuesto se está próximo al potencial, para el caso del Impuesto a la Renta de Personas Físicas o Naturales aún puede incrementarse la recaudación efectiva, lo cual implica un claro ejemplo de desbalance en la composición del impuesto. En el cuadro 2 se sintetizan algunos de los resultados del trabajo mencionado para un subconjunto de países.

Argentina, Bolivia, Brasil, Chile, República Dominicana, Ecuador, El Salvador, Guatemala, Honduras, México, Nicaragua, Panamá y Perú, para el IRPF, adicionando Colombia y Uruguay para el total del impuesto a la Renta. 


\begin{tabular}{lll} 
RESULTADOS DE ESTIMACIONES SOBRE RECAUDACIÓN EFECTIVA Y POTENCIAL DEL IMPUESTO \\
& A LA RENTA Y DEL IRPF PARA VARIOS PAÍSES DE AMÉRICA LATINA \\
\hline País & Impuesto a la Renta & Impuesto a la Renta de Personas Físicas \\
\hline Argentina & Por encima del potencial entre 2004 y 2006 & Por debajo del potencial \\
Brasil & Por encima del potencial & Por encima del potencial \\
Chile & Por encima del potencial desde 2005 & Por debajo del potencial \\
El Salvador & Por encima del potencial desde 2003 & Por encima del potencial desde 1994 \\
Guatemala & Por encima del potencial desde 2006 & Por debajo del potencial \\
México & Por encima del potencial entre 1992 y 1993 y en 2008 & Por encima del potencial desde 2000 \\
Perú & Por encima del potencial desde 1996 & Por encima del potencial desde 1997
\end{tabular}

Fuente: Elaboración propia en base a Rossignolo (2012) y Gómez Sabaíni, Jiménez y Rossignolo (2011).

A partir del análisis realizado por Rossignolo (2012) y Gómez Sabaíni, Jiménez y Rossignolo (2011), en el gráfico 3 se calculó el índice de "esfuerzo tributario" para el impuesto a la Renta de Personas Físicas y para el total del impuesto a la Renta, a partir de promediar en forma no ponderada los valores de la recaudación efectiva y de la recaudación potencial estimada para los 15 países analizados en el trabajo mencionado. El índice de "esfuerzo tributario" se calcula como el cociente entre la recaudación actual y la recaudación potencial; un valor inferior a 1 significa que el país está recaudando por debajo de su potencial, mientras que un valor superior a 1 implica lo contrario.

A partir del gráfico siguiente puede establecerse que recién a partir de la década de 2000 los países de América Latina se acercan a su potencial recaudatorio (un valor del índice cercano a uno); para Personas Físicas durante esta década se presentan valores cercanos a inferiores a uno, mientras que para el total del impuesto, si bien se aprecia que la recaudación excede a la potencial, la misma es decreciente al aproximarse al final de la década.

\section{GRÁFICO 3 \\ EVOLUCIÓN DEL “ESFUERZO TRIBUTARIO” DEL IMPUESTO A LA RENTA Y EL IRPF}

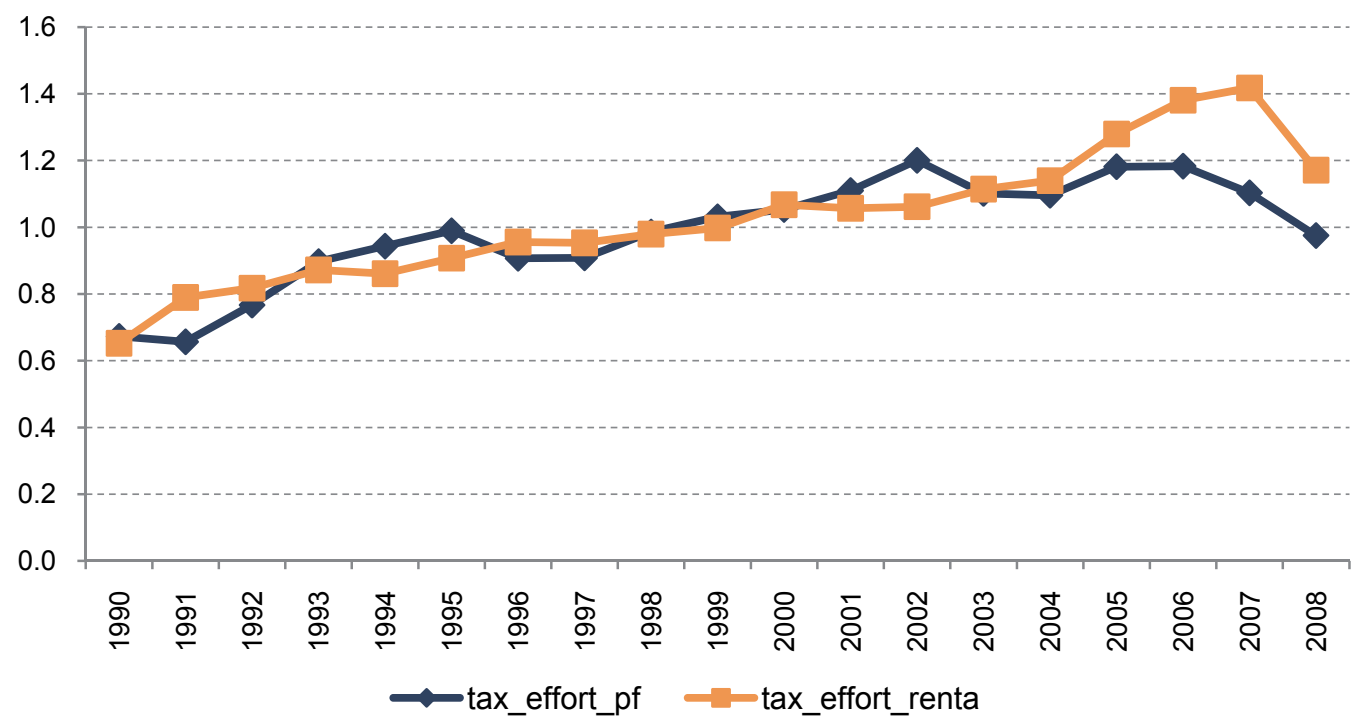

Fuente: Elaboración propia en base a Rossignolo (2012).

En consecuencia, dada la heterogeneidad observada entre países, la determinación sobre la capacidad tributaria depende de las particularidades de cada economía. Puede observarse claramente, sin embargo, que existe mayor margen para aumentar la recaudación del Impuesto a la Renta de Personas 
Físicas dado que se aprecia, a partir de las estimaciones realizadas, que este tributo se encuentra recaudando por debajo de su potencial en mayor medida que el total del impuesto a la Renta.

\section{Las limitaciones que enfrenta el Impuesto a la Renta Personal en América Latina}

Más allá de los condicionantes impuestos por el nivel de ingreso per cápita de los países y el grado de concentración de rentas, se observa que las posibilidades de incrementar la recaudación del Impuesto a la Renta de Personas Naturales (IRPN) en América Latina está condicionada por tres factores fundamentales que son los siguientes: la reducida tasa marginal máxima aplicada en el promedio de los países, la estrecha base imponible por la existencia de un alto nivel de de deducciones y/o exenciones que deja fuera del gravamen a una cantidad importante de ingresos y el alto coeficiente de incumplimiento (evasión y morosidad) que se observa en casi todos los países.

Para ello, se evaluarán distintos aspectos que hacen a las características del IRPF en la región, debiendo enfatizarse que el impuesto a la renta aplicado en los países desarrollados, además de tener un peso absoluto y relativo mayor dentro de sus estructuras tributarias, no sufre las falencias técnicas que muestra este gravamen en la mayoría de los países de América Latina.

\section{El comportamiento de las tasas legales}

Durante las últimas dos décadas, los países de América Latina evidenciaron un proceso de paulatina reducción en los niveles de las alícuotas del impuesto a la renta para personas físicas que las ubicaron, en algunos casos, por debajo de los niveles internacionales.

En relación con las alícuotas marginales máximas, partiendo de tasas promedio para todos los países de América Latina analizados, de 31,5\% para las personas físicas a principios de la década de 1990 , los promedios regionales fueron descendiendo hasta ubicarse ambas alícuotas en torno a los 25 puntos porcentuales para el año 2008. A partir de ese año se experimente un ligero incremento, para pasar a niveles de tasas superiores a los 27,5 puntos en promedio, valor muy inferior del observado en los países desarrollados (especialmente los de Europa Occidental) donde el promedio de la tasa marginal máxima se eleva a casi $40 \%$. En el gráfico 4 se aprecia la evolución de la presión tributaria del IRPN y el comportamiento promedio descendente de las alícuotas marginales máximas.

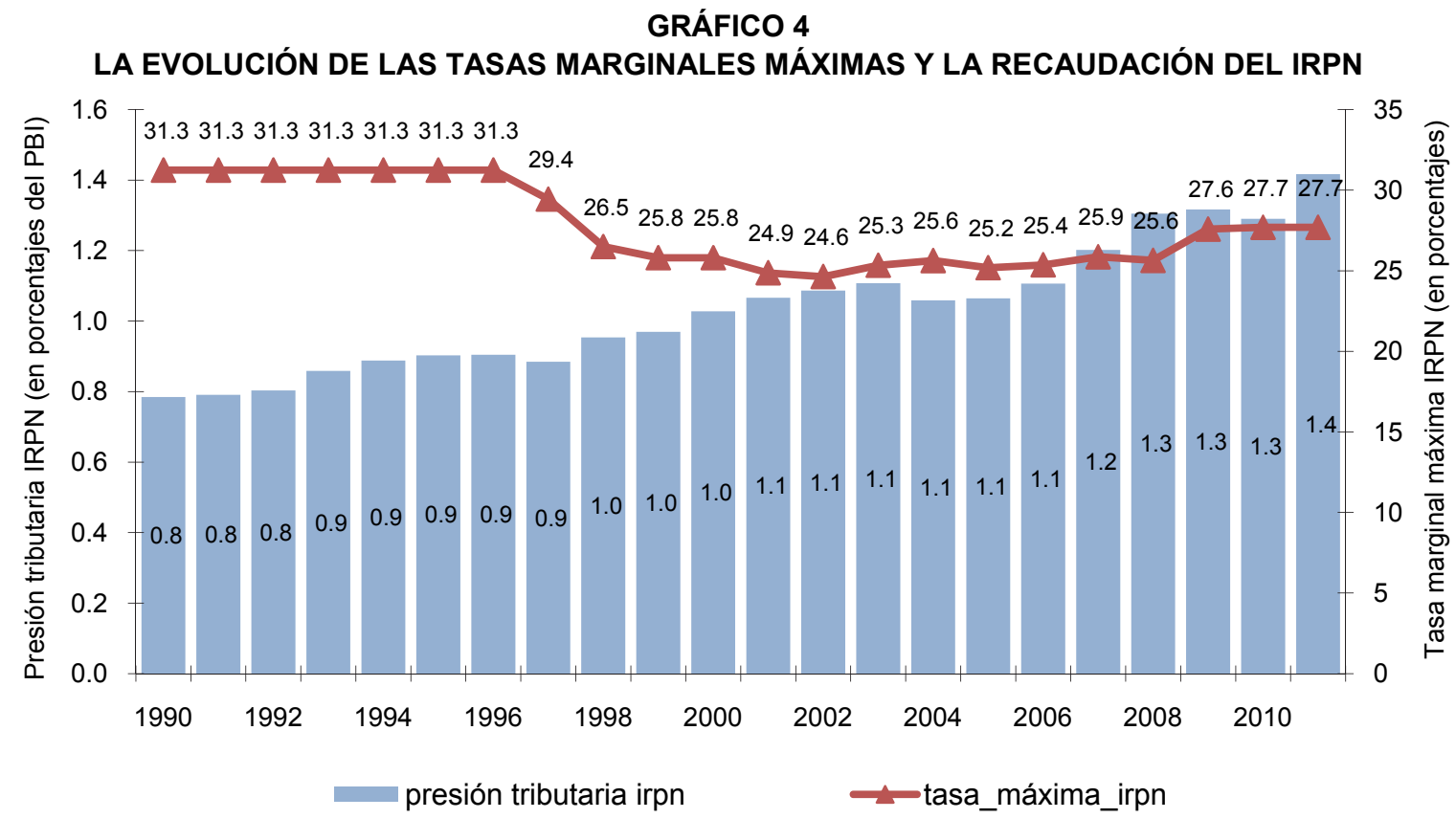

Fuente: Elaboración propia en base a CIAT y CEPALSTAT. 
La reducción de tasas marginales tanto a la imposición a personas físicas como a las sociedades, las cuales han convergido en torno a un promedio del $27 \%$, ha traído como consecuencia la modificación en el tratamiento otorgado a los dividendos de acciones ${ }^{8}$, los que han quedado excluidos, en muchos países de la región, de la base imponible del impuesto a la renta personal a fin de buscar la simetría con otros ingresos de capital como los intereses de colocaciones bancarias o de títulos de deuda, como se verá más adelante.

Por el contrario, las alícuotas marginales mínimas evidenciaron un ligero incremento, al pasar de una tasa promedio de $7,6 \%$ en la década de 1990 a un $8,1 \%$ durante mediados de la década de 2000 para luego crecer alrededor de un punto porcentual en la segunda mitad de la década para toda la región. Las tasas marginales mínimas se han estabilizado en un nivel promedio ligeramente superior al existente en la década de 1990. En efecto, alrededor de 1997 se experimenta un aumento de las alícuotas, que pasan del $6,9 \%$ a un promedio de $9,4 \%$. A principios de la década subsiguiente se aprecia una ligera disminución, hasta los 8,1 puntos en promedio, para luego volver a incrementarse en valores superiores a los 9,5 puntos porcentuales (gráfico 5).

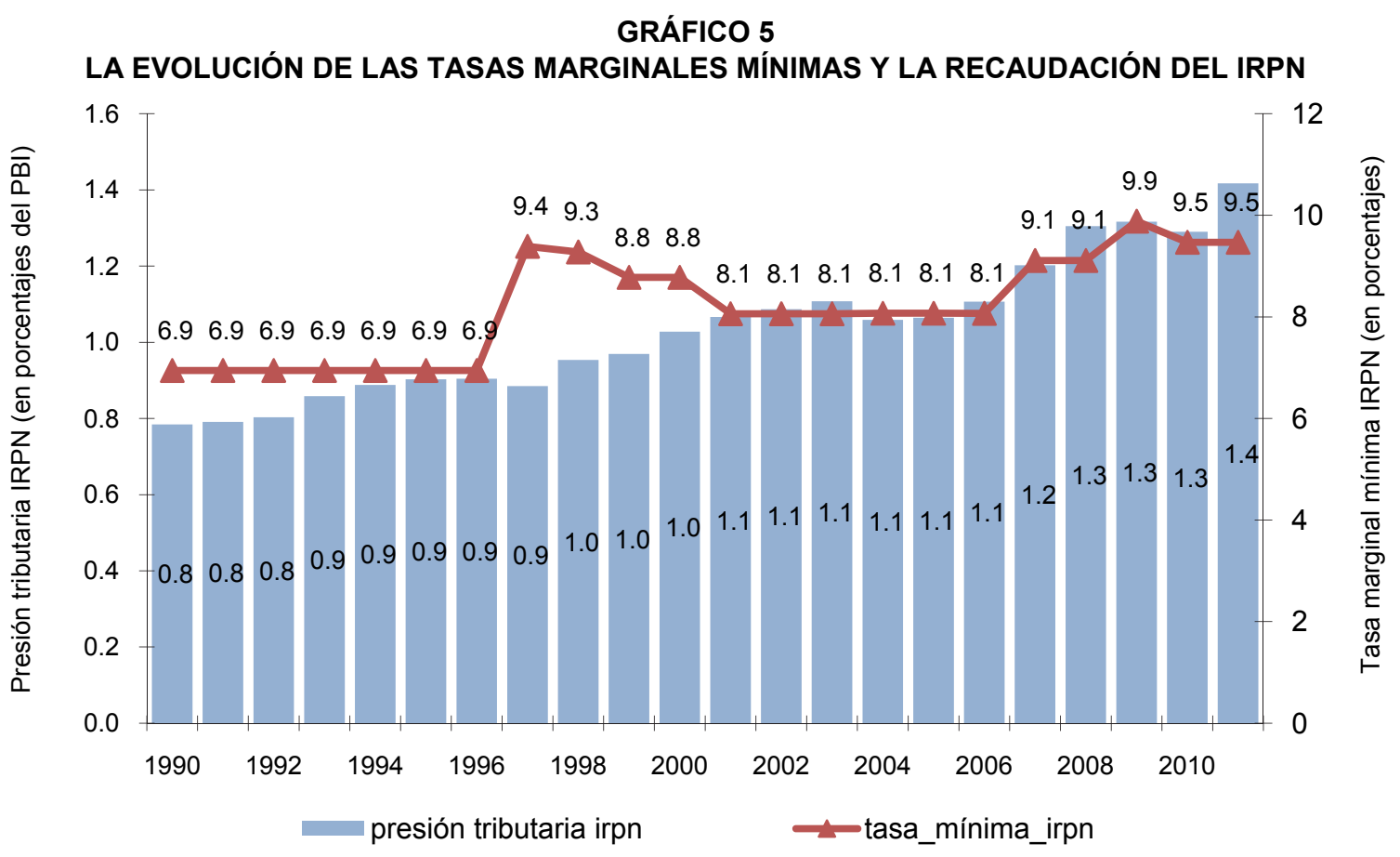

Fuente: Elaboración propia en base a CIAT y CEPALSTAT.

En el gráfico 6 subsiguiente (paneles A. y B.) se presenta la relación entre la recaudación y las tasas mínimas, por un lado, y la relación entre los ingresos fiscales y las tasas marginales más altas, en el panel siguiente. Allí puede verse una relación positiva entre las tasas marginales mínimas y la recaudación del IRPN, y una relación negativa entre las tasas marginales máximas y los ingresos tributarios provenientes del impuesto a la Renta de Personas Físicas.

8 La presente sección sigue a Gómez Sabaíni, Jiménez y Rossignolo (2012). 


\section{GRÁFICO 6 \\ RELACIÓN ENTRE LA RECAUDACIÓN DEL IRPN Y LAS TASAS \\ MARGINALES MÍNIMAS Y MÁXIMAS}

(En porcentajes del PBI)

A. $1990-2001$

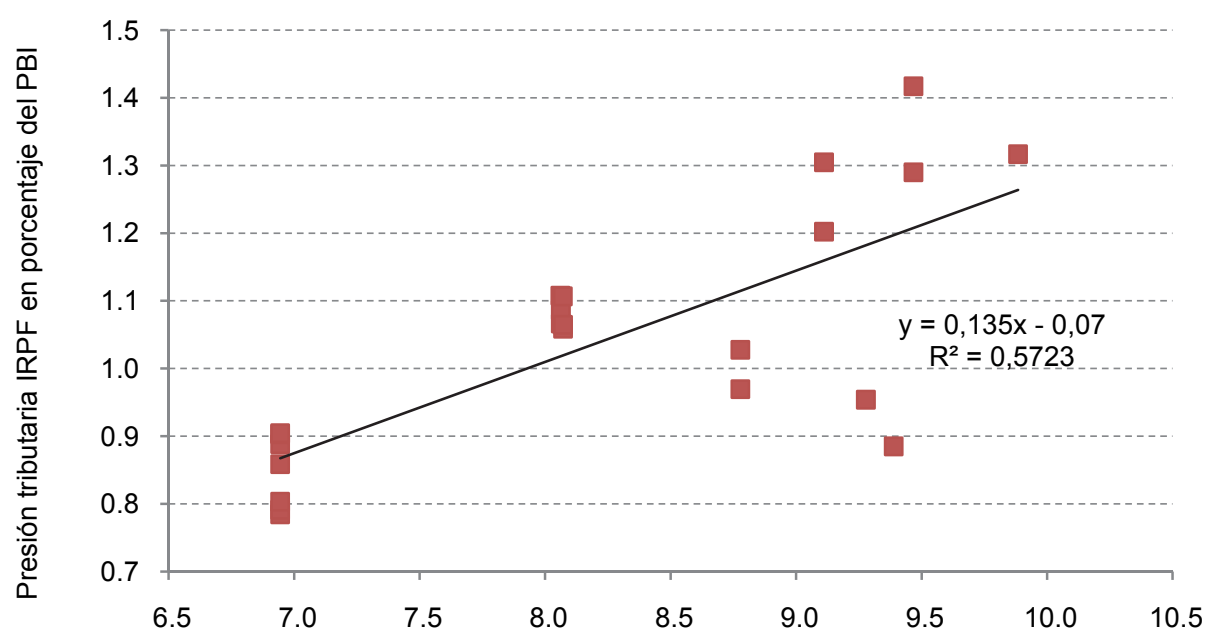

Tasas mínimas en porcentajes

B. $2001-2011$

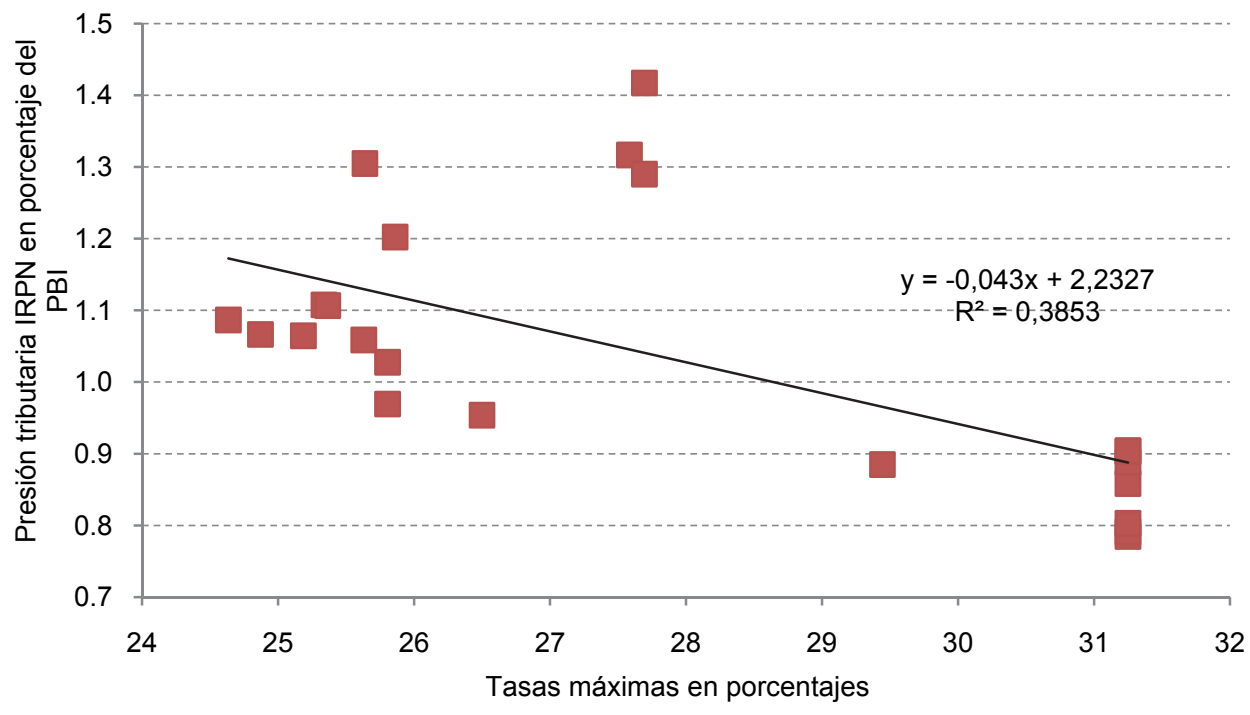

Fuente: Elaboración propia en base a CIAT y CEPALSTAT.

En definitiva, se ha advertido en los últimos años un incremento en las tasas marginales mínimas, lo que afecta a los tramos que concentran la mayor recaudación, y un descenso (seguido de una moderada recuperación) de las alícuotas marginales máximas, lo que impacta en el grado de progresividad del impuesto. En relación con las tasas mínimas, Brasil y México han reducido sus alícuotas a partir del período 2009-2010, mientras que las tasas mínimas de Uruguay y Honduras sufrieron sendos aumentos. En cambio, en varios países (como Ecuador, México y el Uruguay) se ha constatado una tendencia a aumentar las tasas o alícuotas marginales máximas para las Personas Naturales e incluso se han establecido tasas adicionales correspondientes al impuesto sobre la Renta (CEPAL, 2013). Para un análisis detallado de la evolución de las alícuotas legales mínimas y máximos del IRPN en los países de la región se recomienda consultar los cuadros A.1 y A.2 del anexo que figura al final de este trabajo. 


\section{La estrechez de las bases imponibles del IRPN y sus efectos en la equidad}

Dos aspectos fundamentales que determinan la limitada recaudación de la imposición sobre los ingresos personales en América Latina están constituidos por i) el tratamiento en materia de deducciones personales y ganancias no imponibles, y ii) en los también numerosos regímenes de exención o beneficios tributarios genéricamente denominados "gastos tributarios"".

Respecto al primero de los aspectos indicados, Gómez Sabaíni et al (2012) han señalado que mientras que en el promedio de los países de América Latina el tributo se comienza a aplicar cuando se alcanza el nivel de 1,5 veces el nivel de PBI per cápita a la tasa más baja del 10\%, en los países de Europa Occidental el gravamen se tributa a partir de $0,30 \%$ del PBI per cápita, y en los EEUU a partir del $0,2 \%$ de ese indicador.

Además de la elevada evasión asociada al Impuesto sobre la Renta ${ }^{10}$, las concesiones tributarias dadas por exenciones, deducciones, alícuotas diferenciales y otras reglamentaciones que permiten la elusión del gravamen juegan un rol muy importante en reducir la base imponible de los países de América Latina. Por ejemplo, en varios países, hogares con ingresos superiores al promedio están exentos del Impuesto a la Renta debido a los niveles de mínimo no imponible y deducciones personales (Stotsky y WoldeMariam, 2002).

Dado que en los países de la región una gran proporción de personas asalariadas recibe ingresos por debajo del nivel mínimo imponible establecido por la legislación, el Impuesto a la Renta sólo alcanza a un grupo minoritario de individuos que no supera, en el mejor de los casos, el $10 \%$ de la población económicamente activa. A ello se le suma un alto nivel de incumplimiento tributario y de elusión del pago de impuestos por parte de los trabajadores independientes o autónomos ${ }^{11}$.

Una de las justificaciones de la diferencia en el ingreso gravable para aplicar la alícuota mínima del impuesto en las distintas regiones se encuentra justificada por la divergencia en los niveles del ingresos per cápita entre las distintas regiones indicadas y por la necesidad de dejar fuera del gravamen a un nivel de ingreso que considere valores de subsistencia familiar.

Sin embargo, resulta más dificil justificar, por el contrario, el monto a partir del cual se comienza a aplicar la tasa marginal máxima ya que, mientras que en los países desarrollados la misma se aplica a partir de 3 ó 4 veces el PBI per cápita, en los países latinoamericanos dicha alícuota recién comienza a tener efecto a partir de 8,5 veces el ingreso per cápita (USAID, 2011).

En el gráfico 7 se muestra la evolución de los niveles de ingresos gravables mínimos y máximos, expresados en múltiplos del ingreso per cápita, donde puede comprobarse una disminución relativa que resulta ser sustancial para ambos indicadores durante la última década. Este fenómeno pone de manifiesto la virtual ampliación del alcance del tributo a nivel regional que ha permitido la incorporación de un número considerable de contribuyentes al ámbito del gravamen (por la baja relativa del mínimo no imponible) y la aplicación de tasas más elevadas a los contribuyentes alcanzados por el tributo (debido a la merma en el valor al cual se comienza a aplicar la tasa marginal máxima del IRPN). En esta conclusión general, no obstante, subyace cierta heterogeneidad de casos por lo cual, en los cuadros A.3 y A.4 del anexo, se presentan los datos correspondientes a los países de la región en cuanto a los niveles de ingreso mínimo y máximo en múltiplos del PIB per cápita.

\footnotetext{
La presente sección sigue a Gómez Sabaíni, Jiménez y Rossignolo (2012).

10 El trabajo de Gómez Sabaíni, Jiménez y Podestá (CEPAL, 2010) representa una referencia obligada en esta temática, donde se analizan una muestra de siete países a partir de una metodología común.

11 La existencia de Regímenes Simplificados para Pequeños Contribuyentes también reducen la base imponible de este tributo ("monotributo").
} 


\section{GRÁFICO 7 \\ EVOLUCIÓN DE LOS NIVELES DE INGRESO GRAVABLE MÍNIMOS Y MÁXIMOS, AMÉRICA LATINA, PROMEDIOS PARA PAÍSES Y PERÍODOS SELECCIONADOS EN MÚLTIPLOS DEL INGRESO PER CÁPITA}

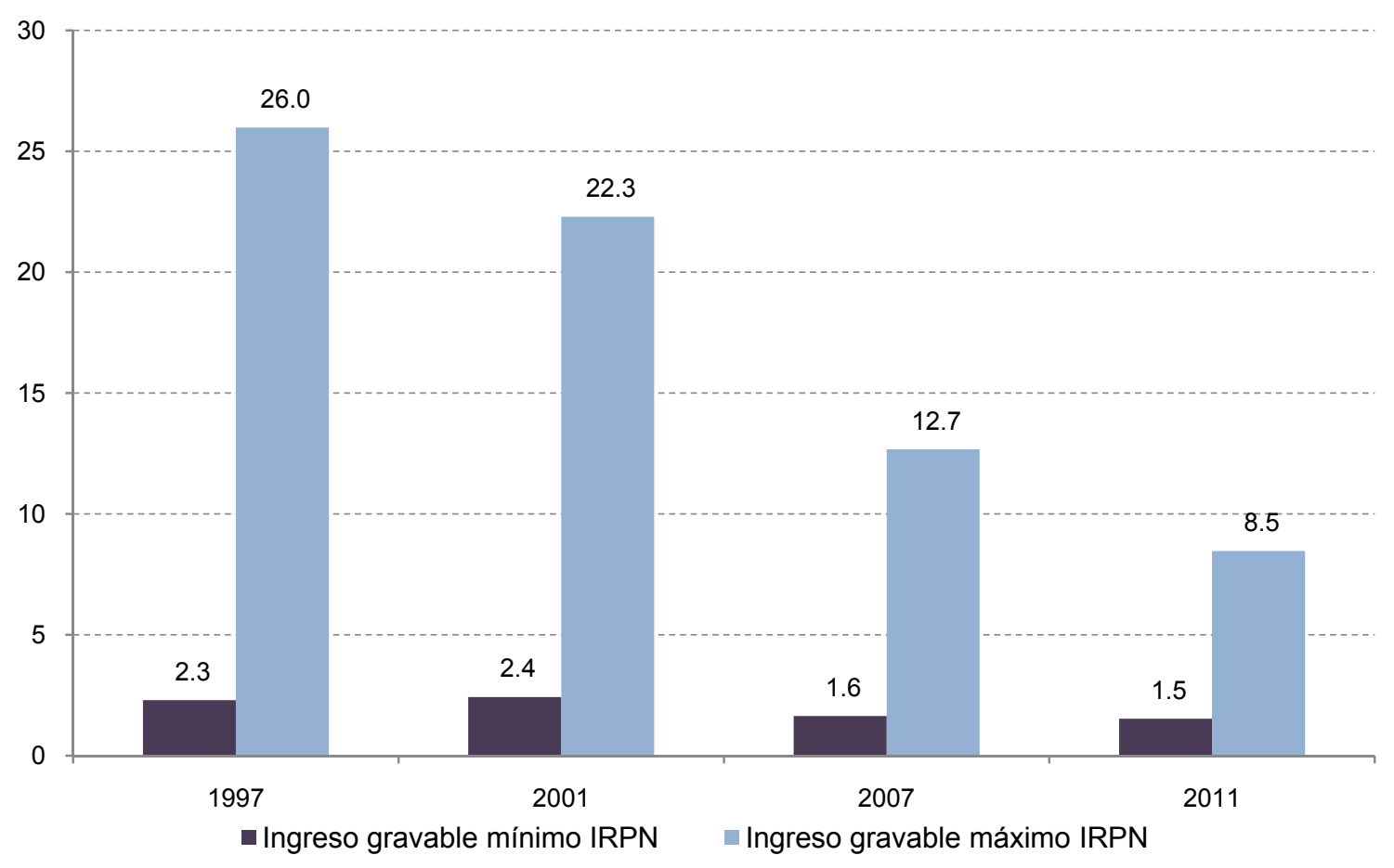

Fuente: Elaboración propia en base a Stotsky y Woldemariam (2002) y USAID Collecting Taxes Database.

Del análisis del gráfico anterior pueden hacerse las siguientes reflexiones. Los valores de los ingresos gravables mínimo y máximo están expresados en múltiplos del ingreso per cápita. Si se tiene en cuenta que el ingreso per cápita promedio para América Latina se incrementó alrededor de un 22\%, la disminución en los niveles de ingreso gravable están explicados fundamentalmente por una adaptación pasiva de las autoridades fiscales de los países de América Latina, dado que los niveles absolutos estarían creciendo menos que el propio ingreso (denominador de la expresión).

Si existen incrementos en los niveles de ingreso per cápita y en los niveles de precios (aquí los niveles de ingreso están expresados en dólares constantes, aunque la comparación debería incluir el comportamiento de los valores corrientes en moneda local para poder captar la evolución de los precios), se generan deslizamientos tributarios; con mínimos no imponibles cuya evolución es menor que la del ingreso per cápita, los contribuyentes "escalan" en los tramos de ingreso sujetos a alícuotas marginales crecientes, lo que conlleva un incremento recaudatorio como el que se ha verificado en América Latina.

Por otra parte, la caída en los valores de ingresos gravables máximos (aquellos a partir de los cuales se tributa la alícuota marginal más alta) dan cuenta de un fenómeno similar, de adaptación "pasiva" de la política fiscal; los "deslizamientos" o "fiscal drags" antes mencionados determinan incrementos en los recursos fiscales, pero éste no es tan elevado como debería: si la desigualdad en la distribución del ingreso es mayor a la relevada por las encuestas de hogares (ver sección respectiva sobre ajustes a los índices de desigualdad), el impuesto no sólo pierde recaudación, sino también progresividad.

Los "deslizamientos" mencionados pueden ejemplificarse para el caso de la Argentina en las figuras subsiguientes. En el gráfico 8 puede apreciarse que, partiendo del período fiscal 1996, más de la mitad de las presentaciones (el 52,5\%) estaban concentradas en el tramo de ingresos más bajos (entre $0 \mathrm{y}$ 10.000 pesos anuales), mientras que el tramo de ingresos más elevados (a partir de 120.000 pesos) 
concentraba el 1,7\% del total de presentaciones. Para 2010, el porcentaje de presentaciones que englobaba el segmento inferior de ganancia sujeta a impuesto era del 14,9\%, mientras que el tramo más elevado abarcaba el $25,2 \%$ del total.

\section{GRÁFICO 8 \\ ARGENTINA: DECLARACIONES JURADAS DEL IMPUESTO A LA RENTA DE PERSONAS FÍSICAS, EVOLUCIÓN DE LA PARTICIPACIÓN DE LAS PRESENTACIONES POR TRAMOS DE GANANCIA SUJETA A IMPUESTO}

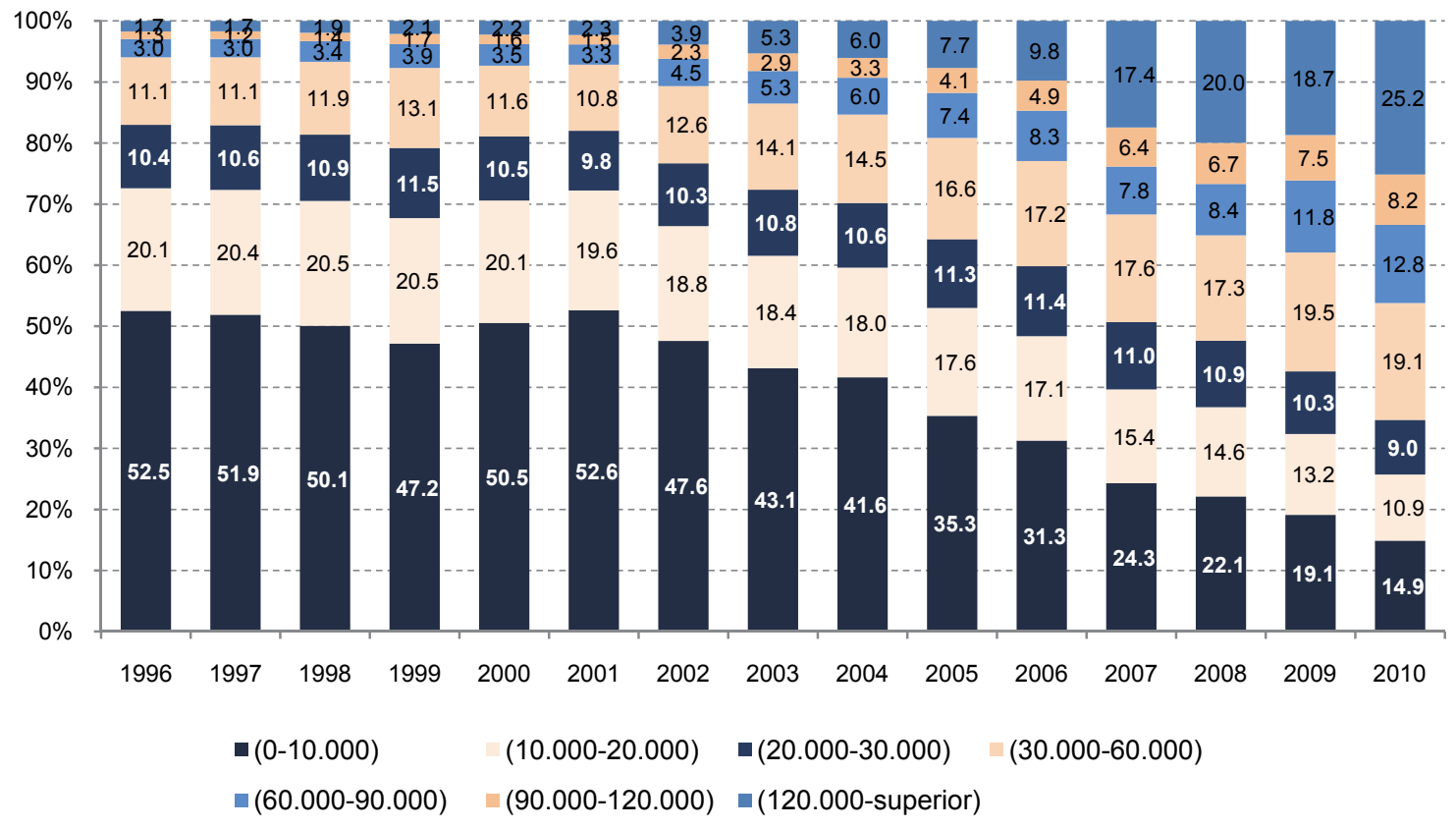

Fuente: Elaboración propia en base a datos de AFIP, Estadísticas Tributarias 1997-2011.

En cuanto a los ingresos gravados que surgen de las presentaciones anteriores, en 1997 el primer tramo concentraba el $27 \%$ del total de ingresos gravados; el tramo más alto, entretanto, abarcaba al 12,3\%. En 2010, más de la mitad de los ingresos gravados (el 57\%) surgía de las declaraciones juradas de los contribuyentes comprendidos en el segmento de ganancia sujeta a impuesto a partir de 120.000 pesos anuales; el tramo inferior comprendía sólo al 4,1\% del total de ingresos gravados (véase el gráfico 9).

Un segundo aspecto a considerar al analizar la reducción en las bases imponibles del gravamen a los ingresos personales está dado por los gastos tributarios. Durante las décadas del 80 y del 90, las bases imponibles de los principales tributos en América Latina sufrieron un proceso de erosión a través del otorgamiento de exenciones impositivas y otros beneficios tributarios que eran justificados, aunque no comprobados, por la necesidad de proveer incentivos para estimular el ahorro, provomer la entrada de IED, estimular el desarrrollo de los mercados financieros y bursátiles, siempre bajo el argumento de que tales beneficios estimularían el consecuente crecimiento de la economía, la reducción de los niveles de desempleo y la promoción de los sectores dinámicos de la economía.

En cuanto a la importancia de los gastos tributarios respecto de la presión tributaria total, se observan países con una participación relativamente baja, alrededor del 10\% (Argentina, Brasil y Perú), otros con una importancia intermedia (Chile, Colombia y Ecuador) y por último, aquellos donde esta relación supera el 50\% (Guatemala y México), siempre teniendo en cuenta las importantes diferencias metodológicas existentes en las estimaciones que restringen todo análisis comparativo (Gómez Sabaíni y Rossignolo, 2009). A continuación se hará referencia en particular a cada uno de los aspectos mencionados. 


\section{GRÁFICO 9}

\section{ARGENTINA: DECLARACIONES JURADAS DEL IMPUESTO A LA RENTA DE PERSONAS FÍSICAS, EVOLUCIÓN DE LA PARTICIPACIÓN DE LOS INGRESOS GRAVADOS POR TRAMOS DE GANANCIA SUJETA A IMPUESTO}

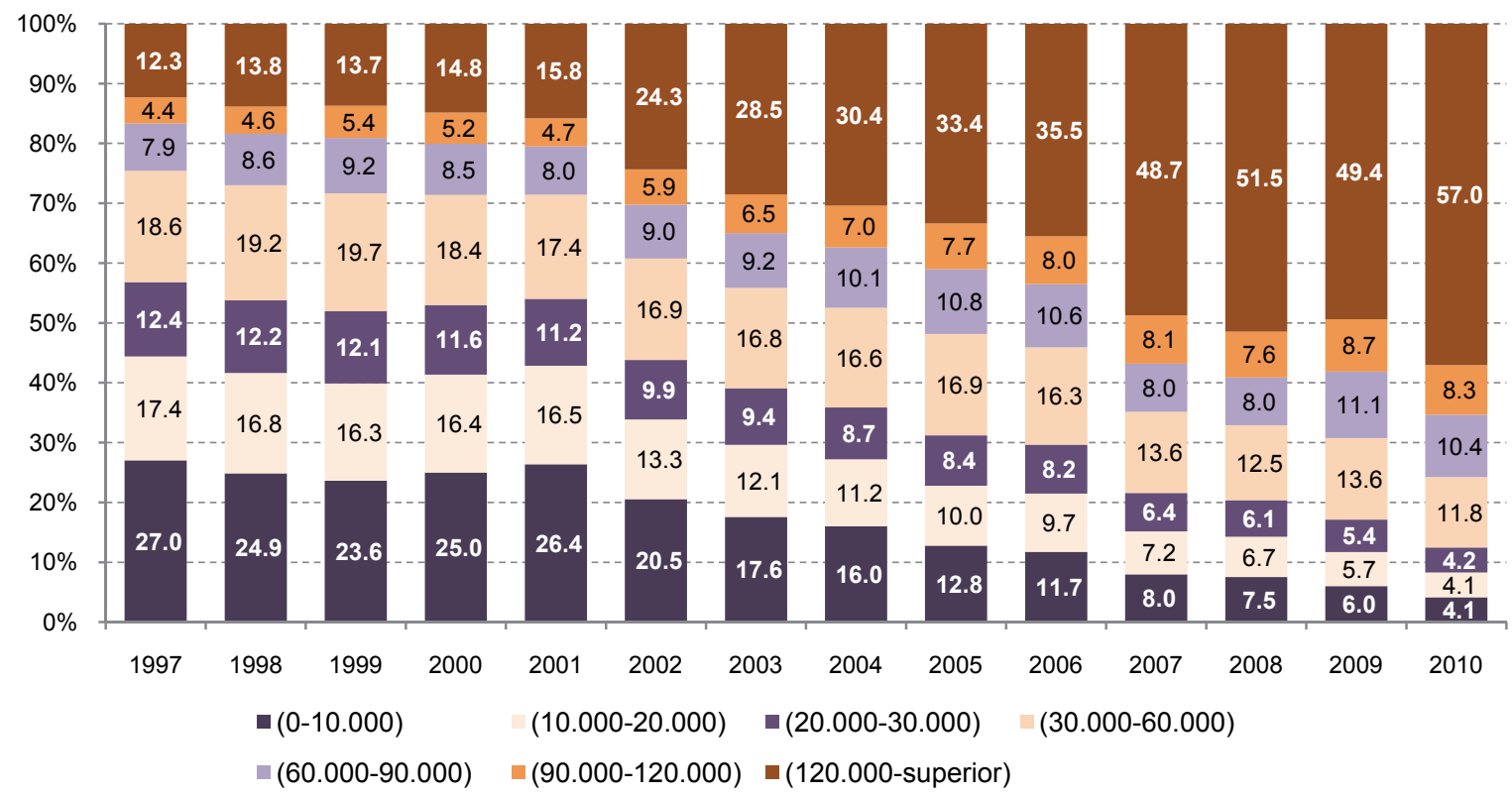

Fuente: Elaboración propia en base a datos de AFIP, Estadísticas Tributarias 1997-2011.

\section{La composición de las fuentes de rentas alcanzadas por el impuesto}

Una de las características de la imposición a la Renta en los países de Latinoamérica es la preponderancia del impuesto sobre Personas Jurídicas en relación a la imposición sobre Personas Físicas o Naturales, a la inversa de lo que ocurre en los países de la OECD.

Sin embargo, existe otra característica relevante que se destaca al considerar la estructura del impuesto, que es el hecho de que la mayor parte del impuesto sobre la renta personal en estos países proviene de trabajadores asalariados tal como surge del gráfico 10. Se destaca como característica relevante el tratamiento diferenciado entre los ingresos del trabajo (rentas ganadas) y los del capital (rentas no ganadas). Al respecto la estrechez de la base imponible potencial limita la aplicación del gravamen de manera mayoritaria a las rentas del trabajo obtenidas en relación de dependencia, ingresadas a través de mecanismos de retención en la fuente de manera directa.

Por ejemplo, una estimación efectuada en relación con el impuesto a la renta de las personas físicas ingresado en el año 2005 para Argentina muestra que más del 60\% del mismo es ingresado a través de retenciones en la fuente pagadora, correspondiendo mayoritariamente a sueldos y salarios pagados, y por otra de parte del $40 \%$ del gravamen restante que es ingresado a través de pagos directos mediante declaraciones juradas de los propios contribuyentes más del $40 \%$ corresponde a renta de la cuarta categoría. Es decir que, en síntesis, cerca del $80 \%$ del gravamen proviene de rentas del trabajo, dependiente e independiente, y solo el $20 \%$ a otras rentas no ganadas. 


\section{GRÁFICO 10 \\ ESTRUCTURA DEL IMPUESTO A LA RENTA PERSONAL EN PAÍSES \\ SELECCIONADOS DE AMÉRICA LATINA}

(En porcentajes sobre el total recaudado)

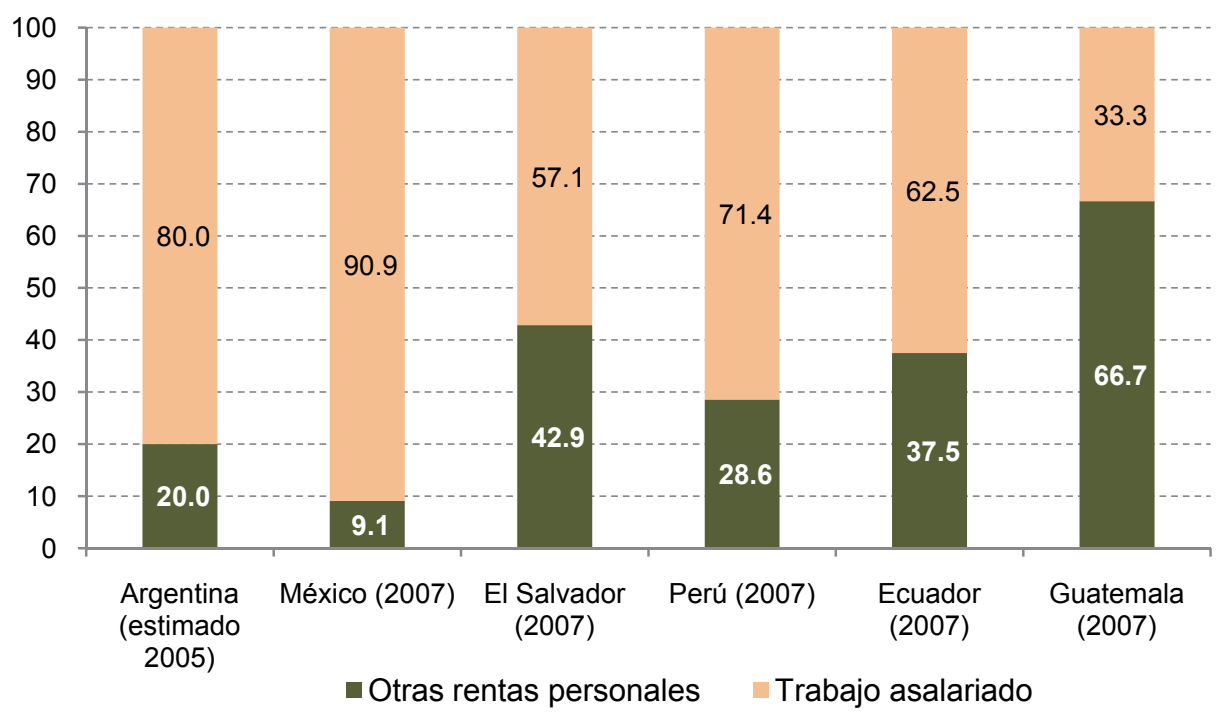

Fuente: Gómez Sabaíni y Rossignolo (2009) y Gómez Sabaíni, Jiménez y Podestá (2010).

Como han señalado Gómez Sabaíni, Jiménez y Podestá (2010), la elevada participación de los trabajadores asalariados en el total de la recaudación de la imposición a la renta personal tiene relación con bases imponibles constituidas principalmente por rentas del trabajo, debido a la existencia de tratamientos preferenciales a las rentas de capital como exenciones o tratamientos especiales para colocaciones financieras, intereses de títulos públicos, beneficios de fondos de inversión, ganancias de capital en bienes inmuebles y acciones. Además en varios países de la región se da un trato más favorable para la reinversión de utilidades.

Estas características constituyen elementos centrales a la hora de evaluar el escaso aporte que este tributo tiene a los efectos de lograr una mejora en la distribución del ingreso. Esto se debe a que los sectores que a la postre están siendo menos alcanzados por el impuesto son los individuos que están concentrados en los tramos de ingresos más elevados dado que, como fuera comentado, los tramos de mayores ingresos están compuestos en mayor medida por individuos cuyos ingresos provienen, en mayor proporción, del capital.

Una de las razones subyacentes a este desbalance en la imposición de la renta proveniente del salario y la renta del capital proviene del hecho de que no existe un único criterio en materia de imposición a la renta, sino que por el contrario, comenzando por sus orígenes y siguiendo por su evolución, los países han ido conformando distintos esquemas de imposición a la renta que difieren entre sí, tanto en los criterios para la determinación de la renta como en el esquema de alícuotas aplicado.

La razón para este comportamiento estriba en el hecho de que en América Latina coexisten países en los que el impuesto sobre la renta típico ha tenido un carácter "cedular", que supone gravar por separado los distintos tipos o cédulas de renta que percibe un mismo contribuyente (por trabajo asalariado, por intereses recibidos por depósitos, por dividendos obtenidos por acciones, entre otros). Estos problemas han determinado que gran parte de la imposición sobre la renta personal recaiga sobre los salarios de los trabajadores en relación de dependencia, con un impacto recaudador limitado. Por otro lado, existen los casos en los que la base imponible debe estar compuesta por el conjunto de rentas percibidas por la persona durante el período tributario, lo que se denomina el principio de la renta global. 
Adicionalmente, a lo largo de los años los países han incorporado en muchos casos reformas tendientes a mejorar la imposición a las sociedades (reformulación de los principios jurisdiccionales, ampliación del concepto de renta gravada, adopción de normas en materia de tributación internacional, especialmente en lo que hace a la aplicación de precios de transferencia), adecuándolo a estándares internacionales.

Este proceso de reformas no se ha verificado sin embargo en el ámbito de la renta de las personas físicas, ya que en su tratamiento se han aplicado normas que excluyen a la consideración de los dividendos de acciones como parte de la renta global de las personas. Esta fragmentación de la renta personal también es observada en materia de los ingresos generados por las colocaciones de tipo financiero, cualquiera sean éstas, las que por distintas circunstancias han quedado libres de gravamen en una gran cantidad de países, o bien se encuentran sujetas a un tratamiento más beneficioso en razón de las tasas aplicadas (Gómez Sabaíni et al, 2010).

En este amplio espectro de tratamiento de la imposición a la renta se encuentran en un extremo, por ejemplo, el caso de Chile, en donde los sujetos de la tributación deben ser, en último término, las personas naturales, por lo que los impuestos que pagan las personas jurídicas son sólo a cuenta de los impuestos personales. En Chile la base imponible debe estar compuesta por el conjunto de rentas percibidas por la persona durante el período tributario, lo que se denomina el principio de la renta global (Jorratt, 2009). El impuesto que se tributa es el denominado Impuesto Global Complementario (IGC), que es un impuesto progresivo cuyas tasas varían de $0 \%$ a $40 \%$ y debe ser declarado y pagado anualmente por todas las personas naturales residentes, y a él confluyen todas las rentas percibidas durante dicho período, tales como honorarios, retiros de empresas, dividendos, ganancias de capital, etc. Cuando las rentas son obtenidas por personas extranjeras o no residentes, el IGC se reemplaza por el Impuesto Adicional (IA).

La Ley de Impuesto a la Renta distingue entre las rentas del capital, de Primera Categoría, y las rentas del trabajo, la Segunda Categoría. Las primeras son gravadas con el "Impuesto de Primera Categoría" (IPCA), cuya tasa es de un 17\% y opera como un anticipo de los impuestos personales que deben pagar los accionistas, socios o dueños de las empresas, por los dividendos o retiros de utilidades. Una característica esencial del Impuesto a la Renta es la integración del IPCA, que grava las utilidades de las empresas, con el IGC o el IA, que afectan a las utilidades distribuidas, por la vía de permitir la utilización del primero como crédito contra estos últimos.

La tributación que afecta a las rentas de los activos financieros que existen en el mercado es heterogénea, y depende del tipo de instrumento financiero que las genera, la persona que las percibe; y el monto de las mismas. Los intereses de depósitos a plazo y cuentas de ahorro por ejemplo, tributan sobre base percibida, mientras que las ganancias en cuotas de fondos mutuos y fondos de inversión lo hacen sobre base realizada. En los cuadros A.5, A.6 y A.7 del Anexo se sintetizan los tratamientos tributarios específicos sobre intereses, dividendos y rendimientos en vehículos de inversión colectiva, como fondos de inversión y fondos mutuos (fuente: CIAT, 2013).

De acuerdo con Jorratt (2009), la Ley de Impuesto a la Renta trata de manera distinta las ganancias de capital de los siguientes activos: acciones; bonos; derechos sociales; bienes raíces; bienes muebles; pertenencias mineras y derechos de agua; derechos de propiedad intelectual o industrial; bienes en participación de herencia y bienes en liquidación de sociedad conyugal; acciones y derechos de una sociedad legal minera o contractual minera; derechos o cuotas bienes raíces poseídos en comunidad; y vehículos.

Por otra parte, las ganancias de capital en algunos activos y bajo determinadas circunstancias están exentas de impuestos o no están gravadas, como es el caso de las acciones con alta presencia bursátil. En los casos en que sí están gravadas, afectas, ya sea a los impuestos normales o al Impuesto Único de Primera Categoría, la base imponible sobre la cual se aplican los impuestos corresponde a la diferencia entre el precio de venta del activo y su costo de adquisición, ajustado por la variación de precios. En el caso de bonos e instrumentos de este tipo, la ganancia de capital se determina como la diferencia entre el precio de venta y su costo de adquisición descontando lo rescatado. 
En Argentina, el Impuesto a las Ganancias distingue netamente entre las personas físicas y las sociedades de capital, como sujetos. Aunque algunas normas generales son de aplicación a uno y otro caso, es conveniente para este análisis, que ambas situaciones se traten separadamente. Por dicho motivo, esta primera sección se refiere sólo a las personas físicas.

Las personas físicas, incluidas las sucesiones indivisas, están gravadas por la totalidad de sus ganancias, originadas en cuatro categorías de fuentes: rentas del suelo, rentas de capitales, beneficios de empresas y remuneración del trabajo personal. Quienes residen en el país están obligados por la totalidad de sus ganancias obtenidas en el país o en el exterior, pudiendo computar como pago a cuenta del impuesto, las sumas abonadas en el exterior por gravámenes análogos. En el caso de los no residentes, las ganancias originadas en bienes situados o actividades realizadas dentro de los límites del país, están también alcanzadas.

Una de las razones que determina en Argentina la reducida participación relativa del impuesto a la Renta de Personas Físicas estriba, además de los mencionados casos de elevado nivel decílico de la renta gravada, y el bajo nivel de cumplimiento, en el tratamiento diferenciado entre rentas del trabajo asalariado y rentas del capital. Esto tiene su origen en la gran amplitud de las exenciones que beneficia a las rentas de capital provenientes de colocaciones financieras, intereses de títulos públicos, tratamiento independiente de los dividendos, y numerosas exenciones como la exoneración de todas las ganancias de capital que obtienen las personas físicas por cualquier concepto que sea ${ }^{12}$.

En el cuadro A.8 del anexo se detalla el tratamiento de los principales tipos de rentas financieras obtenidas en el país según el sujeto que las obtiene. Allí puede verse que las colocaciones en instituciones financieras (depósitos en caja de ahorro, a plazo fijo, etc. en instituciones financieras regidas por ley se encuentran exentas para las personas físicas. En particular, se destaca que los dividendos de acciones de sociedades constituidas en el país pueden estar sujetos a retención del 35\%, si los resultados que se distribuyen no pagaron el $35 \%$ en cabeza de la sociedad. Las rentas de títulos públicos emitidos por el Estado Nacional, las provincias o los municipios están exentas si los beneficiarios son personas físicas, mientras que las rentas de Obligaciones Negociables de Sociedades Argentinas constituidas en el país, considerando que existe oferta pública también están exentas si los perceptores son personas físicas.

En el otro extremo se puede mencionar el caso de Guatemala, país en el que el impuesto a la Renta (ISR) la unidad contribuyente es el negocio, se grava la renta territorial, el sistema es de carácter cedular, y las rentas del capital cuentan con un trato más favorable que las otras fuentes gravables. Existen dos regímenes para las personas jurídicas y naturales que realizan actividades empresariales: el régimen general y el optativo: en el primer régimen las empresas y las personas naturales aplican el 5\% sobre los ingresos brutos; en el segundo las empresas y las personas naturales pueden optar por aplicar el $31 \%$ sobre su renta neta ${ }^{13}$.

Las ganancias de capital tienen un tratamiento diferenciado en la ley, que define que los contribuyentes que aplican el régimen general sobre ingresos brutos deben pagar el $10 \%$ sobre las ganancias de capital. Por su parte, aquellos que optaron por el tratamiento sobre la renta imponible deben pagar el 31\%, no siendo posible compensar los resultados del ejercicio con las ganancias o pérdidas de capital.

De manera similar que en el caso de Guatemala, en el mismo plano de tratamientos diferenciados a las distintas rentas se encuentra EI Salvador. Cabrera y Guzmán (2009) señalan que "a pesar de que figuran como parte de la renta obtenida, los ingresos provenientes del capital tienen un trato más favorable que aquellas generadas por el trabajo".

El Impuesto sobre la Renta grava la obtención de rentas provenientes del trabajo, cualquiera sea su forma de pago, las originadas en la actividad empresarial de cualquier naturaleza, las rentas del capital

Cetrángolo y Gómez Sabaíni (2007).

La presente sección sigue a Cabrera (2009). 
y toda clase de productos, ganancias, beneficios o utilidades, cualquiera que sea su origen ${ }^{14}$. Entre las renta no gravadas se encuentran las jubilaciones o pensiones, los intereses, premios y otras utilidades que provengan de los depósitos bancarios obtenidos por personas naturales, el valor del arrendamiento de la casa, habitación, quinta o esparcimiento, las ganancias de capital provenientes de la venta de bienes inmuebles, y las utilidades o dividendos para el socio o accionista, incluyendo ganancias de capital provenientes de la compraventa de acciones o cualquier otro beneficio que obtengan las personas naturales generados en este tipo de inversiones, entre otros conceptos ${ }^{15}$.

Esta última exención está sujeta a la condición de que la sociedad que distribuye las mismas las haya declarado y haya pagado el impuesto correspondiente. El principio territorial aplicado por corresponde al principio de fuente, a las rentas obtenidas en el país por los sujetos domiciliados o no. Dado que las rentas financieras no están alcanzadas por el tributo, ni los dividendos de acciones, el tributo pierde globalidad, limitándose en particular a gravar las rentas de trabajo, así como algunas otras rentas varias de menor significación. Así, quedan alcanzados por el impuesto sólo los dividendos distribuidos por actividades exentas siempre que sus accionistas no hayan sido eximidos del impuesto, junto con los ingresos por intereses de personas jurídicas.

El caso de Uruguay resulta singular. A partir del año 2007, la introducción de un modelo dual de imposición a los ingresos ha supuesto una importante simplificación tributaria. En general, las personas físicas que no realizan actividades económicas quedan sometidas al Impuesto sobre la Renta de las Personas Físicas (IRPF); pero las sociedades constituidas en el país, los establecimientos permanentes de las empresas no residentes, con un criterio similar al de la OECD, así como las personas físicas con actividades empresariales (si optan por ello) son gravadas por el Impuesto sobre la Renta de las Actividades Económicas (IRAE). EL IRAE tributa con una alícuota del 25\% sobre las utilidades obtenidas por los sujetos pasivos netas, sin un mínimo imponible.

El cierre de este esquema de sujeción de la renta obtenida en Uruguay viene dado por la existencia del Impuesto sobre la Renta de no Residentes (IRNR), cuyo tenor grava a las personas físicas o jurídicas no residentes sin establecimiento permanente mediante una alícuota proporcional del $12 \%$, aplicable sobre la renta bruta y sin mínimo imponible, aunque existen algunas alícuotas reducidas, concretamente, del 3 y del 5\% para los intereses de obligaciones, depósitos y otros títulos de Deuda y del $7 \%$ para los dividendos y utilidades que, previamente, estuvieron sujetas como beneficios al IRAE. En el Cuadro A.9 del Anexo se resumen las alícuotas aplicadas para cada tipo de rentas del capital.

El modelo dual de IRPF uruguayo se basa en la idea central de gravar las rentas del trabajo de forma separada de las rentas del capital (intereses, dividendos y utilidades, alquileres, ganancias de capital): las primeras con una escala progresiva de alícuotas y las segundas con una tasa proporcional. Por su parte, las pensiones, por razones puramente organizativas y de gestión, se sujetan a un tributo aparte, gestionado por una unidad administrativa diferente de la DGI, denominado Impuesto a la Asistencia a la Seguridad Social (IASS) que recae sobre las pensiones privadas y públicas y otras rentas de la pasividad, excluyéndose del IRPF y del IRNR y afectándose a los recursos del Banco de Previsión Social. La mencionada tasa proporcional sobre las rentas del capital es igual a la tasa marginal inferior que grava los rendimientos del trabajo, siendo ésta un "ancla" del sistema, la tasa mínima a partir de la cual se empiezan a gravar las rentas. A su vez, la tasa marginal máxima que grava las rentas del trabajo, es equivalente al tipo que sujeta las rentas (netas) empresariales (Barreix y Roca, 2007).

Párrafos atrás se mencionaba el hecho de que las tasas marginales máximas del impuesto a la Renta habían convergido en torno al $27 \%$. Esto generó que el tratamiento a los dividendos de las sociedades haya sido modificado durante los últimos años como una consecuencia directa de la

14 Esta sección sigua a Gómez Sabaíni, J. C. (2005), op. cit.

15 Las ganancias de capital tienen un trato diferenciado. Cuando son realizadas en un plazo menor a un año tributan a una tasa del $10 \%$ siempre y cuando correspondan a personas naturales o jurídicas que no se dediquen a la compraventa de bienes muebles o inmuebles, en caso contrario la ganancia de capital se computará como parte de su ingreso imponible. Cuando el período sea mayor a un año el cálculo se hace en función al número de años por los cuales se ha poseído el bien y la renta imponible del giro ordinario. Sin embargo, cuando este plazo supere los seis años desde la fecha de adquisición, dichas rentas estarán exentas del impuesto mencionado. 
reducción de las tasas marginales máximas aplicadas a los ingresos de las personas físicas. Como se pudo apreciar en los ejemplos anteriores, y puede comprobarse en los casos de Ecuador, México y Perú (véase el cuadro A.10 del anexo), los dividendos han quedado excluidos, en muchos países de la región, de la base imponible del impuesto a la renta personal con el fin de buscar la simetría con otros ingresos de capital como los intereses de colocaciones bancarias o de títulos de deuda.

Por una parte, la mencionada tendencia al tratamiento diferenciado de este tipo de ingresos ha significado un tratamiento celular y proporcional a los ingresos provenientes de los dividendos accionarios, es decir, una desviación del concepto de renta global. Por la otra, Gómez Sabaíni et al (2010) concluyen que es lógico que la renta proveniente de la compra de acciones deba guardar una simetría con la proveniente de otras colocaciones financieras, a fin de evitar arbitrajes entre las distintas formas de colocación de los ahorros. Este argumento y las dificultades existentes para determinar la renta en presencia de fenómenos inflacionarios, han determinado que la mayoría de los países analizados hayan excluido o dejado exentos del gravamen los ingresos provenientes de colocaciones financieras, por lo que el impuesto a la renta personal ha quedado casi exclusivamente limitado a gravar las rentas del trabajo personal.

\section{Reformas recientes que tienden al fortalecimiento del tributo}

Las cuestiones mencionadas en los párrafos anteriores han determinado que gran parte de la imposición sobre la renta personal recaiga sobre los salarios de los trabajadores en relación de dependencia, y que este impuesto tenga por consiguiente un impacto recaudador limitado. Sin embargo, y pese a las limitaciones referidas, en los últimos años se han verificado algunas reformas al impuesto sobre la renta en América Latina y el Caribe, las que han sido más numerosas en los últimos años (2007-2012) que en períodos anteriores, aunque han diferido en cuanto a su cobertura y profundidad. Las reformas pueden sintetizarse de la siguiente manera, según el Panorama Fiscal de América Latina 2013 de CEPAL ${ }^{16}$.

En varios países (como Chile, Ecuador, El Salvador, Estado Plurinacional de Bolivia, Honduras, México, Perú y Uruguay) hubo una tendencia a aumentar las alícuotas (de empresas o personas naturales), o a establecer tasas adicionales correspondientes al impuesto sobre la renta.

Por el contrario, en otros países las tasas se redujeron aunque, a fin de compensar las referidas disminuciones, simultáneamente se tendió a ampliar la base imponible (los casos de Guatemala, Nicaragua, Panamá y República Dominicana).

La mayoría de las reformas, sin embargo, y tanto en Centroamérica como en América del Sur, procuraron ampliar la base imponible del impuesto sobre la renta. Se ha extendido la tributación al conjunto de ingresos del trabajo y de las rentas de capital, incluida la aplicación de impuestos a dividendos (Colombia, El Salvador, Guatemala, Nicaragua, Panamá, Perú y República Dominicana).

En algunos casos, la ampliación de ciertas exenciones o deducciones permitidas (Chile, Panamá) o el aumento del mínimo exento en algunos países (Guatemala, Nicaragua, Panamá), si bien han disminuido la base imponible del impuesto sobre la renta, estas reducciones fueron compensadas con el establecimiento de impuestos mínimos y la reducción de exenciones en la mayoría de los casos, o la precisión de gastos deducibles con el fin de limitar su alcance.

El establecimiento o la modificación de impuestos mínimos sobre los ingresos societarios en los últimos años han permitido fortalecer la recaudación del impuesto sobre la renta y aumentar el control de la evasión impositiva ${ }^{17}$; en Costa Rica se optó por gravar el activo fijo de las empresas, y en la Argentina se aplica sobre el valor de los activos brutos.

El impuesto mínimo que grava el patrimonio o los activos netos es utilizado en Colombia, Ecuador, Panamá y Uruguay. En Guatemala se aplica el impuesto de solidaridad que grava con una alícuota del 1\%

\footnotetext{
Sin embargo, un detalle de estas reformas recientes puede consultarse en los cuadros K y L del Anexo.

Ver Gómez Sabaíni y Jiménez (2011).
} 
sobre activos netos o ingresos brutos, el que sea mayor. Un caso singular es el de México, donde a partir de 2008 se reemplazó el impuesto que tomaba como base el activo bruto de la empresa (impuesto al activo o IMPAC) mediante la implementación de un gravamen inspirado en el flat tax (una modalidad de impuesto mínimo a tasa única), denominado impuesto empresarial de tasa única (IETU).

Cabe consignar que en la mayoría de las reformas se han incluido normas de tributación internacional nuevas o revisadas, aplicados en gran parte a precios de transferencia y también a paraísos fiscales y a no residentes.

Varias reformas se han inspirado en el impuesto dual existente en los países escandinavos, por ejemplo, en el caso de Uruguay. Como ya fuera señalado, a partir del año 2007 este país comenzó a gravar por separado las rentas del trabajo, con tasas progresivas del $10 \%$ al $25 \%$ (que subió al $30 \%$ en 2012), y las rentas del capital, con una tasa proporcional del 12\%, excepto los dividendos que tributan a una tasa del 7\% (Barreix y Roca, 2007). La reforma tributaria uruguaya del año 2006 constituye un caso singular a nivel regional por sus características propias, por su enfoque global y por los resultados logrados. Tanto ésta como otras reformas tributarias aplicadas en años recientes en los países de Sudamérica se presentan con mayor detalle en el anexo (véase el cuadro A.11).

Al respecto, Romano (2008) ha señalado que esta reforma no sólo permitió aumentar la participación de la imposición directa (sin incrementar la presión tributaria total) sino que además tuvo efectos positivos en el aspecto distributivo. Esta reforma, que también incluyó una leve rebaja de la tasa general del IVA, priorizó el fortalecimiento del Impuesto sobre la Renta Personal (IRP) para lo cual se redujo significativamente el número de tributos vigentes, simplificando el sistema y permitiendo una mejor asignación de recursos de la Administración Tributaria hacia los impuestos de mayor rendimiento recaudatorio. Por otra parte, se incrementó el porcentaje de rentas de las personas físicas alcanzadas por el IRP y se incrementó el porcentaje de la carga impositiva soportada por los dos deciles de más altos ingresos, aumentando la progresividad del IRP y tornando más equitativo al sistema tributario uruguayo en su conjunto.

En Perú también se incorporaron algunos elementos de imposición dual y desde 2009, además de aplicarse una escala progresiva de tasas (del 15\% al 30\%) sobre los ingresos provenientes de rentas del trabajo, las rentas del capital comenzaron a gravarse con una tasa proporcional del 6,25\% (sobre el $80 \%$ de la renta gravable). Como excepción se incluyeron los dividendos, que tributan a una tasa del $4,1 \%$, y los intereses de ahorros y depósitos bancarios de personas naturales, exoneradas desde 2010 (CEPAL, 2013).

La República Dominicana y varios países de Centroamérica (El Salvador, Guatemala, Honduras, Nicaragua y Panamá) aprobaron reformas tributarias en igual sentido y fijaron alícuotas uniformes para gravar las rentas de capital que se sitúan entre un 10\% y un 15\% (con excepciones en los casos de rentas percibidas por los no residentes), que se conjugan con tasas mayores para las utilidades empresariales y tasas progresivas para las rentas del trabajo (CEPAL, 2013). El detalle de las reformas aplicadas en los países centroamericanos puede consultarse en el cuadro A.12 del anexo.

\section{E. La tributación patrimonial y las debilidades estructurales que limitan su desarrollo}

Resulta un hecho ya conocido que la importancia relativa de los impuestos al patrimonio ha sido históricamente muy reducida en los países de América Latina, al punto de ser prácticamente ignorada como alternativa en los debates que tratan sobre herramientas para mejorar el impacto distributivo de los sistemas tributarios de la región.

No obstante, en años recientes, la tributación directa sobre la propiedad ha suscitado creciente interés entre los funcionarios y académicos tanto de países desarrollados como de aquellos en vías de desarrollo. Esto se ha debido a que, además de presentar una serie de ventajas en materia de eficiencia $\mathrm{y}$ equidad, se ha reconocido a estos impuestos como una herramienta viable para generar un flujo relativamente estable de recursos tributarios, con bajos costos de cumplimiento y de administración tributaria y escasos efectos distorsivos sobre el empleo y el crecimiento del PIB. Asimismo, dado que 
en la mayoría de los países de la región la riqueza patrimonial se halla altamente concentrada, estos tributos constituyen una forma válida y provechosa para gravar a las familias de los sectores más ricos de cada población.

Tal como señalan De Cesare y Lazo Marín (2008), este tipo de tributación comprende una amplia gama de impuestos ${ }^{18}$. Además de los conocidos impuestos recurrentes sobre la propiedad y/o posesión de bienes inmuebles, en América Latina también son utilizados el impuesto a la transferencia de bienes inmuebles entre vivos (donaciones) y el impuesto a la propiedad de los vehículos automotores, mientras que algunos países han establecido un impuesto recurrente sobre el patrimonio neto. Un caso particular está constituido por los impuestos aplicados sobre movimientos y transacciones financieras y de capital, los cuales fueron incorporados en un conjunto acotado de países durante la última década y mostraron un muy aceptable rendimiento recaudatorio (Gómez Sabaíni y Morán, 2013).

En el cuadro 3 se presentan los datos de recaudación tributaria asociada a estos gravámenes para el año 2010, donde se detallan los diferentes tipos de tributos que recaen sobre el patrimonio de acuerdo a la clasificación internacional. Como puede observarse, la recaudación promedio obtenida por 15 países de América Latina a través de la imposición patrimonial resulta igual a $0,83 \%$ del PBI, lo cual es menos de la mitad respecto del promedio mostrado por la $\operatorname{OECD}(1,77 \%$ del PBI).

\section{CUADRO 3 \\ ESTRUCTURA DE LA RECAUDACIÓN DE LOS IMPUESTOS PATRIMONIALES EN PAÍSES DE AMÉRICA LATINA Y LA OECD, AÑO 2010}

(En porcentajes del $P B I$ )

\begin{tabular}{|c|c|c|c|c|c|c|c|}
\hline & $\begin{array}{l}\text { Propiedad } \\
\text { inmueble }\end{array}$ & $\begin{array}{c}\text { Riqueza } \\
\text { neta }\end{array}$ & $\begin{array}{l}\text { Herencias y } \\
\text { donaciones }\end{array}$ & $\begin{array}{l}\text { Transacciones } \\
\text { financieras y } \\
\text { de capital }\end{array}$ & $\begin{array}{c}\text { No } \\
\text { recurrentes }\end{array}$ & $\begin{array}{l}\text { Otros } \\
\text { recurrentes }\end{array}$ & $\begin{array}{l}\text { Total imp. } \\
\text { patrimonio }\end{array}$ \\
\hline Argentina & 0,35 & 0,36 & - & 2,31 & - & - & 3,02 \\
\hline Brasil & 0,42 & - & 0,06 & 0,82 & - & 0,56 & 1,86 \\
\hline Chile & 0,50 & - & 0,04 & 0,18 & - & - & 0,72 \\
\hline Colombia & 0,58 & 0,36 & - & 0,59 & - & - & 1,53 \\
\hline Costa Rica & 0,25 & - & - & 0,08 & - & 0,01 & 0,34 \\
\hline Ecuador & - & - & - & - & - & - & 0,00 \\
\hline El Salvador & - & - & - & 0,08 & - & - & 0,08 \\
\hline Guatemala & 0,19 & - & - & 0,00 & - & - & 0,19 \\
\hline México & 0,20 & - & - & 0,10 & - & - & 0,30 \\
\hline Panamá & 0,40 & - & - & 0,11 & - & 0,28 & 0,79 \\
\hline Paraguay & 0,29 & - & - & 0,02 & - & 0,00 & 0,31 \\
\hline Perú & 0,20 & - & - & 0,32 & - & - & 0,52 \\
\hline $\begin{array}{l}\text { República } \\
\text { Dominicana }\end{array}$ & 0,18 & - & 0,01 & 0,45 & 0,03 & - & 0,67 \\
\hline Uruguay & - & 1,13 & - & 0,17 & - & 0,04 & 1,34 \\
\hline $\begin{array}{l}\text { Venezuela } \\
\text { (República } \\
\text { Bolivariana de) }\end{array}$ & - & - & 0,02 & - & - & - & 0,02 \\
\hline
\end{tabular}

18 En rigor, las clasificaciones tributarias adoptadas por los organismos internacionales (OCDE, FMI, Banco Mundial) distinguen entre seis categorías de tributos patrimoniales: 1) impuestos recurrentes sobre bienes inmuebles; 2) impuestos recurrentes sobre la riqueza neta; 3) impuestos a las transferencias por sucesión, herencia o donaciones; 4) impuestos sobre las transacciones financieras y de capital; 5) otros impuestos recurrentes sobre la propiedad y; 6) otros tributos no recurrentes sobre la propiedad, incluyendo las contribuciones de mejoras. 
Cuadro 3 (conclusión)

\begin{tabular}{lccccccc}
\hline & $\begin{array}{c}\text { Propiedad } \\
\text { inmueble }\end{array}$ & $\begin{array}{c}\text { Riqueza } \\
\text { neta }\end{array}$ & $\begin{array}{c}\text { Herencias y } \\
\text { donaciones }\end{array}$ & $\begin{array}{c}\text { Transacciones } \\
\text { financieras } y \\
\text { de capital }\end{array}$ & $\begin{array}{c}\text { No } \\
\text { recurrentes }\end{array}$ & $\begin{array}{c}\text { Otros } \\
\text { recurrentes }\end{array}$ & $\begin{array}{c}\text { Total imp. } \\
\text { patrimonio }\end{array}$ \\
\hline AL - 15 & 0,32 & 0,62 & 0,03 & 0,40 & 0,03 & 0,18 & 0,78 \\
\hline Alemania & 0,45 & - & 0,18 & 0,21 & - & - & 0,84 \\
Canadá & 3,13 & 0,09 & - & 0,16 & 0,19 & - & 3,57 \\
Dinamarca & 1,37 & - & 0,22 & 0,33 & - & - & 1,92 \\
España & 0,88 & 0,01 & 0,23 & 0,76 & 0,16 & 0,01 & 2,05 \\
Estados Unidos & 3,03 & - & 0,14 & - & - & - & 3,17 \\
Francia & 2,47 & 0,23 & 0,40 & 0,56 & - & - & 3,66 \\
Italia & 0,62 & 0,14 & 0,03 & 1,10 & 0,06 & 0,10 & 2,05 \\
Japón & 2,13 & - & 0,26 & 0,29 & - & - & 2,68 \\
Países Bajos & 0,70 & 0,00 & 0,29 & 0,47 & - & - & 1,46 \\
Reino Unido & 3,40 & - & 0,18 & 0,62 & - & - & 4,20 \\
\hline OCDE - 34 & 1,05 & 0,16 & 0,12 & 0,42 & 0,02 & 0,01 & 1,78 \\
\hline
\end{tabular}

Fuente: Elaboración propia sobre la base de OECDStats (incluso para los países de América Latina).

Sin embargo, detrás de la brecha entre ambos grupos de países en términos cuantitativos, debe señalarse las diferencias en la composición de este tipo de tributación para cada uno de ellos y entre los distintos países. Así, en América Latina cerca de la mitad del monto promedio de recursos tributarios corresponde a impuestos sobre transacciones financieras y de capital (entre los cuales se ha destacado, en años recientes, el impuesto sobre operaciones financieras), otra porción importante $(38,5 \%)$ corresponde a los impuestos recurrentes sobre bienes inmuebles y el resto engloba a los demás tributos patrimoniales con una participación mayoritaria de los gravámenes sobre la riqueza o patrimonio neto (aunque sólo se encuentren vigentes en 3 países latinoamericanos ${ }^{19}$ ). En cambio, entre los países de la OECD predomina el impuesto sobre la propiedad inmueble, seguido por los impuestos transaccionales y, muy por detrás, los impuestos sobre herencias, legados y donaciones (ampliamente difundido) y los tributos que gravan el patrimonio neto (activos).

Por otra parte, tanto en América Latina como en la OECD, las diferencias entre países son muy grandes y obligan a ser cauteloso a la hora del análisis. Esto se ve reflejado en la recaudación total de la imposición patrimonial así como en los principales tributos que la componen: en los gravámenes sobre transacciones financieras y de capital, Argentina constituye un caso paradigmático a nivel regional, algo similar a la situación de España e Italia entre los países desarrollados. En los impuestos sobre la propiedad inmueble las diferencias son aún más amplias en la OECD (ver cuadro 3), aunque en general se ubican por encima de los países latinoamericanos en cuanto a la recaudación obtenida.

A pesar de la diversidad de tributos patrimoniales y de los magros ingresos tributarios que aportan en los países de la región, algunos de ellos resultan de especial interés para los objetivos de este trabajo en virtud de las posibilidades que brindan para aplicar impuestos con un impacto distributivo progresivo -que complementen los efectos derivados de la imposición sobre la renta personal-, cuya carga impositiva recaiga con mayor peso relativo (y alcance de manera efectiva) sobre los individuos de rentas más elevadas.

En primer lugar, el impuesto sobre la propiedad inmueble es reconocido a nivel internacional como la más importante fuente de recursos propios para los gobiernos subnacionales y los expertos generalmente concuerdan en cuanto a las ventajas que posee en ese sentido. En teoría y aún con

19 Por otra parte, en varios países de la región el monto neto de activos es utilizado también para aplicar impuestos mínimos del ISR. 
imperfecciones, este tributo tiene un gran potencial para generar un monto considerable, su grado de cumplimiento puede ser relativamente bajo y su base imponible no se agota a lo largo del tiempo.

Precisamente, en los países de la región el impuesto sobre la propiedad inmueble es el instrumento más comúnmente aceptado y utilizado como fuente de recursos fiscales en los niveles inferiores de gobierno. Este gravamen suele tomar la forma de pagos anuales realizados por el propietario, cuyo monto está vinculado con alguna medida del valor económico del bien inmueble gravado, el cual es periódicamente revaluado a través de un índice de actualización. Sin embargo, Sepúlveda y MartínezVázquez (2011) encuentran importantes diferencias, que generalmente inciden sobre el desempeño recaudatorio, en cuanto a los arreglos institucionales vinculados a este tributo en particular.

La mayoría de los países de América Latina asignan la potestad tributaria del impuesto sobre la propiedad inmueble a sus respectivos gobiernos locales o municipales, pero se registran excepciones donde este impuesto sigue estando bajo la órbita del gobierno central (República Dominicana), o donde alguna autoridad sobre los impuestos sigue estando en dicho nivel de gobierno (por ejemplo, Brasil para los impuestos rurales, Guatemala y Panamá) o en el nivel provincial (Argentina). En la mayoría de los casos, a los municipios también se les otorga cierta autoridad para modificar las tasas impositivas, a veces dentro de límites legislados, pero aquí también hay excepciones. Por ejemplo, Chile no delega esa atribución a los municipios y los estados o provincias en México y Argentina también comparten dicha potestad con las autoridades nacionales.

Como ya se enfatizó, el rendimiento recaudatorio de estos tributos es exiguo en todos los países latinoamericanos donde se aplica y esto se explica por una combinación de factores que limitan su correcto funcionamiento como fuente de recursos propios subnacionales. Entre ellos, se destacan la baja capacidad operativa y la ineficiencia de las administraciones tributarias de los gobiernos locales, los bajos ratios de cobertura en el registro de catastro, los elevados niveles de morosidad y una considerable subvaluación de las propiedades debido a la falta sistemática de una adecuada actualización de los valores catastrales ${ }^{20}$. Asimismo, la alta visibilidad de estos tributos — característica esencial de los mismos - atenta muchas veces en contra de su correcto funcionamiento y administración puesto que fuertes presiones políticas estimulan la concesión de beneficios fiscales, como exenciones, tratamientos preferenciales y amnistías, así como también la reducción de tasas o mantenimiento de subvaluaciones, todo lo cual contribuye a erosionar la base del tributo y reduce su progresividad y su impacto redistributivo final.

Un segundo impuesto patrimonial con potencial relevancia a la hora de gravar las altas rentas es el que recae sobre las transmisiones de bienes a título gratuito, ya sea inter vivos (donaciones) o mortis causa (sucesiones, herencias y legados). Según De Cesare y Lazo Marín (2008), su aplicación está mucho menos difundida que el impuesto sobre la propiedad inmueble, pudiendo ser identificada en países como Brasil, Chile, Ecuador, El Salvador, Nicaragua, República Dominicana, Uruguay y Venezuela.

Generalmente, la base imponible de estos tributos corresponde al valor de los bienes y derechos sucesorios menos las deducciones permitidas en cada caso. Los gastos pasibles de deducción varían entre los países examinados. En general, los gastos deducibles incluyen aquellos decurrentes de la última enfermedad, funeral, apertura de sucesión, deudas hereditarias $\mathrm{y}$, en algunos casos, impuestos adeudados. En la práctica, el impuesto comprende la idea de gravar el patrimonio neto transmitido.

Aunque varían enormemente entre países, las alícuotas aplicadas suelen ser progresivas y, en algunos casos, selectivas de acuerdo al hecho imponible (por ejemplo, en República Dominicana o Uruguay). En Venezuela y Nicaragua, las tasas son progresivas de acuerdo al crecimiento de la base y selectivas según el grado de parentesco con el heredero legatario. Las mismas tasas se aplican en los casos de donaciones en Venezuela. Dependiendo del valor de los bienes transmitidos, existe una serie de deducciones aplicables al impuesto que varían desde $5 \%$ hasta $40 \%$, según la edad o parentesco del beneficiado.

20 Sepúlveda y Martínez-Vázquez (2011), a través del análisis econométrico, han explorado los principales determinantes del pobre rendimiento de estos impuestos en los países de América Latina. 
En el caso de Ecuador el impuesto se aplica en el marco del Impuesto a la Renta. De esta manera, son objetos del impuesto a la renta los acrecimientos patrimoniales de personas naturales o sociedades provenientes de herencias, legados y donaciones, recayendo sobre los beneficiarios la escala de alícuotas del impuesto a la renta aunque con tratamientos preferenciales para los menores de edad y aquellos con consanguinidad de primer grado con el causante. Para estos últimos las alícuotas aplicadas van de 3\% a $18 \%$ según el monto gravado mientras que, para otros colaterales de $2^{\circ}, 3^{\circ}$ y $4^{\circ}$ grado y no parientes, dichas tasas se ubican entre el 5\% y el 35\% para los mismos tramos.

Por su parte, la característica principal del sistema chileno consiste en la acumulación de todas las donaciones y legados durante la vida del beneficiario que provengan de un mismo causante, incluso los bienes de chilenos en el extranjero, a los que se deduce el monto de impuesto pagado en países extranjeros. Las alícuotas se aplican según distintos montos de unidades tributarias anuales y varían según el grado de consanguinidad o parentesco: del 1\% al $25 \%$ para el primer grado; de $1,2 \%$ a $30 \%$ para $2^{\circ}, 3^{\circ}$ y $4^{\circ}$ grado; y de $1,4 \%$ a $35 \%$ para no parientes.

A diferencia de los demás casos en la región, Uruguay grava las transmisiones patrimoniales en general con un mismo tributo. De esta manera, son objetos del impuesto las transmisiones de capital tanto las realizadas a título gratuito como a título oneroso. Los hechos gravados tributan un $2 \%$ al enajenante y un $2 \%$ al adquirente, en el caso de las donaciones; y para otros contribuyentes (herederos y legatarios) un 4\%, a excepción de los casos en línea recta ascendente o descendente con el causante cuya alícuota es de un 3\%. En el año 2006 se creó un adicional de 1\%, que alcanza a todos los hechos y actos cuando el objeto del impuesto es un inmueble rural. En este caso, los adquirentes y otros contribuyentes afrontarán una alícuota del 5\%, a excepción de los herederos y legatarios en línea recta ascendente o descendente con el causante cuya alícuota será de un $4 \%$.

El Impuesto a la Transmisión por Causa de Muerte y Donaciones (ITCMD) está reglado por la Constitución Federal de Brasil. Sin embargo, a nivel nacional no se fija un mínimo exento ni tampoco una escala progresiva de alícuotas, ya que la competencia pertenece a cada uno de los Estados y al Distrito Federal, los cuales ponen en vigencia el impuesto bajo la promulgación de una ley complementaria. Como lo dice su nombre, este impuesto grava las transmisiones por causa de muerte y donaciones de cualquier bien o derecho. En el caso de inmuebles la base imponible es el valor de mercado, mientras que para los derechos será utilizado su propio valor.

Antiguamente varios Estados poseían alícuotas progresivas, pero fueron derogadas en los últimos años aplicando alícuotas uniformes. La alícuota máxima es fijada por el Senado Federal y es del 8\%. En la práctica este impuesto que debiera gravar todo el patrimonio generalmente sólo tiene en cuenta a los inmuebles, gravados habitualmente a una tasa fija del 4\%. Sin embargo, no se observa un criterio unívoco entre las alícuotas de herencias y donaciones entre Estados. Por ejemplo, mientras en Río Grande do Sul y Pernambuco se aplican mayores tasas sobre las herencias que las donaciones (4\% vs. $3 \%$ y $5 \%$ vs. $2 \%$ respectivamente), en San Pablo y Minas Gerais aplican igual alícuota en ambas modalidades de transferencia ( $4 \%$ y $5 \%$, respectivamente).

Un último ejemplo que merece ser señalado es el correspondiente al Impuesto a la Transmisión Gratuita de Bienes (ITGB) que fuera introducido - en realidad, fue reformado el ya existente - por la provincia de Buenos Aires en Argentina (potestad subnacional). Tal como señalan Lódola y Velasco (2011), el rediseño de este tributo se condujo priorizando el objetivo de equidad distributiva por sobre los resultados recaudatorios, para lo cual la reforma se orientó hacia la aplicación de un impuesto personal, global y progresivo con una determinada incidencia sobre los estratos de ingresos más altos. La innovación técnica en este impuesto estuvo en que se grava la transmisión de bienes a título gratuito (como en los demás casos analizados) pero la carga del mismo no recae sobre el causante sino sobre cada uno de los beneficiarios al momento de recibir la transmisión de bienes. Además, esto lo diferencias tanto de los tradicionales tributos sobre activos netos y complementa la función redistributiva de la imposición sobre la renta personal. La progresividad y alcance del ITGB se asegura a partir de la existencia de mínimas exenciones (vivienda única del causante, bienes de pequeñas empresas familiares, etc.), alcanzando la totalidad del enriquecimiento con independencia del lugar de radicación de los 
bienes, donde los sujetos domiciliados en otras jurisdicciones deben pagar a la jurisdicción subnacional el monto correspondiente a los bienes situados en tal territorio.

Por último, a pesar de su potencial incidencia sobre los contribuyentes de rentas más elevadas, sólo dos países de América Latina aplican en la actualidad un impuesto sobre la riqueza o los activos netos.

En Argentina, el Impuesto sobre Bienes Personales es establecido y administrado a nivel nacional y su base imponible es el valor total de los bienes poseídos al 31 de diciembre de cada año, valuados de acuerdo con las disposiciones legales y reglamentarias. Las tasas son progresivas y selectivas, variando de 0,5 a $1,5 \%$, y abarca los bienes situados en el país y en el exterior tanto de las personas físicas domiciliadas en el país como de las sucesiones indivisas radicadas en el mismo.

En Uruguay, el Impuesto al Patrimonio (PAT) recae básicamente sobre el patrimonio de las personas físicas, los núcleos familiares, las sucesiones indivisas, las personas jurídicas constituidas en el extranjero y los sujetos pasivos del Impuesto a las Rentas de Actividades Empresariales (IRAE). Las tasas del impuesto son selectivas, se aplican por escalonamientos progresivos y oscilan entre el $0,7 \mathrm{y}$ $3,5 \%$ del valor del patrimonio neto, el cual comprende los bienes situados, colocados o utilizados económicamente en el país y se excluyen los bienes situados fuera del país. Son incluidos básicamente los inmuebles, vehículos automotores y los medios de transporte marítimo, derechos de usufructo, muebles y semovientes de la explotación agropecuaria, los seguros de vida y las rentas vitalicias. 



\section{La imposición a la renta y sus efectos en la distribución del ingreso en América Latina}

\section{A. Principales resultados observados en distintos estudios}

El objetivo de esta sección apunta a analizar una de las causas del incremento observado en la recaudación del impuesto a la Renta en América Latina. El propósito es determinar si las razones para el incremento de la recaudación estriban en políticas tributarias que hayan apuntado a reducir los problemas existentes, o si parecen más relacionados con un ajuste pasivo de los gobiernos ante incrementos generales en los niveles de base imponible.

El siguiente recuadro contiene una referencia metodológica, útil para dotar de un marco teórico que permita estudiar las cuestiones distributivas, para luego presentar los datos de la evolución efectiva y discrecional de bases imponibles y alícuotas legales.

\section{RECUADRO 2}

\section{CONCEPTOS TEÓRICOS PARA EL ANÁLISIS DE INCIDENCIA DISTRIBUTIVA DE LOS TRIBUTOS}

La manera más difundida de efectuar el análisis de una determinada distribución del ingreso resulta ser la denominada curva de Lorenz, que grafica la proporción acumulada del ingreso total contra el porcentaje acumulado de la población; en otros términos, evalúa qué porcentaje del ingreso total concentra una determinada proporción acumulada de la población ${ }^{a}$.

La curva de Lorenz está determinada por la fórmula

$$
L_{x}=\int_{0}^{y} \frac{x f(x) d x}{\mu}
$$

, con $p=F(y)$ y siendo $\mu$ el ingreso medio. Para interpretar esta ecuación nótese que y es el valor tal que el p por ciento de la población tiene ingresos menores a este valor. La ambigüedad en la comparación entre dos períodos distintos surge al reflejarse cruces en las curvas de Lorenz; es allí donde debe apelarse a distintos indicadores que ponderen los lugares de la distribución en donde estos cruces ocurren.

El indicador más utilizado en las comparaciones es el denominado índice de Gini. El mismo mide el área que se encuentra por debajo de la curva de Lorenz y la línea de perfecta desigualdad. Los valores extremos para este índice de desigualdad son uno, para perfecta desigualdad, y cero, para la perfecta igualdad. 


\section{Recuadro 2 (conclusión)}

Las formulaciones para el cálculo del Gini parten de considerar que $G=A /(A+B)$, siendo $A_{\text {el área situada }}$ entre la curva de Lorenz y la línea de perfecta igualdad, y $B$ la parte correspondiente al sector comprendido entre la curva y los extremos del gráfico, es decir, la perfecta desigualdad. En términos continuos, el Gini se calcula mediante la fórmula $G=1-2 \int_{0}^{1} L(p) d p$, siendo $\mu$ el ingreso medio.

El índice de Gini depende del orden de los individuos en la distribución; una transferencia de una persona rica a otra pobre de la distribución tiene mucho mayor efecto en la caída del indicador si ésta se realiza entre individuos más próximos a la media de la distribución que si éstos estuviesen más alejados de la misma, y por ende, más próximos a los extremos ${ }^{b}$.

Dado que la distribución del ingreso se revela, en general, desigual, existen entonces varias maneras de influir sobre la misma en aras de alcanzar un mayor grado de equidad social. Es aquí donde surgen las políticas presupuestarias: el efecto conjunto de impuestos y gastos públicos asume el papel redistributivo y su efecto final reflejará la influencia sobre el estado de situación anterior.

La asignación por deciles de los montos de impuestos pagados por los individuos genera una carga tributaria, al computar el cociente que recae en cada uno sobre el total recaudado. A partir de ello surge una Curva de Concentración

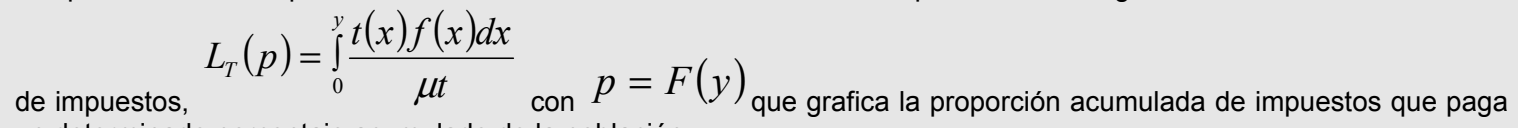
un determinado porcentaje acumulado de la población.

Esta curva, por definición compatible a la de Lorenz, genera el índice asimilable al Gini para la distribución del ingreso, el índice de Concentración de impuestos.Por analogía con el índice de Gini, entretanto, se construye el de Concentración de impuestos $C_{t}=1-2 \int_{0}^{1} L_{T}(p) d p$

El efecto final sobre la distribución del ingreso se refleja, entonces, en la Curva de Concentración del Ingreso post-

impuestos, que proviene de la diferencia entre ambas curvas,

$$
L_{x-T}(p)=\int_{0}^{y} \frac{(x-t(x)) f(x) d x}{\mu(1-t)} \text { con } p=F(y)_{\text {siendo }}
$$
$\mu(1-t)$ el ingreso medio.

A partir de la curva de concentración de impuestos puede determinarse el índice de Kakwani, dado por $K_{T}=C_{t}-G_{x}$

Gini, por lo cual es más desigual la distribución del ingreso que la de la carga tributaria y el sistema en su conjunto es regresivo; a la inversa, un Kakwani positivo demuestra que la Curva de Concentración de impuestos está por debajo de la de Lorenz, generando los impuestos un efecto de mejora en la distribución del ingreso.

El efecto redistributivo está determinado por el peso relativo de cada tributo, medido a través del índice de ReynoldsSmolensky (RS), el que está determinado, sin considerar reordenamientos, por la diferencia entre el Gini antes de impuestos y el Gini después de impuestos, $R S_{T}=G_{x}-C_{T}$ donde, si el índice es positivo, los impuestos generan un efecto de mejora en la distribución del ingreso.

Puede demostrarse ${ }^{d}$ que, si el ingreso post acción del gobierno depende sólo de la política impositiva, las medidas de Reynolds Smolensky y de Kakwani están relacionadas de la siguiente forma, donde t denota la tasa impositiva media o el tamaño del impuesto (presión tributaria): $R S_{T}=-(t /(1-t)) K_{T}$

Esta descomposición permite separar el efecto distributivo total en dos partes: uno debido a cambios en la progresividad y otro a cambios en la tasa efectiva media o el tamaño del impuesto, pudiendo ambos efectos ser interdependientes. Por ejemplo, si existe una estructura impositiva progresiva y el ingreso se incrementa por razones ajenas a la política fiscal, la tasa impositiva media aumentará ${ }^{\mathrm{e}}$. Estas cuestiones se tratarán en las secciones subsiguientes.

Fuente: Santiere, Gómez Sabaíni y Rossignolo (2000).

a La presente sección sigue a Gómez Sabaíni, Harriague y Rossignolo (2011); Ahumada, Canavese, Gasparini, Porto y Sanguinetti (1996); Gasparini y Porto (1992), y Gasparini, Cicowiez y Sosa Escudero (2013).

b A partir de ello, Atkinson establece la necesidad de poner de manifiesto los juicios de valor sobre la aversión a la desigualdad en un índice que involucre una función de utilidad social que incluya un parámetro que varíe de acuerdo a cada uno de los supuestos alternativos. Para un valor del mismo igual a cero, se estaría postulando una función de utilidad social que valora de igual manera a cada individuo de la distribución; un valor del parámetro que tienda a infinito lleva a un criterio tipo Rawls (la distribución del ingreso mejora sólo si lo hace el ingreso del individuo de menor ingreso), con lo que existe una amplia gama de valores que abarca a todos los posibles juicios de valor sobre la distribución. Un valor del ponderador igual a 0,5 refleja un ordenamiento, al comparar distintas distribuciones del ingreso, similar al que resulta de aplicar el índice de Gini.

c Lambert, P. (1993).

d Ver Ahumada, Canavese, Gasparini, Porto y Sanguinetti (1996); Gasparini y Porto (1992), y Gasparini, Cicowiez y Sosa Escudero (2013).

e La explicación sigue a Ahumada, Canavese, Gasparini, Porto y Sanguinetti (1996). 
La existencia de alícuotas marginales decrecientes, el elevado nivel decílico de la renta gravada, la abundancia de tratamientos diferenciales en relación con deducciones y rentas no gravadas (aspectos que se desarrollarán más adelante), conllevan a generar un impuesto sobre la Renta de Personas Físicas cuyo impacto redistributivo es bajo y cuya recaudación está concentrada en los tramos de mayores ingresos.

El cuadro 4 subsiguiente permite confirmar que, aún cuando en todos los países (con la excepción de Perú) el Impuesto a la Renta de Personas Naturales es claramente progresivo en su diseño tributario, posee un efecto muy reducido sobre la distribución del ingreso en virtud de su escasa participación dentro de las estructuras tributarias vigentes en la región. Por ejemplo, en Ecuador las estimaciones muestran la existencia de un gravamen sobre los ingresos personales con una elevada progresividad — con un índice de Kakwani igual a 0,423 y donde el $20 \%$ de la población con más altos ingresos paga más del 90\% del impuesto- pero muy bajo impacto redistributivo, situación que se repite, para la mayoría de los países, a excepción de los casos de Colombia, República Dominicana y Chile, en donde la reducción en el Gini post impuesto a la Renta de Personas Físicas reflajada en el índice de Reynolds Smolensky es superior a $0,02^{21}$.

\section{CUADRO 4 \\ RESULTADOS DE ESTUDIOS SOBRE INCIDENCIA DISTRIBUTIVADEL IMPUESTO A LA RENTA DE PERSONAS NATURALES EN AMÉRICA LATINA}

\begin{tabular}{|c|c|c|c|c|c|c|c|c|c|}
\hline \multirow[b]{2}{*}{ País } & \multirow[b]{2}{*}{ Año } & \multicolumn{5}{|c|}{ Índices } & \multicolumn{3}{|c|}{ Quién paga el impuesto } \\
\hline & & $\begin{array}{c}\text { Gini pre } \\
\text { impuestos }\end{array}$ & $\begin{array}{l}\text { Cuasi Gini } \\
\text { impuestos }\end{array}$ & Kakwani & $\begin{array}{l}\text { Gini post } \\
\text { impuestos }\end{array}$ & $\begin{array}{l}\text { Reynolds } \\
\text { Smolensky }\end{array}$ & $\begin{array}{c}40 \% \\
\text { inferior }\end{array}$ & $\begin{array}{c}20 \% \\
\text { superior }\end{array}$ & $\begin{array}{c}20 \% \\
\text { superior/ } \\
40 \% \text { inferior }\end{array}$ \\
\hline Colombia & 2004 & 0,5370 & 0,8940 & 0,3570 & 0,4590 & 0,0780 & $0 \%$ & $99 \%$ & 497,0 \\
\hline $\begin{array}{l}\text { República } \\
\text { Dominicana }\end{array}$ & 2004 & 0,5106 & 0,9057 & 0,3951 & 0,4759 & 0,0347 & $0 \%$ & $97 \%$ & - \\
\hline Chile & 2006 & 0,5791 & 0,9677 & 0,3886 & 0,5584 & 0,0207 & $0 \%$ & $99 \%$ & - \\
\hline Uruguay & 2006 & 0,4995 & 0,8630 & 0,3635 & 0,4875 & 0,0120 & $0 \%$ & $92 \%$ & 230,3 \\
\hline Argentina & 2008 & 0,4839 & 0,9375 & 0,4536 & 0,4738 & 0,0101 & $0 \%$ & $98 \%$ & - \\
\hline EI Salvador & 2006 & 0,5034 & 0,8281 & 0,3247 & 0,4947 & 0,0087 & $1 \%$ & $90 \%$ & 90,0 \\
\hline Costa Rica & 2004 & 0,5770 & 0,9098 & 0,3328 & 0,5692 & 0,0078 & $0 \%$ & $96 \%$ & 874,6 \\
\hline Brasil & 2003 & 0,6180 & 0,9243 & 0,3063 & 0,6113 & 0,0067 & $1 \%$ & $94 \%$ & 156,7 \\
\hline Nicaragua & 2001 & 0,5963 & 0,9441 & 0,3478 & 0,5905 & 0,0058 & $0 \%$ & $94 \%$ & - \\
\hline Panamá & 2003 & 0,6364 & 0,8803 & 0,2439 & 0,6312 & 0,0052 & $2 \%$ & $96 \%$ & 54,0 \\
\hline Honduras & 2005 & 0,5697 & 0,9000 & 0,3303 & 0,5647 & 0,0050 & $0 \%$ & $95 \%$ & - \\
\hline Ecuador & 2004 & 0,4080 & 0,8310 & 0,4230 & 0,4040 & 0,0040 & $0 \%$ & $93 \%$ & 311,0 \\
\hline $\begin{array}{l}\text { Venezuela } \\
\text { (Reública } \\
\text { Bolivariana de) }\end{array}$ & 2004 & 0,4230 & 0,8400 & 0,4170 & 0,4210 & 0,0020 & $0 \%$ & $100 \%$ & - \\
\hline Guatemala & 2000 & 0,5957 & 0,9115 & 0,3158 & 0,5946 & 0,0011 & $2 \%$ & $93 \%$ & 48,8 \\
\hline Perú & 2004 & 0,5350 & 0,5820 & 0,0470 & 0,5340 & 0,0010 & $10 \%$ & $64 \%$ & 6,7 \\
\hline
\end{tabular}

Fuente: Barreix, A., Bès, M. y Roca, J. (2009); Barreix, A., Roca, J. y Villela, L. (2006); Gómez Sabaíni, J.C., Harriague, M. y Rossignolo, D. (2011); Rezende, F. y Afonso, J. (2010); Roca, J. (2010); y Jorrat, M. (2010).

Nota: Los países fueron ordenados según el valor estimado del índice Reynolds-Smolensky, donde un valor positivo de la diferencia entre los coeficientes de Gini después y antes de impuestos indica un impacto positivo sobre la distribución del ingreso.

21 A diferencia de lo que ocurre en los países de la OECD, en donde el sistema tributario es progresivo y el efecto distributivo es igualador (ver Gómez Sabaíni y Rossignolo (2011), Gómez Sabaíni (2006)). 
El índice Cuasi Gini, entretanto, presenta el elevado grado de concentración de la recaudación del impuesto; a excepción del caso de Perú, en el resto de los países el impuesto es soportado, en más del $92 \%$, por el $20 \%$ de ingresos más elevados. Esto se refleja en el hecho de que en Colombia, República Dominicana, Chile, Argentina, Costa Rica, Panamá, Honduras y Venezuela, el 20\% de ingresos más elevados concentra más del $95 \%$ del total de la recaudación del impuesto, y el $40 \%$ de ingresos inferiores prácticamente no soporta la carga del impuesto en ninguno de los casos mencionados.

Es interesante analizar cómo cambia el efecto distributivo total para un país entre dos períodos, Adaptando la formulación que presentan Gasparini, Cicowiez y Sosa Escudero (2013) para el caso del impacto presupuestario neto, puede mostrarse que la diferencia en la desigualdad medida por el Gini después de considerar el impacto de las políticas públicas es, asumiendo gastos que se distribuyen en forma proporcional al ingreso, es la siguiente ${ }^{22}$ :

$$
G_{X-T}^{A}-G_{X-T}^{B}=\left(G_{X}^{A}-G_{X}^{B}\right)-\left(t^{A} K_{T}^{A}-t^{B} K_{T}{ }^{B}\right)
$$

Donde:

$G_{X-T}^{A}-G_{X-T}^{B}$ : diferencia entre los índices de Gini después de impuestos entre el período A y el período $\mathrm{B}$

$\left(G_{X}^{A}-G_{X}^{B}\right):$ diferencia entre los índices de Gini antes de impuestos entre el período A y el período B $\left(t^{A} K_{T}^{A}-t^{B} K_{T}{ }^{B}\right):$ diferencia en el impacto de los impuestos entre el período A y el período B

En consecuencia el Gini post acción fiscal puede ser superior en el momento B al de la situación inicial A por: a) desigualdad de mercado superior; b) recaudación tributaria menor, c) menor progresividad de los impuestos.

En el cuadro 5 se presenta un ejemplo de los cálculos anteriores para el caso de Argentina ${ }^{23}$. Entre 1997 y 2006 se aprecia un incremento en el efecto distributivo del impuesto a la Renta de Personas Físicas, calculado como $G_{X-T}^{2006}-G_{X-T}^{1997}$. El mismo se explica por:

- una disminución en la desigualdad pre acción fiscal (fila $b$ )), de 0,035 (de 0,548 a 0,513);

- un incremento en la tasa impositiva media sobre el ingreso disponible (de $1,53 \%$ a 3,03\%);

- un incremento en la progresividad del impuesto (el índice de Kakwani aumenta de 0,255 a 0,369$)$.

En las filas $d$ a $h$ se descompone el cambio en la desigualdad después de impuestos, manteniendo constantes las demás variables, si bien se reconoce que las tres variables son interdependientes por estar cambiando la distribución subyacente sobre la cual se calcula la incidencia distributiva del impuesto.

La fila $d$ muestra cuál habría sido el impacto sobre progresividad si la tasa impositiva media hubiera permanecido constante. Este impacto $(0,002)$ es menor al inicial (de 0,007). En términos de cambio en el Gini post impuestos, el efecto distributivo es menor, dado que muestra una caída de 0,035 cuando la inicial era de 0,042 .

Si la progresividad (medida a partir del índice de Kakwani) hubiera permanecido constante, en la fila $f$ se muestra que el efecto habría sido de 0,004 , superior al caso de tasa impositiva constante anterior, con lo cual la caída en el Gini es también mayor al caso de tasa constante (fila $g$ ), de 0,039 . Con un Gini pre impuestos constante, entretanto, la desigualdad sólo se habría reducido en 0,007.

22 Esta fórmula también puede utilizarse para calcular la diferencia en el impacto distributivo neto entre un país latinoamericano y uno desarrollado, en donde A es el país latinoamericano y B el país desarrollado.

23 Cabe consignar que los datos presentados en el cuadro 4 y el cuadro 5 no son estrictamente comparables, dado que los del cuadro 16 fueron calculados con los microdatos de las encuestas y los del cuadro 17 con promedios por deciles. 


\section{CUADRO 5 \\ ARGENTINA: COMPARACIÓN DE LOS EFECTOS DISTRIBUTIVOS DEL IMPUESTO A LA RENTA PARA DIFERENTES PERÍODOS}

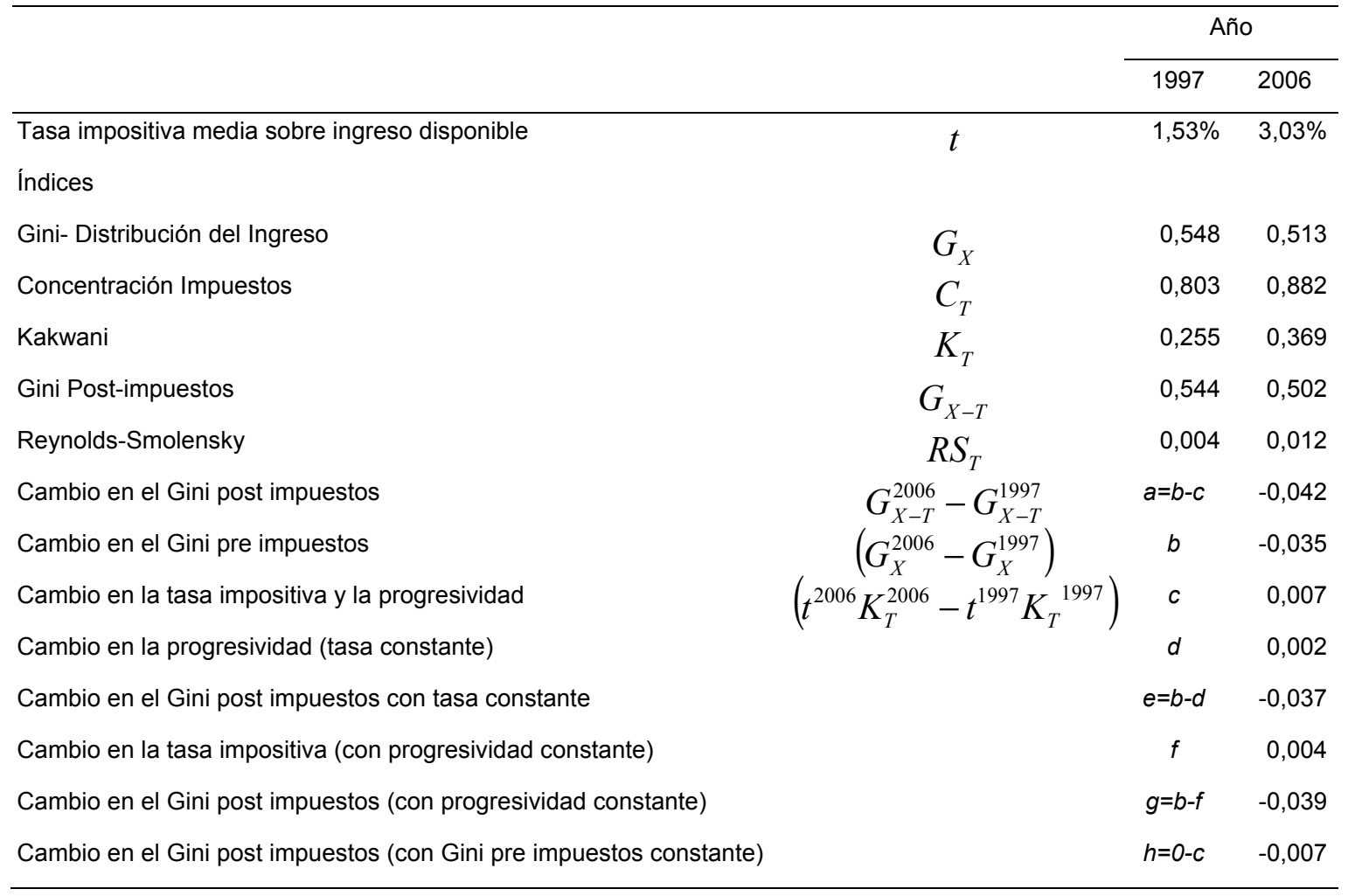

Fuente: Elaboración propia en base a Santiere, Gómez Sabaíni y Rossignolo (2000) y Gómez Sabaíni y Rossignolo (2009).

Los resultados anteriores muestran claramente, en primer lugar, que el efecto distributivo de los impuestos depende de la desigualdad antes de la acción fiscal. En segundo, en Argentina, y probablemente también en el resto de América Latina ${ }^{24}$, el incremento en el efecto distributivo igualador del impuesto sobre la Renta de Personas Físicas se debe al fuerte efecto del aumento en la recaudación tributaria, que se presenta en la primera parte del trabajo, y en una medida menor, al aumento de la progresividad del impuesto

El hecho de que el impacto distributivo de los impuestos sobre la renta resulte sustancialmente inferior en América Latina en relación con los países desarrollados se debe, tanto a la menor recaudación del impuesto a la Renta de Personas Físicas, de acuerdo a lo que se explicara en las secciones anteriores, como a una desigualdad de mercado superior, aunque en este punto no existe gran consenso en la literatura ${ }^{25}$. Sobre el tercero de los aspectos, el de la progresividad de los impuestos, se hará referencia más adelante.

Como se ha mencionado dos son las maneras en las que el sector público puede incrementar la recaudación del IRPN en forma pasiva, esto es, asumiendo invariabilidad discrecional sobre alícuotas y alcance de las bases imponibles (bases gravadas) ${ }^{26}$. La primera corresponde al incremento de la base

24 Sería menester, para fortalecer el argumento, contar con evidencia comparable para el caso de Latinoamérica. Sin embargo, los estudios existentes consisten en estimaciones puntuales para períodos y países determinados, y las metodologías empleadas difieren fuertemente a lo largo del tiempo, sobre todo en lo que concierne a la utilización de microdatos provenientes de encuestas o datos agregados. Esto implica que las comparaciones deben hacerse con sumo cuidado.

25 Ver Gómez Sabaíni y Rossignolo (2011), Gasparini et. al. (2009), Gasparini y Lustig (2011).

26 Sobre ambos puntos discutirá más adelante. 
imponible: si los niveles de mínimos no gravados y tasas no varían, un aumento del ingreso gravado incrementa la recaudación impositiva. La otra manera de incrementar la recaudación, con mínimos y tasas constantes, es a través de un aumento en la concentración del ingreso, es decir, con un incremento en la participación en el ingreso total de los sectores alcanzados por el gravamen.

El gráfico 11 subsiguiente ilustra este punto. Se asumen dos distribuciones hipotéticas, la 1 y la 2 , con el mismo ingreso total; entre la situación 1 y la 2 opera una redistribución de ingresos desde los tramos 1,2 y 3 por un total de 150, hacia el tramo 10, el más rico. Si el nivel de mínimo no imponible no cambia (como en el supuesto, en donde es de 1000), la recaudación del impuesto al ingreso se incrementa, aún manteniendo una alícuota constante. En este trabajo se postula que este comportamiento es el que ha predominado en los países de América Latina en la última década.

En el gráfico 12 puede apreciarse, en el eje izquierdo, el comportamiento del ingreso per cápita, el que, aún medido en dólares constantes, evidencia un importante crecimiento en la última década en relación con la anterior (el promedio de la década de 2001-2011 es superior al del período 1990-2001 en alrededor de un 22\%), mientras que en el eje derecho se mide la presión tributaria del IRPN, el cual, como fuera explicitado anteriormente, evidencia un importante crecimiento.

Lo advertido en el gráfico anterior puede reexpresarse de manera similar a partir de evidenciar la correlación entre la recaudación del impuesto y el ingreso per cápita para todo el período analizado, la cual resulta elevada para ambos subperíodos (gráfico 13, paneles A. y B.). Esto coincide con el comentario expresado en un principio, en donde se afirmaba que la recaudación había aumentado debido al proceso de crecimiento económico experimentado en la región.

En el gráfico 14 se aprecian los valores del índice de Gini de desigualdad de los ingresos y su relación con la recaudación del IRPF. Allí pueden dos comportamientos diferenciados: por un lado, para el período 1990-2001 se aprecia un aumento de la recaudación y un crecimiento de la desigualdad; a partir del año 2002, se aprecia un crecimiento de la recaudación con una notable caída en la desigualdad de ingresos antes de la acción de la política pública ${ }^{27}$.

Lo anteriormente expresado se evidencia en el gráfico 15 subsiguiente, paneles A. y B., en los cuales se muestran las relaciones entre ambas variables. Las mismas son elevadas pero muestran dos períodos bien diferenciados: un primer tramo de correlación positiva entre la recaudación y la desigualdad, y otra en que la recaudación crece pero se observa una disminución en el índice de Gini.

Este comportamiento es evidencia de algún fenómeno que no está siendo reflejado en los datos con los que se cuenta, es decir que en el segundo período, la desigualdad expuesta en las encuestas muestra una disminución cuando probablemente la misma se haya incrementado, dado que la recaudación del IRPN debería estar relacionada positivamente con la desigualdad. Típicamente, la medición sobre desigualdad en la distribución del ingreso se lleva a cabo mediante datos de encuestas de hogares, cuyo alcance difiere de la base imponible del impuesto a la Renta, dado que no incluye entre los ingresos relevados a los tramos de rentas elevadas. La sección siguiente de este trabajo está destinada a abordar estas cuestiones.

27 Ver Lustig (2012). 


\section{EJEMPLOS HIPOTÉTICOS DE DISTRIBUCIÓN DEL INGRESO Y NIVELES DE MÍNIMOS}

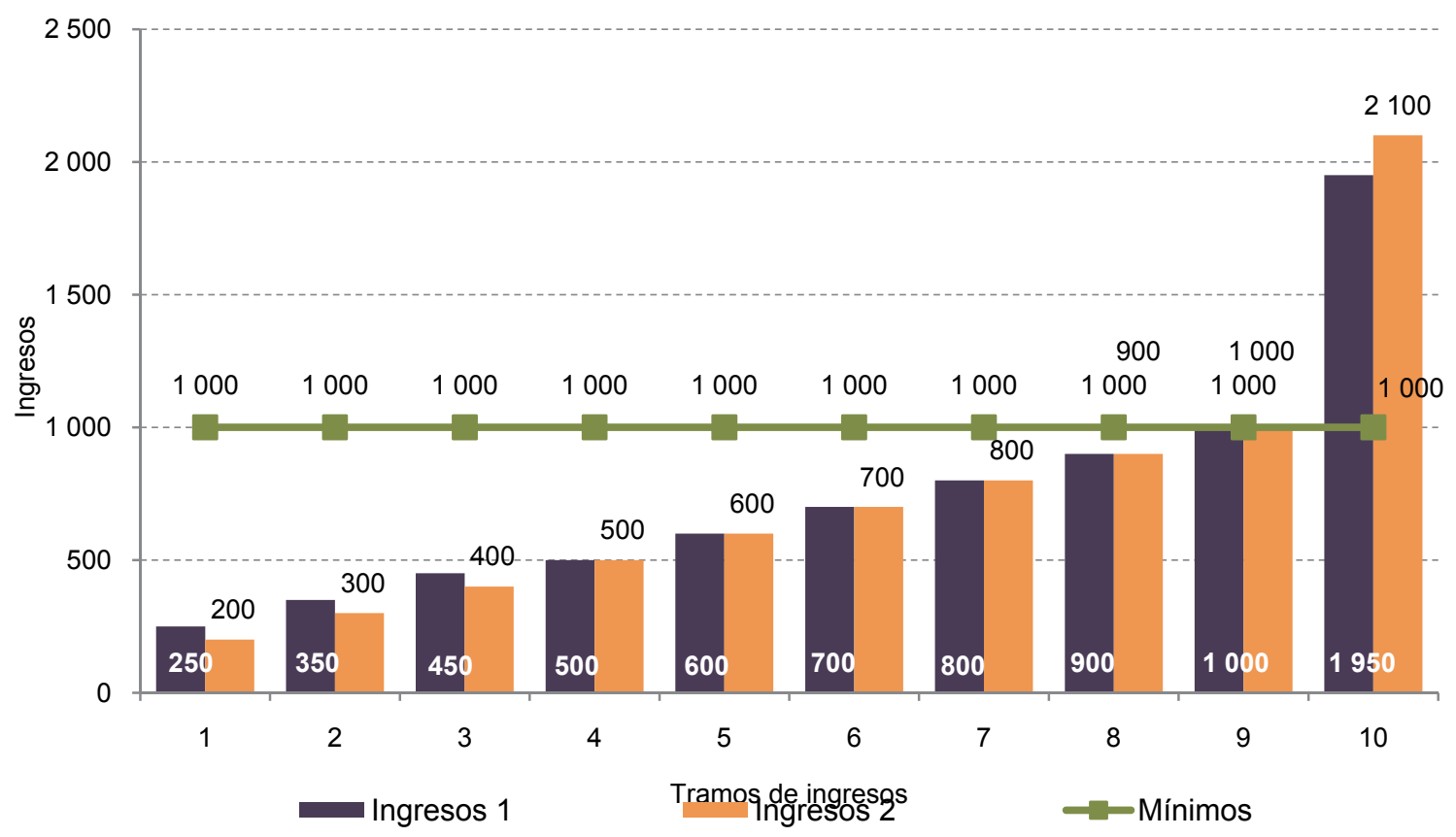

Fuente: Elaboración propia.

GRÁFICO 12

EVOLUCIÓN DE LA RECAUDACIÓN DEL IRPN Y DEL INGRESO PER CÁPITA

(En dólares corrientes)

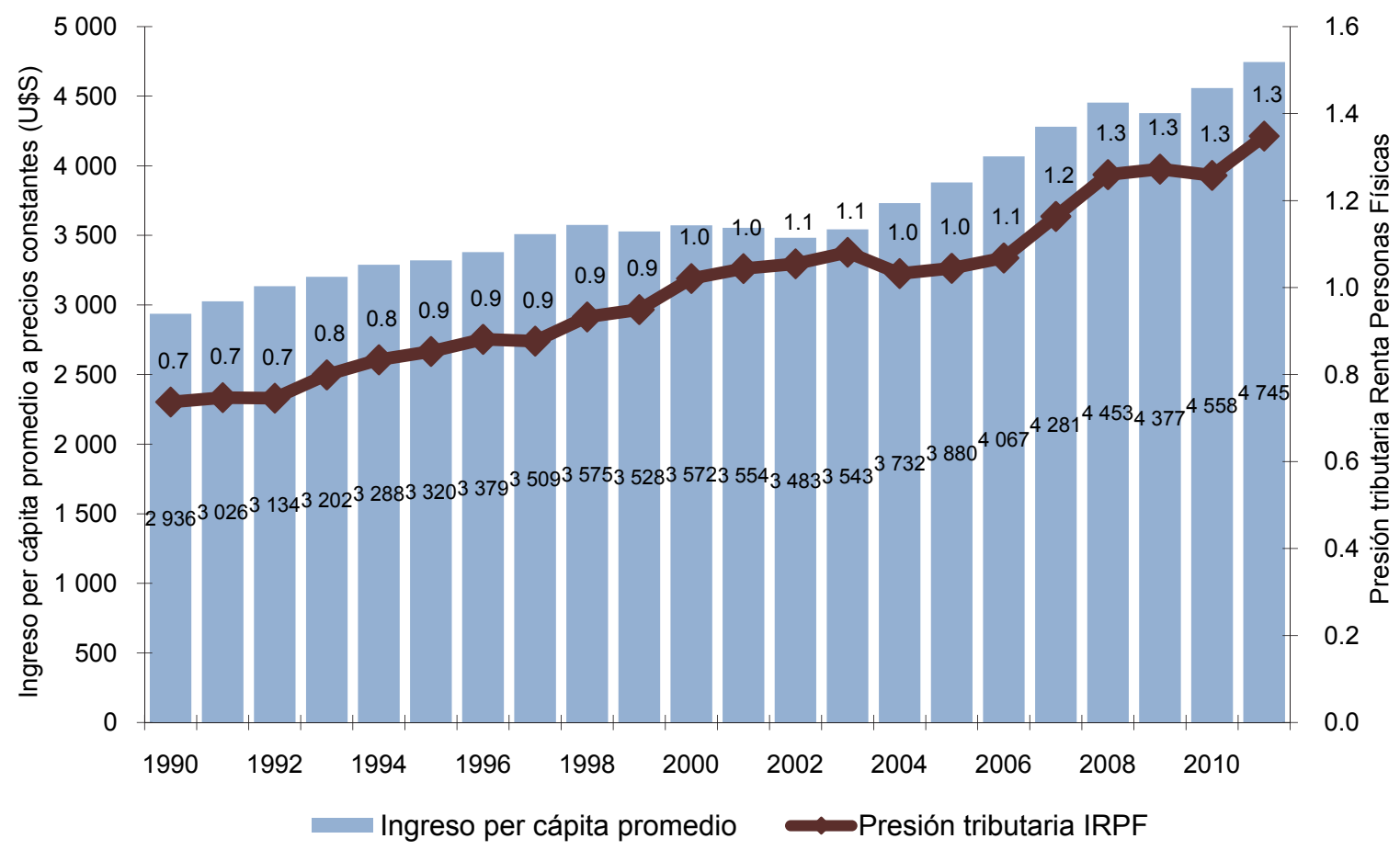

Fuente: Elaboración propia en base a CEPALSTAT. 


\section{GRÁFICO 13}

RELACIÓN ENTRE LA RECAUDACIÓN DEL IRPN Y EL INGRESO PER CÁPITA

(En porcentaje del PBI y en dólares corrientes)

A. $1990-2001$

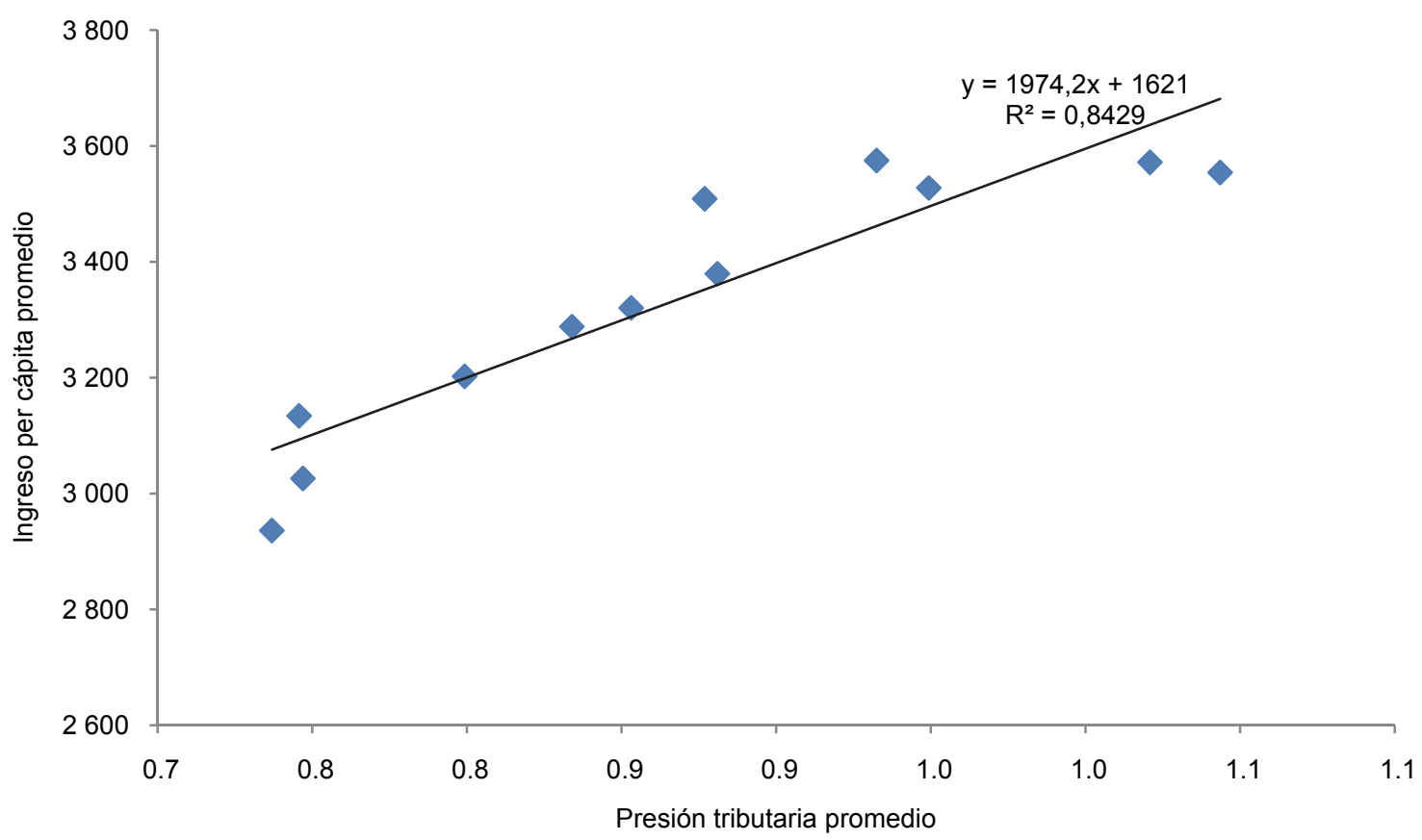

B. $2001-2011$

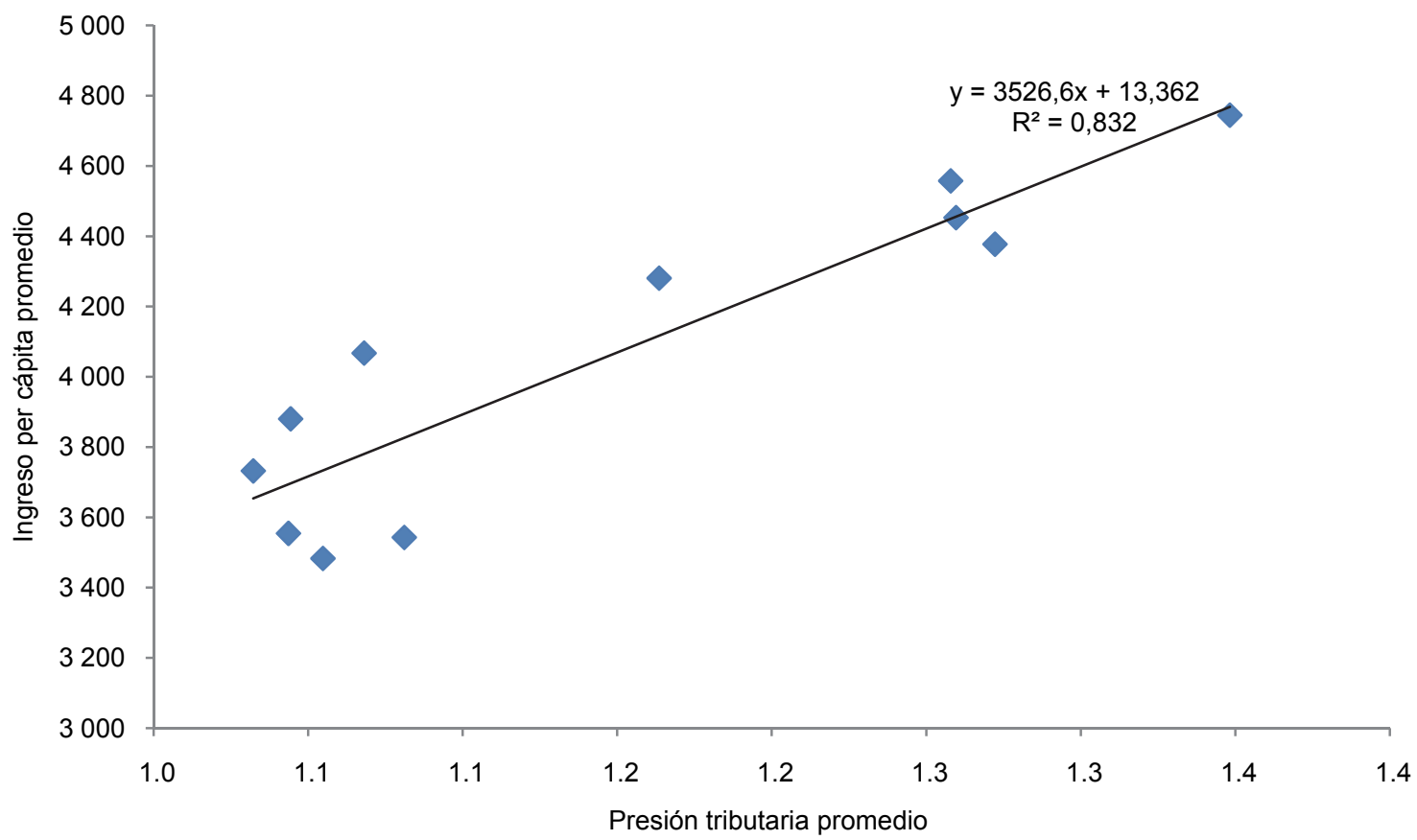

Fuente: Elaboración propia en base a CEPALSTAT. 


\section{GRÁFICO 14 \\ EVOLUCIÓN DE LA RECAUDACIÓN DEL IRPN Y LA DESIGUALDAD \\ (En porcentajes)}

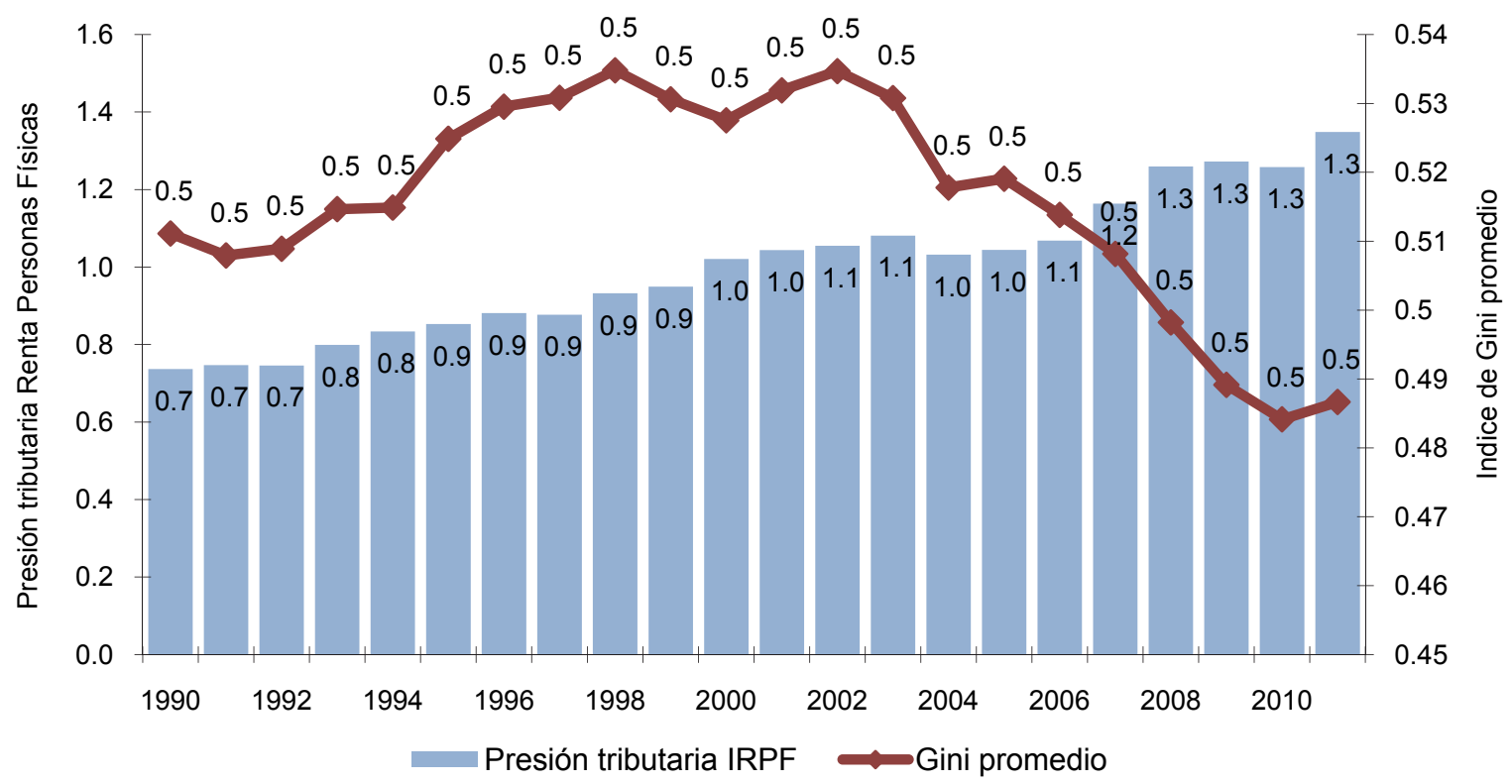

Fuente: Elaboración propia en base a CEPALSTAT, IDLA y SEDLAC.

\section{GRÁFICO 15 \\ RELACIÓN ENTRE LA RECAUDACIÓN DEL IRPN Y EL ÍNDICE DE GINI \\ (En porcentajes del $P B I$ )}

A. $1990-2001$

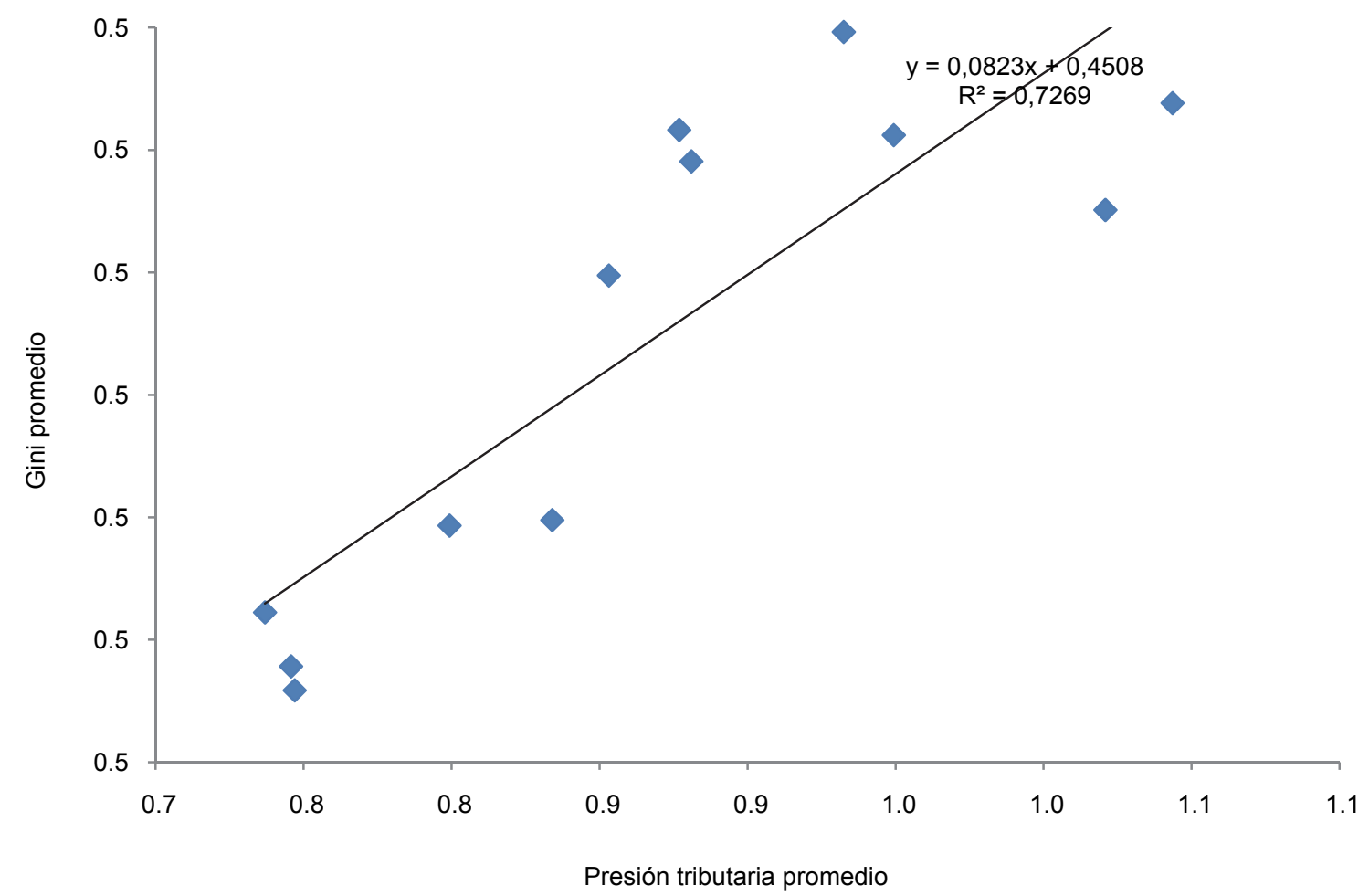


Gráfico 15 (conclusión)

B. $2001-2011$

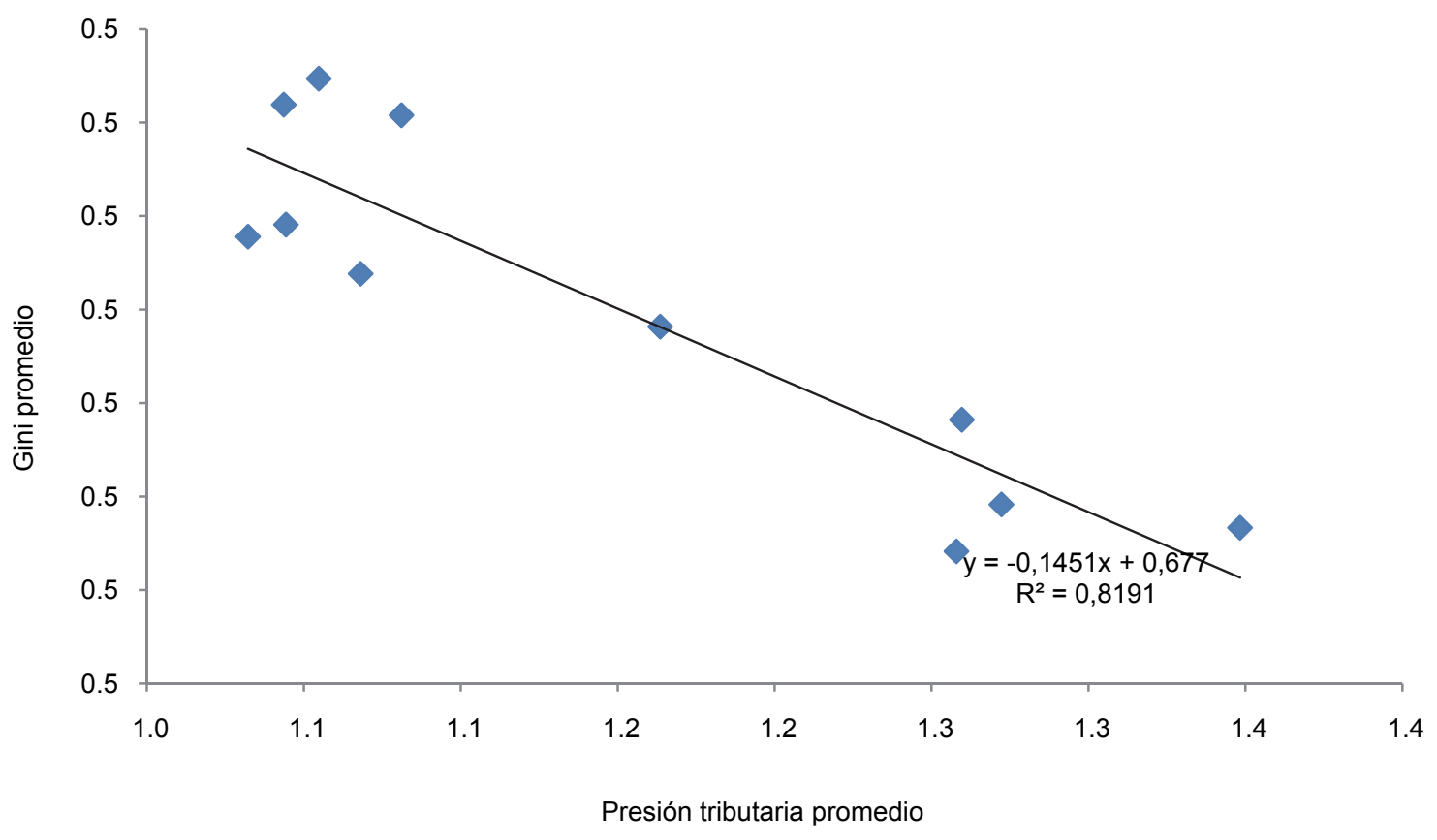

Fuente: Elaboración propia en base a CEPALSTAT, IDLA y SEDLAC.

\section{B. Las limitaciones que plantea la información de las encuestas de hogares}

Una característica típica de las encuestas de hogares es el hecho de que ésta no registra los "verdaderos" ingresos de la población. Este fenómeno puede dividirse en tres partes: la falta de respuesta, parcial o total, a la encuesta; la subdeclaración de ingresos, y la subcaptación de perceptores.

En el primero de los casos, para corregir por falta de respuesta es usual corregir mediante procedimientos de imputación de ingresos no declarados, estableciendo simulaciones de ingresos a partir de determinados parámetros de los hogares; estos ajustes se llevan a cabo en los estudios más recientes de las mencionadas encuestas. Algunos relevamientos más recientes efectúan ajustes a los ingresos por lo que se denomina "renta imputada de la vivienda", o del "consumo de bienes durables" (los hogares propietarios de vivienda no necesitan arrendar y pueden utilizar ese ingreso con otros fines)

En cuanto al segundo, lo imprescindible del ajuste se hace visible cuando, comparando los niveles de Cuentas Nacionales con los totales de las encuestas, se verifica que la subdeclaración es muy diferente según la fuente de ingreso de los perceptores. Si la subdeclaración fuera proporcional al ingreso real para todos los individuos, la distribución del bienestar y la incidencia tributaria no se vería afectada.

Es una práctica habitual, sin embargo, considerar que las encuestas captan relativamente bien los ingresos por jubilación o trabajo asalariado, pero fallan en registrar adecuadamente los ingresos del capital. Como la participación de las categorías de ingresos (asalariados, jubilados, patrones, cuentapropistas, rentistas) es diferente en cada decil, (en particular, los ingresos de las personas ricas están compuestos en una mayor proporción por ingresos de capital), el hecho de no incluir un ajuste implicaría que los ingresos de estas personas tenderían a estar más subvaluados que el resto ${ }^{28}$.

28 Gómez Sabaíni, Harriague y Rossignolo (2011) y Gasparini (1998). 
Para llevar a cabo este ajuste, el procedimiento habitual es efectuar una corrección por subdeclaración a partir de la información de Cuentas Nacionales, proyectando la estructura del Ingreso Disponible (cuenta del Ingreso Nacional) por factores (asalariados, cuentapropistas, empleadores, capitalistas, jubilados y otros) a los datos de las encuestas.

Adicionalmente a lo anterior, debe considerarse el hecho de que la distribución funcional del ingreso (es decir, los ingresos por fuente) varían según el tramo de ingreso. Como la participación de esas categorías (asalariados, jubilados, patrones, cuentapropistas, rentistas) es diferente en cada decil, el ajuste por categorías lleva naturalmente a un ajuste por deciles.

En América Latina, CEPAL ha aplicado tradicionalmente un ajuste de estas características ${ }^{29}$. A continuación se presentará en forma sintetizada la metodología, mientras que en el gráfico 16 subsiguiente se presentan en términos comparativos los valores de los índices de Gini para la fuente $\mathrm{CEPAL}^{30}$ y la fuente CEDLAS e IDLA, en promedios no ponderados para América Latina. La metodología comprende las siguientes etapas:

a) Crear una cuenta de hogares en las Cuentas Nacionales.

b) Imputar ingresos cero y no reportados en la encuesta.

c) Agrupar los ingresos de las Cuentas Nacionales y las encuestas en seis grupos: ingresos laborales netos de impuestos y contribuciones a la seguridad social, beneficios empresariales, pensiones y otros beneficios a la seguridad social, renta de la propiedad, renta imputada de la vivienda propia y transferencias.

d) Comparar el valor per cápita de cada uno de los seis agregados en ambas fuentes para obtener un coeficiente de ajuste.

e) Multiplicar el ingreso de cada fuente de cada hogar por el coeficiente de ajuste, y obtener los estadísticos distributivos a partir de ello.

\section{GRÁFICO 16}

ÍNDICES DE GINI PARA AMÉRICA LATINA

(En promedios no ponderados)

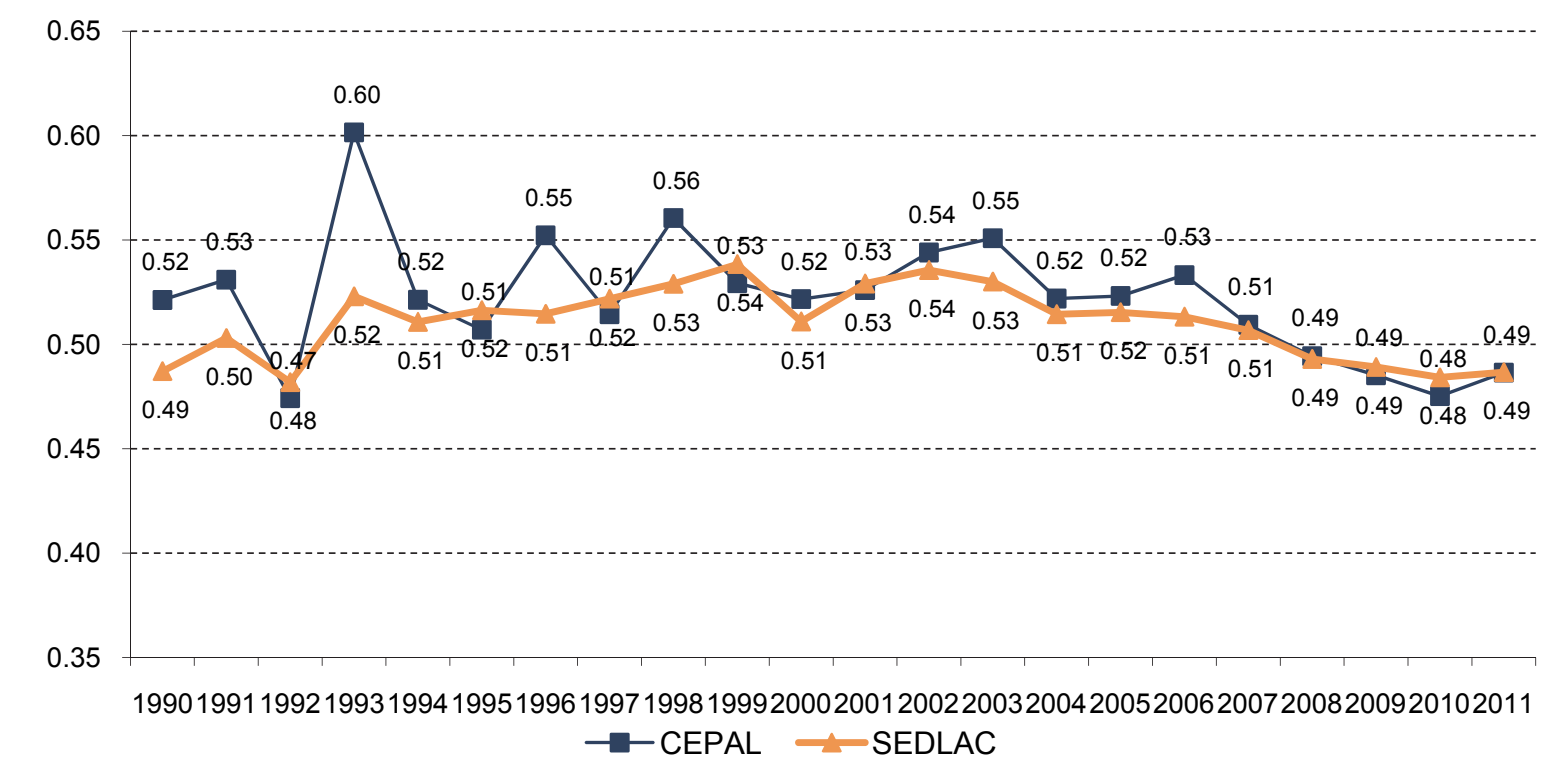

Fuente: SEDLAC e IDLA, y CEPALSTAT.

La presente sección sigua a Gasparini, Cicowiez y Sosa Escudero (2013).

30 Refiere al total urbano. 
Sin embargo, la metodología de ajuste por subdeclaración no está exenta de controversias ${ }^{31}$. La disponibilidad de información, los universos con los cuales se establecen las comparaciones, las definiciones aplicables sobre ingreso disponible, que es aquel cuya cuenta se emplea para el ajuste, determinan que no exista una metodología homogénea e incontrastable con el fin de aplicarla a lo largo de los distintos períodos ${ }^{32}$. Las falencias de la información de base (el sistema de Cuentas Nacionales de cada país) llevan a algunos investigadores a no recomendar este tipo de ajustes, debido sobre todo a sus efectos sobre las estimaciones de pobreza (sobrestima la reducción de la pobreza a lo largo del tiempo y exagera las diferencias en los niveles de pobreza entre países) ${ }^{33}$.

El tercer caso corresponde a la subcaptación de perceptores. Las encuestas no captan a los individuos con más altos niveles de ingresos. Este problema es verificable aún después de corregir por subdeclaración de ingresos; a partir de las comparaciones entre los ingresos gravados que surgen de los datos de las declaraciones juradas del impuesto a la Renta, y las simulaciones de ingresos gravados a partir de aplicar el ajuste por subdeclaración anteriormente mencionado, se advierte que surgen grandes diferencias ${ }^{34}$.

Con el fin de ilustrar sobre este punto, Gasparini et al (2013) presentan una comparación entre diferentes países de América Latina a partir de los cuales se presenta el ingreso total individual promedio mensual en dólares de 2008 de las dos personas más ricas relevadas en las encuestas de hogares, resaltando la importancia de los ingresos del trabajo en la estructura de ingreso de los ricos captados por las encuestas. De la lectura del cuadro 6, surge como evidente el hecho de que existen ingresos individuales, en las distintas economías, superiores a los relevados en las encuestas.

\section{CUADRO 6}

INGRESO INDIVIDUAL PROMEDIO DE LAS DOS PERSONAS DE MAYORES INGRESOS INDIVIDUALES Y PROPORCIÓN DE INGRESOS LABORALES

\begin{tabular}{llcr}
\hline & Año & $\begin{array}{c}\text { Ingresos individuales } \\
\text { (en dólares de 2008) }\end{array}$ & $\begin{array}{c}\text { Proporción de ingresos } \\
\text { laborales }\end{array}$ \\
\hline Argentina & 2006 & 13461 & 15 \\
Bolivia (Estado Plurinacional de) & 2005 & 7018 & 71 \\
Brasil & 2007 & 69433 & 100 \\
Chile & 2006 & 141700 & 96 \\
Colombia & 2006 & 19054 & 100 \\
Costa Rica & 2006 & 23193 & 7 \\
Ecuador & 2006 & 17624 & 100 \\
El Salvador & 2005 & 89399 & 100 \\
Guatemala & 2006 & 35110 & 100 \\
Honduras & 2006 & 59324 & 50 \\
México & 2006 & 37754 & 100 \\
Nicaragua & 2005 & 16535 & 100 \\
Panamá & 2006 & 11668 & 100 \\
Paraguay & 2007 & 92455 & 99 \\
Perú & 2006 & 17430 & 51 \\
Uruguay & 2006 & 27162 & 98 \\
Venezuela (República Bolivariana de) & 2006 & 10651 & 50 \\
\hline
\end{tabular}

Fuente: Gasparini et al (2013).

\footnotetext{
31 Otro ajuste posible consiste en utilizar datos de ingresos y consumos; si dos familias tienen patrones de consumo similares, pero ingresos diferentes, puede existir presunción de subdeclaración (Gasparini et al (2013)).

32 Otra herramienta de gran utilidad para realizar los ajustes consiste en emplear registros administrativos.

33 Gasparini et al (2013).

34 Ver Di Gresia (2000) para un análisis inicial del caso argentino.
} 
Las encuestas fallan, en consecuencia, en captar los ingresos de los perceptores de renta más elevados. En particular, el decil de ingresos más elevados (que inclusive en la información de las encuestas de hogares es el que presenta mayor varianza entre sus ingresos) es el que se encuentra subcaptado.

Es por esta razón que resulta de suma relevancia analizar la evolución de la participación en el ingreso de los tramos de renta elevada, que no son captados adecuadamente por el decil de ingresos más altos de las encuestas, sino que concentran el $1 \%$, o el $0,1 \%$ de los ingresos más altos. Este sector, denominado "súper ricos", ha sido el objeto de análisis de una serie de estudios llevados a cabo en los países avanzados y que han tenido su correlato en algunas investigaciones realizadas en América Latina. Esta serie de trabajos analiza la evolución de la concentración del ingreso de los tramos más elevados a partir de la información proveniente de las declaraciones juradas del Impuesto a la Renta.

En las próximas secciones se presentarán, en primer lugar, algunos ejemplos de estimaciones realizadas para varios países en el caso de los ajustes por subdeclaración, y en segunda instancia, la metodología y resultados utilizados en el caso de la incorporación de los tramos de ingresos más elevados serán objeto de análisis de las siguientes secciones.

\section{El ajuste por subdeclaración de ingresos utilizado en distintos estudios de América Latina}

En el presente apartado se presentarán resultados de estimaciones realizadas en América Latina en relación con la subdeclaración de ingresos y el ajuste utilizando datos de Cuentas Nacionales, para países seleccionados ${ }^{35}$.

\section{El caso de Argentina}

En Argentina, la falta de bases estadísticas suficientes impide hacer una investigación ad-hoc de la subdeclaración en la encuesta, con las características antes mencionadas. Se trató entonces de encontrar antecedentes en estudios previos, localizándose cálculos diferentes, los que se mencionarán a continuación.

En un trabajo presentado por Heber Camelo en el Taller Regional sobre Medición del Ingreso en las Encuestas de Hogares (Buenos Aires, Noviembre de 1998) se revalorizó una investigación realizada como subproducto del cambio de base 1986 de las Cuentas Nacionales; la información era relativamente antigua pero los coeficientes guardaban actualidad y coherencia ${ }^{36}$.

En el estudio de Santiere y Gómez Sabaíni (1999) sobre incidencia distributiva de los impuestos, después de una evaluación de los antecedentes mencionados, se adoptaron los correctores propuestos en Camelo (1998) que se traducen en un ajuste global de 47\% respecto a los niveles de la encuesta, debidamente desagregado, aplicados a los tres años estudiados (1986, 1993 y 1997), habida cuenta que la brecha de subdeclaración parece guardar una relativa constancia.

En un estudio sobre pobreza llevado a cabo por el Banco Mundial (1994), se utilizan índices correctores - siempre por estratos de ingreso y fuente de los mismos- que aparecen como suministrados por CEPAL, sin que se precise el documento o el origen específico del dato ${ }^{37}$.

En una publicación sobre incidencia distributiva de los impuestos, Leonardo Gasparini (1998) trabaja en el mismo sentido, presentando un conjunto de coeficientes que se basan en información preliminar, tanto para la EPH como para la ENGH y que surgen de estimaciones a partir de datos macroeconómicos ${ }^{38}$.

\footnotetext{
35 Dado que los autores han participado en trabajos que han incorporado el ajuste por subdeclaración en Argentina, se expondrán con un detalle ligeramente mayor los ajustes referidos a este país.

36 Camelo, H. (1998).

37 Banco Mundial (2004).

38 Gasparini, L. (1998).
} 
Llach y Montoya, entretanto, ${ }^{39}$ calculan coeficientes de subdeclaración por fuente para los años 1986 y 1993, mientras que Santiere, Gómez Sabaíni y Rossignolo (2000) también utilizan coeficientes de ajuste, que fueron calculados por la Dirección de Programación del Gasto Social a partir de datos de la Dirección Nacional de Cuentas Nacionales del Ministerio de Economía. Gómez Sabaíni, Harriague y Rossignolo (2011), y Gaggero y Rossignolo (2011) utilizan un procedimiento similar.

En este último caso, los coeficientes empleados implican un ajuste del 18\% sobre los ingresos de asalariados, un aumento del $31 \%$ sobre las jubilaciones y pensiones, mientras que los intereses y alquileres se multiplican por 5,6; cuentapropistas, por 2,08 y empleadores por un coeficiente de 3,06 (véase los cuadros 7 y 8 ).

\section{CUADRO 7}

ARGENTINA: SUBDECLARACIÓN EN LA EPH, ESTIMACIONES REALIZADAS EN ESTUDIOS ALTERNATIVOS

(Porcentajes respecto al ingreso declarado)

\begin{tabular}{lccc}
\hline & $\begin{array}{c}\text { Camelo Heber } \\
(1998)\end{array}$ & $\begin{array}{c}\text { Banco Mundial } \\
(1994)\end{array}$ & $\begin{array}{c}\text { Santiere-Gómez Sabaíni } \\
(1999)\end{array}$ \\
\hline Quintiles & 23 & 10 & 23 \\
I & 28 & 17 & 28 \\
II & 32 & 22 & 32 \\
III & 42 & 29 & 42 \\
V & 66 & 65 & $51 / 81^{\text {a }}$ \\
Fuente de ingreso & & & \\
Salarios & 9 & 5 & \\
Ganancias Empresas & 89 & 10 & \\
Jubilaciones y pensiones & 8 & 1,431 & \\
Rentas e intereses & 1,481 & 39 & \\
Porcentaje de ajuste global & 47 & & \\
\hline
\end{tabular}

Fuente: Las enunciadas en las notas al pie del texto.

a El ajuste aplicado para el noveno decil fue de 1,51, el aplicado para el décimo decil, de 1,81.

\section{CUADRO 8 \\ ARGENTINA: COEFICIENTES DE AJUSTE POR SUBDECLARACIÓN DE INGRESOS, FACTORES DE CORRECCIÓN}

\begin{tabular}{lccccc}
\hline Fuente de ingresos & $\begin{array}{c}\text { Llach-Montoya } \\
1986\end{array}$ & $\begin{array}{c}\text { Llach-Montoya } \\
1993\end{array}$ & $\begin{array}{c}\text { Gasparini 1996 } \\
\text { (ENGH) }\end{array}$ & $\begin{array}{c}\text { Gasparini 1996 } \\
\text { (EPH) }\end{array}$ & $\begin{array}{c}\text { Santiere, Gómez } \\
\text { Sabaíni y } \\
\text { Rossignolo } \\
2000 / 2002\end{array}$ \\
\hline Salarios & 1,343 & 1,282 & 1,28 & 1,49 & 1,18 \\
Ganancias empresariales & 2,061 & 1,606 & & 1,05 & 5,63 \\
Alquileres e intereses & 4,162 & 8,5 & 31,42 & 1,06 & 1,31 \\
Jubilaciones y pensiones & 1,361 & 1,478 & 1,03 & 1,24 & 2.08 \\
Cuenta propia & 1,912 & 1,833 & 2,02 & 5,52 & 3.06 \\
Patrones & 1,912 & 1,833 & 1,24 & & \\
\hline
\end{tabular}

Fuente: Las enunciadas en las notas al pie del texto.

39 Llach y Montoya (1999). 
Como fuera mencionado en la discusión metodológica, los coeficientes de ajuste por subdeclaración generan un impacto en la distribución del ingreso; las estadísticas distributivas se calculan a partir de la distribución del ingreso ajustada. Es interesante, entonces, evaluar los resultados de los estudios que utilizan estos ajustes.

Una distribución puede ser analizada por lo que expresa su propio contenido, pero adquiere mayor valor explicativo cuando se puede comparar con presentaciones similares, en el tiempo y en el espacio. Con la finalidad, el esquema que sigue agrupa los porcentajes de ingreso para los estratos bajos (20\% inferior), medios $(70 \%)$ y altos (10\% del universo de hogares), enfocando los tres años de la investigación en el trabajo de Santiere y Gómez Sabaíni (2000).

\section{CUADRO 9}

ARGENTINA: ESQUEMA DE LA DISTRIBUCIÓN DEL INGRESO, 1986, 1993 Y 1997

\begin{tabular}{cccccc}
\hline \multirow{2}{*}{ Años } & \multirow{2}{*}{ Tipología } & \multicolumn{4}{c}{ Porcentaje de familias } \\
\cline { 3 - 5 } & & $20 \%$ de menor ingreso & $70 \%$ de ingreso medio & $10 \%$ de mayor ingreso & \multirow{2}{*}{ Gini } \\
\cline { 3 - 5 } & & \multicolumn{2}{c}{ Porcentaje del ingreso captado por cada estrato } \\
\hline 1986 & Corregido & 3,99 & 58,02 & 37,99 & 0,48 \\
1993 & Corregido & 3,50 & 58,95 & 37,55 & 0,49 \\
1997 & Corregido & 3,44 & 56,67 & 39,89 & 0,51 \\
\hline
\end{tabular}

Fuente: Santiere y Gómez Sabaíni (2000).

Entre 1986 y 1997 aumenta la desigualdad (obsérvese el último decil) en desmedro de las clases intermedias y manteniendo muy baja la participación de los estratos de menores recursos. Se analizan en conjunto el primero y segundo decil, pues el $10 \%$ más bajo de la población suele mostrar características atípicas en las encuestas (tales como una propensión a consumir en que el gasto supera al ingreso, la evidencia de ayuda de familiares ó allegados, la aparición de subsidios en especie que las encuestas no captan, etc.).

El cuadro 9 anterior pone de relieve una pequeña caída en el ingreso relativo del $20 \%$ más pobre (de 3,99 a 3,44\% del ingreso anual), en dos escalones descendentes. Los sectores medios (en una definición muy amplia que incluye a medios-pobres) recuperan un punto de su participación (de 58,02 a $58,95 \%$ ) entre 1986 y 1993. Están representando a una masa importante de asalariados, que ven revalorizados sus ingresos fijos al pasar de la alta inflación a la estabilidad, pero pierden más de dos puntos porcentuales entre 1993 y 1997, cuando el modelo de ajuste actúa plenamente (58,95 a 56,67\%).

Con respecto al $10 \%$ más rico, su captación del ingreso varía en forma inversa a la del sector medio, reduciéndose levemente de 1986 a 1997 y ganando más de dos puntos porcentuales de 1993 a 1997. Otra lectura de la distribución de 1997 permite constatar que el 20\% más rico polariza el 56,5\% del ingreso y que el $80 \%$ restante de la población retiene sólo el $43,5 \%$ del ingreso.

El perfil distributivo utilizado en el trabajo de Santiere, Gómez Sabaíni y Rossignolo (2000) implicó el análisis comparativo de dos alternativas distributivas, denominadas A y B. La Alternativa A fue definida como la que clasifica el ingreso total familiar y no sufrió ningún tipo de ajuste. Es la que más se acerca a la distribución original de la encuesta. Varios factores contribuyen a hacer más igualitaria (menos concentrada) a esta distribución. Por ejemplo, la subdeclaración resta comparativamente más ingresos a los deciles altos; los ingresos de las familias se distribuyen casi siempre en forma más igualitaria que los ingresos de los individuos; etc.

La Alternativa B recepta todos los ajustes encarados en la investigación (corrección del subregistro, equivalencia de componentes de la familia en términos de adulto, economía de escala interna a la familia). Además, se trata de individuos y no de familias. Cada uno de estos factores "desplaza" en alguna medida la curva distributiva, lo que lleva a los valores de la segunda línea del cuadro. Si en la primera alternativa, 
sólo el 29,22\% era absorbido por el decil más rico; en la Alternativa B éste último capta el 45,11\%. El índice de Gini es 0,48 en el primer caso y 0,55 en el segundo (véase el cuadro 10).

ARGENTINA: ESQUEMA DE LA DISTRIBUCIÓN DEL INGRESO, 1997

\begin{tabular}{llcccc}
\hline & & \multicolumn{4}{c}{ Porcentaje de casos } \\
\cline { 3 - 4 } Años & Tipología & 20\% de menor ingreso & $70 \%$ de ingreso medio & 10\% de mayor ingreso & \multirow{2}{*}{ Gini } \\
\cline { 3 - 4 } & & \multicolumn{2}{c}{ Porcentaje del ingreso captado por cada estrato } \\
\hline 1997 & No corregido & 6,63 & 64,15 & 29,22 & 0,48 \\
1997 & Corregido & 3,08 & 51,81 & 45,11 & 0,55 \\
\hline
\end{tabular}

Fuente: Santiere. Gómez Sabaíni y Rossignolo (2000).

En el cuadro 11 se muestran los resultados de los trabajos más recientes sobre la materia; ambos utilizan como coeficientes de ajuste los expuestos en el cuadro 8. Gómez Sabaíni, Harriague y Rossignolo (2011) realizan un análisis de incidencia distributiva para Argentina con datos de 2008. Puede advertirse una reducción importante de la desigualdad entre 1997 y 2008, medida por el índice de Gini, conjuntamente con una reducción en la participación del top 10\% de ingresos más elevados.

Gaggero y Rossignolo (2011), con datos de 2010, calculan la alternativa de ingresos ajustados y la de ingresos no ajustados; la corrección por subdeclaración de ingresos incrementa el valor del índice de Gini en alrededor de cinco puntos, de manera similar a lo que acontece con la participación del decil de ingresos más elevados sobre el total (cabe consignar que el share del decil más alto se ve adicionalmente incrementada por la inclusión de la Renta por Activos Externos del Sector Privado No Financiero)

\section{CUADRO 11 \\ ARGENTINA: ESQUEMA DE LA DISTRIBUCIÓN DEL INGRESO, 2008 Y 2010}

\begin{tabular}{llcccc}
\hline & & \multicolumn{4}{c}{ Porcentaje de casos } \\
\cline { 3 - 4 } Años & Tipología & 20\% de menor ingreso & $70 \%$ de ingreso medio & \multirow{2}{*}{ 10\% de mayor ingreso } & \multirow{2}{*}{ Gini } \\
\cline { 3 - 4 } & & \multicolumn{2}{c}{ Porcentaje del ingreso captado por cada estrato } & 0,484 \\
\hline 2008 & Corregido & 3,60 & 60,60 & 35,80 & 0,430 \\
2010 & Sin corregir & 4,48 & 63,33 & 32,20 & 0,479 \\
2010 & Corregido & 3,75 & 59,19 & 37,06 & 0 \\
\hline
\end{tabular}

Fuente: Gómez Sabaíni, Harriague y Rossignolo (2011) y Gaggero y Rossignolo (2011).

\section{El caso de Chile}

La metodología de ajuste por subdeclaración en el caso de Chile está planteada en el trabajo de Feres (1996), quien presenta, con motivo de la sexta ronda de la Encuesta de Caracterización Socioeconómica Nacional (CASEN-VI), un análisis de validación realizado con el objetivo de corregir errores de no respuesta y subdeclaración de ingresos reportados en la encuesta. Para ello se utilizaron los datos provenientes de las cuentas del ingreso, construidas a partir de la información de las Cuentas Nacionales ${ }^{40}$.

Primeramente se debieron adaptar los datos del marco de Cuentas Nacionales a los conceptos de ingresos de la encuesta, a saber: remuneración de empleados, excedente de explotación, prestaciones de

\footnotetext{
40 Otro trabajo que analiza la representatividad de las encuestas al relevar los ingresos más elevados (top 1\% y $2 \%$ ) es el trabajo de Friedman y Hofman (2013), que compara los resultados de dos encuestas, la CASEN (a nivel nacional) y la ESI (Encuesta Suplementaria de Ingresos), a nivel regional.
} 
la seguridad social, rentas de la propiedad, excedente del sector propietario de vivienda (identificando los arriendos imputados y efectivos), y transferencias corrientes y donaciones, para arribar al Ingreso Disponible de los Hogares.

El método de ajuste consistió en imputar a cada tipo o fuente de ingreso investigada en la encuesta las discrepancias porcentuales observadas entre el monto global registrado en la encuesta y su equivalente de cuentas nacionales ${ }^{41}$. La imputación operó sobre la base de los siguientes supuestos:

- la subdeclaración de ingresos en la encuesta se asocia más al tipo de ingreso que a la magnitud del mismo;

- el monto no declarado de cada tipo de ingreso es igual a la discrepancia entre aquél que consigna la encuesta y la estimación correspondiente de cuentas nacionales;

- la subdeclaración de ingresos sigue un patrón de elasticidad unitaria.

La excepción a esto último la constituyen los ingresos de la propiedad en efectivo; como se asume que la percepción de los mismos está concentrada en las personas de altos ingresos, se optó por imputar al 20\% de mayores ingresos la discrepancia entre ambas fuentes, en proporción al ingreso de cada uno de los perceptores. Se consideró como ingreso de los perceptores al ingreso total de todas las fuentes, menos subsidios monetarios y alquiler imputado, con excepción de los ingresos del capital que se computan sin ajuste.

Se calculan en consecuencia las discrepancias entre las estimaciones de la encuesta y sus homónimos de cuentas nacionales, determinándose los factores o coeficientes de ajuste a aplicar a cada tipo de ingreso de la encuesta. Se presenta a continuación, en los cuadros 12 y 13, el valor de los coeficientes y la resultante de los ajustes a nivel de los deciles de la distribución del ingreso.

\section{CUADRO 12 \\ CHILE: COEFICIENTE DE AJUSTE DE LOS INGRESOS MEDIDOS EN LA ENCUESTA CASEN 1994 Y 1996}

\begin{tabular}{lll}
\hline \multirow{2}{*}{ Fuente de ingreso } & \multicolumn{2}{c}{ Factor de ajuste } \\
\cline { 2 - 3 } & 1994 & 1996 \\
\hline Sueldos y salarios & 1,071 & 0,990 \\
Ingresos del trabajo independiente & 1,513 & 2,043 \\
Prestaciones de la seguridad social & 1,435 & 1,398 \\
Rentas de la propiedad & 1,060 & 1,064 \\
Alquiler imputado & 0,475 & 0,454 \\
Ingreso autónomo & 1,272 & 1,331 \\
Ingreso total & 1,151 & 1,194 \\
\hline
\end{tabular}

Fuente: Feres (1996).

Nota: El factor de ajuste de las rentas de la propiedad está expresado como proporción del ingreso autónomo del $20 \%$ de receptores individuales de más altos ingresos. Ingreso autónomo: ingreso total excluidos los subsidios monetarios y el alquiler imputado.

$41 \quad$ La presente sección sigue a Feres (1996). 


\section{CUADRO 13 \\ CHILE: FACTORES DE AJUSTE DE LOS INGRESOS DE LOS HOGARES, SEGÚN DECILES DE LA DISTRIBUCIÓN DEL INGRESO PER CÁPITA AJUSTADO}

\begin{tabular}{|c|c|c|c|c|}
\hline \multirow{2}{*}{ Deciles } & \multicolumn{2}{|c|}{ Ingreso autónomo } & \multicolumn{2}{|c|}{ Ingreso total } \\
\hline & 1994 & 1996 & 1994 & 1996 \\
\hline Total & 1,273 & 1,333 & 1,152 & 1,195 \\
\hline 1 & 1,181 & 1,124 & 1,010 & 0,971 \\
\hline 2 & 1,170 & 1,130 & 1,042 & 0,997 \\
\hline 3 & 1,176 & 1,146 & 1,047 & 1,022 \\
\hline 4 & 1,180 & 1,140 & 1,050 & 1,011 \\
\hline 5 & 1,189 & 1,178 & 1,059 & 1,047 \\
\hline 6 & 1,197 & 1,207 & 1,069 & 1,064 \\
\hline 7 & 1,216 & 1,237 & 1,084 & 1,095 \\
\hline 8 & 1,235 & 1,283 & 1,107 & 1,150 \\
\hline 9 & 1,267 & 1,320 & 1,139 & 1,190 \\
\hline 10 & 1,359 & 1,504 & 1,262 & 1,378 \\
\hline
\end{tabular}

Fuente: Feres (1996).

En uno de los trabajos más conocidos sobre impacto distributivo de los impuestos en Chile, Engel, Galetovic y Raddatz (1999) utilizan la encuesta CASEN para calcular la distribución del ingreso previa a la acción fiscal con datos de 1996. En sus cálculos asumen que cada individuo declara correctamente su ingreso. Adicionalmente, los datos de la encuesta fueron ajustados por CEPAL, con lo cual una vez que los ponderadores apropiados son aplicados, el ingreso total per cápita de la muestra coincide con los valores de las Cuentas Nacionales para cada categoría de ingreso.

La manera de aplicar los ponderadores es a partir de imputar, proporcionalmente para cada categoría de ingreso, la diferencia entre los valores de la encuesta CASEN y los de Cuentas Nacionales, con la excepción de los ingresos del capital, los que se asignan en su totalidad al quintil de ingresos más elevados.

Jorratt (2010), en su análisis de la incidencia de los impuestos y el gasto público en Chile con datos de 2003, reconoce que en las encuestas de hogares existe una significativa subdeclaración de los ingresos familiares. Como el porcentaje de subdeclaración es potencialmente distinto para las distintas fuentes de ingresos y estratos de renta, los resultados de un estudio de incidencia pueden ser erróneos si es que previamente no se realiza un ajuste a los ingresos. Utiliza para ello las variables de ingreso de la encuesta CASEN previamente sometidas a un procedimiento de ajuste, mediante el cual los valores originales son amplificados por un factor de corrección para hacerlos coincidir con los ingresos reportados en las Cuentas Nacionales

La variable de la encuesta CASEN que más se aproxima al ingreso antes de la política fiscal es el ingreso autónomo ${ }^{42}$, que incorpora los ingresos líquidos (después de impuestos y cotizaciones sociales) del trabajo dependiente, los ingresos del trabajo independiente, las rentas de capitales mobiliarios, las ganancias de capital realizadas, los ingresos por arriendos de bienes raíces, los retiros de utilidades, los dividendos de acciones, las pensiones y jubilaciones, el cobro de seguros de desempleo, las pensiones asistenciales, el autoconsumo, el autosuministro, el valor locativo y las donaciones.

Sin embargo, esta variable fue sometida a algunos ajustes. En primer lugar, se sumó las cotizaciones para fondos de pensiones y salud, puesto que la encuesta pregunta respecto de los ingresos líquidos. En segundo lugar, y por la misma razón, se sumó el impuesto a la renta. Por último, se restaron

42 La presente sección sigua a Jorratt (2010). 
las pensiones asistenciales, puesto que estas no tienen un componente de contraprestación, por lo que corresponden a un subsidio monetario.

En el cuadro 14 se presentan en forma agrupada los resultados en términos de concentración de ingreso pre fiscal para los estudios mencionados. El 10\% de mayor ingreso capta el $41 \%$ del ingreso total para el estudio de Engel et al, mientras que para el de Jorratt el porcentaje es del 47,2\%. El valor del índice de Gini que surge de la distribución así construida es de 0,4883, para el estudio de Engel; para Jorratt el mismo índice arroja un valor de 0,5791.

CHILE: ESQUEMA DE LA DISTRIBUCIÓN DEL INGRESO

\begin{tabular}{|c|c|c|c|c|}
\hline \multirow{3}{*}{ Años } & \multicolumn{3}{|c|}{ Porcentaje de casos } & \multirow{3}{*}{ Gini } \\
\hline & $20 \%$ de menor ingreso & $70 \%$ de ingreso medio & $10 \%$ de mayor ingreso & \\
\hline & \multicolumn{3}{|c|}{ Porcentaje del ingreso captado por cada estrato } & \\
\hline 1996 & 4,03 & 54,87 & 41,09 & 0,4883 \\
\hline 2003 & 2,88 & 49,89 & 47,22 & 0,5791 \\
\hline
\end{tabular}

Fuente: Engel et al. (1999), Jorratt (2010).

\section{El caso de Ecuador}

En su análisis sobre la tributación directa, y con el objetivo de realizar una estimación sobre la evasión en el impuesto a la Renta de Personas Físicas en Ecuador, Roca (2009) lleva a cabo un ajuste por subdeclaración diferencial por fuente de ingresos al comparar las cifras de la Encuesta de Condiciones de Vida 2005/2006 con las cifras de Cuentas Nacionales.

El autor mencionado reconoce que estudios realizados para diferentes países (incluidos los desarrollados) han identificado significativos niveles de subestimación -por no respuesta y subdeclaración - en los ingresos captados por las Encuestas de Hogares. Algunos de estos estudios, por otra parte, han determinado que esta subestimación está asociada a las fuentes de ingreso, registrándose los niveles de no respuesta y subdeclaración más altos en las rentas del capital y de trabajadores independientes, siendo significativamente menores en salarios y pensiones. Si esta subestimación diferencial por fuentes de ingreso también implica una subestimación diferencial por estratos de renta (las rentas de capital son percibidas por los estratos más ricos), la estimación de la recaudación de IRPN, de la distribución del ingreso pre-fiscal y, finalmente, del impacto redistributivo del IRPN puede arrojar resultados incorrectos sin una corrección previa. A continuación, se muestran los resultados de los ajustes a los ingresos captados por la ECV.

Para el caso del ingreso de patrones y cuentapropistas, la diferencia entre los ingresos de la ECV y el ingreso mixto de Cuentas Nacionales se atribuyó a subdeclaración, dado que ya están controladas las no respuestas, multiplicándose los valores de la ECV por 2,18, asumiendo que así hecho el ajuste, la fracción de ingreso subdeclarada es independiente del nivel de ingreso.

Con relación a las rentas del trabajo en relación de dependencia, aún dejando fuera a los jornales, que puede suponerse que las Cuentas Nacionales no captan adecuadamente, el total de estas remuneraciones salariales según la ECV supera al estimado por las Cuentas Nacionales. Esto induce a pensar que las Cuentas Nacionales tampoco captan adecuadamente rubros como horas extras, comisiones y propinas y los fringe benefits. Dado esto, se ha optado por no efectuar ningún ajuste y tomar como válidas las cifras de la ECV.

En las pensiones, el Instituto Nacional de Estadística y Censos ya ha controlado las no respuestas. Por tanto, la diferencia entre la ECV y la información de las instituciones de seguridad social se atribuyó a subdeclaración, multiplicándose los valores de la ECV por 1,38. 
En cuanto a los alquileres, no existe una cifra con la cual compararlos porque el Banco Central no elabora la cuenta de asignación del ingreso primario, donde se detallan las rentas de la propiedad. Teniendo en cuenta que las Encuestas de Hogares suelen no subestimar los alquileres se ha decidido dar por válido el monto informado por la ECV.

Para realizar el ajuste de las rentas del capital, se procedió en forma diferente a la utilizada en el caso de patrones y cuentapropistas, pensiones y remesas, cuando se supuso que la diferencia entre la ECV y la información alternativa (Cuentas Nacionales u otras fuentes) se debía a subdeclaración.

En el caso de las rentas del capital, existe experiencia sobre que la mayoría de sus perceptores directamente no las informan en las Encuestas de Hogares, por lo que se ha decidido imputar la diferencia encontrada a no respuesta. Para ello, se ha seguido a Engel et al (1998), de quienes se tomó el procedimiento; como resultado del mismo, el 93\% de los intereses imputados correspondió a individuos pertenecientes al decil 10, el de más altos ingresos. De manera similar se procedió para el caso de los intereses de bonos, dividendos y acciones; como resultado de este procedimiento, casi el $95 \%$ de los ingresos provenientes de estas fuentes correspondió a individuos pertenecientes al decil 10, el de más altos ingresos.

En relación a las remesas, según el Banco Central del Ecuador, las mismas representaron en 2005, casi 3,5 veces la cifra que surge de la ECV. El 30\% más pobre de la población recibe, de acuerdo al procesamiento de la ECV realizado en este trabajo, un 33\% de las remesas, mientras que el $30 \%$ más rico recibe un $34 \%$ de las mismas. Resulta difícil, por tanto, imputar a no-respuestas de un grupo poblacional específico la diferencia entre la ECV y el BCE (o parte de ésta). En consecuencia, dicha diferencia se ha atribuido a subdeclaración, multiplicándose los valores de la ECV por 3,42 (véase el cuadro 15).

CUADRO 15

COEFICIENTES DE AJUSTE POR SUBDECLARACIÓN DIFERENCIALES POR FUENTE

\begin{tabular}{lc}
\hline Ingreso mixto (patrones y cuentapropistas) & 2,18 \\
Remuneraciones de asalariados & 0,95 \\
Pensiones & 1,38 \\
Alquileres & - \\
Intereses de préstamos personales y de depósitos a plazo fijo & - \\
Utilidades y dividendos & 6,60 \\
Ayudas y remesas & 3,42 \\
Otras transferencias & - \\
\hline
\end{tabular}

Fuente: Roca (2009).

La distribución del ingreso pre-fiscal en Ecuador, estimada para el año 2005 a partir del procesamiento de la ECV, con los ajustes mencionados, arroja los siguientes resultados. El porcentaje del ingreso total percibido por el $10 \%$ más rico de la población $(52,1 \%)$ es casi 25 veces el que percibe el $20 \%$ más pobre $(2,1 \%)$, mientras que el $70 \%$ intermedio concentra el $45,7 \%$. Ecuador presenta, entonces, el patrón generalizado en América Latina: una muy alta concentración del ingreso en los estratos más ricos de la sociedad. El índice de Gini de la distribución del ingreso pre-fiscal estimado es 0,628. Roca nota que CEPAL informa para Ecuador un índice de Gini menor: 0,526, y atribuye la diferencia a los ajustes realizados en el trabajo. En particular:

a) aproximadamente un $90 \%$ del ajuste por no respuesta de utilidades y dividendos - se multiplican por 6,6 los valores de la ECV—, resulta imputado al decil de más altos ingresos;

b) $45 \%$ del ajuste por subdeclaración de los ingresos independientes de patrones $\mathrm{y}$ cuentapropistas personas físicas — se multiplican por 2,18 los valores de la ECV—, resulta imputado al decil 10; y, en menor medida, 
c) la decisión de partir del ingreso pre-fiscal y, por tanto, no considerar las transferencias públicas (Bono de Desarrollo Humano y Bono de la Vivienda), que tienen un impacto redistributivo positivo.

\section{El caso de Uruguay}

Para el caso de Uruguay, Grosskoff (1996) enumera las fuentes de ingreso a comparar al momento de compatibilizar ingresos provenientes de las encuestas e ingresos de Cuentas Nacionales, y las cuestiones que deben tenerse en cuenta al momento de realizar los ajustes. Los distintos tipos de ingresos de los hogares son: remuneración del trabajo asalariado; ingresos del empleo independiente: ingresos mixtos de los empleadores y de los trabajadores por cuenta propia; rentas de la propiedad (intereses, dividendos, alquileres); transferencias de la Seguridad Social (pensiones y jubilaciones), y otras transferencias.

En Grosskoff (1996) e INE-CEPAL (1996) se presenta una comparación entre los ingresos y perceptores, por fuente de renta y quintil, de ingresos provenientes de la Encuesta Continua de Hogares (ECH) y la Encuesta de Gastos e Ingresos de los Hogares (EGIH), la que, por cobertura geográfica, temporal y cantidad de perceptores, se asemeja en mayor medida a las cifras marco de Cuentas Nacionales, para 1994/5.

De acuerdo con estas estimaciones, el ingreso corriente con valor locativo por hogar estimado a partir de la EGIH para Montevideo es un 11\% superior al de la ECH par igual período, siendo inferior en el primer decil y más alto en el resto de los tramos de la distribución (véase el cuadro 16). Para el interior urbano el comportamiento decílico es similar, con un ingreso superior en alrededor de un $12 \%$.

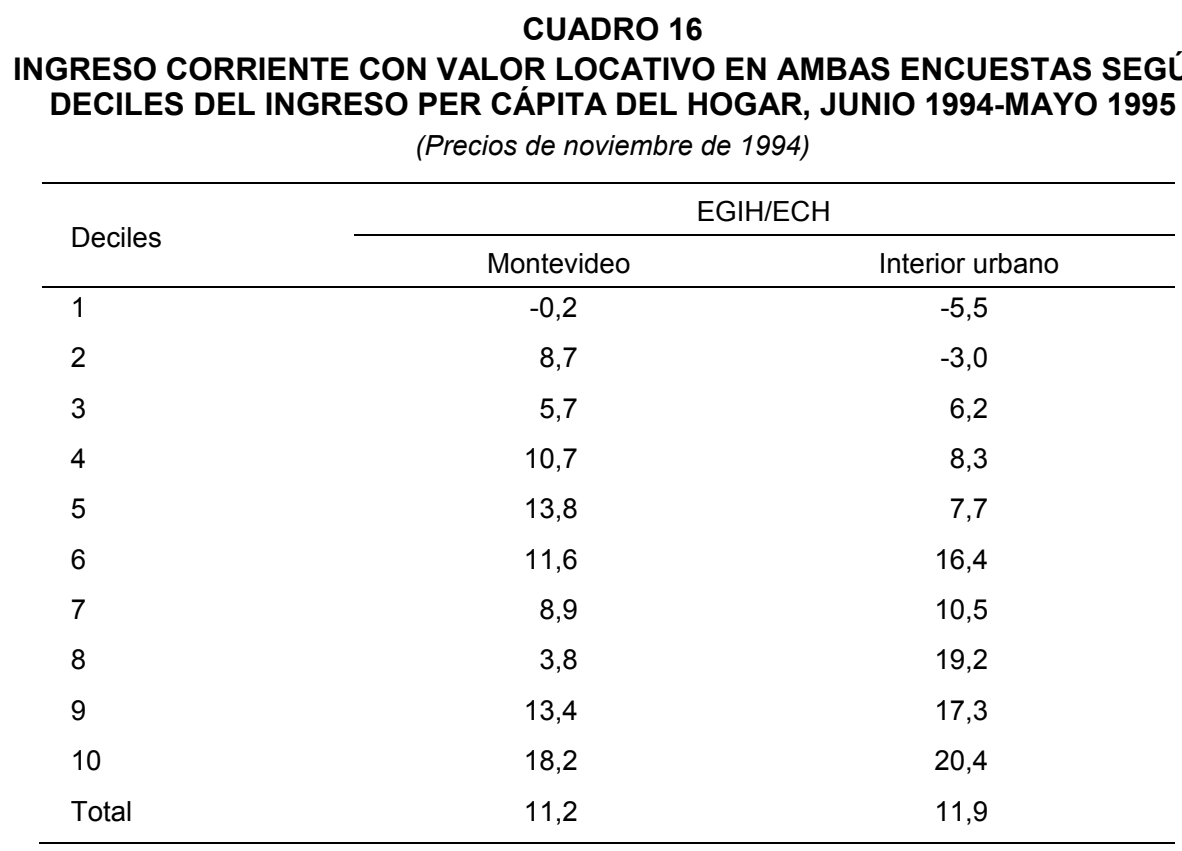

Fuente: INE-CEPAL (1996).

La comparación de los montos de ingresos totales por fuente (véase el cuadro 17) arroja que, para Montevideo, las mayores diferencias se observen en transferencias y subsidios, ingreso de los patrones y alquileres e intereses, mientras que en el interior urbano las diferencias en el valor locativo son también importantes. 
CUADRO 17

RELACIÓN ENTRE LOS INGRESOS DE LA EGIH SOBRE LOS DE LA ECH POR TIPO DE INGRESO SEGÚN ÁREA GEOGRÁFICA, MONTEVIDEO E INTERIOR

(En porcentajes, $\mathrm{ECH}=100$ )

\begin{tabular}{lcccccccc}
\hline EGIH/ECH & $\begin{array}{c}\text { Ingreso del } \\
\text { hogar }\end{array}$ & $\begin{array}{c}\text { Sueldos y } \\
\text { salarios }\end{array}$ & $\begin{array}{c}\text { Cuenta } \\
\text { propia }\end{array}$ & Patrón & $\begin{array}{c}\text { Jubilaciones } \\
\text { y pensiones }\end{array}$ & $\begin{array}{c}\text { Alquileres } \\
\text { e intereses }\end{array}$ & $\begin{array}{c}\text { Transferencias } \\
\text { y subsidios }\end{array}$ & $\begin{array}{c}\text { Valor } \\
\text { locativo }\end{array}$ \\
\hline Montevideo & 111,2 & 103,3 & 114,4 & 147,0 & 99,3 & 146 & 164,3 & 110,7 \\
Interior & 111,9 & 105,1 & 112,1 & 129,4 & 95,2 & 181 & 131,3 & 125,6 \\
\hline
\end{tabular}

Fuente: INE-CEPAL (1996).

En relación con la contribución de cada rubro sobre el total, en Montevideo la fuente que tiene mayor incidencia en la variación total son los ingresos de los patrones, mientras que en el interior urbano el valor locativo contribuye con casi un $40 \%$ de la diferencia (véase el cuadro 18 ).

CUADRO 18

CONTRIBUCIÓN A LA DIFERENCIA DE LOS INGRESOS EN AMBAS ENCUESTAS, POR TIPO DE INGRESO SEGÚN ÁREA GEOGRÁFICA, MONTEVIDEO E INTERIOR

(En porcentajes)

\begin{tabular}{lcccccccc}
\hline EGIH/ECH & $\begin{array}{c}\text { Ingreso } \\
\text { del hogar }\end{array}$ & $\begin{array}{c}\text { Sueldos y } \\
\text { salarios }\end{array}$ & $\begin{array}{c}\text { Cuenta } \\
\text { propia }\end{array}$ & Patrón & $\begin{array}{c}\text { Jubilaciones } \\
\text { y pensiones }\end{array}$ & $\begin{array}{c}\text { Alquileres } \\
\text { e intereses }\end{array}$ & $\begin{array}{c}\text { Transferencias } \\
\text { y subsidios }\end{array}$ & $\begin{array}{c}\text { Valor } \\
\text { locativo }\end{array}$ \\
\hline Montevideo & 100,0 & 12,5 & 14,6 & 31,4 & $-0,9$ & 10,1 & 16,0 & 16,2 \\
Interior & 100,0 & 17,2 & 12,9 & 16,1 & $-7,3$ & 13,2 & 9,0 & 38,9 \\
\hline
\end{tabular}

Fuente: INE-CEPAL (1996).

El ingreso corriente promedio por perceptor de la EGIH es un $10 \%$ superior al estimado por la $\mathrm{ECH}$ en Montevideo (cabe consignar que en este caso la comparación de los ingresos por fuente se realizó sin expandir al total poblacional). Los ingresos por alquileres e intereses son los que presentan mayor disparidad entre las dos encuestas, lo que obedece fundamentalmente a lo que ocurre en el quintil superior, donde la EGIH capta un ingreso superior en un 37\% al de la ECH (véase el cuadro 19). Para el interior urbano, la diferencia es de 10,8\%, siendo el rubro de mayor variación el de jubilaciones y pensiones, seguido de cerca por las transferencias y subsidios (véase el cuadro 20).

CUADRO 19

PROMEDIO DE LOS INGRESOS DE LOS PERCEPTORES POR QUINTILES, SEGÚN FUENTES DEL INGRESO PER CÁPITA DEL HOGAR, MONTEVIDEO, JUNIO 1994-MAYO 1995

\begin{tabular}{lrrrrrr}
\hline & \multicolumn{7}{c}{ Quintiles } \\
\cline { 2 - 7 } Cociente EGIH/ECH & \multicolumn{1}{c}{ 1 } & 2 & 3 & 4 & 5 & Total \\
\hline Fuente & & & & & & \\
Sueldos y salarios & $-8,2$ & 7,0 & 13,8 & 5,8 & 0,7 & 2,7 \\
Cuenta propia & $-24,4$ & $-13,8$ & $-23,1$ & $-21,1$ & 12,3 & $-16,1$ \\
Patrones & 91,5 & $-8,1$ & $-9,4$ & 10,0 & 3,1 & 10,9 \\
Jubilaciones y pensiones & 5,8 & $-1,9$ & 6,9 & 13,7 & 7,4 & 3,7 \\
Alquileres e intereses & $-1,6$ & $-0,9$ & $-6,2$ & 8,2 & 36,6 & 23,9 \\
Transferencias y subsidios & $-36,7$ & $-34,4$ & 10,7 & $-14,6$ & 24,6 & $-7,7$ \\
\hline Ingresos corrientes sin valor locativo & $-5,8$ & 8,3 & 11,9 & 9,8 & 22,7 & 10,1 \\
\hline
\end{tabular}

Fuente: INE-CEPAL (1996). 
CUADRO 20

PROMEDIO DE LOS INGRESOS DE LOS PERCEPTORES POR QUINTILES, SEGÚN FUENTES DEL INGRESO PER CÁPITA DEL HOGAR, INTERIOR, JUNIO 1994-MAYO 1995

\begin{tabular}{lrrrrrr}
\hline & \multicolumn{7}{c}{ Quintiles } \\
\cline { 2 - 7 } Cociente EGIH/ECH & 1 & 2 & 3 & 4 & 5 & Total \\
\hline Fuente & & & & & \\
Sueldos y salarios & $-8,0$ & $-0,6$ & $-0,7$ & $-3,2$ & 16,5 & 1,5 \\
Cuenta propia & $-15,2$ & $-9,7$ & $-6,4$ & $-5,5$ & 1,5 & $-6,2$ \\
Patrones & $-10,1$ & $-8,9$ & 23,2 & $-1,2$ & $-7,7$ & $-5,2$ \\
Jubilaciones y pensiones & 3,0 & 13,1 & 2,7 & 13,4 & 11,2 & 9,3 \\
Alquileres e intereses & 8,3 & 31,9 & $-4,5$ & $-2,9$ & 18,4 & 8,0 \\
Transferencias y subsidios & $-30,2$ & 13,8 & 58,0 & 66,5 & 12,1 & 8,5 \\
Ingresos corrientes sin valor locativo & $-5,7$ & 9,6 & 11,4 & 12,2 & 20,0 & 10,8 \\
\hline
\end{tabular}

Fuente: INE-CEPAL (1996).

El ejercicio de aparear la EGH y la EGIH muestra que los ingresos de la primera se encuentran subestimados en alrededor de un 11\%; al comparar con estimaciones del ingreso disponible realizado por la CEPAL, el estudio concluye que la estimación del ingreso proveniente de Cuentas Nacionales se encuentra subestimada en un 5,6\%.

Roca (2010) reconoce que los ajustes por no respuesta y subdeclaración tienen mucho más de "arte" que de "ciencia" y dependen de las fuentes de información externas (a la Encuesta de Hogares) disponibles. Lo habitual es, siguiendo la sugerencia de CEPAL, comparar, para las diferentes fuentes de ingresos, los valores que surgen de la Encuesta de Hogares con los de Cuentas Nacionales.

Roca (2010) realiza la comparación para los ingresos del trabajo (sueldos y salarios), los ingresos de los trabajadores independientes (patrones y cuentapropistas) y las transferencias recibidas (incluidas las jubilaciones). De la comparación con las Cuentas Nacionales resulta que la EGIH capta satisfactoriamente estas fuentes de ingreso, coincidiendo con los resultados de Grosskoff y de INE-CEPAL.

No sucede lo mismo en el caso de las rentas del capital - alquileres, intereses, dividendos y otros-, donde la no respuesta y/o subdeclaración son notorias, pero no realiza el ajuste correspondiente. Los resultados que arroja su estudio determinan que el $20 \%$ de menores ingresos concentra un $3,1 \%$ del ingreso total, el $70 \%$ intermedio abarca el $60,6 \%$ del total del ingreso, mientras que el $10 \%$ más rico concentra el 36,3\% del total. El coeficiente de Gini resultante es 0,4995. 



\section{La importancia de las altas rentas y las posibilidades de su medición}

\section{A. Hacia una definición de los "muy ricos"}

Hay varias definiciones estadísticas de los ricos y súper-ricos, basadas en medidas del ingreso (flujo), del patrimonio (acervo) o de ambos. También se puede distinguir entre definiciones absolutas y relativas. Las definiciones basadas en los deciles o percentiles superiores son definiciones relativas, en tanto que la línea de afluencia y los umbrales de riqueza son medidas absolutas ${ }^{43}$ :

- Deciles, ventiles o percentiles superiores. Esta es una definición relativa de los ricos. En este caso, los ricos serían el sector de la población ubicado en el tramo superior de la distribución del ingreso, es decir en el 10 y el 5 por ciento superior, en tanto que los pertenecientes al $1 \mathrm{o}$ al 0,1 por ciento podrían caracterizarse como "súper-ricos".

- Línea de afluencia: De manera similar al método de línea de pobreza, que corresponde al tramo inferior de ingresos, se puede identificar el tramo superior y determinar la proporción de individuos que pueden definirse como "ricos", a partir de una línea de afluencia (ingreso) (Sen, 1988). Quienes se ubican por sobre la línea de afluencia pueden considerarse como "ricos" y, al igual que en el caso de la línea de pobreza, se pueden emplear simplemente criterios numéricos o cuantitativos para medir la proporción de ricos en una sociedad.

- Umbrales de riqueza. Según la definición de Atkinson (2006), se puede definir a los ricos como las personas cuyo patrimonio equivale a 30 veces el ingreso medio per cápita, de un país. El múltiplo elegido se basa en una tasa de retorno del 3,5 por ciento anual (rendimiento de los activos de largo plazo), dado que ese nivel generaría intereses iguales al ingreso medio

43 Esta sección sigue a Jiménez y Solimano (2012). 
per cápita. Dicho nivel de patrimonio permitiría a una persona vivir de los intereses (retorno) devengados por su patrimonio y tener un nivel estándar (o promedio) de vida ${ }^{44}$.

Atkinson (2006) considera "súper ricos" (multimillonarios) a quienes tienen un patrimonio equivalente a 30 × 30 veces el ingreso medio, es decir aquellos que pueden vivir de los "intereses de los intereses". También define como "globalmente ricos" a quienes poseen un ingreso superior en más de 20 veces el ingreso medio mundial. A su vez los "mega-ricos" o billonarios serían quienes tienen un patrimonio equivalente a $30 \times 30 \times 30$ veces el ingreso medio per cápita. Las personas clasificadas en esta última categoría de Atkinson corresponden aproximadamente a los billonarios incluidos en la lista de la revista Forbes.

Los "globalmente ricos" constituían en 1990 el 0,14\% de la población mundial pero recibían el $5,4 \%$ del ingreso mundial, representando alrededor de 7,4 millones de personas. Este número cayó desde el $0,23 \%$ en 1910 , pasando por un $0,1 \%$ en 1950 para luego volver a incrementarse entre 1970 y 1990 , duplicándose la cantidad de "súper ricos" en los Estados Unidos.

El estudio sobre la distribución de los individuos de altos ingresos ha renacido, de un tiempo a esta parte, en el interés de los investigadores. Ha existido, de un tiempo a esta parte, un marcado esfuerzo en revitalizar los estudios sobre la distribución de los ingresos más elevados utilizando información de las declaraciones juradas del impuesto sobre la Renta personal pero habían sido dejados de lado ante el surgimiento de los microdatos provenientes de encuestas de hogares.

Los mismos comienzan siguiendo las fuentes y métodos tradicionales utilizados en el trabajo pionero de Kuznets (1953) sobre la participación de los ingresos más elevados en Estados Unidos ${ }^{45}$. Los mencionados trabajos de Kuznets fueron continuados por el trabajo de Piketty sobre la distribución de los "top incomes" en Francia en el largo plazo, para concluir en la sucesión de estudios que han avanzado en la construcción de las participaciones de los ingresos más elevados a lo largo del tiempo (abarcando gran parte del siglo veinte y los inicios del siglo XXI) en más de veinte países. Estos trabajos han sido compilados en varias publicaciones recientes, las más importantes de las cuales están reunidas en las publicaciones de Atkinson y Piketty (2007, 2010). Cabe consignar que la información sobre ingresos permite, siempre de acuerdo a las características legislativas de cada país, discriminar el ingreso según su fuente, lo que habilita para analizar los cambios en la composición de los ingresos (asalariados, renta del capital, cuenta propia, empleadores, etc.) de los tramos más elevados.

En la presente sección se presentará en primer lugar la metodología empleada, en segundo, las limitaciones de la misma, y en tercer lugar, algunos resultados sintetizados de los estudios.

\section{B. Las metodologías empleadas para su determinación}

El valor agregado de contar con información tributaria para analizar los ingresos radica en el hecho de que una buena cantidad de países han publicado, de manera sistemática y regular, tabulaciones basadas en las declaraciones juradas del impuesto a la renta. Estas tabulaciones presentan los ingresos declarados segmentados por tramos de ingresos antes de impuestos, divididos por fuente de ingreso según el caso, e informando las deducciones que reducen el impuesto determinado.

Sin embargo, la utilización de esta información encierra tres problemas de índole metodológica al momento de intentar calcular las participaciones de los tramos superiores en el ingreso total. Los dos primeros se relacionan con controles totales de consistencia; el primero consiste en la necesidad de relacionar el número de personas declarantes de impuestos con algún control para poder determinar cuánto representan los que han declarado impuestos en relación con el total. El segundo, entretanto,

\footnotetext{
44 Este límite es similar al aplicado por las empresas comerciales de gestión de activos como Cap Gemini, que consideran ricos a quienes tienen un patrimonio líquido de un millón de dólares (se excluye de esta definición las casas y otros bienes raíces de su propiedad) (Jiménez y Solimano (2012)).

45 Por ejemplo, uno de los trabajos pioneros en Argentina sobre el análisis del impacto distributivo de los impuestos fue llevado a cabo en los años 60 por Herschel, quien empleaba datos de ingresos provenientes de declaraciones juradas de impuestos.
} 
busca determinar, una vez definido el ingreso disponible, el nivel de ingreso de control que será considerado como denominador del ingreso del los tramos de ingresos más altos en la estimación.

El tercer problema radica en el hecho de que, dado que los ingresos están presentados por tramos, y como no se dispone de la base de datos de las declaraciones juradas, se requiere una metodología de interpolación para construir la distribución continua asociada a los ingresos presentados, siendo la más utilizada la interpolación de Pareto. A continuación se explicitarán estas cuestiones con un mayor grado de detalle.

\section{Control total por población}

Para calcular el universo de contribuyentes totales, lo que permitirá analizar cuánto representan los que declararon en el impuesto a la Renta sobre el total, debe tenerse en cuenta en primer lugar la unidad contribuyente del impuesto. En algunos países (Canadá, Nueva Zelanda, Reino Unido desde 1990), la unidad contribuyente es el individuo (individual filing), lo que determina que el control total natural sea la población adulta, definida como los residentes totales de una determinada edad o por encima de ella.

En consecuencia, el porcentaje que concentra el percentil de ingresos más altos estará midiendo los ingresos concentrados por los individuos adultos. En otros países, la unidad contribuyente es la familia (Reino Unido antes de 1990), siendo definida ésta como un matrimonio conviviente con hijos, o un adulto con hijos. El control total utilizado en este caso por Atkinson es el número total de personas de por lo menos 15 años neto del número de mujeres casadas.

En Estados Unidos las mujeres casadas pueden llenar declaraciones juradas en forma individual, aunque la proporción es reducida. En Argentina, también el sistema apunta hacia individual filing, aunque se considera un sistema mixto, dado que existen activos comunes cuyas rentas las concentra el esposo.

Los efectos de utilizar la unidad individual en detrimento de la unidad familia dependerán de la distribución de ingresos conjunta. Saez y Veall (2005), en el caso de Canadá, computan las participaciones de los salarios más altos tanto para el caso de individual filing como para joint filing desde 1982. Encuentran que los ingresos top individuales superan a los ingresos familiares en un 5\%.

\section{Control total de ingresos}

El objetivo es relacionar los ingresos declarados en la información tributaria (numerador del ingreso que los tramos más elevados concentran) con un control total comparable para el total de la población. Dado que se utilizan diferentes enfoques, debe analizarse con cuidado cada caso en particular para poder habilitar a una comparación entre distintos países a lo largo del tiempo.

Una aproximación parte del ingreso declarado y le adiciona el ingreso del los no declarantes (Atkinson (2005) para el Reino Unido, y Piketty y Saez (2003) para Estados Unidos). Este enfoque tiene la particularidad de tomar la definición de ingreso que surge de la legislación, y las estimaciones consecuentes cambiarán con las variaciones de la legislación (por ejemplo, la inclusión, en determinado momento, de las ganancias de capital en la base imponible del impuesto a la Renta).

La idea es estimar el ingreso total que habría sido declarado si todos los contribuyentes hubieran declarado impuestos, tanto para el caso de los impuestos autodeclarados como en el caso de los impuestos de asalariados cuyas declaraciones juradas son realizadas por sus empleadores.

Un segundo enfoque parte de un control externo total, como los datos de ingresos provenientes de las Cuentas Nacionales (Piketty (2000, 2003) para Francia; Saez and Veall (2005) para Canadá). Esta metodología apunta a ajustar la información impositiva de manera homogénea, corrigiendo por ejemplo por ingresos faltantes, pero subsisten significativas entre los conceptos de ingreso de ambas fuentes. De acuerdo con lo explicitado anteriormente, la misma es conceptualmente asimilable a la metodología empleada para ajustar los datos de las Encuestas de Hogares.

Los siguientes son los pasos necesarios para vincular los ingresos de Cuentas Nacionales con los provenientes de las declaraciones juradas del impuesto a la Renta. La metodología arranca desde el 
ingreso personal, corrigiendo por los ingresos no provenientes de los hogares (incluye los fondos de pensión) y las contribuciones y aportes a la seguridad social tanto por parte de los empleadores como de los asalariados.

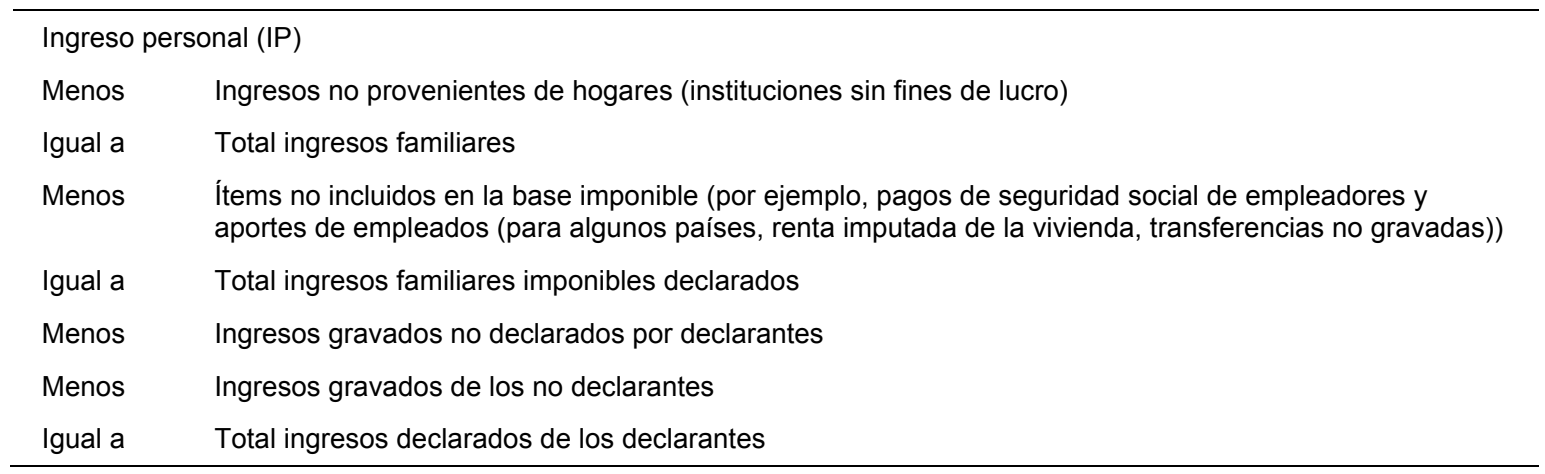

Atkinson (2007) compara los dos métodos para el caso del Reino Unido; el ingreso total estimado por el primer método, mediante la estimación del ingreso de los no declarantes es inferior en un 10\% a la estimación por el segundo método para la primera parte del siglo veinte, e inferior en $15 \%$ para la segunda.

Adicionalmente, para una parte importante de los estudios, la definición de ingreso utilizada para presentar las tabulaciones varía a lo largo del tiempo, con lo cual deben hacerse correcciones con el fin de homogeneizar los resultados. Las correcciones mencionadas incluyen, por ejemplo, los cambios en la presentación de la información de ingresos antes de deducciones a ingresos después de deducciones, lo que se puede corregir de encontrarse disponible la información sobre deducciones por tramos de ingresos, asumiendo que no hay reordenamiento entre los contribuyentes antes y después de las mismas ${ }^{46}$.

\section{El método de interpolación de Pareto}

Los datos de declaraciones juradas de impuestos están presentados en forma de tabulaciones por tramos de ingresos, en donde los tramos no coinciden, en general, con los tramos de ingresos objeto del análisis (por ejemplo el $1 \%$ más rico). Es necesario interpolar para establecer valores para calcular los porcentajes de ingresos que concentran estos sectores.

La ley de Pareto para ingresos elevados está dada por la siguiente función de distribución acumulativa para el ingreso $y$, donde $k$ y $\alpha$ son parámetros dados, $\mathrm{y} \alpha$ es el denominado parámetro de Pareto.

$$
1-F(y)=(k / y)^{\alpha}(k>0, \alpha>1)
$$

La correspondiente función de densidad está dada por

$$
f(y)=\alpha k^{\alpha} / y^{(1+\alpha)}
$$

La propiedad clave de las distribuciones de Pareto es que el ratio de ingreso medio $y^{*}(y)$ de individuos con ingreso mayor que $y$ a $y$ no depende del tramo de ingreso $y$ (es constante)

$$
y^{*}(y)=\left\lfloor\int_{z>y} z f(z) d z\right] /\left[\int_{z>y} f(z) d z\right]=\left[\int_{z>y} d z / z^{\alpha}\right] /\left[\int_{z>y} d z / z^{(1+\alpha)}\right]=\alpha y /(\alpha-1)
$$

Con $y^{*}(y) / y=\beta$, con $\beta=\alpha /(\alpha-1)$, siendo $\beta$ la inversa del coeficiente de Pareto, que es el utilizado en estos estudios por ser intuitivamente más comprensible.

46 Muchos estudios analizan adicionalmente los cambios ante la inclusión o no de ganancias de capital. 
En consecuencia, si $\beta=2$, el ingreso promedio de individuos con ingreso superior a $\$ 100,000$ es $\$ 200,000$ y el ingreso promedio de individuos con ingreso superior a $\$ 1$ millón es $\$ 2$ millones. Un valor de $\beta$ más elevado implica una "cola" más ancha en la distribución, lo cual significa mayor proporción de ingresos concentrados en los tramos superiores. Para Estados Unidos, el coeficiente crece de 1,69 en 1976 a 2,89 en 2007 implicando un incremento en la participación del percentil de mayores ingresos de $7,9 \%$ a $18,9 \%$. En Francia, entretanto, el coeficiente se ha mantenido estable a lo largo del tiempo entre 1,65 y 1,75 , implicando que la concentración del percentil superior se ha mantenido constante entre $7,5 \%$ y $8,5 \%$.

En Argentina, los valores del coeficiente son superiores a 2,5 hasta principios de los años 50, luego decrecen a valores inferiores a 1,8 hacia inicios de la década de 1970, para luego volver a crecer hacia valores cercanos a 2,5 a principios de la década de 2000.

Según Atkinson, Piketty y Saez (2011), el coeficiente $\beta$ varía entre 1,5 y 3; los valores comprendidos entre 1,5 y 1,8 expresan baja desigualdad (donde el top $1 \%$ concentra entre el 5 y el $10 \%$ del ingreso), mientras que valores superiores a 2,5 indican elevada desigualdad (el percentil más alto concentra entre el 15 y el $20 \%$ del total de la renta).

\section{Las limitaciones metodológicas para la estimación de las altas rentas}

Las metodologías mencionadas no están exentas de limitaciones. La primera es que ponen énfasis sólo en los tramos de ingresos superiores, y no analizan la evolución del resto de la distribución. Como fuera expresado, a diferencia del índice de Gini, por ejemplo, que evalúa en mayor proporción a los sectores medios, este tipo de análisis sólo hace referencia a los tramos de ingresos más elevados.

La segunda de las limitaciones es que consideran ingresos antes de impuestos, con lo cual ignoran posibles reordenamientos que podrían resultar de la acción de la política fiscal. Adicionalmente, la construcción de la información proveniente de las declaraciones juradas de impuestos a partir de consolidar un control total por ingresos -según se verá a continuación- asume que, en el caso en que la información sobre ingresos estuviera presentada en valores netos de deducciones, el acrecentamiento del ingreso que devendría de volver a incorporar en las rentas los montos deducidos no generan, se asume, un reordenamiento en los individuos según su ingreso.

En tercer lugar, la definición de ingreso y la unidad de observación pueden variar entre distintos países, y aún dentro de un mismo país por los cambios en la legislación, si es que éstos hubieren existido. Tanto en el caso de la unidad contribuyente, que ya fuera mencionado, como la incorporación dentro de la base imponible de determinadas rentas que inicialmente no hubieren estado gravadas, o, a la inversa, el establecimiento de una exención sobre determinadas rentas genera heterogeneidades que impactan fuertemente en la comparación a realizar entre distintos países.

Adicionalmente, la utilización de información proveniente de ingresos declarados está sujeta a controversia debido a que la información impositiva es recolectada como parte de un proceso administrativo que difiere de las necesidades de los estudios de esta característica, teniendo en cuenta definición de ingresos, unidad contribuyente, etc.

En cuarta instancia, y tal vez la crítica más importante, se destaca que las estimaciones pueden estar sesgadas debido a la evasión o elusión impositiva. Aquellos que declaran impuestos tienen incentivos, sobre todo los de ingresos más elevados, a no revelar la totalidad de sus ingresos con el fin de reducir su obligación tributaria.

Por ejemplo, los perceptores de salarios elevados podrían tener incentivos a que su remuneración fuera en forma de opciones. No existe una metodología homogénea de incorporación de los montos evadidos o eludidos en la información de ingresos declarados, con lo cual esto puede generar distorsiones de relevancia a la hora de comparar distintos países a lo largo del tiempo. Sobre este particular pueden estar afectando de manera muy significativa grados de incumplimiento tributario 
diferenciales a lo largo de los distintos países, como así también las amnistías tributarias afectan a la evolución de las participaciones de las rentas elevadas.

\section{Los efectos de las tasas marginales máximas en la concentración de los ingresos}

La literatura que ha analizado la evolución de la distribución del ingreso, focalizando su enfoque en el estudio de la participación de los tramos de ingresos más elevados a partir de la utilización de los datos sobre ingresos provenientes de las declaraciones juradas del impuesto a la Renta del Personas Físicas, ha procurado, en trabajos muy recientes, relacionar las concentraciones de ingresos mencionadas con las tasas marginales máximas del IRPN para los países desarrollados.

Alvaredo et al (2013) señalan que a lo largo del siglo veinte las tasas marginales más altas del impuesto a la Renta han seguido un patrón de U invertida ${ }^{47}$. En los Estados Unidos, por ejemplo, estas alícuotas fueron superiores al $70 \%$ a principios de la década de 1920 y fueron consistentemente superiores al 60\% entre 1932 y 1981. Sin embargo, un buen número de países se ha embarcado en una política de disminución de alícuotas (la tasa marginal máxima en Francia en 2010 fue sólo 10 puntos porcentuales más baja que en 1950, mientras que la de los Estados Unidos fue menos de la mitad del valor de 1950). En el gráfico 17 se muestra la evolución de las tasas marginales máximas para Estados Unidos, Francia, Alemania y el Reino Unido a partir de 1980, con datos de la OECD.

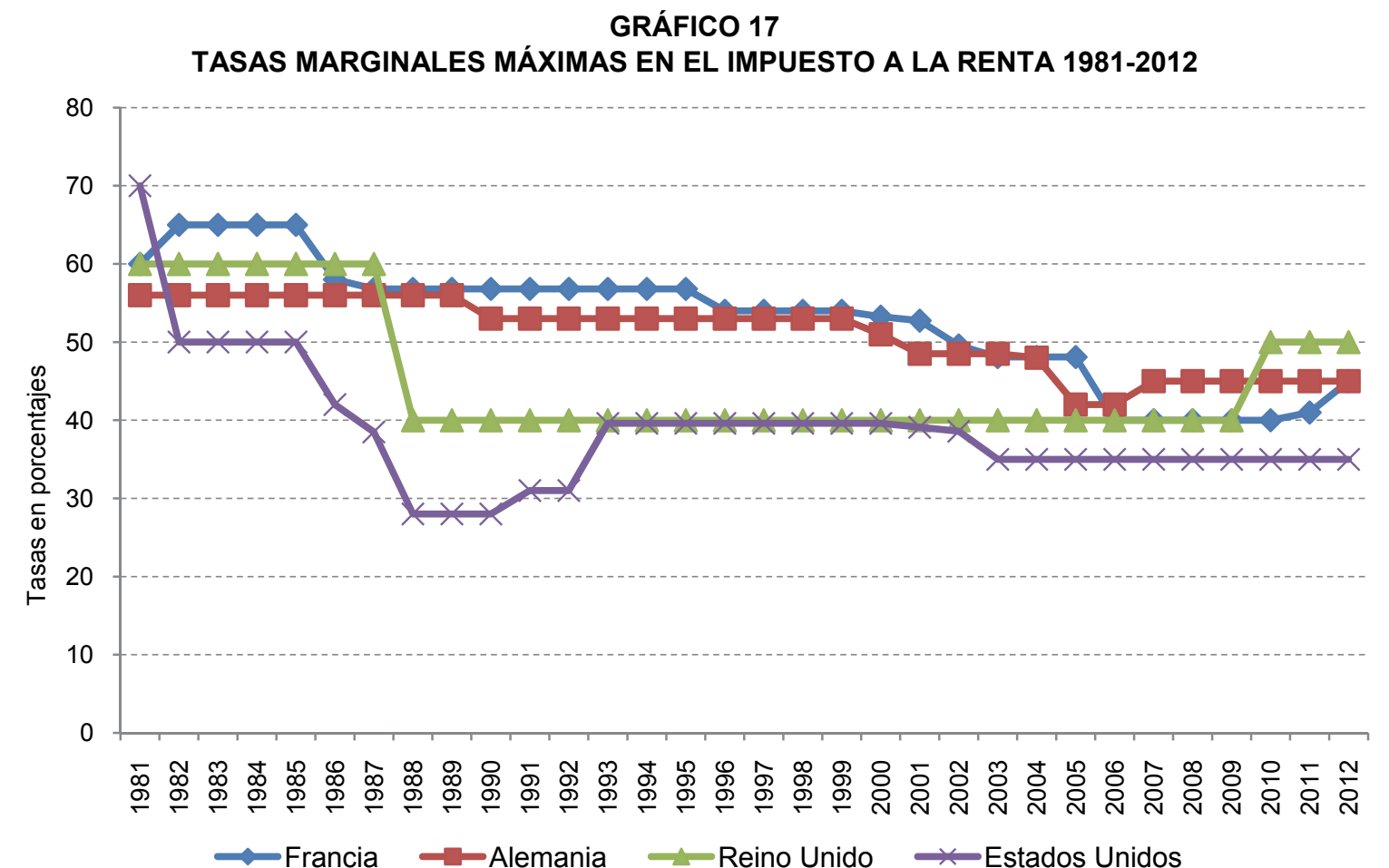

Fuente: Elaboración propia en base a OECD Tax Database.

47 Esta sección sigue a Alvaredo et. al (2013). 
En el gráfico 18, Alvaredo et al (2013) muestran los cambios en las tasas marginales más altas del IRPN desde 1960 con los cambios en las participaciones del 1\% de ingresos más elevados para 18 países de altos ingresos. Se puede apreciar una elevada correlación (no se muestra causalidad) entre las reducciones en las tasas marginales más altas y la concentración de top 1\% de ingresos pre acción físcal, a la inversa de lo que ocurre en países en los que no ha existido reducción de alícuotas, en los que no se advierten incrementos en el ingreso que concentra el $1 \%$ más rico.

\section{GRÁFICO 18 \\ CAMBIOS EN LAS PARTICIPACIONES DE LOS INGRESOS MÁS ELEVADOS Y LAS TASAS MARGINALES MÁXIMAS DEL IRPN}

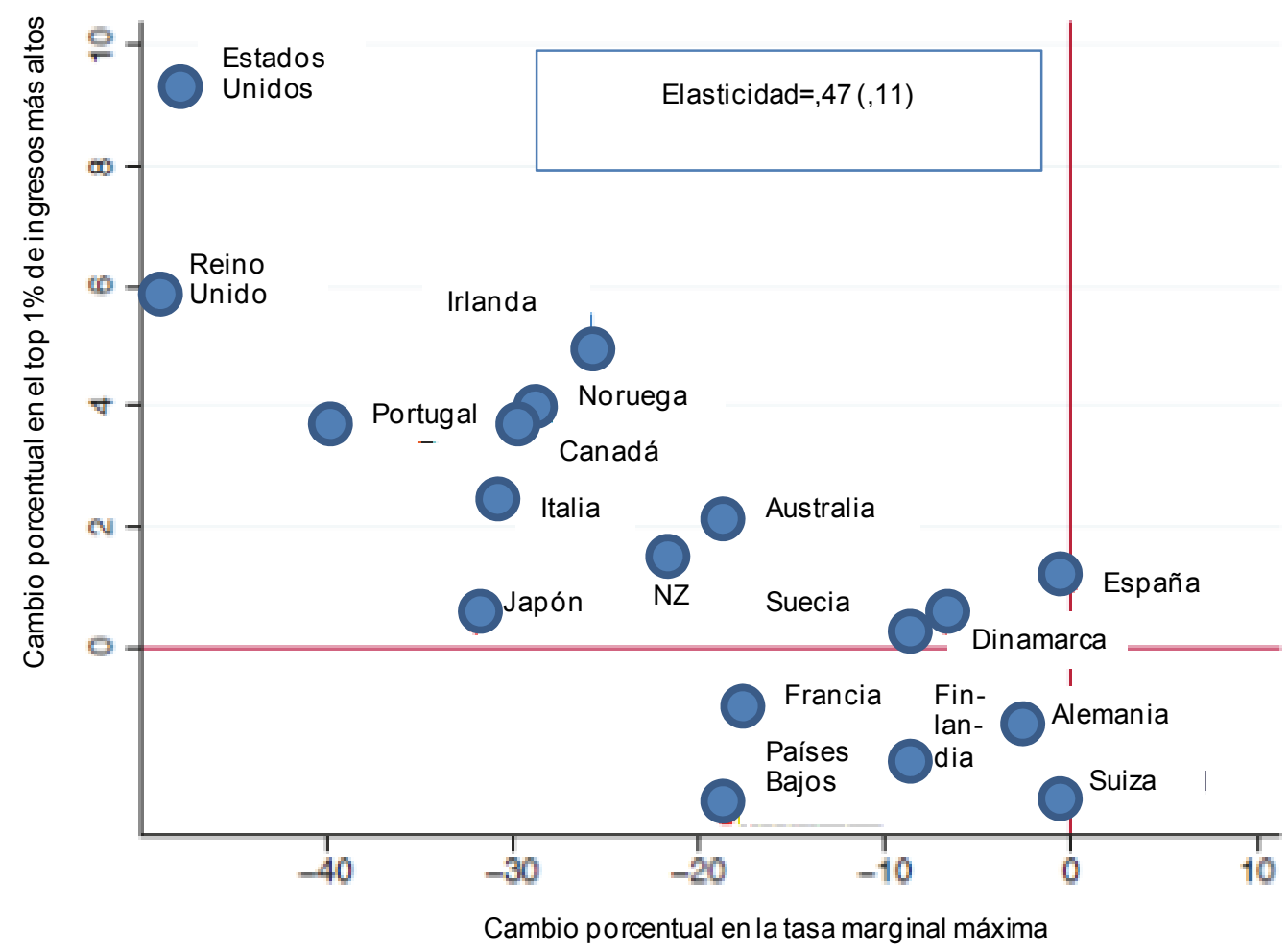

Fuente: Reproducido de Alvaredo et al (2013).

Estos resultados son consistentes con las aseveraciones de los párrafos anteriores en relación con el comportamiento del IRPN en América Latina, en donde, si bien se aprecia un incremento en la recaudación, la caída en las tasas marginales máximas y los niveles de ingreso gravable más elevados hacen que el impuesto pierda progresividad.

De acuerdo con estos autores, la correlación negativa puede ser explicada de varias maneras. Una explicación (Slemrod) sugiere que las disminuciones de tasas determinan que los perceptores de ingresos elevados, al no estar ahora gravados, no tengan incentivos a eludir o evadir impuestos y reporten ahora correctamente los ingresos que detentan a los organismos recaudatorios, lo cual constaría de este modo en la información relevada en las declaraciones juradas de los impuestos.

Sin embargo, esta explicación resulta poco satisfactoria, dado que la inclusión dentro de la información relevada de las rentas del capital (utilizadas principalmente como mecanismo para reducir obligaciones tributarias) hace que los porcentajes de ingreso que concentran los individuos de ingresos elevados crezcan en una proporción equivalente a aquéllos que no incluían esta fuente de ingreso dentro de sus estimaciones. 
En consecuencia, otra de las explicaciones alternativas consiste en proponer un modelo de oferta (Feldstein), en donde tasas más bajas impulsan un crecimiento de la actividad económica incitando a los perceptores de ingresos elevados a ofertar más trabajo e incentivar el crecimiento económico.

Explicaciones más recientes, sin embargo, dan cuenta de los avances de las teorías de la búsqueda, que se trasuntan en modelos de job-matching, en donde un trabajo emerge como resultado de la costosa creación de una vacante por el empleador y la búsqueda por parte del trabajador. El matching crea un superávit positivo y hay Nash bargaining sobre la división del superávit, lo que determina una proporción $\beta$ de la que se apropia el trabajador, y (1- $\beta)$, que retiene el empleador.

Si la proporción $\beta$ crece, el asalariado captura una proporción mayor de ese superávit. Las bajas en las tasas marginales máximas llevaron a que los perceptores de ingresos más elevados (el 1\%, por ejemplo) comenzaran a pujar agresivamente para incrementar su participación relativa (a expensas del restante $99 \%$ ). 


\section{Principales resultados de los estudios sobre las altas rentas en la distribución del ingreso}

\section{A. El contexto internacional: grandes avances en la comprensión y cuantificación del fenómeno}

En esta sección se sintetizarán resultados de los estudios realizados. Adicionalmente, se establecerán consideraciones relacionadas al impacto sobre la desigualdad global y a la delimitación de los individuos considerados "ricos".

Los resultados de los estudios se dividen en tres instancias. El primer objetivo es analizar la evolución de la participación de los tramos de ingresos más elevados sobre el total de ingresos en diferentes países; el propósito del segundo es fragmentar la participación de los tramos de ingresos elevados en segmentos más reducidos, para analizar la concentración de los ingresos, mientras que el tercero es evaluar los cambios en la composición de los ingresos de los tramos de rentas más elevadas, en función de la fuente del ingreso.

En primer lugar, la mayoría de los países ha experimentado una importante caída en las participaciones de los tramos de ingresos más elevados en la primera parte del siglo veinte, haciéndose más marcadas en los períodos cercanos a la Segunda Guerra Mundial o la Gran Depresión.

En la segunda parte del siglo pasado, los ingresos concentrados por los tramos superiores comenzaron a experimentar un crecimiento paulatino y constante, el que sin embargo varía de acuerdo a los países analizados. En los países angloparlantes de Occidente, Europa, América del Norte, Australia y Nueva Zelanda, China e India, se advierte un incremento importante en las participaciones de los tramos más elevados; en los países del sur de Europa y los países nórdicos, también se aprecia un incremento en las participaciones de los ingresos más elevados pero de menor envergadura que en los casos anteriores. Por el contrario, en los países de la Europa Continental (Francia, Alemania, Holanda, Suiza) y Japón experimentan incrementos modestos en los tramos de ingresos elevados en las últimas décadas.

Sin embargo, en contraste con el comportamiento anterior, en donde los incrementos están relacionados con el percentil superior, los incrementos resultan ser de menor significación para los 
tramos que les siguen inmediatamente en la distribución. Adicionalmente, las mejoras en las participaciones de los ingresos más altos estuvieron asociadas a los ingresos laborales, provenientes del salario, en oposición a la primera etapa del siglo, lo que implica que la proporción de ingresos correspondientes a la renta del salario sea sustancialmente mayor que en los momentos anteriores.

Como puede apreciarse en el gráfico 19, paneles a) a j) subsiguientes, la participación de los tramos de altos ingresos ha crecido significativamente en la mayoría de los países. En Estados Unidos, como fuera expresado anteriormente, se recupera de manera importante a partir de la década de 1970, alcanzando a 2011 los valores más altos de la historia de acuerdo a los datos relevados (46,5\%). De los países que se presentan, Italia y Japón exhiben un comportamiento similar aunque en el primero de los casos mencionados la serie no es tan prolongada.

\section{GRÁFICO 19 \\ PARTICIPACIÓN DE LOS TRAMOS DE INGRESOS MÁS ELEVADOS EN PAÍSES SELECCIONADOS}

A. Estados Unidos

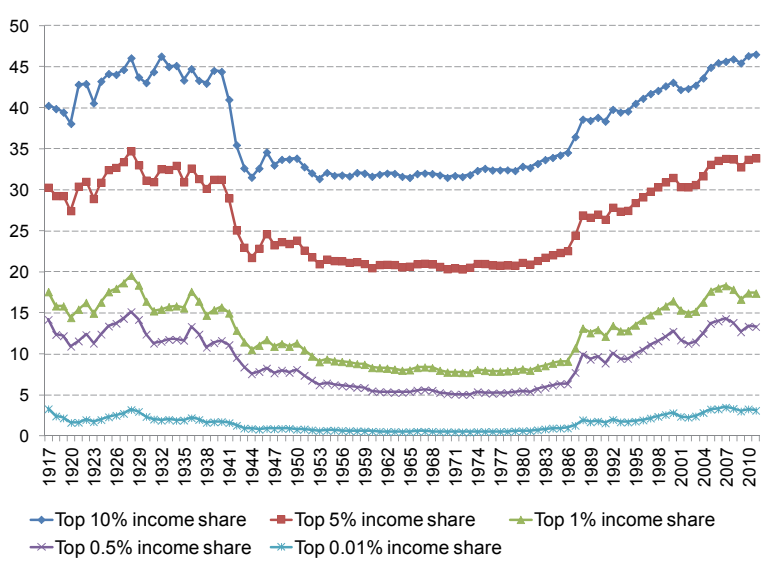

C. Suecia

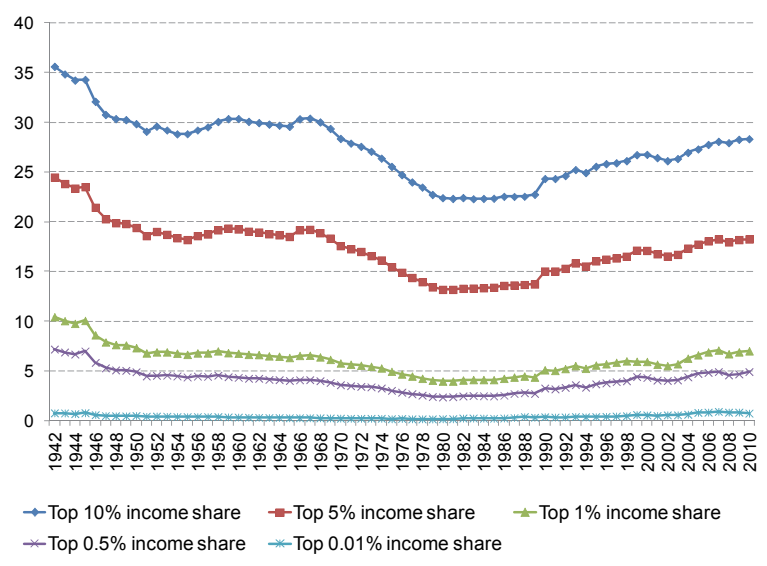

B. Francia

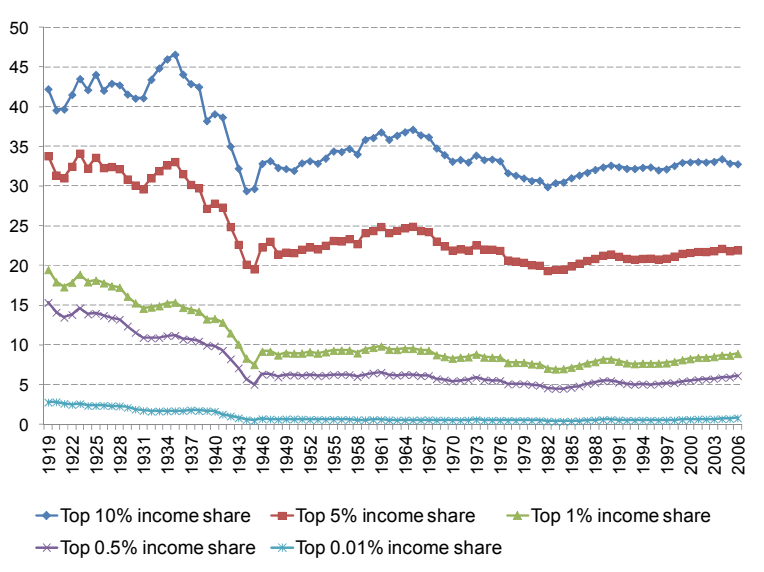

D. Australia

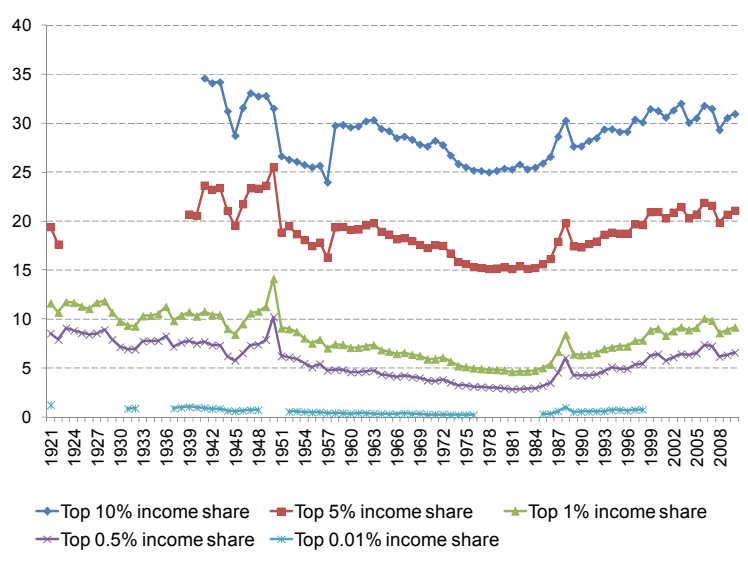


Gráfico 19 (conclusión)

\section{E. Italia}

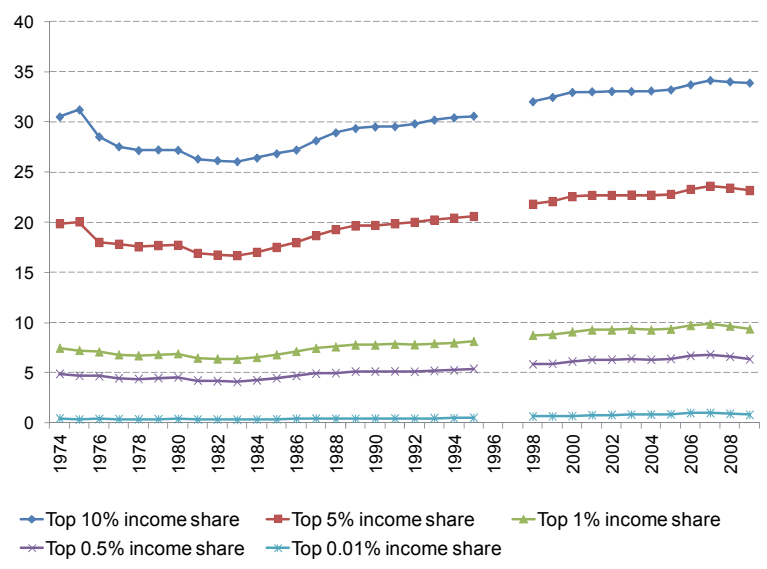

G. India

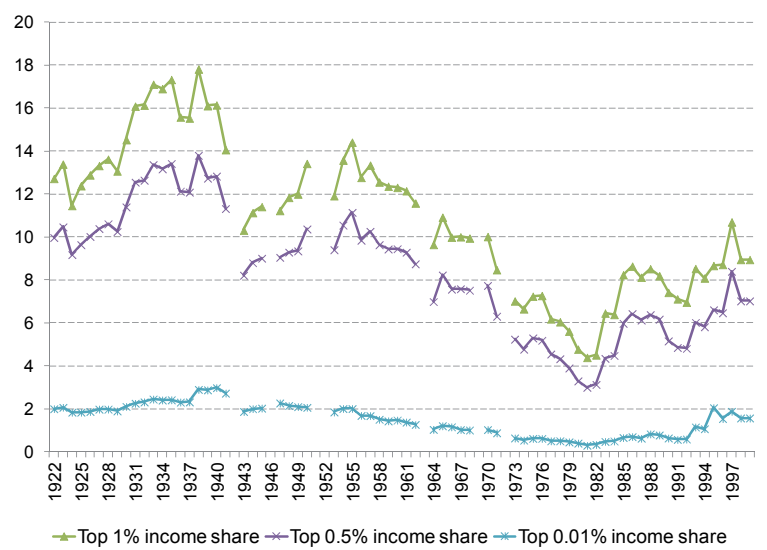

I. Noruega

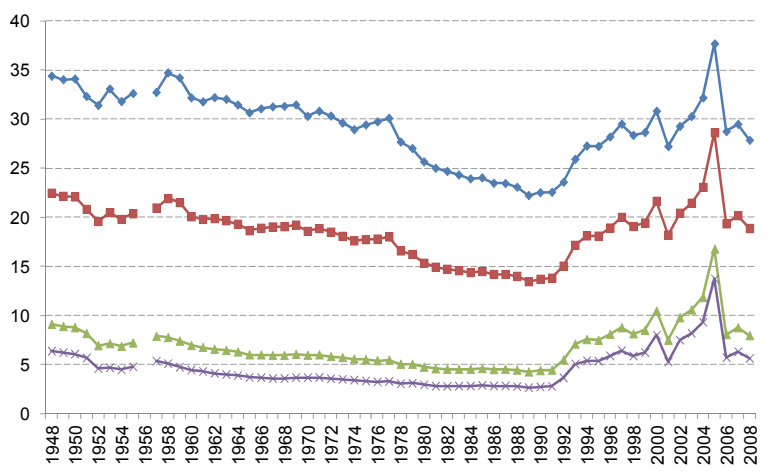

$\rightarrow$ Top $10 \%$ income share $\rightarrow$-Top $5 \%$ income share $\quad \rightarrow$ Top $1 \%$ income share

* Top $0.5 \%$ income share *Top $0.01 \%$ income share

\section{F. España}

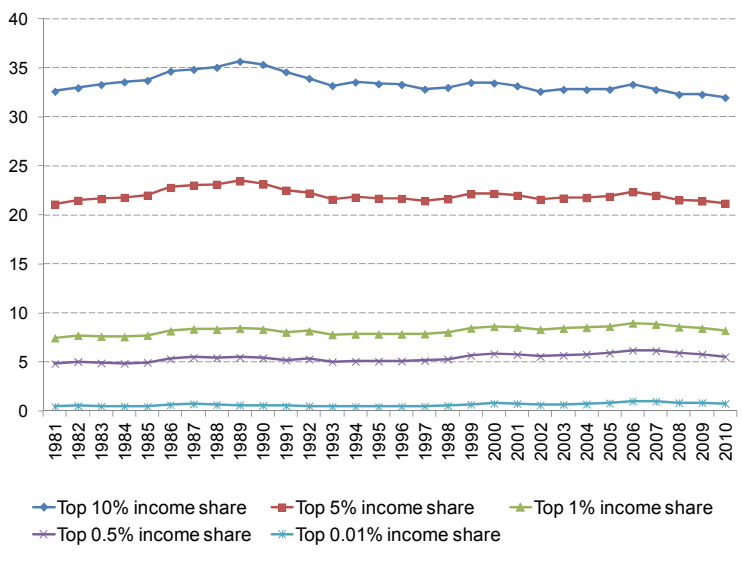

H. Japón

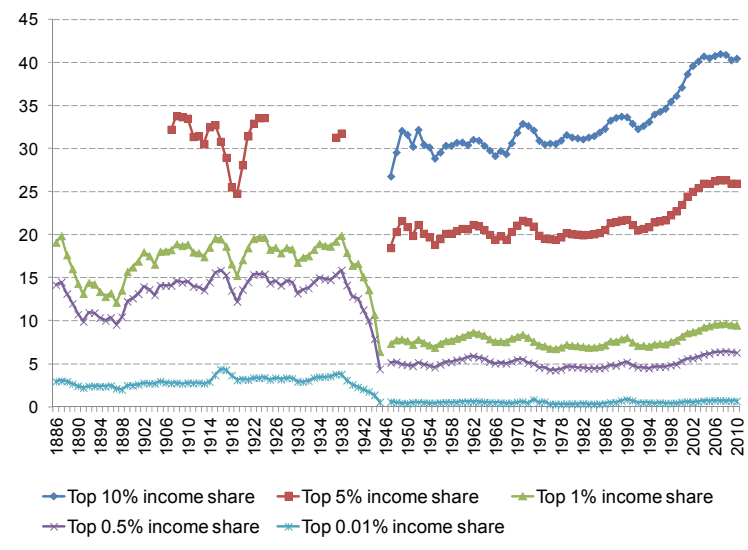

J. Canadá

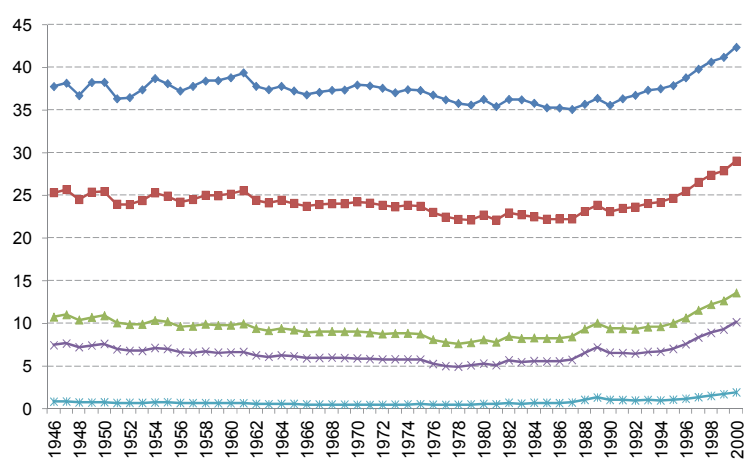

$\rightarrow$ Top $10 \%$ income share $\rightarrow$-Top $5 \%$ income share $\rightarrow$ Top $1 \%$ income share

*Top $0.5 \%$ income share $*$ Top $0.01 \%$ income share

Fuente: Elaboración propia en base a The World Top Incomes Database.

En Francia, por ejemplo, si bien la porción de ingresos que concentran los "top incomes" crece, no alcanza a recuperar la significación alcanzada en los años 30, al igual que lo que acontece para el caso de Suecia y Australia, en donde si bien la concentración de los tramos más elevados se incrementa, no alcanza a los niveles máximos de la serie. 
Noruega y la India muestran comportamientos similares: elevadas concentraciones del ingreso en las décadas de 1930 y 1940, respectivamente; una caída de relevancia alrededor de la década de 1970, y una recuperación de la participación de los tramos de ingresos elevados a partir de la década de 1990, aunque los valores están aún muy alejados de los máximos en el caso de la India, mientras que en Noruega los superan. Canadá muestra estabilidad en las series, pero la concentración crece hacia el final de los períodos analizados

Alvaredo et al $(2013)^{48}$ identifican, a grandes rasgos, dos tipos de comportamientos: países como Estados Unidos experimentan curvas con forma de U (curva de Kuznets invertida), mientras que Europa Continental y Japón muestran patrones con forma de L, en donde las concentraciones de ingresos experimentadas en los tramos superiores no han recuperado aún el nivel alcanzado hacia mediados del siglo $\mathrm{XX}$.

En el gráfico 20 (paneles a) a j)) se divide el decil de ingresos más elevados en cinco partes: el $0,1 \%$ más rico; el tramo entre el $0,1 \%$ más rico y el siguiente $0,5 \%$; el tramo entre el $0,5 \%$ más rico y el percentil más rico, el tramo entre el $1 \%$ más afluente y el $5 \%$ más rico, y por último, el tramo que va entre el $5 \%$ más rico y el $10 \%$ más afluente.

Para el caso de Estados Unidos, se advierte un crecimiento importante de la relevancia del tramo de $0,1 \%$ del total de ingresos, exhibiendo una curva en forma de $\mathrm{U}$, es decir que hacia los períodos más recientes se advierte un cambio en la composición del decil de ingresos más elevados, en donde el percentil de ingresos más altos gana relevancia en el percentil más alto.

Para el caso de Francia, entretanto, el comportamiento es el opuesto: la participación del top 0,1\% cae significativamente hacia la Segunda Guerra Mundial, y luego experimenta un crecimiento moderado. En Suecia, si bien hacia mediados de la década de 1970 las participaciones de las dos particiones más relevantes alcanzan proporciones similares, a partir de ese período la brecha se hace cada ver mayor.

Algunos casos de países poseen características particulares. Para la India, por ejemplo, para los últimos períodos relevados, el tramo de mayor concentración resulta ser el top $0,1 \%$, relegando a un segundo lugar al comprendido entre el $0,1 \%$ y el $0,5 \%$. Japón muestra, después de la Segunda Guerra Mundial, un importante aumento de la brecha entre los tramos que más concentran (el top 1\%-5\% y el top 5\%-10\%), y los que menos ingreso concentran.

En tercera instancia, y en relación con la composición de los ingresos, en la primera parte del siglo XX los mismos estaban compuestos, en una gran mayoría, por ingresos del capital, en oposición a los ingresos laborales, lo que implica que la caída en la participación de los altos ingresos corresponde principalmente a una disminución en los ingresos del capital. En contraste, las participaciones de los tramos inmediatos subsiguientes, cuya composición mayoritaria corresponde a la renta de asalariados, no experimentó en esos períodos una caída semejante.

48 Alvaredo F., Atkinson, A., Piketty, T. y Saez, E. (2013) op. cit. 


\section{GRÁFICO 20 \\ DESCOMPOSICIÓN DE LOS TRAMOS DE INGRESOS MÁS ELEVADOS PARA PAÍSES SELECCIONADOS}

\section{A. Estados Unidos}

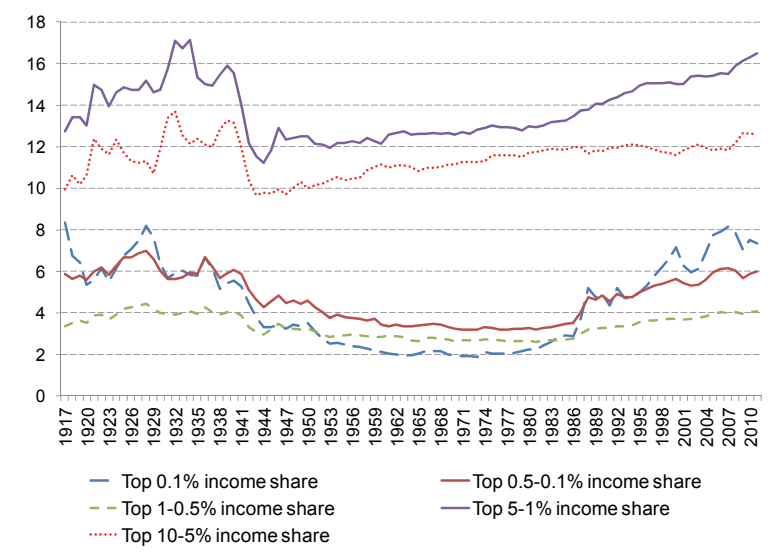

C. Suecia

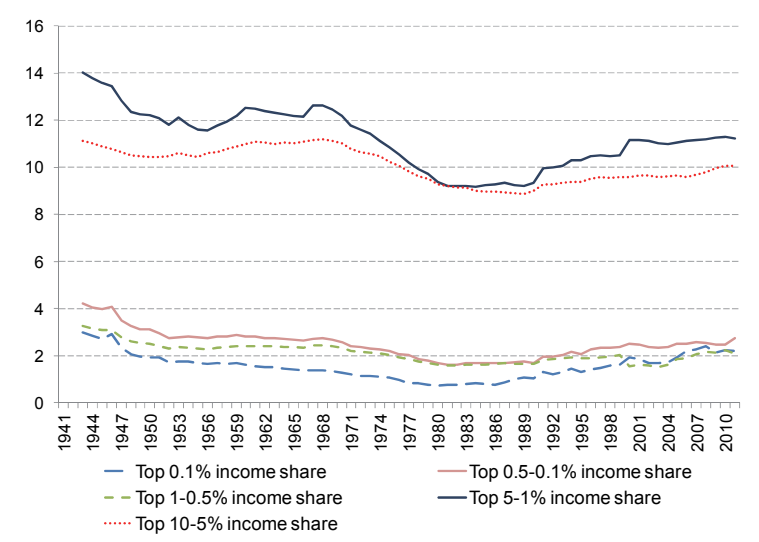

E. Italia

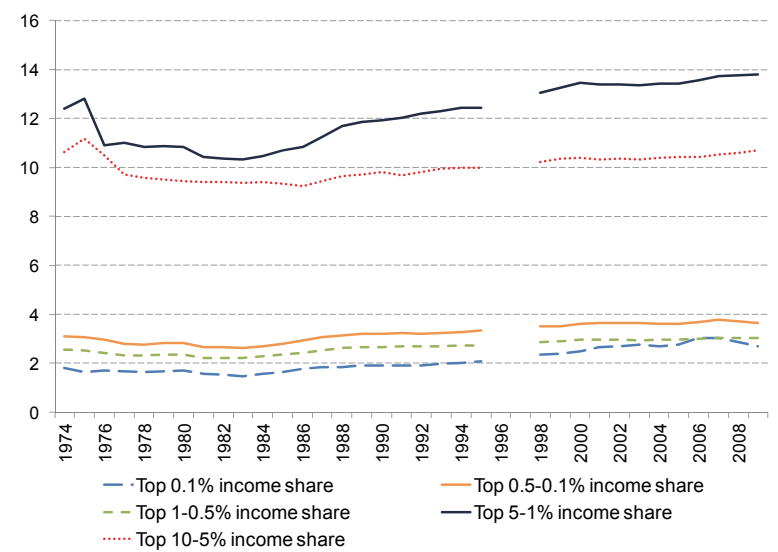

B. Francia

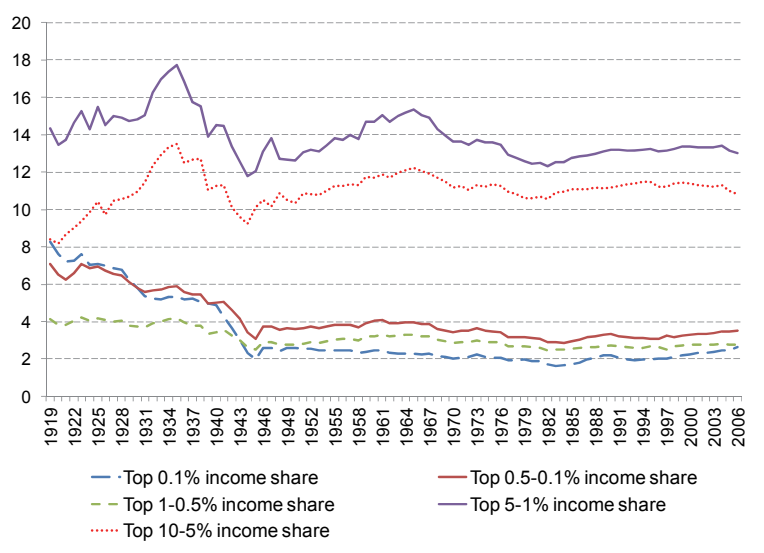

D. Australia

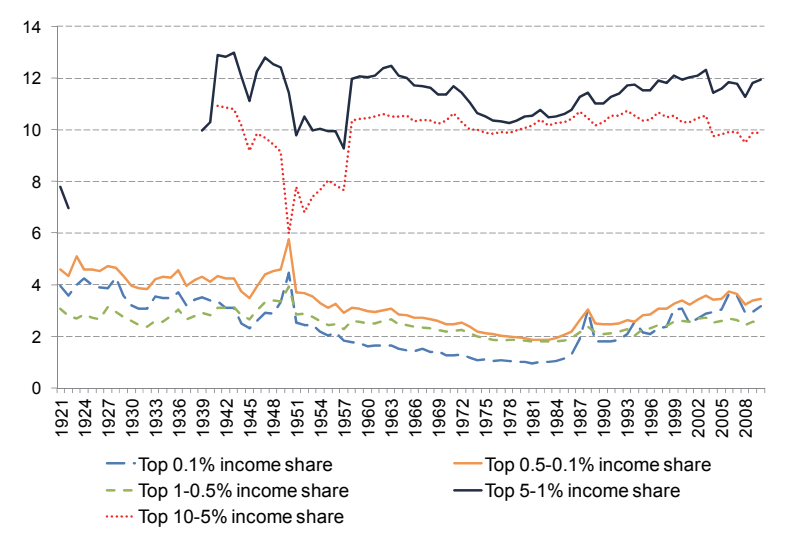

F. España

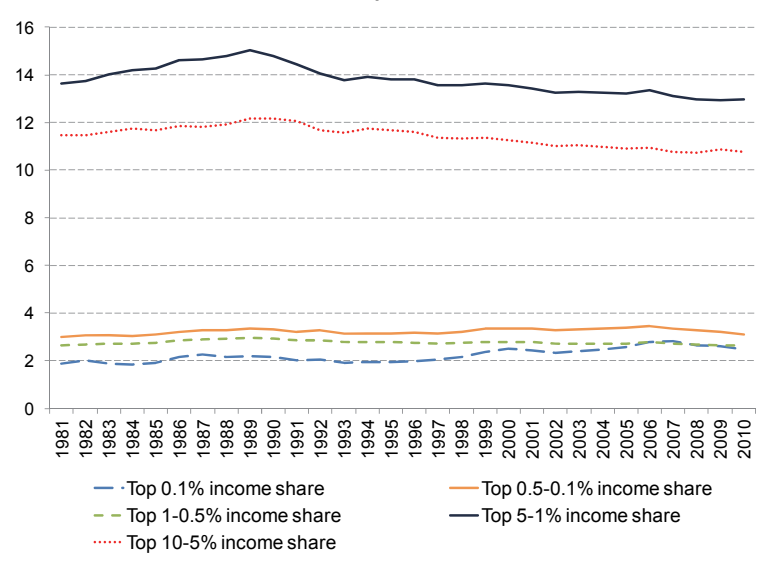


G. India

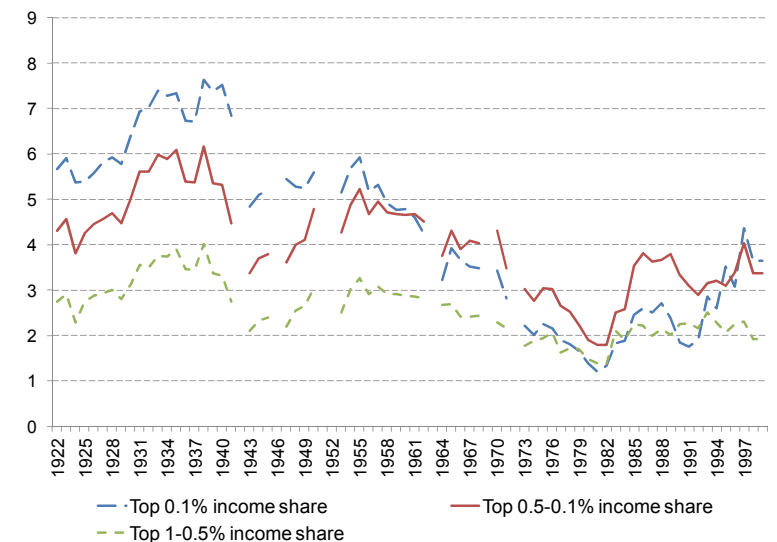

I. Noruega

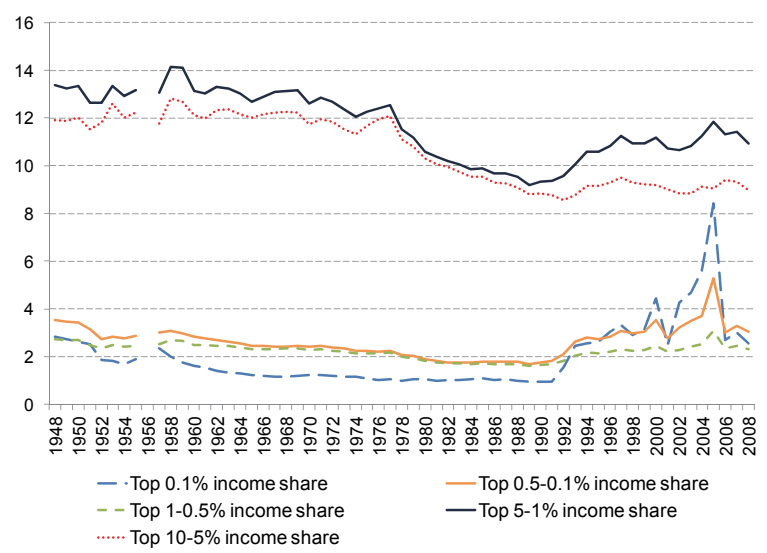

H. Japón

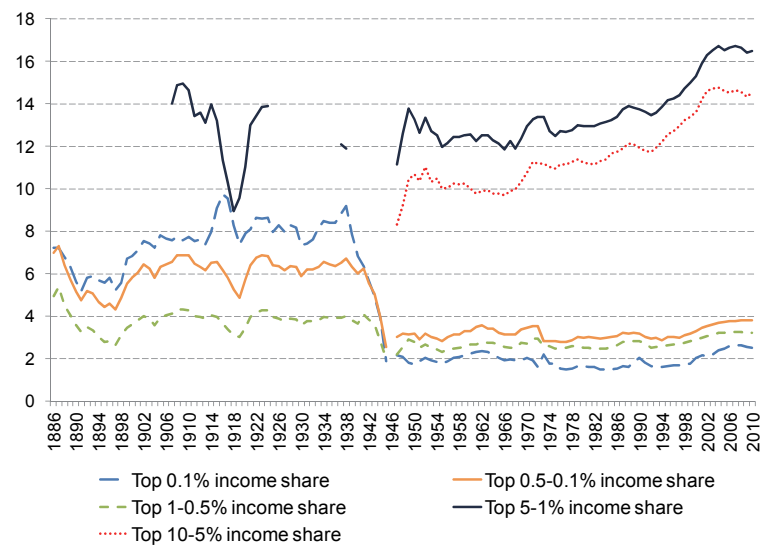

J. Canadá

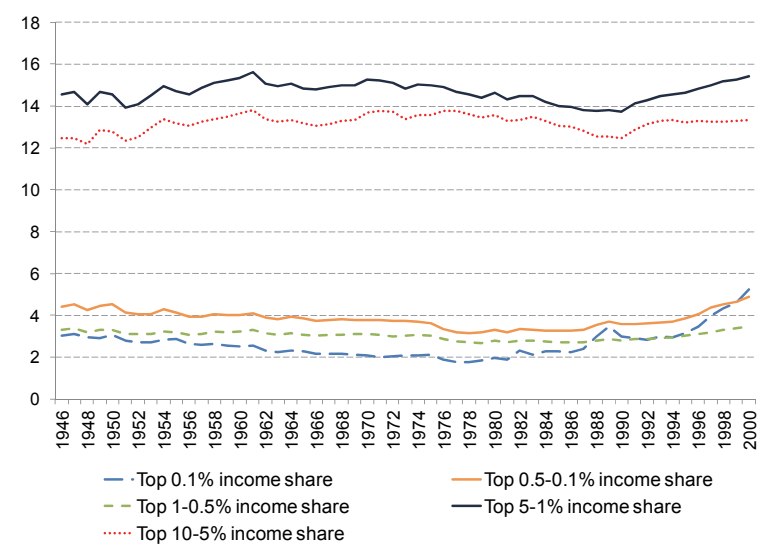

Fuente: Elaboración propia en base a The World Top Incomes Database.

En el gráfico 21 (paneles a) a g)) se presenta la evolución de la composición de los ingresos, es decir, los ingresos por fuente, para varios países. En Estados Unidos, para el 0,1\% de ingresos más altos, es decreciente la proporción de ingresos correspondiente a salarios (y también ingresos de empleadores), mientras que para el caso de Francia los salarios se mantienen prácticamente constantes, y la participación de la renta del capital crece a expensas de la renta empresarial. El crecimiento de la participación de los salarios también se aprecia en Canadá y en España.

Lo anteriormente expresado puede apreciarse también en el cuadro 21. En algunas economías emergentes de gran tamaño, como la India, también se acentuó la concentración del ingreso en los niveles superiores (aumento de la participación de las rentas más altas). En los años más recientes se ha observado una tendencia similar de mayor desigualdad en Argentina y en países del sur de Europa como España. 


\section{GRÁFICO 21 \\ COMPOSICIÓN DE LOS INGRESOS DEL PERCENTIL DE INGRESOS MÁS ELEVADOS}

\section{A. Estados Unidos}

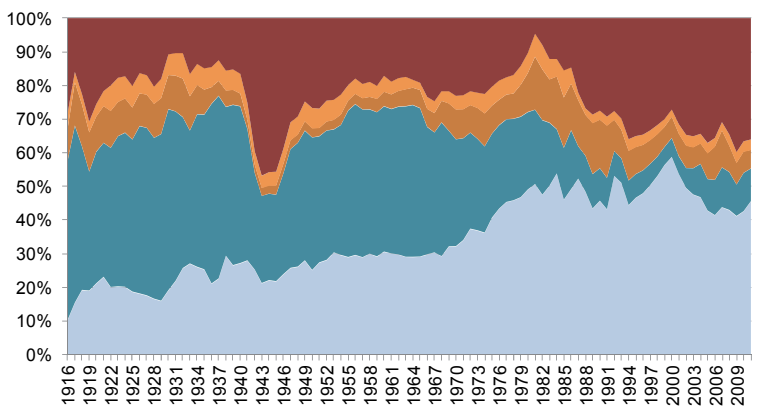

Top $0.1 \%$ income composition-Wages, salaries and pensions

Top $0.1 \%$ income composition-Dividends

- Top $0.1 \%$ income composition-Interest Income

Top $0.1 \%$ income composition-Rents

- Top $0.1 \%$ income composition-Entrepreneurial income

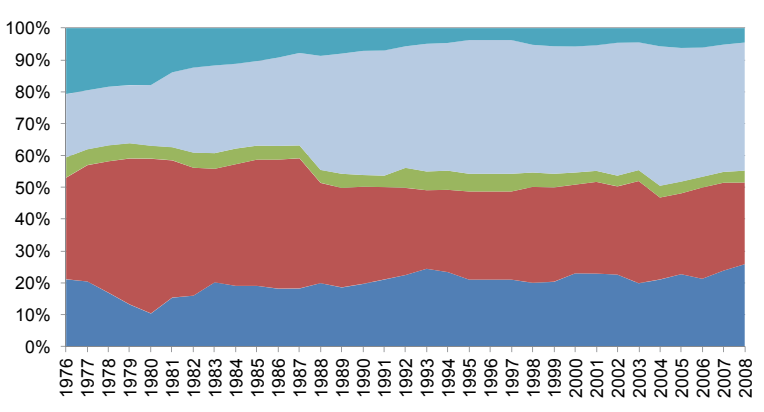

- Top $0.1 \%$ income composition-Wages, salaries and pensions

- Top $0.1 \%$ income composition-Capital income

- Top $0.1 \%$ income composition-Rents

- Top $0.1 \%$ income composition-Self-employment income

- Top $0.1 \%$ income composition-Entrepreneurial income

\section{E. Australia}

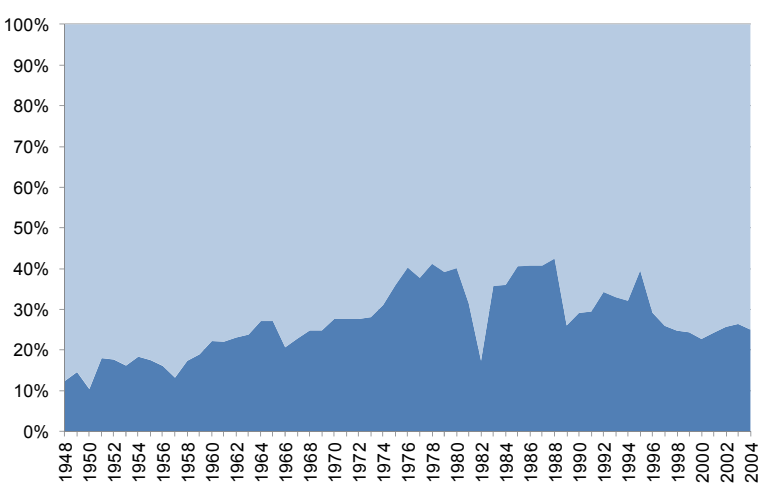

- Top $0.1 \%$ income composition-Wages, salaries and pensions

-Top $0.1 \%$ income composition-Non-wage income

\section{B. Francia}

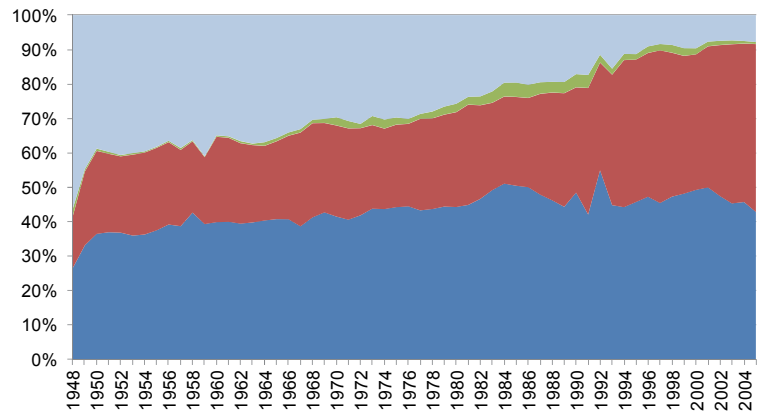

Top $0.1 \%$ income composition-Wages, salaries and pensions

- Top $0.1 \%$ income composition-Capital income

- Top $0.1 \%$ income composition-Farming income

- Top $0.1 \%$ income composition-Business income (industry, commerce)

\section{España}

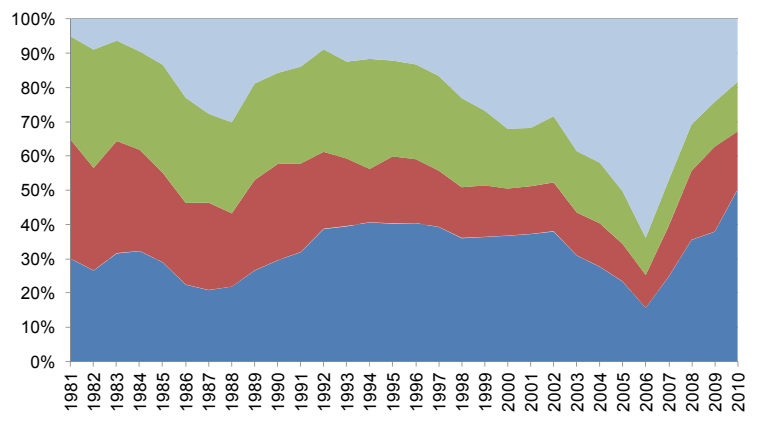

- Top $0.1 \%$ income composition-Wages, salaries and pensions

- Top $0.1 \%$ income composition-Capital income

- Top $0.1 \%$ income composition-Entrepreneurial income

- Top $0.1 \%$ income composition-Capital gains

\section{F. Canadá}

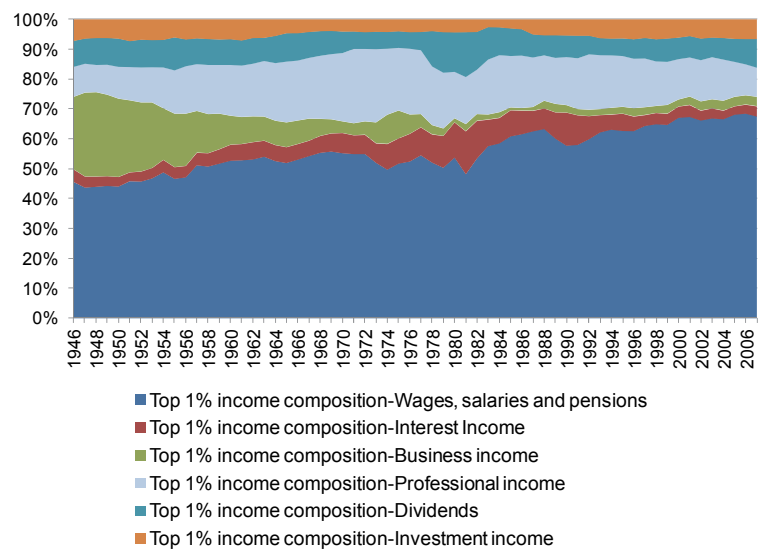

Fuente: Elaboración propia en base a The World Top Incomes Database. 


\section{COMPARACIÓN DE LA PARTICIPACIÓN DE LOS TRAMOS DE INGRESOS ELEVADOS}

\begin{tabular}{|c|c|c|c|c|c|c|}
\hline & \multicolumn{3}{|c|}{ Participación del top 1\% } & \multicolumn{3}{|c|}{ Participación del top $0,1 \%$} \\
\hline & $\begin{array}{c}\text { Alrededor de } \\
1949\end{array}$ & $\begin{array}{l}\text { Alrededor de } \\
2005\end{array}$ & $\begin{array}{c}\text { Tasa de } \\
\text { crecimiento } \\
\text { en porcentaje }\end{array}$ & $\begin{array}{c}\text { Alrededor de } \\
1949\end{array}$ & $\begin{array}{l}\text { Alrededor de } \\
2005\end{array}$ & $\begin{array}{c}\text { Tasa de } \\
\text { crecimiento } \\
\text { en porcentaje }\end{array}$ \\
\hline Indonesia & 19,87 & 8,46 & $-57,42$ & 7,03 & 1,34 & $-80,94$ \\
\hline Argentina & 19,34 & 16,75 & $-13,39$ & 7,87 & 7,02 & $-10,80$ \\
\hline Irlanda & 12,92 & 10,30 & $-20,28$ & 4,00 & & \\
\hline Países Bajos & 12,05 & 5,38 & $-55,35$ & 3,80 & 1,08 & $-71,58$ \\
\hline India & 12,00 & 8,95 & $-25,42$ & 5,24 & 3,64 & $-30,53$ \\
\hline Alemania & 11,60 & 11,10 & $-4,31$ & 3,90 & 4,40 & 12,82 \\
\hline Reino Unido & 11,47 & 14,25 & 24,24 & 3,45 & 5,19 & 50,43 \\
\hline Australia & 11,26 & 8,79 & $-21,94$ & 3,31 & 2,68 & $-19,03$ \\
\hline Estados Unidos & 10,95 & 17,42 & 59,09 & 3,34 & 7,70 & 130,54 \\
\hline Canadá & 10,69 & 13,56 & 26,85 & 2,91 & 5,23 & 79,73 \\
\hline Singapur & 10,38 & 13,28 & 27,94 & 3,24 & 4,29 & 32,41 \\
\hline Nueva Zelandia & 9,98 & 8,76 & $-12,22$ & 2,42 & 2,51 & 3,72 \\
\hline Suiza & 9,88 & 7,76 & $-21,46$ & 3,23 & 2,67 & $-17,34$ \\
\hline Francia & 9,01 & 8,73 & $-3,11$ & 2,61 & 2,48 & $-4,98$ \\
\hline Noruega & 8,88 & 11,82 & 33,11 & 2,74 & 5,59 & 104,01 \\
\hline Japón & 7,89 & 9,20 & 16,60 & 1,82 & 2,40 & 31,87 \\
\hline Finlandia & 7,71 & 7,08 & $-8,17$ & & 2,65 & \\
\hline Suecia & 7,64 & 6,28 & $-17,80$ & 1,96 & 1,91 & $-2,55$ \\
\hline España & & 8,79 & & & 2,62 & \\
\hline Portugal & & 9,13 & & 3,57 & 2,26 & $-36,69$ \\
\hline Italia & & 9,03 & & & 2,55 & \\
\hline China & & 5,87 & & & 1,20 & \\
\hline
\end{tabular}

Fuente: Elaboración propia en base a Atkinson, Piketty y Saez (2011).

Se advierten adicionalmente observan importantes diferencias entre países en lo que respecta a la participación del 0,1 y el 1 por ciento y los siguientes cuatro cuantiles más altos. Alrededor del año 2005, Canadá, los Estados Unidos, Reino Unido y Singapur integraban el grupo de países en los que el 1 por ciento más rico (ingresos más altos) tenía una participación superior al 12 por ciento (Atkinson, Piketty y Saez (2011)). Por otra parte, Australia, China, España, Finlandia, Francia, la India, Italia, Japón, Nueva Zelandia, los Países Bajos, Portugal, Suecia y Suiza integraban el grupo en los que la participación del 1 por ciento más rico fluctuaba entre el 5 y el 10 por ciento ${ }^{49}$.

Atkinson, Piketty y Saez (2011) identifican tres razones para subrayar la importancia de analizar la evolución de la participación de estos sectores en la concentración del ingreso, además de la preocupación por la desigualdad en la distribución, que determina que los países apliquen políticas de transferencias monetarias, subsidios e impuestos progresivos con el objeto de lograr una distribución del ingreso más igualitaria.

49 Jiménez y Solimano (2012), op. cit. 
Los individuos de ingresos muy altos son un grupo numéricamente muy reducido (insignificante en términos estadísticos), como porcentaje de la población, pero cuya participación en el ingreso nacional si es significativa (esto se hace más marcado en los países con alta desigualdad de ingresos). En Estados Unidos, de acuerdo con Atkinson, Piketty y Saez (2011), si bien el top 1\% de ingresos concentra una proporción muy reducida de la población, captura un $23,5 \%$ del total del ingreso (datos a 2007).

Adicionalmente, el incremento de la participación de los ingresos elevados tiene un impacto importante en el crecimiento del producto. En el cuadro 22 puede verse que el ingreso real por hogar creció alrededor de un 1,2\% en promedio para el período comprendido entre 1976 y 2007.

CUADRO 22

LA CONCENTRACIÓN DE INGRESOS EN EL TOP 1\% Y EL CRECIMIENTO DEL INGRESO PROMEDIO EN ESTADOS UNIDOS

\begin{tabular}{lcrr}
\hline & $\begin{array}{c}\text { Período } \\
1976-2007\end{array}$ & $\begin{array}{c}\text { Período } \\
1993-2000\end{array}$ & $\begin{array}{c}\text { Período } \\
2002-2007\end{array}$ \\
\hline Tasa de crecimiento promedio anual del ingreso real & $1,2 \%$ & $4,0 \%$ & $3,0 \%$ \\
Tasa de crecimiento promedio anual del ingreso del top 1\% & $4,4 \%$ & $10,3 \%$ & $10,1 \%$ \\
Tasa de crecimiento promedio anual del ingreso del 99\% inferior & $0,6 \%$ & $2,7 \%$ & $1,3 \%$ \\
Fracción del crecimiento del ingreso total captado por el top 1\% & $58,0 \%$ & $45,0 \%$ & $65,0 \%$ \\
\hline
\end{tabular}

Fuente: Atkinson, Piketty y Saez (2011).

Sin embargo, el ingreso promedio que surge de excluir el 1\% más rico creció a una tasa del 0,6\%, mientras que el tramo más rico aumentó su ingreso promedio en un 4,4\%. Al dividir el último período en dos etapas (correspondientes a las expansiones económicas de los períodos de Clinton y Bush), puede advertirse que, si bien en ambos períodos los ingresos promedio del top 1\% crecieron a tasas similares, en el primero de los mencionados la tasa de crecimiento del ingreso promedio del $99 \%$ inferior fue del 2,7\%, mientras que en el otro lapso la misma se redujo al 1,3\%. Esto confirma el hecho de que la parte del crecimiento del ingreso total promedio fue capturada en una proporción mucho mayor por el tramo de ingresos más elevados.

Comparando internacionalmente el comportamiento evidenciado en Estados Unidos, en donde entre 1975 y 2006 el ingreso real por hogar total creció un 32,2\%, mientras que el ingreso del 99\% inferior se incrementó un 17,9\%, en Francia, para el ingreso total el porcentaje de crecimiento total fue del $27,1 \%$, mientras que si se excluye al $1 \%$ más alto, el crecimiento fue del $26,4 \%^{50}$. De esta manera puede verse que si bien el crecimiento fue mayor en promedio en Estados Unidos, el mismo ocurre a expensas de reducir la participación del $99 \%$ inferior en el total del ingreso.

\section{B. Las consecuencias del ajuste de los altos ingresos en la desigualdad global}

Si bien, como se explicitara con anterioridad, los individuos que concentran los ingresos superiores constituyen una parte reducida del total, los mismos comprenden una parte significativa de los ingresos y por ende su inclusión determina una parte importante de los cambios en la desigualdad.

El indicador más utilizado en las comparaciones es el denominado índice de Gini. Mide el área que se encuentra por debajo de la curva de Lorenz; es decir, entre el gráfico de ésta y la línea de perfecta desigualdad; dicho de otro modo, el Gini compara las áreas por encima y por debajo de la curva. Los valores extremos para este índice de desigualdad son uno, para perfecta desigualdad, y cero, para la perfecta igualdad.

50 Atkinson, Piketty y Saez (2011). 
El índice de Gini depende, sin embargo, del orden de los individuos en la distribución, cambiando de acuerdo a la diferencia de rango entre ellos, a la vez de establecer que una transferencia de una persona rica a otra pobre de la distribución tiene mucho mayor efecto en la caída del indicador si ésta se realiza entre individuos más próximos a la media de la distribución que si éstos estuviesen más alejados de la misma, y por ende, más próximos a los extremos.

La medición convencional efectuada a través del índice de Gini debe corregirse para captar a estos tramos de la distribución, dado que este índice, por construcción, otorga mayor peso relativo a las transferencias operadas en la parte central de la distribución. A esto se suma el hecho, ya mencionado, de que en las encuestas de hogares se suele subestimar considerablemente la proporción de ingresos más altos.

Atkinson (2007) desarrolló una fórmula mediante la cual se corrige el índice de Gini convencional para tomar en cuenta la proporción de los individuos con ingresos más altos, a los que considera numéricamente infinitesimales. Si el parámetro $S$ se define como la participación en el ingreso de los individuos con más altos ingresos (por ejemplo, el 1 por ciento superior) y $G^{*}$ como el Gini del resto de la población (por ejemplo, el 99 por ciento inferior), se puede demostrar que el Gini total "real" o corregido es igual a $G^{*}(1-S)+S$.

Mediante la aplicación de la fórmula de Atkinson y usando datos de Argentina y los Estados Unidos, Alvaredo (2010) demuestra que el aumento del coeficiente de Gini en ambos países en las últimas décadas puede atribuirse en gran medida al incremento de la participación en el ingreso de los individuos de rentas más altas, lo que refleja la importancia de considerar la participación de los ingresos más altos en una medición adecuada del coeficiente de Gini.

Por lo tanto, a nivel empírico los coeficientes de Gini calculados con datos de las encuestas de hogares, que tienden a ignorar sistemáticamente los ingresos superiores, no presentan una verdadera visión de la evolución de la desigualdad en los países. El coeficiente de Gini corregido sería varios puntos superior, como en el caso del ajuste por subdeclaración, al coeficiente estándar sin la corrección cuando la concentración del ingreso en los niveles más altos es elevada. De acuerdo con Atkinson, Piketty y Saez (2011), un incremento en la participación del top 1\% del 14\%, como la que ocurrió en Estados Unidos entre 1976 y 2006, generó un incremento en el Gini del 8,4\%, superior al 7,2\% de la medición oficial.

En el cuadro 23 puede advertirse la comparación de la evolución del los índices de Gini, tanto para el caso de las encuestas de hogares como para el caso de la encuesta "corregida", tomando en cuenta para la mencionada corrección la participación en el ingreso del top 1\% más rico con información proveniente de declaraciones juradas de impuestos.

Para Estados Unidos, el índice de Gini pasa de 39,8 a 40,5, excluyendo las rentas del capital, y al 41,1, incluyendo a los ingresos del capital en 1997. En 2006, mientras tanto, de acuerdo a la encuesta de hogares el índice de Gini había crecido a 47, mientras que, si se corrige por inclusión del top 1\% el índice crece a 49,3 excluyendo las ganancias de capital y a 51,9 incluyéndolas.

\section{CUADRO 23
LA EVOLUCIÓN DEL ÍNDICE DE GINI EN ESTADOS UNIDOS, COMPARACIÓN CON ENCUESTAS DE HOGARES}

\begin{tabular}{lll}
\hline & 1976 & 2006 \\
\hline CPS data & 39,8 & 47,0 \\
CPS data (99\% inferior) & 35,5 & 38,6 \\
CPS data (corrigiendo el top 1\% con data que excluye las ganancias de capital) & 40,5 & 49,3 \\
CPS data (corrigiendo el top 1\% con data que incluye las ganancias de capital) & 41,1 & 51,9 \\
\hline
\end{tabular}

Fuente: Atkinson, Piketty y Saez (2011).

Por añadidura, es evidente que los individuos pertenecientes a los tramos de ingresos elevados tienen relevancia no sólo al interior de cada país, sino que afectan la desigualdad del ingreso global. De acuerdo con estimaciones de Francois Bourguignon y Christian Morrisson (2002), el valor del índice de 
Gini mundial se incrementó de 0,61 en 1910 a 0,64 en 1950, a un 0,657 en 2002. Para definir cómo afectan los "súper ricos" a este panorama, debe buscarse una medida que permita distinguir a los individuos caracterizados de esta manera a lo largo del tiempo en distintos países.

Atkinson, Piketty y Saez (2011) dan cuenta de un fenómeno similar en los Estados Unidos. Neto de los impuestos federales, en 1976 el percentil de ingresos más altos recibía el 5,8\% del total del ingreso antes de impuestos, y soportaba el $24 \%$ del total de impuestos a nivel federal. En 2007, ese tramo de ingresos concentraba el $17,3 \%$ del total del ingreso antes de impuestos, concentrando aproximadamente el $74 \%$ del total de impuestos, dando cuenta de un significativo incremento en la capacidad contributiva de este tramo de ingresos.

\section{La situación en América Latina: escasos análisis y limitados resultados observados}

Si bien algunos resultados de los estudios realizados fueron presentados en las secciones anteriores, el presente apartado se explayará con un mayor grado de detalle sobre los análisis realizados para países de América Latina. Los mismos comprenden los casos de Argentina, Chile y Colombia.

\section{El caso de Argentina}

Alvaredo $(2007,2010)$ señala que Argentina ha estado tradicionalmente identificada como una de las economías con menor desigualdad relativa a los demás países de Latinoamérica, pese a sus recurrentes crisis macroeconómicas, y ostenta un mayor grado de igualdad en la distribución del ingreso que Chile, México y Brasil.

La información tomada como base para analizar la desigualdad en la distribución surge de la Encuesta Permanente de Hogares, relevada por el INDEC (Instituto Nacional de Estadística y Censos), ha ido incorporando paulatinamente a aglomerados poblacionales hasta alcanzar actualmente a más del 60 por ciento de la población total $(70 \%$ de la población urbana. Sin embargo, como la información relevada por esta encuesta en relación con los ingresos elevados es deficiente, debido a causas variadas, como la no inclusión explícita por diseño muestral, falta de respuesta o eliminación ex post de valores extremos, surge como imprescindible, si el objetivo es analizar la participación de los tramos de ingresos elevados, complementar esta información con los datos provenientes de las declaraciones juradas del impuesto a la Renta personal, las que sí contienen a estos perceptores.

Los datos de las declaraciones juradas del impuesto a la Renta no están exentos de inconvenientes. La definición de ingreso gravado y de unidad que tributa tienden ambas a variar con el tiempo de acuerdo a las leyes impositivas, como así también la forma en que las ganancias de capital y las rentas del capital están alcanzadas por la normativa legal. Así como hay una predisposición a subdeclarar ciertos tipos de ingresos, también los contribuyentes se enrolan en una serie de acciones tendientes a reducir su carga tributaria, inclusive de manera legal (elusión). Cabe aclarar sin embargo, que tanto la desagregación y la amplitud de la información de declaraciones juradas de que se dispone es bastante inferior que la perteneciente a los países desarrollados.

El impuesto a la Renta en Argentina es individual, por lo cual las unidades tributarias definidas en el estudio (es decir, el universo de contribuyentes potencialmente obligados a tributar) se aproxima mediante el número de personas en la población de 20 años o más. El ingreso es el ingreso bruto antes de deducciones e incluye todos los ítems de ingresos reportados en las declaraciones juradas: salarios y pensiones, empleo por cuenta propia, ingreso de los empleadores, dividendos, intereses y renta de la inversión, excluyendo las ganancias de capital.

Alvaredo $(2007,2010)$ realiza estimaciones para el caso de Argentina; la serie construida, a partir de la información disponible de la AFIP (Administración Federal de Ingresos Públicos), comienza a partir de 1932. En el gráfico 22 (paneles a) y b)) se presentan los datos de los cálculos realizados por este autor. 


\section{GRÁFICO 22 \\ ARGENTINA: EVOLUCIÓN DE LOS TRAMOS DE INGRESOS MÁS ELEVADOS}

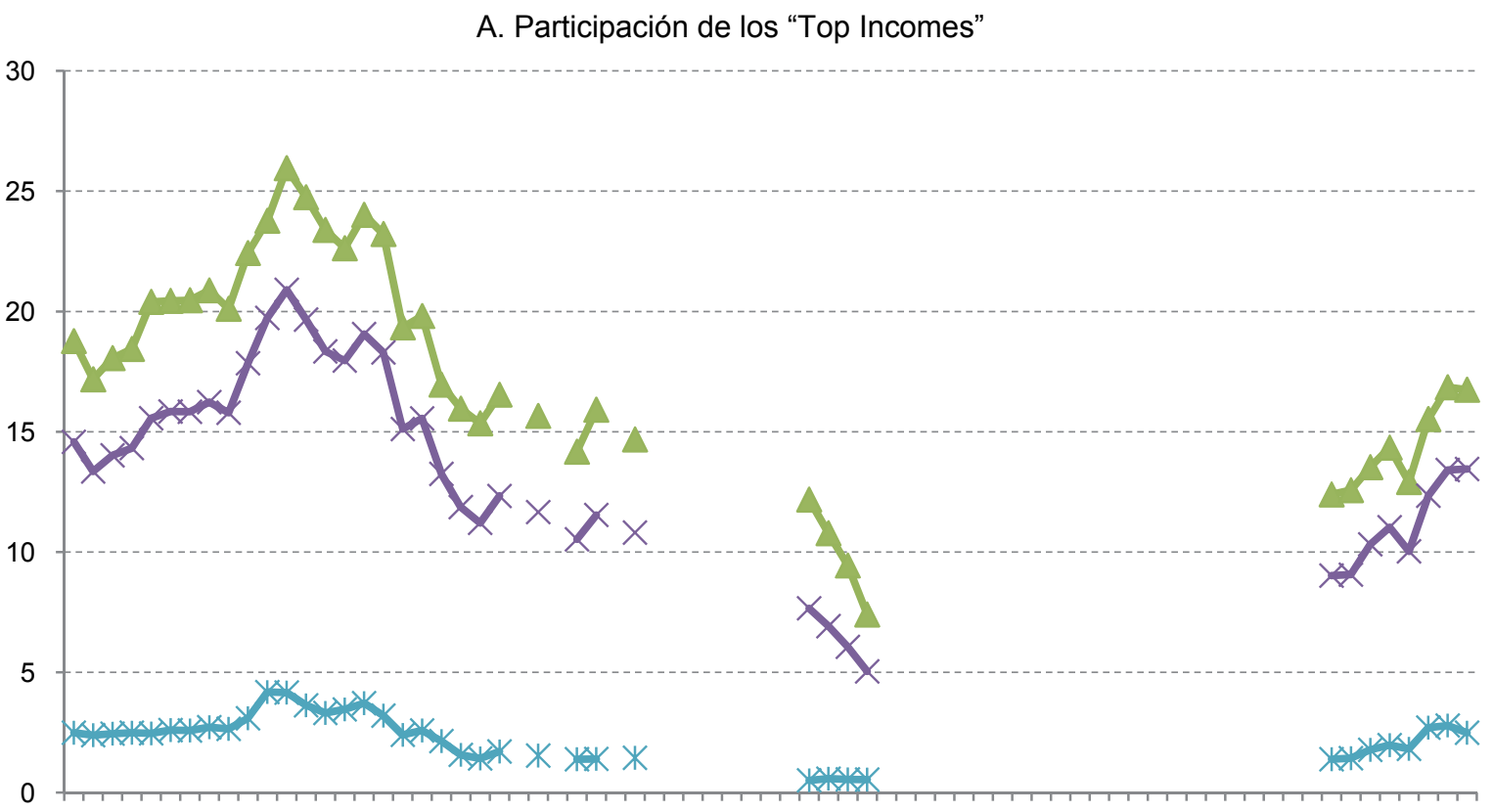

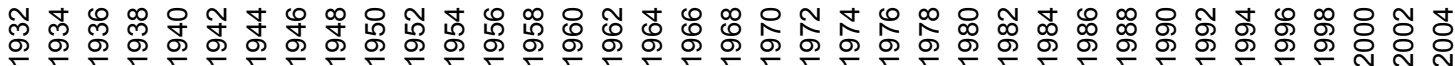
Top $1 \%$ income share ${ }^{-}$Top $0.5 \%$ income share ${ }^{-}$Top $0.01 \%$ income share

B. Descomposición del 1\% de ingresos más elevados

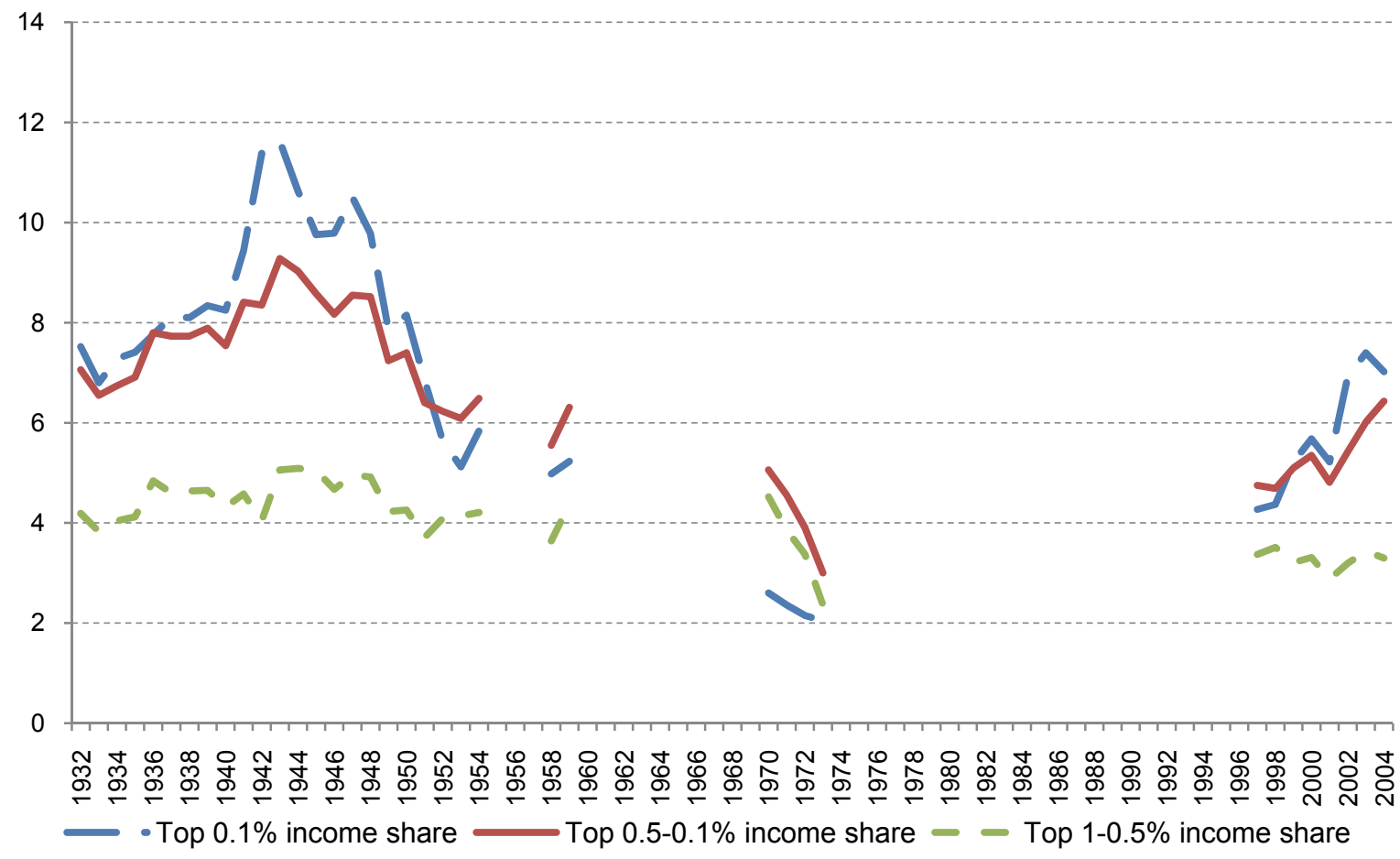

Fuente: Elaboración propia en base a The World Top Incomes Database. 
Argentina presenta elevadas concentraciones del ingreso en las décadas de 1930 y 1940, una caída de relevancia alrededor de la década de 1970, y una recuperación de la participación de los tramos de ingresos elevados a partir de la década de 1990, aunque los valores están muy alejados de los máximos. Entretanto, en Argentina, la descomposición del 1\% más rico muestra que, al interior del mismo, a lo largo del período analizado de acuerdo a los datos disponibles el segmento que más ingresos concentra es el $0,1 \%$ más afluente.

En el cuadro 24 puede advertirse que alrededor del año 1949, en Argentina el 1 por ciento más rico (ingresos más altos) tenía una participación superior al 19 por ciento (Atkinson, Piketty y Saez (2011)), mientras que para 2005, la misma decreció un $13,4 \%$. La participación del top $0,1 \%$ también decreció, del 7,8\% al 7,0\%.

\begin{tabular}{lccc}
\multicolumn{4}{c}{ CUADRO 24 } \\
& $\begin{array}{l}\text { ARGENTINA: COMPARACIÓN DE LA PARTICIPACIÓN } \\
\text { DE LOS TRAMOS DE INGRESOS ELEVADOS }\end{array}$ \\
\hline & Alrededor de 1949 & Alrededor de 2005 & Tasa de crecimiento \% \\
\hline Participación del top 1\% & 19,34 & 16,75 & $-13,39$ \\
Participación del top $0,1 \%$ & 7,87 & 7,02 & $-10,80$ \\
\hline
\end{tabular}

Fuente: Elaboración propia en base a Atkinson, Piketty y Saez (2011).

Como puede apreciarse en el gráfico 22, la serie analizada no está exenta de interrupciones en los datos, pero recobra continuidad a partir de 1997, con lo cual los resultados a presentar en esta sección, a diferencia de las anteriores, se limitan al período 1997-2004.

Los resultados del estudio muestran que entre 1997 y 2004 la participación del 1\% de ingresos más elevados se incrementó en un 35\%, al pasar del 12,4\% del ingreso a un $16,8 \%$, con una caída en el año 2001 al 12,9\% (véase el gráfico 23). La participación del 0,1\%, entretanto, creció del 4,3\% en 1997 al 7\%, en 2004 (un incremento del 64,4\%), mientras que la parte correspondiente al $0,01 \%$ más afluente se incrementó aún en mayor medida, al crecer un 79\% entre 1997 y 2004 (desde el 1,4\% al 2,5\%).

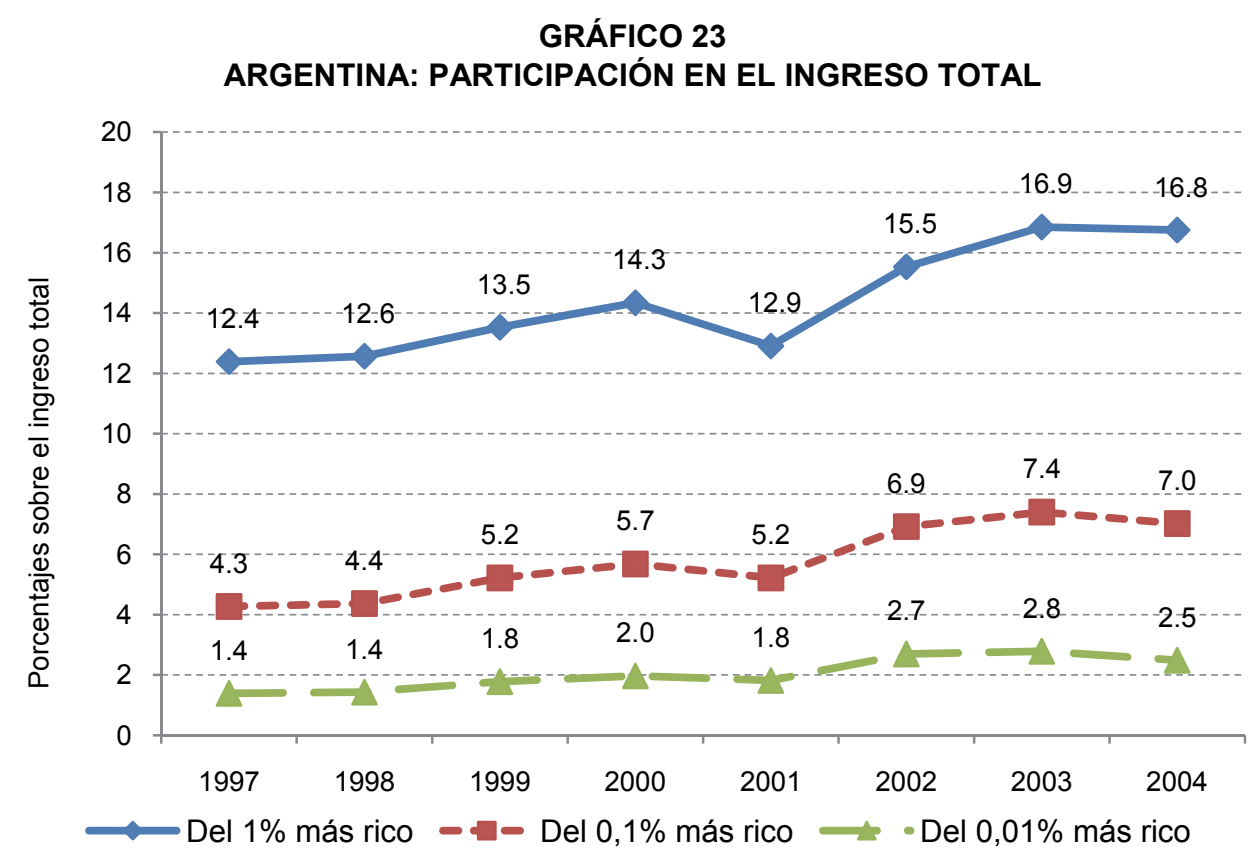

Fuente: Elaboración propia en base a Alvaredo (2010). 
En el gráfico 24 se descompone la evolución de la participación del 1\% más rico en el ingreso total. El incremento del ingreso del $1 \%$ más rico, del $12,4 \%$ al $16,8 \%$ está explicado por un crecimiento de la proporción que concentra el $0,01 \%$ más afluente, que creció del $1,4 \%$ al $2,5 \%$ del total como se describiera anteriormente; mientras que el tramo entre el $0,01 \%$ al $0,1 \%$ también aumenta, del 2,9\% al $4,5 \%$, y el tramo entre el $0,1 \%$ y el $1 \%$ experimenta un incremento del $8,1 \%$ al $9,7 \%$.

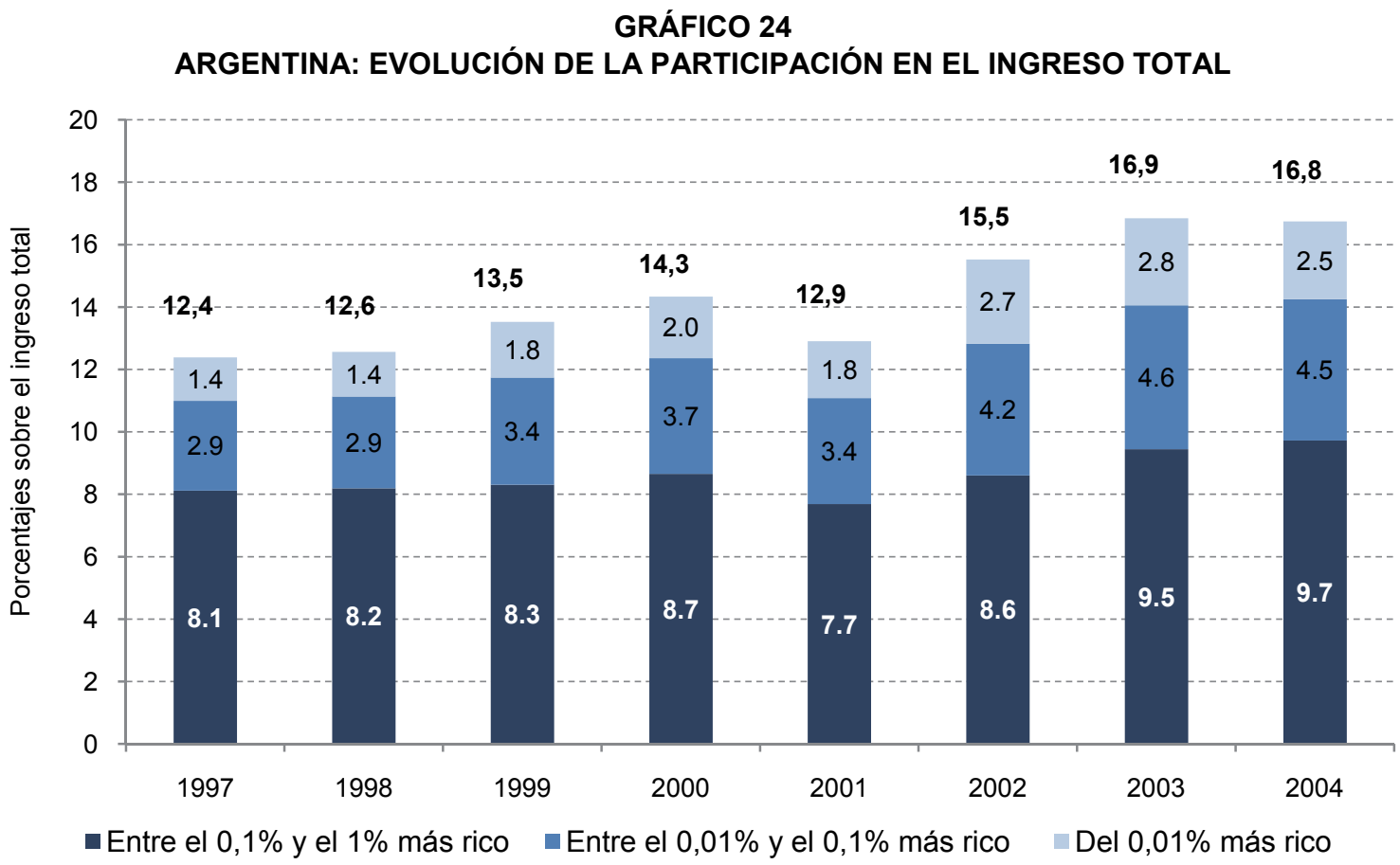

Fuente: Elaboración propia en base a Alvaredo (2010).

A partir del procesamiento de las declaraciones juradas del Impuesto a la Renta, tanto Alvaredo (2010) como Di Gresia (2000) realizan una comparación, por tramos de ingresos determinados en las escalas del impuesto, de los ingresos gravados de acuerdo a la información tributaria con la que surgiría de la Encuesta Permanente de Hogares. En el cuadro 25 se advierte que la encuesta no incluye a los individuos (presentaciones) de los tramos de ingresos más elevados. Los mismos representan, para el estudio de Di Gresia (2000), alrededor del 0,5\% del total de declaraciones juradas, mientras que para Alvaredo (2010) esta proporción ascendería al 1,5\%.

En consecuencia, de acuerdo con Alvaredo (2010), puede asumirse que los ingresos de los más ricos no están evidentemente incluidos en la muestra de la encuesta de hogares. Esto permite "corregir" el índice de Gini que proviene de la información muestral, incluyendo los tramos de ingresos más elevados no relevados en la EPH.

En el gráfico 25 se muestra la evolución del índice de Gini del ingreso por adulto equivalente para el período 1997-2010, junto con el comportamiento de este índice de desigualdad "corregido", con una hipótesis de mínima, tanto con la inclusión del 1\% más rico (abarcando a los contribuyentes no incluidos en la estimación de Alvaredo (2010)), como también incorporando al 0,1\% más afluente (para incluir a los individuos no captados según la estimación de Di Gresia (2000)). 
ARGENTINA: COMPARACIÓN POR TRAMOS DE INGRESOS GRAVADOS, AFIP Y EPH

\begin{tabular}{|c|c|c|c|c|c|c|c|c|c|}
\hline \multirow{2}{*}{\multicolumn{2}{|c|}{$\begin{array}{c}\text { Tramos de ingresos } \\
\text { gravados }\end{array}$}} & \multirow{2}{*}{\multicolumn{3}{|c|}{ Información AFIP }} & \multicolumn{5}{|c|}{ Simulación EPH } \\
\hline & & & & & \multicolumn{3}{|c|}{ Di Gresia (2000) } & \multicolumn{2}{|c|}{ Alvaredo (2010) } \\
\hline Desde & Hasta & $\begin{array}{l}\text { Presenta- } \\
\text { ciones }\end{array}$ & $\begin{array}{l}\text { Ingresos } \\
\text { gravados } \\
\text { (millones } \\
\text { de pesos) }\end{array}$ & $\begin{array}{l}\text { Recaudación } \\
\text { (millones de } \\
\text { pesos) }\end{array}$ & $\begin{array}{l}\text { Presenta- } \\
\text { ciones }\end{array}$ & $\begin{array}{l}\text { Ingresos } \\
\text { gravados } \\
\text { (millones } \\
\text { de pesos) }\end{array}$ & $\begin{array}{c}\text { Recaudación } \\
\text { (millones de } \\
\text { pesos) }\end{array}$ & $\begin{array}{l}\text { Presenta- } \\
\text { ciones }\end{array}$ & $\begin{array}{l}\text { Ingresos } \\
\text { gravados } \\
\text { (millones } \\
\text { de pesos) }\end{array}$ \\
\hline 1 & 10000 & 356793 & 2002 & 3 & 341976 & 2687 & 29 & 278573 & 2520039 \\
\hline 10001 & 20000 & 359544 & 5220 & 32 & 523953 & 7826 & 147 & 1084653 & 15600000 \\
\hline 20001 & 30000 & 198613 & 4878 & 76 & 264796 & 6473 & 180 & 327086 & 8131826 \\
\hline 30001 & 40000 & 113129 & 3915 & 101 & 271539 & 9338 & 226 & 117165 & 4139473 \\
\hline 40001 & 50000 & 68388 & 3054 & 111 & 209708 & 9541 & 345 & 42057 & 1882858 \\
\hline 50001 & 60000 & 42882 & 2345 & 106 & 105813 & 5997 & 292 & 21110 & 1158234 \\
\hline 60001 & 80000 & 48631 & 3351 & 189 & 99891 & 6954 & 387 & 19238 & 1329835 \\
\hline 80001 & 100000 & 26136 & 2329 & 159 & 56372 & 4997 & 286 & 8196 & 732496 \\
\hline 100001 & 150000 & 23455 & 2818 & 246 & 42062 & 5244 & 465 & 3834 & 428004 \\
\hline 150001 & 200000 & 8555 & 1466 & 149 & 13391 & 2288 & 192 & 976 & 152213 \\
\hline 200001 & 300000 & 6616 & 1596 & 180 & 9198 & 2125 & 359 & & \\
\hline 300001 & 500000 & 3849 & 1456 & 166 & 32 & 10 & 2 & 1345 & 487354 \\
\hline 500001 & 1000000 & 1895 & 1259 & 138 & 38 & 27 & 6 & 160 & 115200 \\
\hline 1000001 & 1500000 & 411 & 489 & 49 & & & & & \\
\hline 1500001 & 2000000 & 181 & 337 & 33 & & & & & \\
\hline 2000001 & 3000000 & 31 & 85 & 6 & & & & & \\
\hline 3000001 & 5000000 & 49 & 187 & 15 & & & & & \\
\hline Más de & 5000000 & 26 & 227 & 22 & & & & & \\
\hline \multicolumn{2}{|l|}{ Total } & 1259184 & 37014 & 1779 & 1938769 & 63507 & 2916 & 1904393 & 36677532 \\
\hline \multicolumn{5}{|c|}{ Presentaciones no relevadas por las encuestas } & $0,5 \%$ & & & $1,5 \%$ & \\
\hline
\end{tabular}

Fuente: Elaboración propia en base a Alvaredo (2010) y Di Gresia (2000).

\section{GRÁFICO 25 \\ ARGENTINA: EVOLUCIÓN DEL COEFICIENTE DE GINI EPH Y AJUSTADO CON DATOS DE DECLARACIONES JURADAS DEL IMPUESTO A LA RENTA}

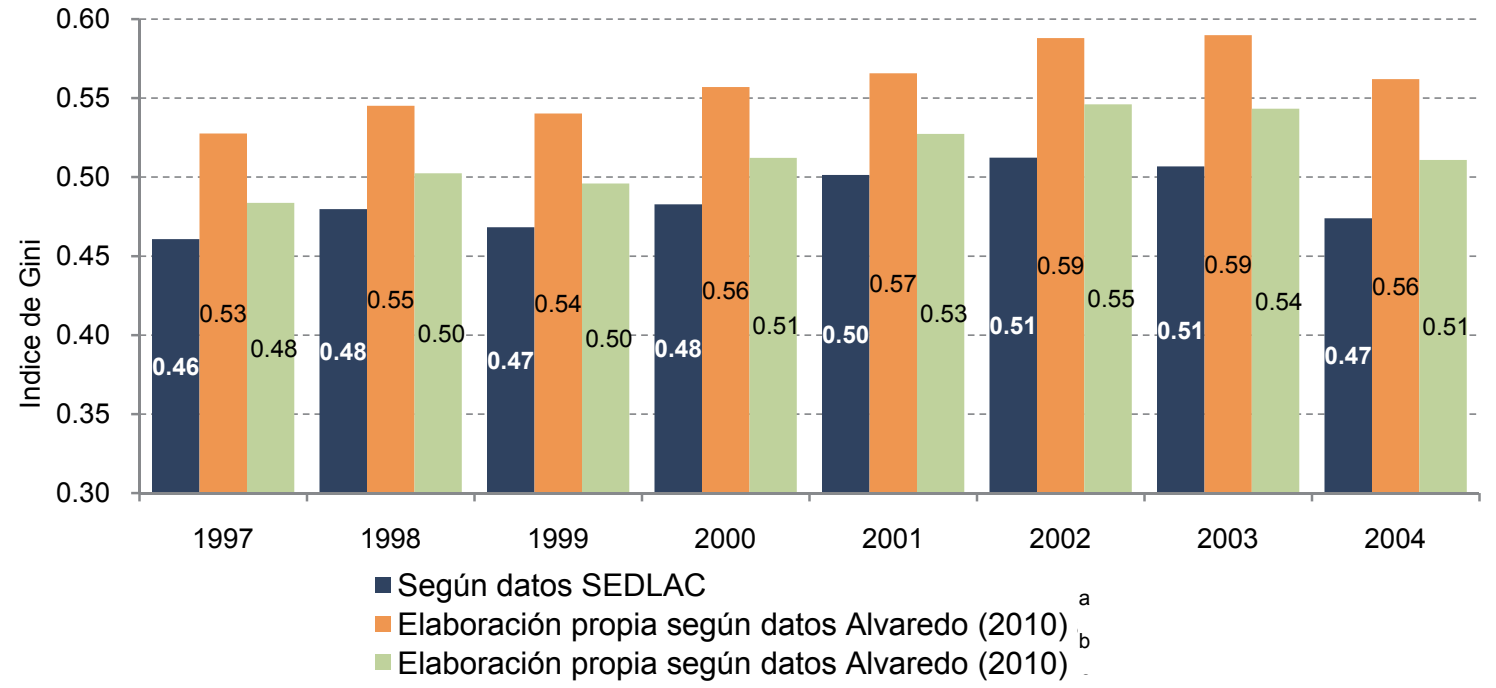

Fuente: Elaboración propia en base a Alvaredo (2010).

a Este coeficiente de Ginl se calcula a partir de las estimaciones que corrigen el ingreso del 1\% más rico de la población.

b Este coeficiente de Ginl se calcula a partir de las estimaciones que corrigen el ingreso del $0,1 \%$ más rico de la población. 
El índice de Gini según las encuestas creció un 2,9\% entre 1997 y 2004 (de 0,461 a 0,474); si se incluye al $1 \%$ más rico, el incremento en la desigualdad sería del 6,5\% (de 0,528 a 0,562). La inclusión del 0,1\% más afluente habría expandido el índice desde el 0,484 de 1997 al 0,511 de 2004 (un 5,6\%). Tomando los datos de 2003, sin embargo, los aumentos fueron del 9,9\%, para la desigualdad de las encuestas; del 11,8\% incluyendo el 1\% más rico y del $12,3 \%$ si se incorporara el top $0,1 \%$.

Resulta interesante analizar la composición de los ingresos, tanto del top 1\% como del $0,1 \%$, en función de las fuentes de ingresos. En el gráfico 30, para el período 2001-2004, puede advertirse una caída en la participación de los ingresos salariales en el 1\% más rico, al pasar del 49,2\% que esta fuente concentraba en 2001 al 30,3\% en 2004. Esta caída de la participación de los salarios está compensada con un crecimiento de las rentas empresariales o por cuenta propia, la cual incrementa su participación desde el 34,7\% al 45\% en 2004. Si bien las rentas del capital incrementan su participación, las mismas están sujetas a la estrechez de la base imponible en función del alcance de las normativas particulares sobre cuáles son las rentas de este tipo alcanzadas por el impuesto.

De la visualización del gráfico 26 puede advertirse que la desigualdad crece inequívocamente al incorporar el top $1 \%$ en la distribución que surge de las encuestas, de allí lo relevante de utilizar este tipo de estudios para analizar la evolución de la distribución del ingreso. Sin embargo, si se analizan los incrementos experimentados en el índice de Gini al incluir el ajuste por subdeclaración mencionado en la sección correspondiente ${ }^{51}$, el incremento en la desigualdad evidenciado por el valor del índice de Gini es superior en este último caso.

La razón subyacente a este resultado estriba en el hecho de que el ajuste por subdeclaración, si bien se realiza en mayor medida en los tramos de ingresos superiores, abarca a toda la distribución; por el contrario, el ajuste de ingresos realizado al incorporar el tramo de rentas mayores sólo comprende al percentil más alto.

GRÁFICO 26

ARGENTINA: COMPOSICIÓN DEL 1\% DE INGRESOS MÁS ELEVADOS

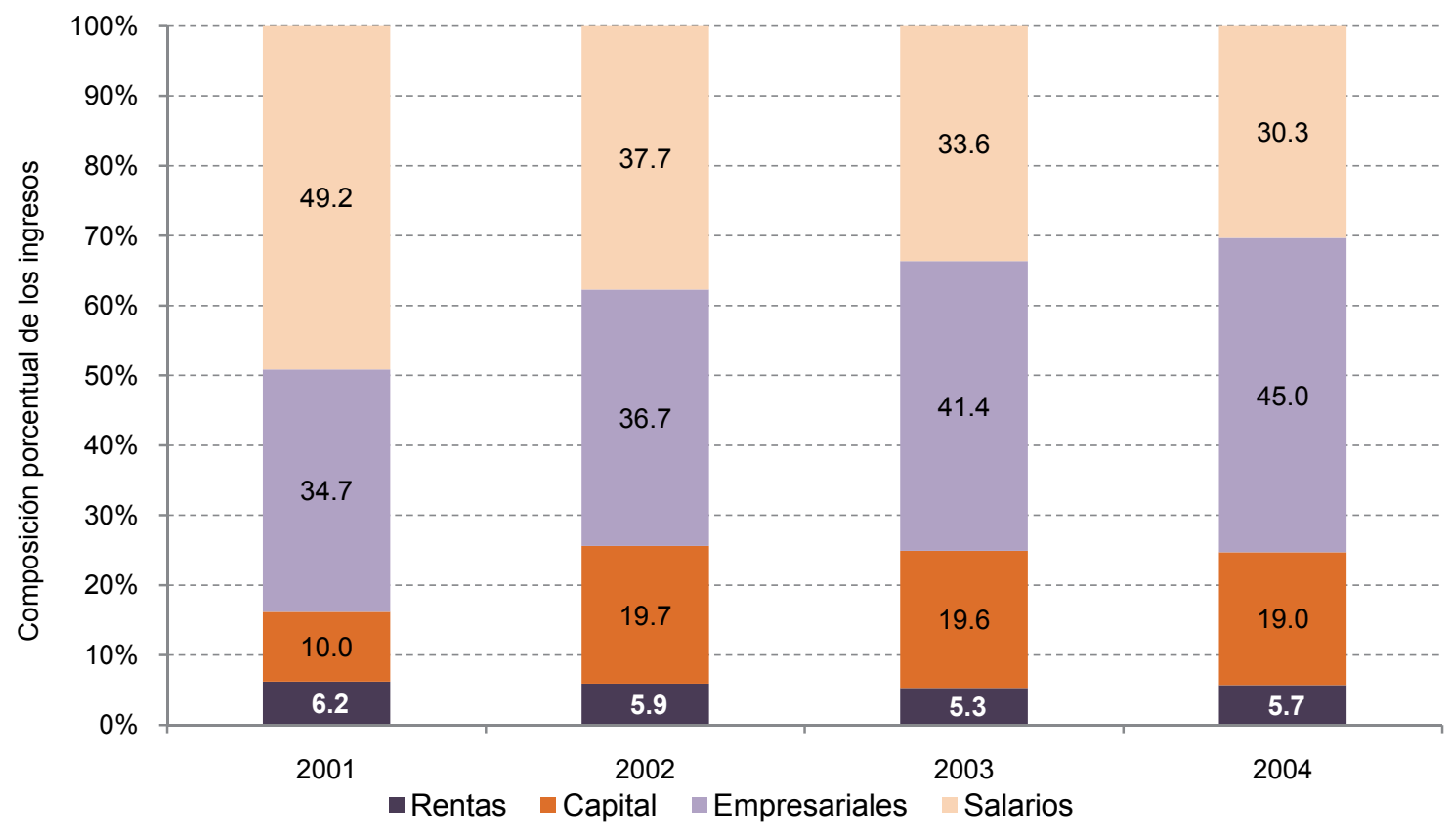

Fuente: Elaboración propia en base a Alvaredo (2010).

${ }^{51}$ Ver sección III.3. 
Como el índice de Gini pondera en mayor medida a los tramos intermedios de la distribución en relación a los extremos, el cambio en el índice de Gini medido a partir de corregir por subdeclaración debería ser superior al corregido mediante declaraciones juradas de impuestos. Es menester combinar los dos enfoques para arribar a una definición más acabada sobre los cambios en la desigualdad.

En el gráfico 27, para el período 2001-2004, también se aprecia una caída en la participación de los ingresos salariales en el 0,1\% más rico, al pasar del 35,9\% que esta fuente concentraba en 2001 al $22,7 \%$ en 2004. A diferencia de la caída de la participación de los salarios, se aprecia un aumento en las rentas empresariales o por cuenta propia, la cual incrementa su participación desde el $54,9 \%$ al $63,8 \%$ en 2004. Como puede advertirse, este tramo de ingresos posee una participación de las rentas empresariales muy superior a las otras fuentes de ingresos; si se compara la participación de las rentas empresariales entre el top $1 \%$ y el top $0,1 \%$, en el primer segmento las mismas explicaban el $45 \%$ del total de ingresos en 2004 , mientras que para el top $0,1 \%$, la importancia cuantitativa crece al $63,8 \%$.

\section{GRÁFICO 27}

ARGENTINA: COMPOSICIÓN DEL 0,1\% DE INGRESOS MÁS ELEVADOS

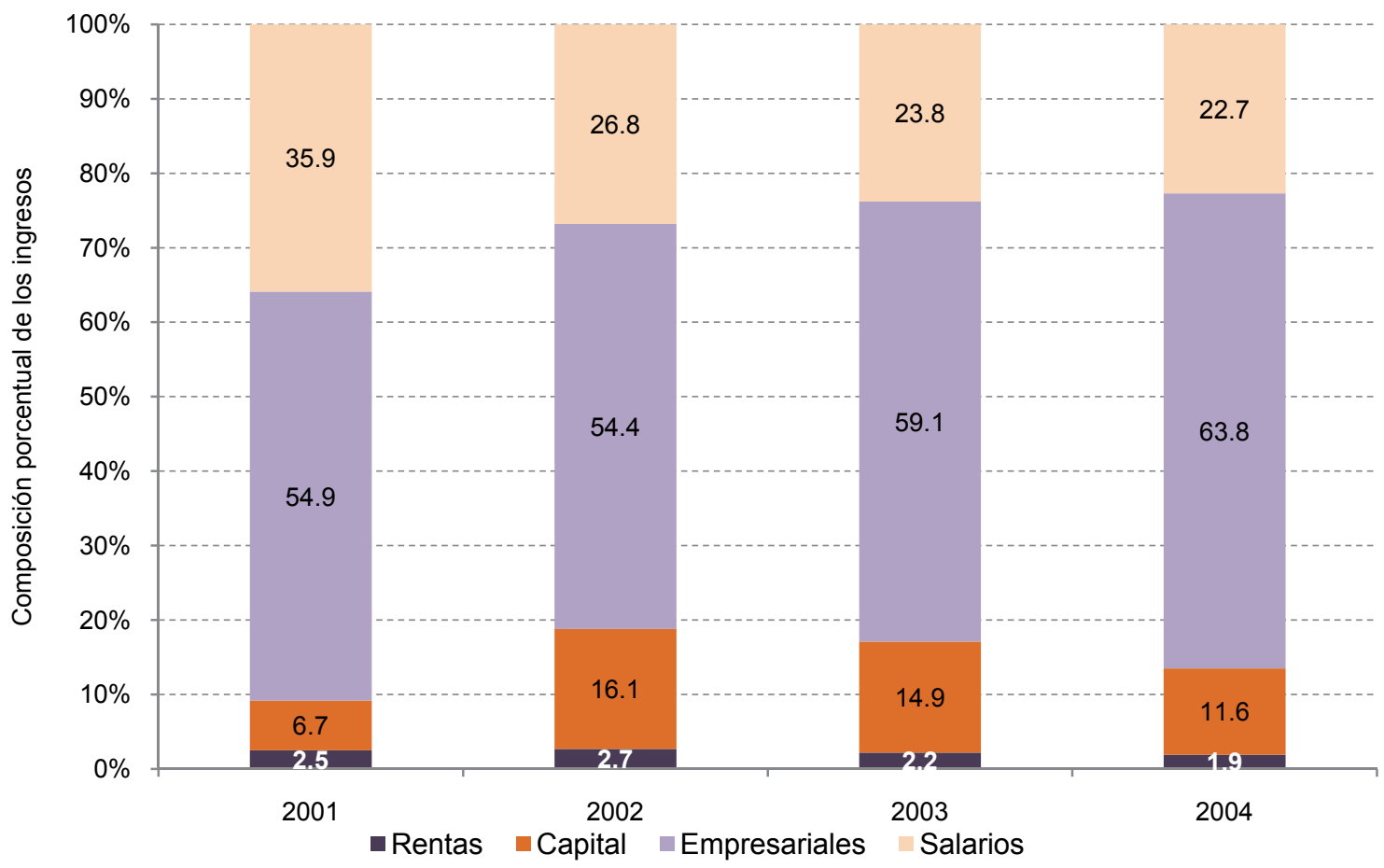

Fuente: Elaboración propia en base a Alvaredo (2010).

\section{El caso de Colombia}

Colombia ha estado caracterizada como uno de los países de América Latina con mayores niveles de desigualdad medidos por el índice de Gini (Ferreira y Ravallion, 2008). Resulta interesante evaluar en qué medida esto es modificado por la incorporación de los tramos de ingresos elevados.

Para Colombia, Alvaredo y Londoño (2013) realizan un análisis considerando el período 1993-2010, a partir de datos de las declaraciones juradas del impuesto a la Renta provistos por DIAN (Dirección de Impuestos y Aduanas Nacionales). Los autores subrayan que Colombia es el primer país en América Latina que provee los microdatos de las declaraciones juradas por un período extenso como el explicitado anteriormente, lo que permite realizar un análisis comparativo con los datos de las encuestas de hogares. 
El ingreso total en el estudio se aproxima a partir de considerar la suma de los ingresos primarios de los hogares, beneficios sociales y transferencias monetarias, netos de las contribuciones patronales, renta imputada de la vivienda y consumo de capital fijo, lo que genera un ingreso disponible de alrededor del 65\% del PBI. Adicionalmente, surgen consideraciones metodológicas a tener en cuenta al trabajar con los microdatos de las declaraciones juradas en relación con el ingreso declarado, debido a la amplitud de conceptos que potencialmente podrían estar incluidos entre las deducciones que los contribuyentes declaran y que les permiten reducir sus obligaciones impositivas. Para salvar este inconveniente, los autores definen, como una corrección ad hoc, el ingreso total como "ingreso bruto" menos la sexta parte de los "costos y deducciones" declarados por los contribuyentes.

El ingreso declarado incluye todos los ítems reportados en las declaraciones juradas, a saber: salarios, empleo por cuenta propia, rentas del capital (abarcando intereses y dividendos), ingresos empresariales (empleadores), e ingresos irregulares (donaciones, herencias, etc.)

Los resultados del estudio determinan que el ingreso en Colombia está altamente concentrado, dado que el top $1 \%$ de la distribución concentró el 20,5\% del ingreso bruto en 2010. Entre 1993 y 2010 la participación del $1 \%$ de ingresos más elevados se mantuvo prácticamente constante entre extremos; sin embargo, la misma ha experimentado fluctuaciones de relevancia a lo largo del período bajo análisis al mostrar una caída en el share al 17,3\% en 2000 y 2001 (ver gráfico 28). La participación del 0,1\%, entretanto, cayó entre 1993 y 2010 un 11,8\%.

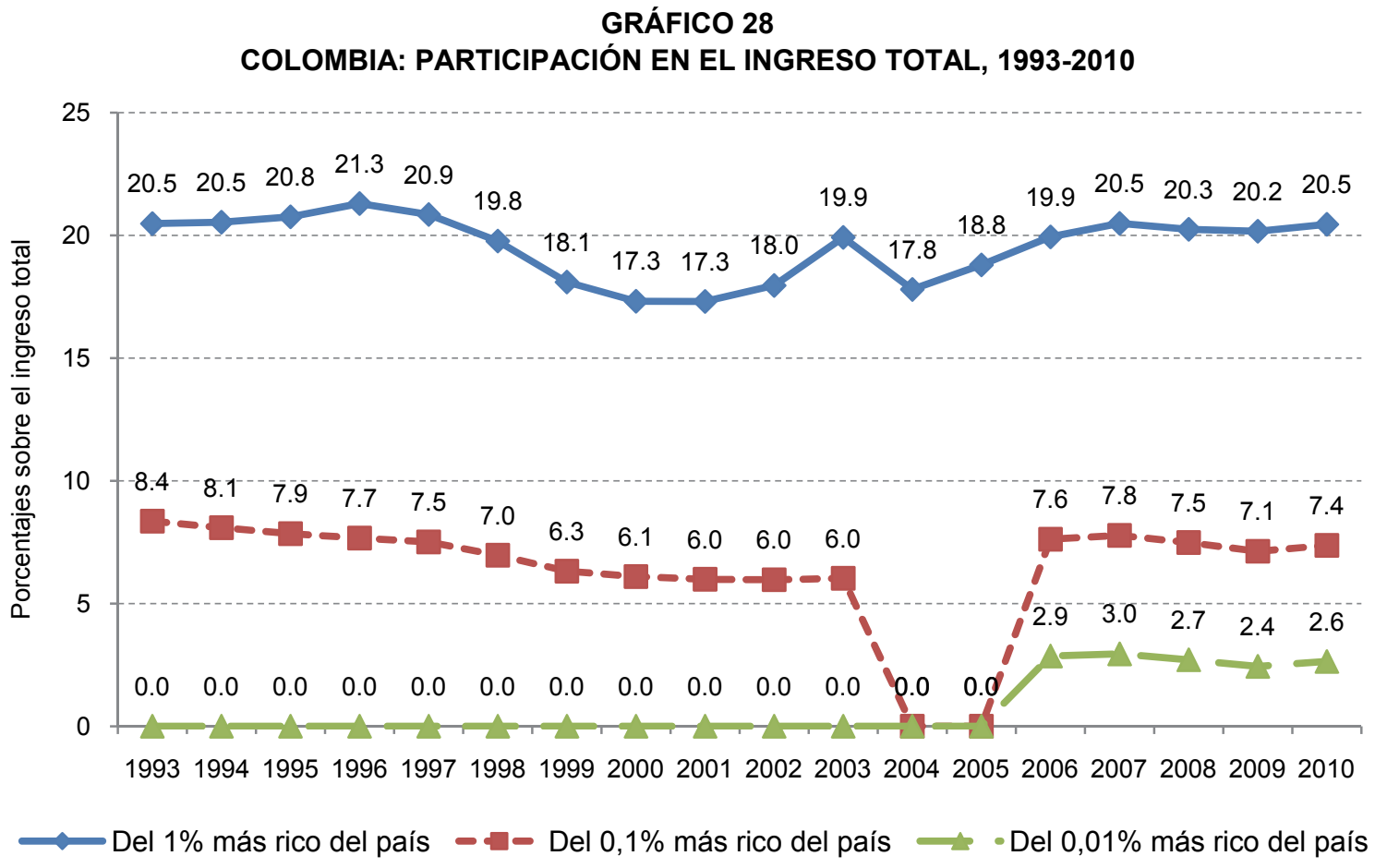

Fuente: Elaboración propia en base a Alvaredo y Londoño (2013).

En el gráfico 29 se descompone la evolución de la participación del 1\% más rico en el ingreso total para los períodos en los que se cuenta con la información de los porcentajes de ingreso que concentran el $0,1 \%$ y el $0,01 \%$ de mayor capacidad económica (2006-2010). El incremento del ingreso del $1 \%$ de mayores ingresos, del 19,9\% al 20,5\% está explicado por un crecimiento de la proporción que concentra el tramo entre el $0,1 \%$ y el $1 \%$, que pasa del $12,3 \%$ al $13,1 \%$ del total, compensando de esta manera las ligeras disminuciones en las participaciones del $0,01 \%$ más afluente, que cayó del 2,9\% al $2,6 \%$ del total, y del tramo entre el $0,01 \%$ al $0,1 \%$, del $4,8 \%$ al $4,7 \%$. 


\section{GRÁFICO 29 \\ COLOMBIA: PARTICIPACIÓN EN EL INGRESO TOTAL, 2006-2010}

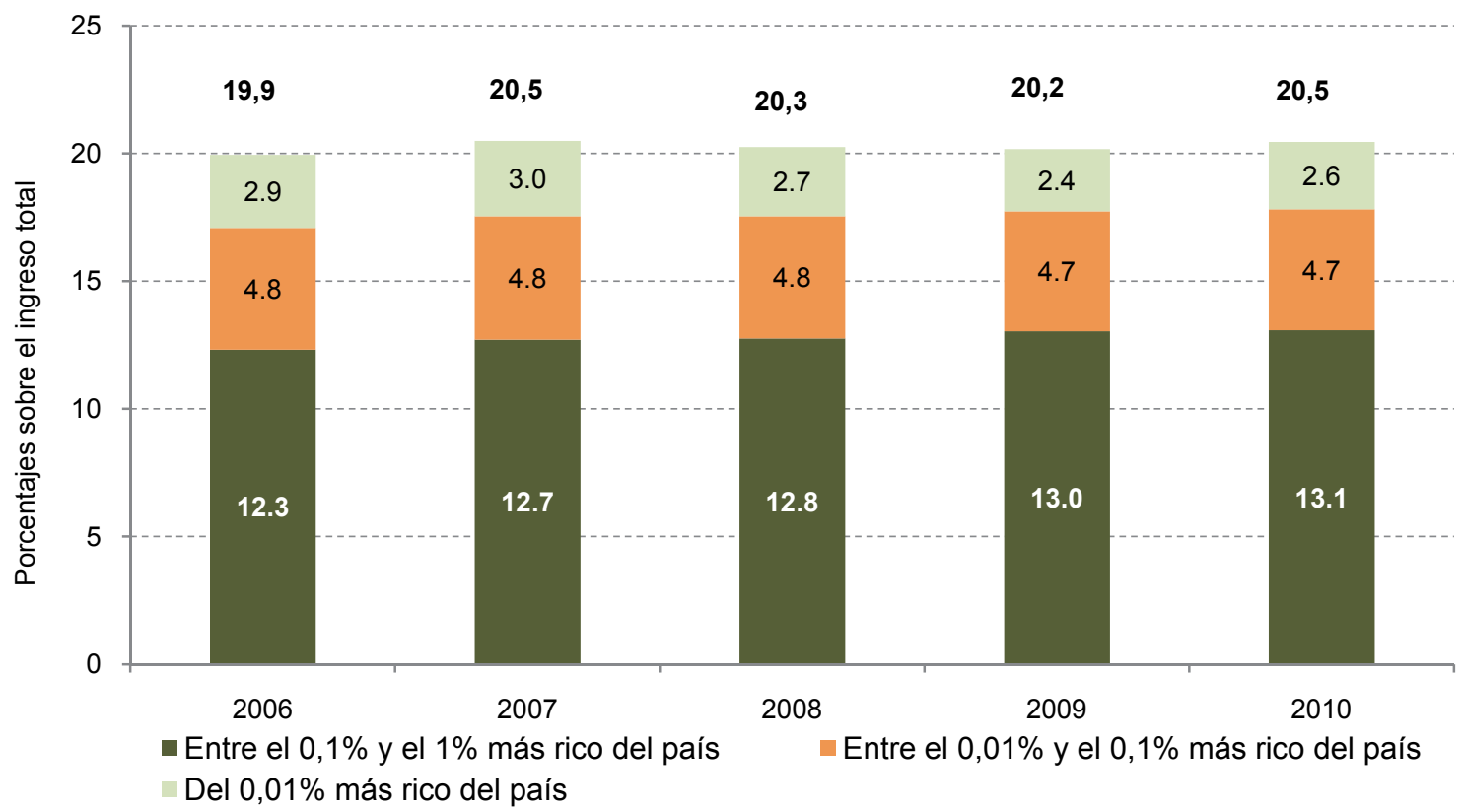

Fuente: Elaboración propia en base a Alvaredo y Londoño (2013).

Mientras las encuestas de hogares muestran que la desigualdad medida a través el índice de Gini se redujo más de un $6 \%$ (de 0,59 en 2007 a 0,55 en 2010), la incorporación del top 1\% corrigiendo los datos de la encuesta matiza ligeramente el mencionado panorama. No sólo los niveles de desigualdad son mayores, sino que además las referidas disminuciones en el índice de Gini son menos marcadas. Lo anterior puede verse en el cuadro 26 y en el gráfico 30.

Para el caso de Colombia, el índice de Gini basado en encuestas era en 2007 de 0,59, el cual desciende a 0,54 en 2008; vuelve a crecer para 2009 a 0,544, y en 2010 a 0,554 . Corrigiendo por la información de las declaraciones juradas, el Gini en 2007 era de 0,612, reduciéndose a 0,572 en 2008, y volviendo a crecer a 0,575 en 2009 y a 0,587 en 2010.

CUADRO 26
LA EVOLUCIÓN DEL ÍNDICE DE GINI EN COLOMBIA, COMPARACIÓN CON ENCUESTAS DE HOGARES

\begin{tabular}{lrrrr}
\hline Año & 2007 & 2008 & 2009 & 2010 \\
\hline Top 1\% ingreso antes de impuestos (declaraciones juradas) (\%) & 19,90 & 19,70 & 19,70 & 20,10 \\
Coeficiente de Gini G (encuestas) & 59,00 & 54,00 & 54,40 & 55,40 \\
Coeficiente de Gini G* (99\% inferior, de encuestas) & 53,30 & 48,40 & 48,70 & 50,00 \\
Coeficiente de Pareto invertido $\beta$ & 2,47 & 2,40 & 2,28 & 2,33 \\
Coeficiente de Gini G corregido con top 1\% de declaraciones juradas & 61,25 & 57,26 & 57,49 & 58,73 \\
\hline
\end{tabular}

Fuente: Alvaredo y Londoño (2013).

Los individuos de ingresos elevados en Colombia son esencialmente rentistas y propietarios del capital, característica que difiere de lo observado en otros países de Latinoamérica (por ejemplo Argentina), en donde puede apreciarse que la mayor proporción de los ingresos de los más ricos corresponden a salarios (si bien, como se mostrara anteriormente, esta tendencia fue revertida en el período de análisis). Alvaredo y Londoño puntualizan que Colombia permanece con un patrón más tradicional de ingresos, en el cual, a diferencia de Estados Unidos y el Reino Unido, los perceptores de ingresos más elevados son aún los propietarios del stock de capital. 


\section{COLOMBIA: LA EVOLUCIÓN DEL ÍNDICE DE GINI DE ENCUESTAS DE HOGARES Y AJUSTADO CON DATOS DE DECLARACIONES JURADAS DEL IMPUESTO A LA RENTA}

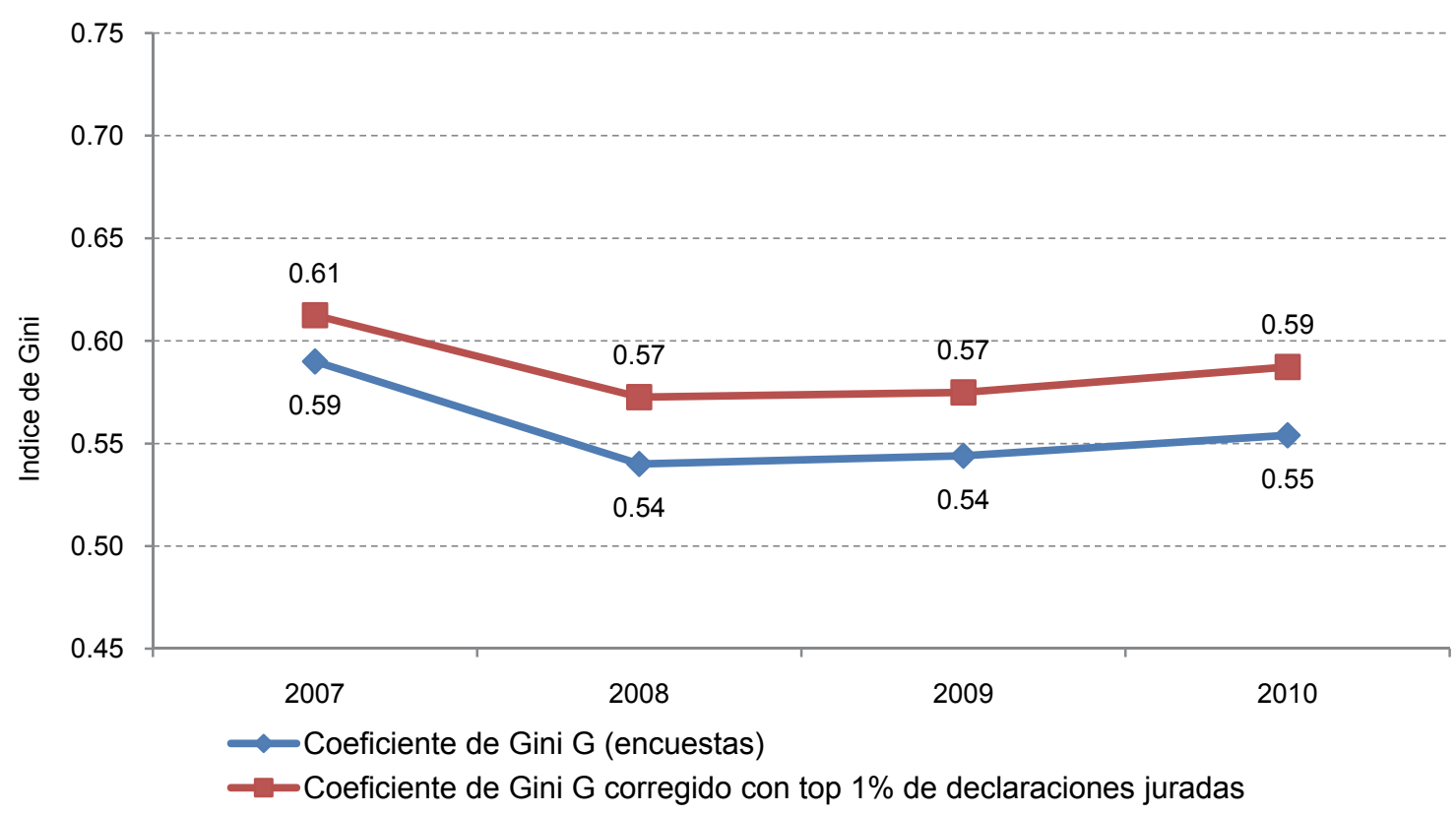

Fuente: Elaboración propia en base a Alvaredo y Londoño (2013).

En el gráfico 31, para el período 2006-2010, se aprecia una constancia en la participación de los ingresos del capital en alrededor del $42,2 \%$ en el caso del top $1 \%$. La participación de los ingresos salariales cae del $29,7 \%$ al $28,6 \%$, y aumenta ligeramente el share de los ingresos empresariales y cuenta propia al $18,4 \%$

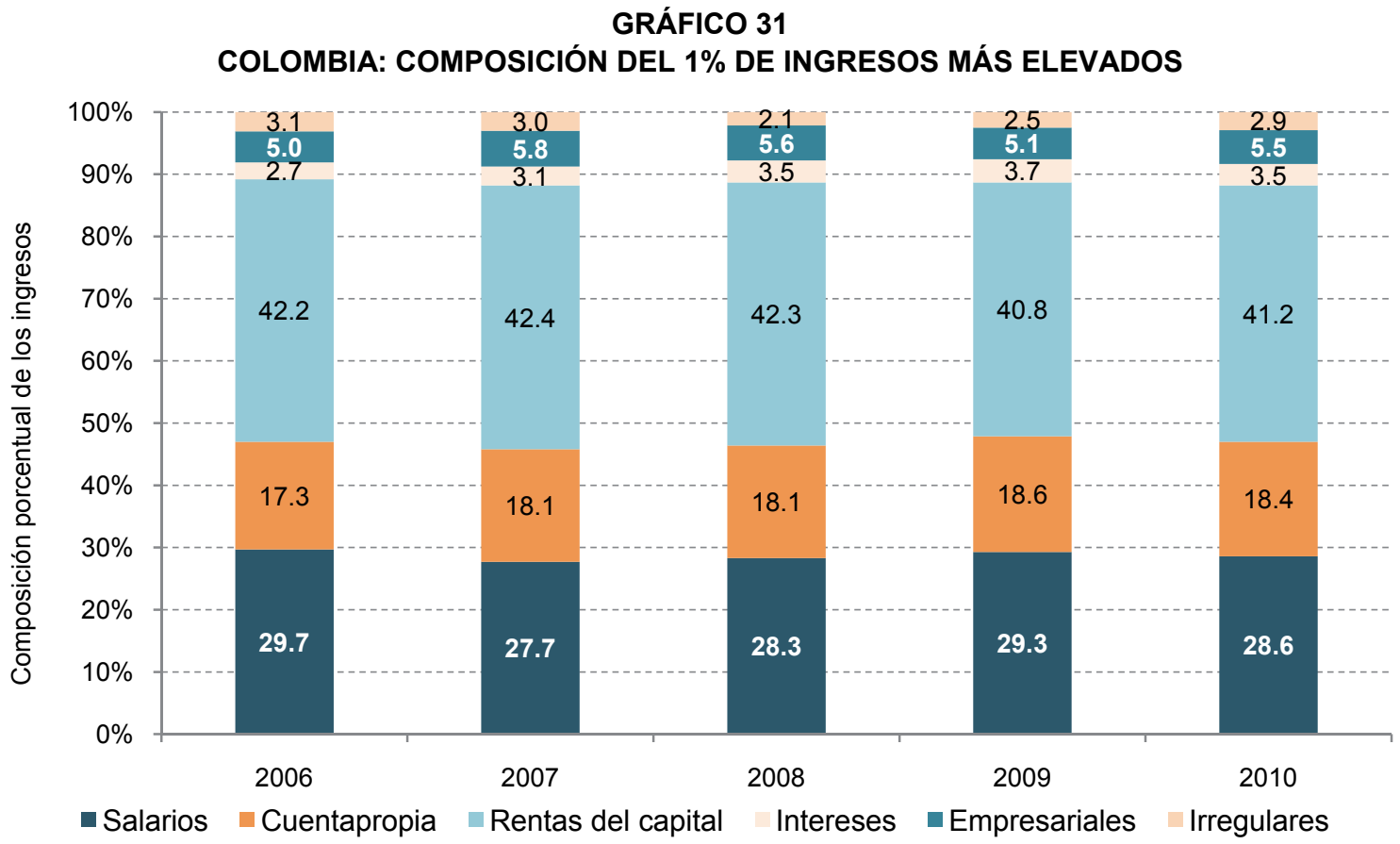

Fuente: Elaboración propia en base a Alvaredo y Londoño (2013). 
En el $0,1 \%$ más rico, las rentas del capital tienen una preponderancia sustancialmente mayor, aunque caen del $60,7 \%$ en 2006 al 57,6\% en 2010. A diferencia de la caída de la participación de los salarios, del $12,2 \%$ al $11,5 \%$, se aprecia un aumento en las rentas empresariales o por cuenta propia, la cual incrementa su participación desde el 14,7\% al 16,5\% en 2010 (véase el gráfico 32).

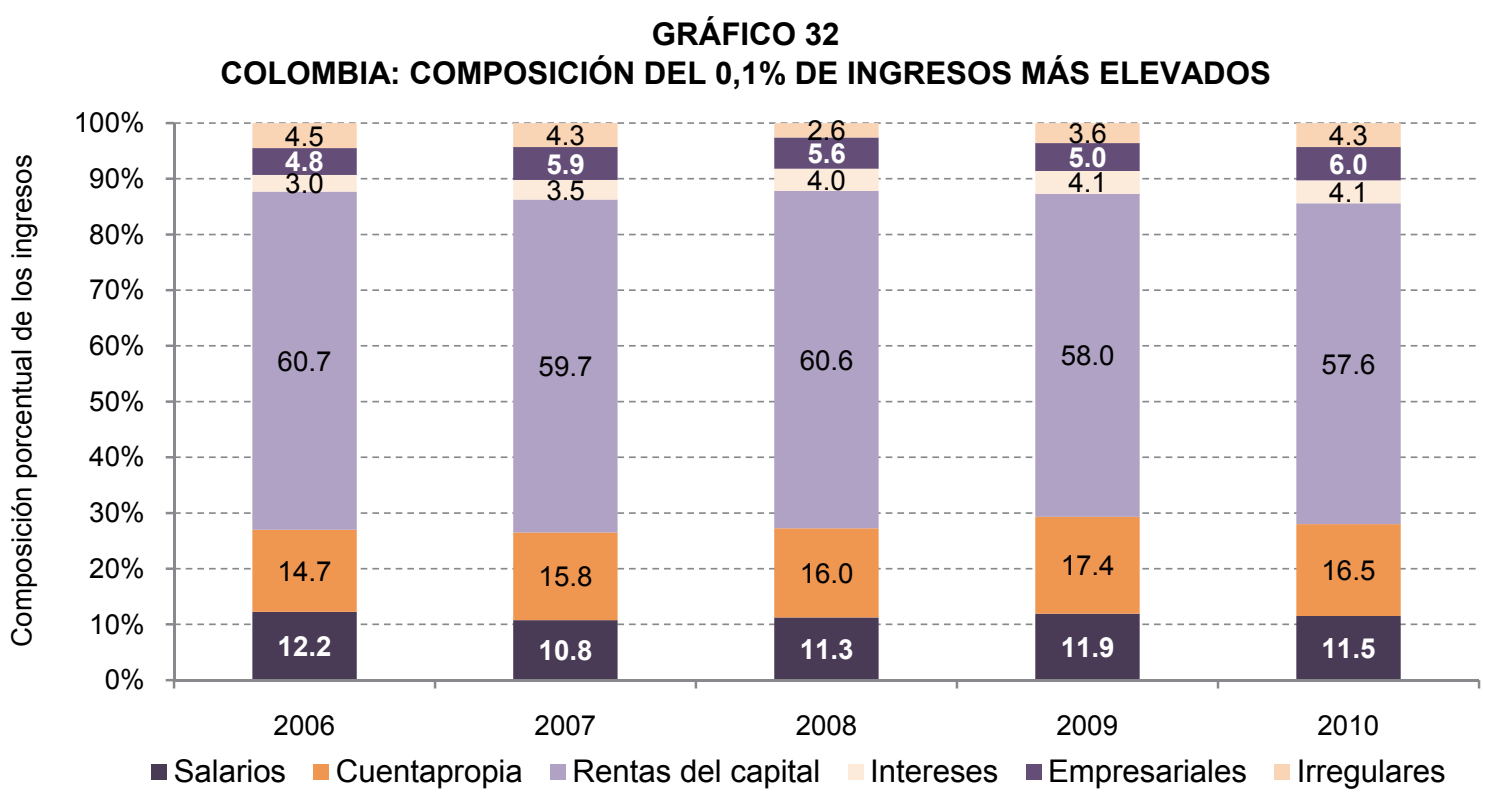

Fuente: Elaboración propia en base a Alvaredo y Londoño (2013).

\section{El caso de Chile}

En un trabajo reciente, López, Figueroa y Gutiérrez (2013) utilizan la metodología desarrollada en Atkinson y Piketty $(2007,2010)$; Atkinson, Piketty y Saez $(2011)$, Alvaredo $(2007,2010)$ y Alvaredo y Londoño (2013) para calcular las participaciones relativas de los individuos de altos ingresos a partir de los datos que surgen de las declaraciones juradas del impuesto a la Renta, con algunas particularidades de adaptación al caso chileno para el período 2005-2010.

Si bien los autores reconocen que los datos provenientes de las declaraciones de impuestos son en general más confiables que los de las encuestas ya que las declaraciones de impuestos son nominativas, tampoco están exentos de sesgos, más allá de las declaraciones juradas fraudulentas.

Los autores justifican la necesidad de realizar ajustes a los ingresos relevados en las declaraciones juradas por dos razones. La primera es que la propiedad del capital en Chile está mucho más concentrada que en la mayoría de los otros países; la concentración del capital en manos de los estratos más ricos es mucho mayor que la concentración de los ingresos declarados al SII (Servicio de Impuestos Internos) por estos grupos. Es importante, en consecuencia, realizar ajustes a los ingresos incluyendo tanto las utilidades no distribuidas por las empresas como las ganancias de capital; como se verá más adelante, incluir utilidades no distribuidas es casi equivalente a incluir ganancias de capital (aunque ambas no pueden incluirse al mismo tiempo ya que están muy relacionadas y de esta manera se incurriría en una doble contabilización) $)^{52}$.

La segunda razón es que en Chile existen incentivos para que los propietarios de acciones de empresas retengan las utilidades y no pagar el impuesto a la renta que ellos deben pagar como receptores de dichas utilidades cuando ellas son repartidas. Cabe consignar que en Chile el impuesto a las ganancias

52 La presente sección sigue a López, Figueroa y Gutiérrez (2013). 
de capital es igual a cero para las acciones de empresas compradas después del año 2001, y el sistema tributario chileno es integrado ${ }^{53}$. El impuesto directo a las utilidades devengadas por las empresas es de $18,5 \%$, mientras que el impuesto marginal a la renta de los contribuyentes de más altos ingresos es del $40 \%$, lo que implica que los incentivos para postergar indefinidamente la distribución de utilidades (o para distribuir sólo el 30\% que la ley exige como mínimo) son muy significativos.

En consecuencia, los autores presentan cuatro resultados distributivos: los que surgen de la encuesta de hogares CASEN, los que surgen de utilizar los datos originales de las declaraciones juradas del impuesto a la Renta provistos por el Servicio de Impuestos Internos, los datos de ingresos de declaraciones juradas ajustados por la inclusión de utilidades no distribuidas de las empresas, y la información de ingresos declarados ajustados por ganancias de capital.

Los datos utilizados para las estimaciones están basados en información oficial del SII de Chile sobre ingresos declarados por las personas naturales para 8 tramos de ingreso declarado (ITI) y también como proporción del ingreso total declarado al SII por las personas naturales. El ITI incluye ingresos del trabajo más las utilidades distribuidas de las empresas (UDN), pero excluye las utilidades no distribuidas de las empresas o ganancias de capital; los 3 tramos tributarios más altos incluyen aproximadamente al $1 \%$ más rico de los contribuyentes.

Para el trabajo, López, Figueroa y Gutiérrez (2013) contaron con información oficial sobre el ingreso efectivo declarado por los contribuyentes al SII. Además, se contó con información sobre la participación de los trabajadores por cuenta propia y con estimaciones sobre las tasas de evasión del impuesto a la Renta. Para calcular el ingreso total control se partió de los datos sobre el ingreso declarado efectivo, al que se sumó una estimación del ingreso imponible no declarado utilizando las tasas de evasión tributaria calculadas por Jorrat (2012).

Los resultados del estudio muestran que entre 2005 y 2010 la participación del 1\% de ingresos más elevados cayó en un $8 \%$, al pasar del $21,6 \%$ del ingreso a un $19,9 \%$ (véase el gráfico 33 ). La participación del 0,1\%, entretanto, disminuyó del 6,6\% en 2005 al 6\%, en 2010 (una reducción del 9\%), mientras que la parte correspondiente al $0,01 \%$ más afluente se redujo aún en mayor medida, al caer un $10 \%$ entre 2005 y 2010 (desde el $2 \%$ al $1,8 \%$ ).

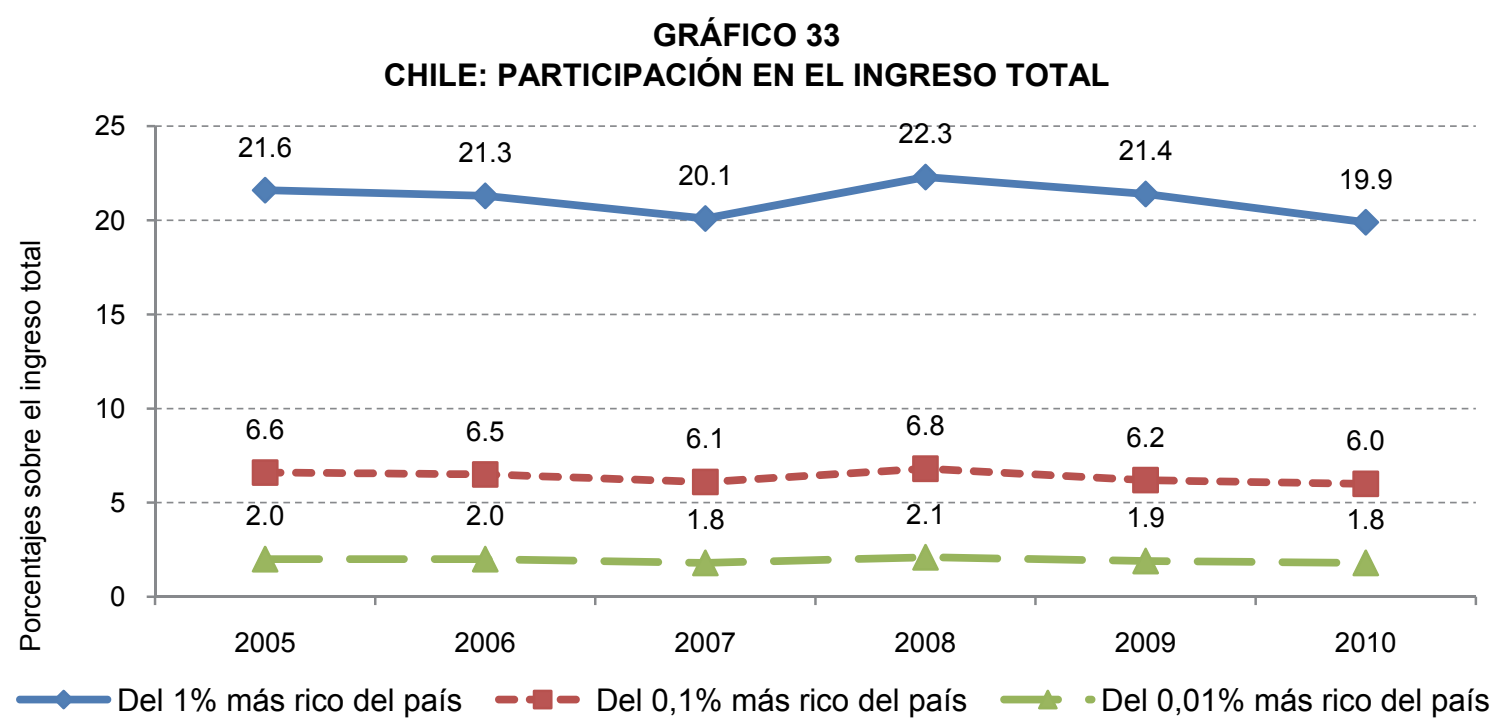

Fuente: López, R., Figueroa, E. y Gutiérrez, P. (2013).

53 El impuesto de primera categoría a las utilidades generadas por las empresas constituye un crédito tributario para el pago del impuesto a la renta que deben hacer los individuos naturales propietarios (accionistas) de la empresa. 
En el gráfico 34 se descompone la evolución de la participación del 1\% más rico en el ingreso total. La disminución del ingreso del 1\% más rico, del 21,6\% al 19,9\% está explicada por la disminución en la proporción que concentra tanto el $0,01 \%$ más afluente, como el tramo entre el $0,01 \%$ al $0,1 \%$ y el tramo entre el $0,1 \%$ y el $1 \%$.

\section{GRÁFICO 34
CHILE: EVOLUCIÓN DE LA PARTICIPACIÓN EN EL INGRESO TOTAL}

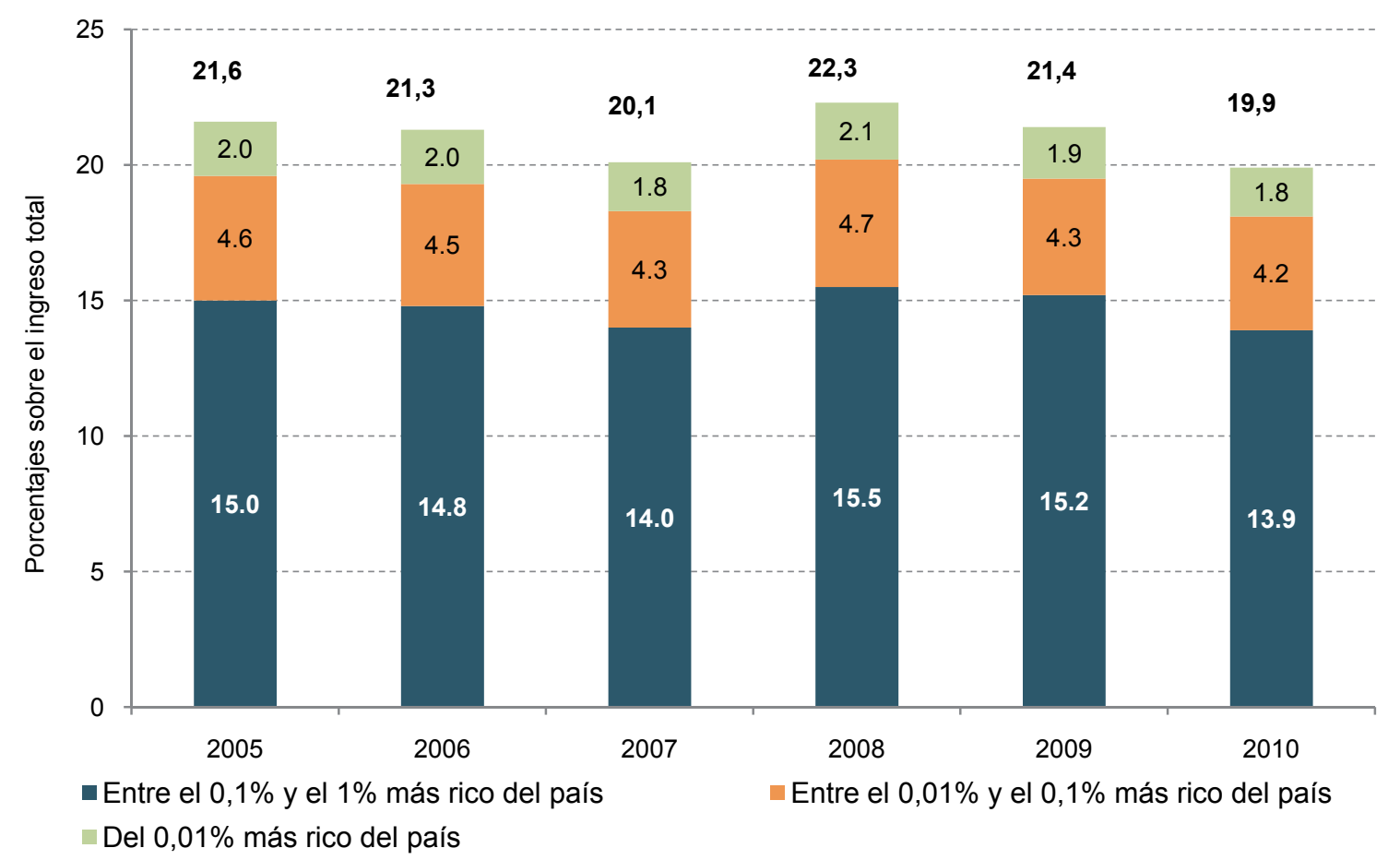

Fuente: Elaboración propia en base a López, R., Figueroa, E. y Gutiérrez, P. (2013).

Sin embargo, como ya se mencionara, las estimaciones hasta aquí presentadas no incluyen las utilidades distribuidas o las ganancias de capital. Por ello, resulta esperable que las comparaciones entre países que se acaban de mostrar sean un tanto sesgadas, ya que las participaciones relativas de los grupos más ricos en el ingreso total para el caso de Chile pueden estar sub-representadas debido a la importancia relativa que tienen las utilidades no distribuidas y/o las ganancias de capital. Con el objeto de corregir este sesgo, los autores desarrollan ajustes para incluir ambos factores.

El cálculo del monto de las utilidades no distribuidas de las empresas privadas del país que recibe el $1 \%$ de los contribuyentes más ricos del país se hace de acuerdo con la siguiente ecuación ${ }^{54}$ :

$$
U T N N R=[U T-U E E-U C P-U D N] \times 0,85
$$

Donde:

UTNNR: utilidades no distribuidas que pertenecen al 1\% de personas naturales más acaudaladas del país

$U T$ : utilidades totales de las empresas del país

$U E E$ : utilidades de empresas extranjeras y de las empresas estatales.

$U C P$ : utilidades totales de las microempresas y de los trabajadores por cuenta propia

54 Ver explicación en López, Figueroa y Gutiérrez (2013). 


\section{$U D N$ : utilidades distribuidas}

El ingreso total de los contribuyentes reportado por el SII (ITI) no incluye las utilidades no distribuidas. Por ello, para calcular las participaciones de los distintos fractiles en el ingreso total, es necesario recalcular el ingreso total de los contribuyentes del país (ITT) de modo que incluya las utilidades no distribuidas de las empresas privadas. El ingreso total de los contribuyentes del país (ITT) se calcula en consecuencia de la siguiente manera:

$$
I T T=I T I+U T-U E E-U D N
$$

Para incluir las ganancias de capital, se calcula el costo de oportunidad de una unidad de utilidad retenida en términos de dividendos netos obtenidos en un sistema tributario integrado, como es el caso de Chile, es: $\theta=(1-m) /(1-t)$

Donde, $m$ es el impuesto a la renta marginal que debe pagar un individuo promedio y $t$ es el impuesto corporativo (en el caso de Chile, para todas las acciones compradas después del año 2001, el impuesto a las ganancias de capital es cero). Dado que el precio de una acción es el valor esperado del valor presente de sus flujos futuros, es posible expresar las utilidades retenidas como ganancias de capital mediante la siguiente fórmula ${ }^{55}: \pi \theta=K_{\text {ganancia }}$

En el cuadro 39 se muestran los resultados de los distintos cálculos realizados, a saber: la encuesta CASEN, los datos de declaraciones juradas del SII, los datos de DDJJ ajustados por utilidades no distribuidas, y los datos de ingresos ajustados por ganancias de capital. Como era esperable de los resultados de Atkinson, Piketty y Saez (2011) para varios países, también para el caso de Chile, las participaciones en el ingreso del país estimadas a partir de los datos de la encuesta CASEN subestiman significativamente la participación del $1 \%$ más rico del país. Por ejemplo, para el año 2010, según los datos reportados por la CASEN, la participación en el ingreso total del país del 1\% de los chilenos más ricos fue solamente de $14,9 \%$, mientras que las estimaciones, a partir de los datos del SII, muestran que la participación fue de 19,9\%. El ajuste por utilidades no distribuidas incrementa la participación del 1\% más acaudalado, determinándose, para 2010, que el mismo concentra el 31,6\% del ingreso total ${ }^{56}$.

Para el caso del $0,1 \%$ más afluente, en el cuadro puede apreciarse que, adicionando las utilidades no distribuidas, el porcentaje que captura este segmento crece al $17,7 \%$ del ingreso total en 2010 , en oposición al 6\% que concentra según la información bruta de las declaraciones juradas y al 3,2\% que surge de la encuesta CASEN.

En el cuadro 27 se muestra también que las participaciones del $1 \%, 0,1 \%$ y $0,01 \%$ de los individuos más acaudalados en el ingreso del país cuando se incluyen las ganancias de capital resultan ser algo menores que sus participaciones cuando se incluye las utilidades no distribuidas de las empresas privadas. Sin embargo, las participaciones promedios de estos fractiles de ingreso en el ingreso total siguen siendo extremadamente altas (29\%, 16\% y 8,9\% respectivamente) para el período 2005-2010.

Asimismo, el coeficiente de Gini para la desigualdad de la distribución del ingreso para el período 2004-2010 calculado con los datos de la encuesta CASEN resulta ser, para este último año de 0,55, mientras que las estimaciones muestran que su valor fue de 0,57 , si se utilizan datos de declaraciones juradas sin corregir, lo que indica que la desigualdad existente en Chile resulta ser significativamente mayor a la reportada oficialmente (gráfico 35).

La inclusión de ganancias de capital hace crecer el índice a 0,62 para 2010, y el mismo se incrementa aún en mayor medida si en lugar de éstas se incorporan las utilidades no distribuidas, lo que lleva a un valor de 0,67. A lo largo del período analizado, la desigualdad medida por el Gini es mayor de incluir las utilidades retenidas que las ganancias de capital, excepto para 2008.

\footnotetext{
Ver López, Figueroa y Gutiérrez (2013).

La explicación sigue a López, Figueroa y Gutiérrez (2013).
} 


\section{CUADRO 27 \\ CHILE: PARTICIPACIONES EN EL INGRESO TOTAL}

(En porcentajes)

\begin{tabular}{|c|c|c|c|c|c|c|}
\hline & 2005 & 2006 & 2007 & 2008 & 2009 & 2010 \\
\hline \multicolumn{7}{|l|}{ Del $1 \%$ más rico del país } \\
\hline Según datos Encuesta CASEN & 16,8 & 14,2 & 14,2 & 14,2 & 14,9 & 14,9 \\
\hline Según datos del SII & 21,6 & 21,3 & 20,1 & 22,3 & 21,4 & 19,9 \\
\hline $\begin{array}{l}\text { Según interpolación de Pareto, incluyendo utilidades } \\
\text { retenidas y corrigiendo por evasión }\end{array}$ & 31,8 & 31,8 & 32,3 & 35,0 & 35,0 & 31,6 \\
\hline $\begin{array}{l}\text { Según interpolación de Pareto, incluyendo ganancias } \\
\text { de capital y corrigiendo por evasión }\end{array}$ & 29,5 & 29,4 & 30,1 & 32,5 & 32,7 & 29,0 \\
\hline \multicolumn{7}{|l|}{ Del $0,1 \%$ más rico del país } \\
\hline Según datos Encuesta CASEN & 4,9 & 3,7 & 3,7 & 3,7 & 3,2 & 3,2 \\
\hline Según datos del SII & 6,6 & 6,5 & 6,1 & 6,8 & 6,2 & 6,0 \\
\hline $\begin{array}{l}\text { Según interpolación de Pareto, incluyendo utilidades } \\
\text { retenidas y corrigiendo por evasión }\end{array}$ & 17,5 & 17,8 & 18,5 & 21,8 & 20,3 & 17,7 \\
\hline $\begin{array}{l}\text { Según interpolación de Pareto, incluyendo ganancias } \\
\text { de capital y corrigiendo por evasión }\end{array}$ & 16,2 & 16,5 & 17,2 & 20,3 & 19,2 & 16,0 \\
\hline \multicolumn{7}{|l|}{ Del $0,01 \%$ más rico del país } \\
\hline Según datos Encuesta CASEN & 1,7 & 0,8 & 0,8 & 0,8 & 0,5 & 0,5 \\
\hline Según datos del SII & 2,0 & 2,0 & 1,8 & 2,1 & 1,9 & 1,8 \\
\hline $\begin{array}{l}\text { Según interpolación de Pareto, incluyendo utilidades } \\
\text { retenidas y corrigiendo por evasión }\end{array}$ & 9,7 & 10,0 & 10,6 & 13,6 & 12,1 & 9,1 \\
\hline $\begin{array}{l}\text { Según interpolación de Pareto, incluyendo ganancias } \\
\text { de capital y corrigiendo por evasión }\end{array}$ & 9,0 & 9,2 & 9,9 & 12,6 & 11,3 & 8,9 \\
\hline
\end{tabular}

Fuente: López, R., Figueroa, E. y Gutiérrez, P. (2013).

\section{GRÁFICO 35}

CHILE: LA EVOLUCIÓN DEL ÍNDICE DE GINI DE ENCUESTAS DE HOGARES Y AJUSTADO CON DATOS DE DECLARACIONES JURADAS DEL IMPUESTO A LA RENTA

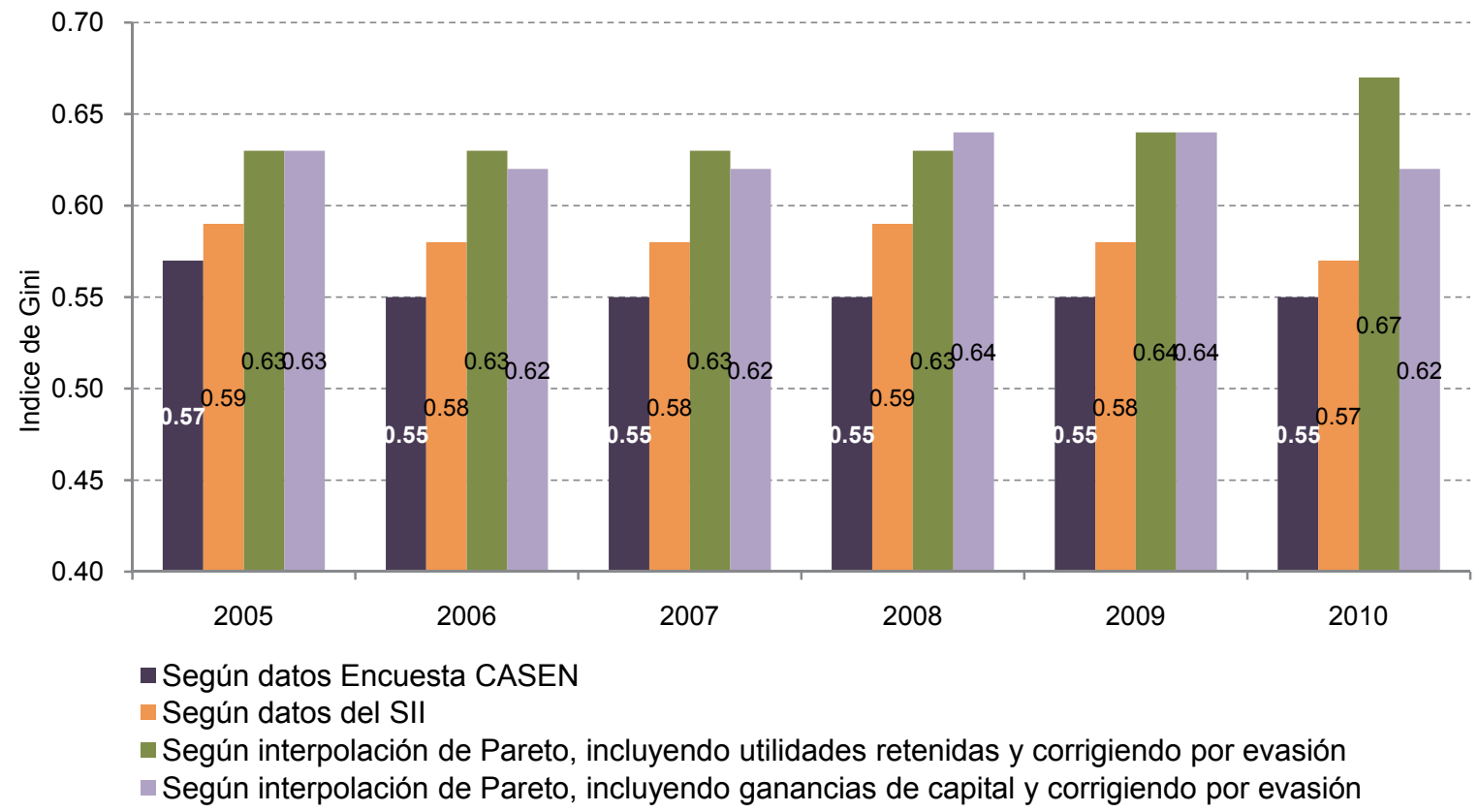

Fuente: Elaboración propia en base a López, R., Figueroa, E. y Gutiérrez, P. (2013). 



\section{Síntesis y reflexiones finales}

La composición de los recursos tributarios en los países de América Latina muestra una estructura sesgada hacia la imposición indirecta, con un menor peso relativo de los impuestos directos y, particularmente, del Impuesto a la Renta de Personas Naturales, el que está enfocado principalmente a gravar las rentas provenientes de la actividad laboral formalizada.

Por el contrario, debe enfatizarse que el impuesto a la renta aplicado en los países desarrollados, además de tener un peso absoluto y relativo mayor dentro de sus estructuras tributarias, no sufre las falencias técnicas que muestra este gravamen en la mayoría de los países de América Latina, a saber: i) tasas efectivas muy inferiores a las tasas legales; ii) tasas proporcionales en lugar de progresivas; iii) bases estrechas del tributo a la renta, con numerosas exenciones que atentan contra la equidad, especialmente en materia de ingresos financieros que benefician a los estratos de altos ingresos, iv) amplios sectores de la población queda fuera del impuesto por efecto del mínimo no imponible, y v) un alto grado de evasión del impuesto especialmente en los contribuyenes no-asalariados. Todo esto desemboca en un Impuesto sobre la Renta Personal que, a pesar de ser formalmente progresivo en su diseño, posee un impacto redistributivo muy reducido.

El análisis de la evolución del comportamiento de los ingresos tributarios en Latinoamérica muestra un crecimiento de relevancia en la recaudación, y, en forma particular, evidencia un incremento en los recursos provenientes del impuesto sobre los ingresos. Por ello, resulta interesante desgranar las causas que pueden haber originado este crecimiento en la recaudación.

Por un lado, el comportamiento de las alícuotas ha sido un elemento de relevancia; así se verifica un aumento de las tasas mínimas, lo que ayuda a incrementar la recaudación, y una disminución de la tasa marginal máxima, lo que, en forma concomitante con las participaciones crecientes de los tramos de ingresos más elevados, lleva a que el impuesto pierda progresividad.

Adicionalmente, y también en forma coincidente con lo anterior, un ligero incremento de los niveles de los mínimos no imponibles (en múltiplos del PBI) da idea del ajuste pasivo por parte de las autoridades tributarias ante incrementos en precios o en ingresos, y una disminución importante de los niveles de renta a partir de los cuales comienza a tributarse con la alícuota máxima. En forma coherente con el comportamiento de las tasas máximas, esto también es una señal de disminución de progresividad del impuesto. 
Otro de los problemas que subyace al diseño de la estructura tributaria en Latinoamérica ha sido el desbalance en el propio impuesto a la Renta Personal: el mismo grava principalmente las rentas del trabajo asalariado y, en mucho menor medida, a las rentas del capital. En ese sentido, se han planteado algunas modificaciones en las bases imponibles (por ejemplo, Uruguay y algunos países de Centroamérica) que han determinado extender la tributación a los ingresos del capital, así como a las ganancias de capital originadas en la valoración de los activos, aunque aún en forma incipiente.

De acuerdo con CEPAL (2013), si bien algunas reformas tributarias aún son muy recientes como para que se manifiesten en un aumento de la carga tributaria, estos factores contribuyeron en diverso grado a que la recaudación del impuesto sobre la renta aumentara, sobre todo a partir de 2002, y a que este tributo se mantuviera en el segundo lugar de importancia en las estructuras tributarias latinoamericanas. El desbalance entre tipos de rentas, no obstante, persiste en la mayoría de los países.

Por otra parte, existen otros factores que también pueden haber contribuido al incremento en la recaudación tributaria global y la proveniente de la imposición sobre ingresos. Así, durante todo el período 1990-2011, el sostenido crecimiento de la carga tributaria total ha estado correlacionado con un incremento proporcional del ingreso per cápita. Sin embargo, si se separa dicho período en aproximadamente dos decenios puede observarse que, mientras que durante la primera parte del mismo se dio un aumento de la desigualdad del ingreso pre-fiscal (continuando la tendencia de los años ochenta), a partir de los primeros años del nuevo siglo se ha verificado una mejora sustancial en la distribución del ingreso en casi todos los países de la región.

Este fenómeno ha sido vinculado a varias causas -políticas, sociales, macroeconómicas- $\mathrm{y}$ ha sido debidamente corroborado y documentado por un conjunto no menor de destacados autores (Gasparini et al, 2009; López-Calva y Lustig, 2010). No obstante, son conocidas asimismo las limitaciones que enfrentan todos los estudios en materia distributiva cuando incluyen estimaciones cuantitativas basadas en datos provenientes de las encuestas de ingresos y gastos de los hogares. Al respecto, estos instrumentos de información suelen fallar en registrar los "verdaderos" ingresos de la población, ya sea por la falta de respuesta -parcial o total-, la subdeclaración de ingresos y la subcaptación de perceptores, debiendo recurrirse a ajustes estadísticos en la mayoría de los casos. Estos problemas se agravan especialmente con los individuos más ricos, los cuales generalmente son contrarios a declarar fielmente la totalidad y la composición real de sus ingresos, quedando fuera del alcance de las encuestas realizadas.

Es por esta razón que resulta de suma relevancia analizar la evolución de la participación en el ingreso de los tramos de renta elevada, que no son captados adecuadamente por el decil de ingresos más altos de las encuestas, sino que concentran el 1\%, o el $0,1 \%$ de los ingresos más altos. Este sector, denominado "súper ricos", ha sido el objeto de análisis de una serie de estudios llevados a cabo en los países avanzados y que han tenido su correlato en algunas investigaciones realizadas en América Latina. Esta serie de trabajos analiza la evolución de la concentración del ingreso de los tramos más elevados a partir de los "datos fiscales" provenientes de las declaraciones juradas del Impuesto a la Renta, los cuales suelen diferir de manera notoria con la información recolectada en las encuestas.

A partir de la utilización de distintas metodologías como la interpolación de Pareto, las cuales no se hallan exentas de limitaciones y debilidades técnicas, las investigaciones realizadas en este campo han podido comprobar que la participación de los tramos de ingresos más elevados ha experimentado grandes oscilaciones a lo largo del tiempo, evidenciando patrones bastante similares para los distintos países en que este fenómeno fue analizado. Se aprecia una participación importante de estos tramos al inicio del siglo veinte, para luego perder preponderancia hacia la mitad del siglo.

Ya hacia fines del siglo pasado estos sectores vuelven a adquirir relevancia cuantitativa en la distribución de la renta, volviendo a alcanzar, en algunos casos, participaciones similares a los registros más elevados. Empero, ahora aparece un cambio de composición: si inicialmente la mayor participación correspondía a las rentas o ingresos del capital (utilidades y dividendos) en detrimento de las demás fuentes de renta, hacia fines del siglo veinte y principios del siglo veintiuno se advierte una mayor participación de la renta proveniente del salario (altos ejecutivos y directores de sociedades) y una menor participación de las rentas del capital. 
En consecuencia, las mediciones convencionales de la desigualdad de ingresos a partir de los datos de las encuestas probablemente estén soslayando un fenómeno de concentración de los ingresos que, debido al propio diseño muestral, no puede analizarse con la información disponible. Esta limitación no es nueva y ha estado implícita, en menor o en mayor medida, en todas las estimaciones de este tipo. Por lo tanto, queda como una materia de discusión el alentador cambio de tendencia en materia distributiva que en los últimos años se ha observado en los países de América Latina, una vez que se hacen los ajustes correspondientes.

Más allá de lo anterior, el hecho de que los datos existentes muestren que la participación de los estratos más ricos de la población ( $1 \%$ o menor) ha crecido en los últimos años - tanto en países desarrollados como subdesarrollados- permite pensar que el sesgo de estimación sería relativamente mayor en los cálculos más recientes $\mathrm{y}$, por ende, la mencionada disminución de la desigualdad habría sido de menor cuantía a la oportunamente cuantificada en la mayoría de los estudios en la materia.

En general, se ha observado que, dado que el coeficiente de Gini -por construcción- otorga mayor peso relativo a las transferencias operadas en la parte central de la distribución del ingreso y que las encuestas de hogares tienden a subestimar a la proporción de ingresos más altos, los resultados obtenidos en las estimaciones no alcanzan a presentar una verdadera visión de la evolución de la desigualdad en los países. Esto es lo que puede observarse en los recientes estudios de este tipo aplicados a países de la región donde, a pesar de las especificidades inherentes a cada caso en particular, se ha podido comprobar que los coeficientes de Gini resultantes serían mayores (y la desigualdad sería mayor) una vez efectuados los ajustes necesarios.

En el caso de Argentina, los resultados del estudio de Alvaredo (2010) han mostrado que entre 1997 y 2004 la participación del 1\% de ingresos más elevados se incrementó en un 35\%, al pasar del 12,4\% del ingreso a un 16,8\%. La participación del 0,1\%, entretanto, creció del 4,3\% en 1997 al 7\%, en 2004 (un incremento del 64,4\%), mientras que la parte correspondiente al $0,01 \%$ más afluente se incrementó aún en mayor medida (desde el 1,4\% al 2,5\%). Dado que la encuesta de hogares (EPH) no incluye a los individuos de los tramos de ingresos más elevados, se pudo comprobar que el coeficiente de Gini en dicho período aumentó más de lo que surge de considerar las encuestas tanto cuando se incluye al $1 \%$ como al $0,1 \%$ más rico de la población. Asimismo, para el período 2001-2004 pudo apreciarse una caída en la participación de los ingresos salariales en el $0,1 \%$ más rico conjuntamente con un aumento en las rentas empresariales o por cuenta propia de estos individuos.

Para Colombia, Alvaredo y Londoño (2013) realizaron un análisis considerando el período 1993-2010 a partir de datos de las declaraciones juradas del impuesto a la Renta. Los resultados del estudio determinaron que el ingreso en Colombia está altamente concentrado, dado que el top $1 \%$ de la distribución concentró el 20,5\% del ingreso bruto en 2010, participación que se mantuvo prácticamente constante entre extremos del período a pesar de ciertas fluctuaciones a lo largo del mismo. Además, mientras las encuestas de hogares muestran que la desigualdad medida a través el índice de Gini se redujo más de un $6 \%$ (de 0,59 en 2007 a 0,55 en 2010), la incorporación del top 1\% corrigiendo los datos de la encuesta matiza ligeramente el mencionado panorama. No sólo los niveles de desigualdad son mayores, sino que además las referidas disminuciones en el índice de Gini son menos marcadas. En cuanto a la composición de las rentas, los individuos de ingresos elevados en Colombia son esencialmente rentistas y propietarios del capital, característica que difiere de lo observado en otros países de Latinoamérica (por ejemplo Argentina), en donde puede apreciarse que la mayor proporción de los ingresos de los más ricos corresponden a salarios.

Para el caso de Chile, López, Figueroa y Gutiérrez (2013) utilizaron una metodología similar a partir de información oficial sobre el ingreso efectivo declarado por los contribuyentes. Sin embargo, en dicho estudio se debieron efectuar ajustes ya que las participaciones relativas de los grupos más ricos en el ingreso total pueden estar sub-representadas debido a la importancia relativa que tienen las utilidades no distribuidas y/o las ganancias de capital. Así, mientras que para el año 2010, según los datos reportados por la encuesta CASEN, la participación en el ingreso total del país del $1 \%$ de los chilenos más ricos fue solamente de $14,9 \%$, las estimaciones a partir de los datos de declaraciones juradas mostraron que dicha participación fue de 19,9\%. El ajuste por utilidades no distribuidas incrementó aún 
más la participación del 1\% más acaudalado para 2010, concentrando el 31,6\% del ingreso total. Asimismo, el coeficiente de Gini de la distribución del ingreso para el período 2004-2010 calculado con los datos de la encuesta CASEN resultó ser de 0,55 para este último año, el cual sería: a) de 0,57 si se utilizan datos de declaraciones juradas sin corregir; b) de 0,62 si se incluyen las ganancias de capital; c) de 0,67 si en lugar de dichas rentas se incorporan las utilidades no distribuidas.

En definitiva, los estudios enfocados en el análisis de los tramos más ricos de la población resultan muy útiles en la medida que permitan corregir las mediciones convencionales sobre desigualdad considerando la participación de dichos hogares en el total del ingreso para evaluar más acabadamente la concentración de los ingresos en la sociedad, compatibilizando la información fiscal proveniente de las declaraciones juradas con los datos obtenidos a través de las tradicionales encuestas de hogares.

Si bien se ha avanzado de manera notable en analizar las participaciones de los altos ingresos en la distribución, y en advertir sobre su aporte a la recaudación del impuesto a la Renta, aún queda mucho camino por recorrer, particularmente en el caso de los países de América Latina, donde este tipo de estudios es bastante reciente o muy escaso. Es menester profundizar el análisis sobre el particular con nuevos estudios que procuren investigar la desigualdad en la distribución a partir de la mejora de la información existente incorporando nuevas herramientas de análisis, como ajustes por subdeclaración de ingresos o datos de declaraciones juradas de impuestos.

Además de lo anterior, vale preguntarse qué caminos podrían seguirse a fin de atender con nuevas reformas a los sectores de altas ingresos en América Latina para que estos contribuyan con una mayor participación en la recaudación. Dicho de otro modo, restaría indagar sobre qué reformas tributarias aun están pendientes en la región para aumentar la recaudación y el alcance efectivo de los impuestos sobre los individuos de más altos ingresos, lo cual mejoraría el impacto distributivo de los sistemas tributarios de la región.

Estas dos preguntas ponen por delante un profundo debate en cuanto a la estructura y composición de aquellas medidas tributarias que pueden ser consideradas aun como una asignatura pendiente en esta materia y que básicamente hacen a la estructura de la imposición a la renta, a los patrimonios personales y a los gravámenes sobre herencias, donaciones y sucesiones.

- El fortalecimiento del Impuesto sobre la Renta de Personas Naturales debe recorrer dos caminos para poder tener un mayor peso en la recaudación. Por un lado, la consideración de todas las rentas que fluyen hacia el sujeto gravado dentro de la base gravable del tributo, sean éstas provenientes de la actividad laboral, empresarial, financiera o mixta. Es decir, es necesario profundizar y efectivizar la aplicación del principio de equidad horizontal en materia de bases imponibles de forma amplia y general. Por otra parte, la estructura y nivel de las tasas a ser aplicada en cada caso puede estar sujeta a distintas consideraciones. Mientras que algunos países han optado por una estructura de imposición dual (moderadamente progresiva para rentas del trabajo y proporcional, con una tasa reducida, para las rentas de capital), otros han mantenido una tasa única para el conjunto de todos los tipos de ingresos (aún cuando, en algunos casos, se hayan excluido a los intereses, dividendos y ganancias de capital de la base gravable del ISR y estén sujetos a un tratamiento particular).

- La capacidad de administrar eficientemente el tributo así como el impacto distributivo que se espera obtener a partir del mismo serán las variables que determinarán el uso de una u otra forma de imposición. El esquema dual, adoptado recientemente por algunos de los países de la región como Uruguay, Perú y la mayoría de los centroamericanos, constituye una "etapa intermedia" entre el "punto de partida" que constituye la deteriorada situación del ISR personal y un "destino final" representado por un esquema global de imposición sobre los ingresos donde, además de las ganancias recaudatorias que exige una reforma gradual del tributo, el principio de equidad horizontal quede efectivamente plasmado. Es decir que, al menos en lo que respecta a la inclusión de las rentas (y a las ganancias) de capital dentro de los alcances impositivos del ISR, el sistema dual puede representar un 1 avance concreto para derribar las fuertes barreras político-económicas que encuentra la generalización del gravamen en muchos de los países de América Latina. 
- Debe considerase que el desarrollo de los procesos informáticos y el manejo de grandes bases de datos, sumados a los sistemas de retención en la fuente permiten actualmente un diseño tributario que estaba fuera del alcance de las Administraciones Tributarias de América Latina hasta hace unas pocas décadas atrás. Sumado a ello, las posibilidades de intercambio de información entre países extiende aún más su ámbito de influencia y la frontera de posibilidades de fiscalización. Por lo tanto, la estructura de alícuotas más conveniente para cada país no debería estar condicionada exclusivamente por las cuestiones administrativas sino que debiera ser el resultado de un intercambio entre los distintos sectores que intervienen en un proceso de reforma tributaria.

- A la vista de los resultados alcanzados, resulta evidente la necesidad de reducir en algunos países el umbral mínimo de exención del ISR personal hasta niveles inferiores o al menos en línea con el PIB per cápita de cada uno de ellos, lo cual ampliaría la base del tributo e incorporaría a un numeroso grupo de contribuyentes de clase media alta al ámbito de alcance del mismo. Algo similar se puede decir del nivel de ingreso al cual comienza a operar la tasa máxima (threshold), cuya modificación puede conducir a ganancias en términos de progresividad. Asimismo, esto puede estar acompañado por una eliminación o disminución en el nivel de aquellas deducciones permitidas cuyo valor es creciente de acuerdo al nivel de ingreso (por ejemplo, por los intereses de hipotecas inmobiliarias).

- Con el fin de mantener el carácter personal del Impuesto sobre la Renta se deberá enfatizar la estructura familiar del contribuyente así como otras características personales en el diseño específico del tributo. Dar un reconocimiento a estos elementos resulta esencial ya que constituyen determinantes centrales tanto de su capacidad recaudatoria como de la incidencia progresiva que debe prevalecer en el gravamen. En décadas pasadas, argumentando motivos de simplificación administrativa, muchos países eliminaron estas consideraciones personales sin tener en cuenta (o despreciando el hecho de) que esto implicaba la erosión de los rasgos básicos de la tributación sobre los ingresos de las personas naturales. Por otra parte, debe reconocerse que los datos de recaudación del ISR personal así como las tasas de evasión estimadas de ninguna manera demuestran que esta orientación haya sido la correcta ni que las Administraciones Tributarias hayan tenido un mayor éxito en lograr un mejor cumplimiento tributario del mismo.

- De igual modo se considera conveniente incorporar en el tratamiento de las rentas regulares que aquellas obtenidas por las personas físicas sean complementadas con la imposición de las ganancias de capital proveniente de incrementos patrimoniales y que fluyen de manera esporádica. En cuanto al tratamiento de estas rentas en cabeza de las empresas no es necesario hacer distinción ya que se da por asumido que las mismas han de tributar de igual manera sobre todas sus rentas sin distinción entre el carácter regular o esporádico de las mismas. Dado que las ganancias de capital se exteriorizan en un momento de tiempo determinado pero son, a su vez, el resultado de un proceso de devengamiento que puede involucrar varios años, se considera que una tasa proporcional, cuyo nivel esté relacionado con el promedio de las rentas regulares, resulta ser más equitativo que una tasa progresiva.

- Como parte del proceso de fortalecimiento de la imposición sobre los sujetos de altos ingresos, y consiguientemente de grandes patrimonios, los países de la región deberán realizar un gran esfuerzo para revalorizar el rol de la tributación patrimonial como fuente de recursos. En la gran mayoría de los casos los problemas son los mismos y, por ende, se aplican con cierta generalidad recomendaciones tales como la ampliación de la base gravable (eliminando exenciones y tratamientos especiales), el aumento de alícuotas y la modernización de los catastros patrimoniales y de la administración tributaria.

- Como fuera señalado, este tipo de tributación comprende una amplia gama de impuestos. Sin embargo, y a pesar de los magros ingresos tributarios que aportan en los países de la región, algunos de ellos resultan de especial interés para los objetivos de este trabajo en virtud de las posibilidades que brindan para aplicar impuestos con un impacto distributivo progresivo - que 
complementen los efectos derivados de la imposición sobre la renta personal一, cuya carga impositiva recaiga con mayor peso relativo (y alcance de manera efectiva) sobre los individuos de rentas más elevadas. En particular, se destacan los impuestos recurrentes sobre la propiedad y/o posesión de bienes inmuebles, el impuesto a la transferencia de bienes inmuebles entre vivos (donaciones) o mortis causa (herencias y sucesiones), el impuesto a la propiedad de los vehículos automotores (donde podrían introducirse alícuotas especiales a los rodados "de lujo"), y el poco difundido impuesto recurrente sobre el patrimonio o activo neto.

- De igual modo, en pos de la equidad que debe prevalecer en el sistema tributario, deberá considerarse la aplicación de un gravamen sobre la transmisión gratuita de bienes (donaciones, legados y herencias). Ya sea como tributo nacional (Chile, Ecuador, Uruguay, entre otros) o subnacional (Brasil y Argentina) la relevancia de este tipo de imposición (vigente en la mayoría de los países desarrollados) no está dada por su generalmente magro resultado recaudatorio sino por sus bajos costos de eficiencia y su incidencia claramente progresiva sobre la distribución del ingreso. Para ello, es fundamental procurar un diseño del gravamen de carácter personal y global con mínimas exenciones. 


\section{Bibliografía}

Ahumada, H., Canavese, A., Gasparini, L., Porto, A. y Sanguinetti, P. (1996): "Impacto distributivo y progresividad de la política fiscal” Documentos de Investigación Instituto Torcuato Di Tella.

Agosin, M., Barreix, A., Machado, R. (2005), "Recaudar para crecer: bases para la reforma tributaria en Centroamérica", Washington, D.C., Banco Interamericano de Desarrollo (BID).

Alvaredo, F. (2007): "The Rich in Argentina over the Twentieth Century. From the conservative republic to the Peronist experience and beyond1932-2004". Working Paper 200702, Paris-Jourdan Sciences Economiques. (2010a), "A Note on the Relationship between Top Income Shares and the Gini Coefficient" Discussion Paper No. 8071, Centre for Economic Policy Research, UK.

(2010b): "The Rich in Argentina over the Twentieth Century, 1932-2004." En Top Incomes: A Global Perspective, ed. Anthony B. Atkinson and Thomas Piketty, 253-98. Oxford and New York: Oxford University Press.

Alvaredo, F. y Londoño, J. (2013): "High Incomes and Personal Taxation in a Developing Economy: Colombia 1993-2010", Working Paper No. 12, Commitment to Equity Project, Center for InterAmerican Policy and Research, Tulane University.

Alvaredo, F., Atkinson, A., Piketty, T. y Saez, E.: "The World Top Incomes Database, online en http://gmond.parisschoolofeconomics.eu/topincomes/.

Álvarez Estrada, D. (2009), "Tributación directa en América Latina, equidad y desafíos. Estudio del caso de México", Serie Macroeconomía del Desarrollo 91, CEPAL, Santiago de Chile.

Arias Minaya, L.A. (2009), "La tributación directa en América Latina, equidad y desafíos. El caso de Perú", Serie Macroeconomía del Desarrollo 95, CEPAL, Santiago de Chile.

Artana, D. y Templado, I. (2010): "Is Argentina Tax Revenue Effort Too High?" Documento de Trabajo $\mathrm{N}^{\circ} 106$ FIEL.

Atkinson, A. (1970) "On the Measurement of Inequality" Journal of Economic Theory, September. (2007a): "The Distribution of Top Incomes in the United Kingdom 1908-2000." En "Top Incomes over the Twentieth Century: A Contrast between Continental European and English-Speaking Countries", ed. Anthony B. Atkinson y Thomas Piketty, 82-140. Oxford and New York: Oxford University Press.

(2007b): "Measuring Top Incomes: Methodological Issues." En "Top Incomes over the Twentieth Century: A Contrast between Continental European and English-Speaking Countries", ed. Anthony B. Atkinson y Thomas Piketty, 18-42. Oxford and New York: Oxford University Press. 
Atkinson, A., y Piketty, T. (eds.) (2007): "Top Incomes over the Twentieth Century: A Contrast between Continental European and English-Speaking Countries". Oxford and New York: Oxford University Press. (eds.) (2010): “Top Incomes: A Global Perspective". Oxford and New York: Oxford University Press.

Atkinson, A., Piketty, T. y Saez, E. (2010): “Top Incomes in the Long Run of History.” En "Top Incomes: A Global Perspective", (ed.) Anthony B. Atkinson and Thomas Piketty, 664-759.Oxford and New York: Oxford University Press.

Atkinson. A. B., Piketty, T. y Saez, E, (2011): "Top Incomes in the Long Run of History" Journal of Economic Literature, 49, 1; 3-71.

Banco Mundial: "Argentine the Surfacing of Argentine's Poor, a Profile”, 1994.

Barreix, A., C. Garcimartín y F. Velayos (2012), "El impuesto sobre la renta personal: un cascarón vaciado", Desarrollo en las Américas (DIA): El futuro de los impuestos en América Latina y el Caribe, Washington, D.C., Banco Interamericano de Desarrollo (BID), en prensa.

Barreix, A., Bes, M. y Roca, J. (2009): "Equidad fiscal en Centroamérica, Panamá y República Dominicana", BID-Eurosocial.

Barreix, A. y Roca J. (2007), "Reforzando un pilar fiscal: el impuesto a la renta dual a la uruguaya". Revista CEPAL No 92, agosto.

Barreix, A., Roca, J. y Villela, L. (2006): "La equidad fiscal en los países andinos", BID-Eurosocial. (2010): "Equidad fiscal en Brasil, Chile, Paraguay y Uruguay", BID-Eurosocial.

Bourguignon, F, y Morrisson, C. (2002): "Inequality among World Citizens: 1820-1990." American Economic Review, 92(4): 727-44.

Burkhauser, R., Feng, S., Jenkins, S. y Larrimore, J. (2009): "Recent Trends in Top Income Shares in the USA: Reconciling Estimates from March CPS and IRS Tax Return Data" National Bureau of Economic Research Working Paper 15320.

Cabrera, M. (2009): "La tributación directa en América Latina, equidad y desafíos: El caso de Guatemala", Serie Macroeconomía del Desarrollo 89, CEPAL, Santiago de Chile.

Cabrera, M. y Guzmán, V. (2009), "La tributación directa en América Latina, equidad y desafíos: El caso de El Salvador", Serie Macroeconomía del Desarrollo 87, CEPAL, Santiago de Chile.

Camelo, H. (1998): "Subdeclaración de ingresos medios en la encuesta de hogares", Segundo Taller Regional de Medición del Ingreso en las Encuestas de Hogares, MECOVI-CEPAL-INDEC, Buenos Aires.

Carbajo Vasco, D. (2013): “La tributación de las rentas del capital en América Latina”, Documento GIZITC-CIAT.

CEPAL (2013): "Panorama fiscal de América Latina. Reformas tributarias y renovación del pacto fiscal".

Cetrángolo, O. y Gómez Sabaíni, J. C. (2007): "Política tributaria en Argentina. Entre la solvencia y la emergencia”, Serie Estudios y perspectivas $N^{\circ} 38$, Oficina de la CEPAL en Buenos Aires. (2007) "La tributación directa en América Latina y los desafíos a la imposición sobre la renta", Serie Macroeconomía del Desarrollo 60, CEPAL, Santiago de Chile. (2009): "La imposición en Argentina: un análisis de la imposición a la renta, los patrimonios y otros tributos considerados directos" Serie Macroeconomía del Desarrollo N 84, CEPAL GTZ.

CIAT (2013): “Tributación de las rentas del capital, y tratamiento tributario y el control de las instituciones financieras en América Latina" Series Comparativas $\mathrm{N}^{\mathrm{0}} 1$.

Corbacho, A., Fretes Cibils, V. y Lora, E. (eds.) (2012): "Recaudar no basta. Los impuestos como instrumento de desarrollo", Banco Interamericano de Desarrollo.

Cowell, F. (1995): "Measuring inequality", LSE Handbooks in Economic Series, Prentice Hall/Harvester Wheatsheaf.

Davoodi, H. and G. Grigorian (2007): “Tax Potential vs. Tax Effort: A Cross-Country Analysis of Armenia's Stubbornly Low Tax Collection". IMF Working Paper $\mathrm{N}^{\circ} 106$.

De Cesare, C y Lazo Martín, J.F. (2008); "Impuestos a los Patrimonios en América Latina", Serie Macroeconomía del Desarrollo No 66, CEPAL, Santiago de Chile, mayo.

De Ferranti, D., Perry, G. y otros (2003): "Inequality In Latin America And The Caribbean: Breaking With History?" World Bank Latin American And Caribbean Studies.

Di Gresia, L. (2000): “Estimación de la evasión del impuesto a las ganancias de personas físicas”, en FIEL, "La economía oculta en la Argentina".

Engel, E.; Galetovic, A. y Raddatz, C. (1999): “Taxes and Income Distribution in Chile: an Unpleasant Redistributive Arithmetic", NBER 10th Annual Inter-American Seminar on Economics, Chile. 
Feenberg, D., y Poterba, J. (1993): "Income Inequality and the Incomes of Very High- Income Taxpayers: Evidence from Tax Returns." En Tax Policy and the Economy", Volume 7, James M. Poterba (ed.), 145-77. Cambridge and London: MIT Press.

Feres, J. (1996): "La medición de los ingresos en la encuesta CASEN-1996" Segundo Taller Regional de Medición del Ingreso en las Encuestas de Hogares, MECOVI-CEPAL-INDEC, Buenos Aires.

Ferreira, F. y Ravallion, M. (2008): "Global poverty and inequality : a review of the evidence," Policy Research Working Paper Series 4623, The World Bank.

Friedman, J. y Hofman, A. (2013): "Inequality and the Top of the Income Distribution in Chile 1990-2012: Questioning the Consensus", mimeo.

Gaggero, J. y Rossignolo, D. (2011): "Impacto del presupuesto sobre la equidad. Cuadro de situación, Argentina 2010" Documento de Trabajo N 40, CEFID-AR.

Gasparini, L., (1998): “Incidencia distributiva del sistema impositivo argentino", en "La reforma tributaria en la Argentina", Fundación de Investigaciones Económicas Latinoamericanas.

Gasparini, L, Cicowiez, M. y Sosa Escudero, W. (2013): "Pobreza y desigualdad en América Latina. Conceptos, herramientas y aplicaciones" CEDLAS, Editorial Temas.

Gasparini, L., Cruces, G, Tornarolli, L. y Marchionni, M. (2009): "A Turning Point? Recent Developments on Inequality in Latin America and the Caribbean" CEDLAS Working Papers 0081, CEDLAS, Universidad Nacional de La Plata.

Gasparini, L. y Lustig, N. (2011): "The Rise and Fall of Income Inequality in Latin America," CEDLAS, Working Papers 0118, CEDLAS, Universidad Nacional de La Plata.

Gasparini, L. y Porto, A. (1992): "Impacto distributivo del gasto público social”. Desarrollo Económico № 110, Volumen 31, enero-marzo 1992.

Goñi, E., Lopez, H., Servén, L., (2008): "Fiscal Redistribution and Income Inequality in Latin America" Policy Research Working Paper WPS4487, Banco Mundial.

Gómez Sabaíni, J. C. (2005): “La tributación a la renta en el Istmo Centroamericano: análisis comparativo y agenda de reformas”, CEPAL-GTZ, Serie Macroeconomía del Desarrollo, N³7.

Gómez Sabaíni, J. (2006): “Cohesión social, equidad y tributación. Análisis y perspectivas para América Latina", CEPAL, Serie Políticas sociales N 127.

Gómez Sabaíni, J., Harriague, M. y Rossignolo, D. (2011): “Argentina. La situación fiscal y los efectos en la distribución del ingreso". Informe elaborado a solicitud de la División de Gestión Fiscal y Municipal del Banco Interamericano de Desarrollo, Washington DC; Serie de Estudios sobre Equidad Fiscal en América Latina EUROSOCIAL - BID (en prensa).

Gómez Sabaíni, J., y Jiménez, J. P. (2011): "Estructura tributaria y evasión impositiva en América Latina" Documento de trabajo 2011/08, Corporación Andina de Fomento.

Gómez Sabaíni, J., Jiménez, J. P. y Podestá, A. (comp.) (2010): “Evasión y equidad en América Latina”, CEPAL-GTZ.

Gómez Sabaíni, J., Jiménez, J. P. y Rossignolo, D. (2012): "Imposición a la Renta Personal y equidad en América Latina. Nuevos desafíos”. CEPAL, Serie Macroeconomía del Desarrollo № 119 (abril 2012).

Gómez Sabaíni, J.C. y Morán, D. (2013); “Política tributaria en América Latina: agenda para una segunda generación de reformas", Serie Macroeconomía del desarrollo 133, CEPAL, Santiago de Chile, junio.

Gómez Sabaíni, J. y Rossignolo, D. (2009): “Argentina. Análisis de la situación tributaria y propuestas de reformas impositivas destinadas a mejorar la distribución del ingreso", en S. Keifman: "Reflexiones y propuestas para mejorar la distribución del ingreso en Argentina", Oficina de la Organización Internacional del Trabajo en Buenos Aires.

Gómez Sabaíni, J., y Rossignolo, D. (2011): "Impacto de las políticas tributarias sobre la equidad en países de América Latina”, en J. Nun (comp.): "La desigualdad y los impuestos Tomo II. Materiales para la discusión", Colección Claves para Todos, Editorial Capital Intelectual.

González, D. (2009): "La política tributaria heterodoxa en los países de América Latina", Instituto Latinoamericano y del Caribe de Planificación Económica y Social. CEPAL.

Grosskoff, R. (1996): “Comparación de las estadísticas de ingresos provenientes de encuestas de hogares con estimaciones externas”, Segundo Taller Regional de Medición del Ingreso en las Encuestas de Hogares, MECOVI-CEPAL-INDEC, Buenos Aires.

Grown, C. (2010): "Taxation and Gender Equality", in Grown, C. and Valodia, I. (2010): "Taxation and Gender Equity: A Comparative Analysis of Direct and Indirect Taxes in Developing and Developed Countries", Routledge International Studies in Money and Banking. 
Herschel, F.J y colaboradores (1963): "Política Fiscal en la Argentina", Programa Conjunto de Tributación OEA/BID, edit. Consejo Nacional de Desarrollo, Buenos Aires (Vol. VI).

IDLA "Income Distribution in Latin America", UNU-WIDER Database, disponible en: http://www.wider.unu.edu/research/current-programme/en_GB/Impact-of-Economic-Crisis.

Instituto Nacional de Estadística-CEPAL (1996): "Evaluación de la captación del ingreso de los hogares", en “Aspectos metodológicos sobre medición de la línea de pobreza: el caso uruguayo". Documentos y Resumen Ejecutivo del Taller Regional de Expertos sobre Medición de la Línea de Pobreza en Uruguay.

Jiménez, J. P., Gómez Sabaíni, J. C., y Podestá, A. (2010): “Tax gap and equity in Latin America and the Caribbean" Fiscal Studies No. 16 Public Finance and Administrative Reform Studies ECLAC-GTZ.

Jiménez J.P. y Podestá A. (2009) “Inversión, incentivos fiscales y gastos tributarios en América Latina”. Serie Macroeconomía del Desarrollo No 77, CEPAL, Santiago de Chile.

Jiménez, J. P. y Solimano, A. (2012): “Elites económicas, desigualdad y tributación”, CEPAL, Serie Macroeconomía del Desarrollo $\mathrm{N}^{\mathrm{O}} 126$.

Jorratt, M. (2009), "La tributación directa en Chile: equidad y desafíos", Serie Macroeconomía del Desarrollo 92, CEPAL, Santiago de Chile.

(2010): "Equidad Fiscal en Chile: Un Análisis de la Incidencia Distributiva de los Impuestos y el Gasto Social", BID-Eurosocial.

Jorratt, M. (2012): “Gastos Tributarios y Evasión Tributaria en Chile: Evaluación y Propuestas”, mimeo.

Kiefer, D. W. (1984) "Distributional Tax Progressivity Indices," National Tax Journal 37, 497-513.

Lambert, P. (1993): "The Distribution and Redistribution of Income” Manchester University Press.

Llach, J. J., y Montoya, S. (1999): "En pos de la equidad. La pobreza y la distribución del ingreso en el Area Metropolitana de Buenos Aires: diagnóstico y políticas”. IERAL, Fundación Mediterránea.

Lódola, A. y Velasco, P. (2011); “El Impuesto a la Transmisión Gratuita de Bienes. Su reincorporación en la Provincia como instrumento eficiente en la búsqueda de la igualdad de oportunidades", Cuadernos de Economía No 78 Ministerio de Economía de la Provincia de Buenos Aires, La Plata, agosto.

López, R., Figueroa, E. y Gutiérrez, P. (2013): “La ‘parte del león’: Nuevas estimaciones de la participación de los súper ricos en el ingreso de Chile”, Serie Documentos de Trabajo N ${ }^{0} 379$, Facultad de Economía y Negocios, Departamento de Economía, Universidad de Chile.

López-Calva, L. y Lustig, N. (2010); "Explaining the Decline in Inequality in Latin America: Technological Change, Educational Upgrading and Democracy" in López-Calva, L. y Lustig, N. (eds.), "Declining Inequality in Latin America: a Decade of Progress?” Brookings Institution Press and UNDP. (2010): "Declining Latin American inequality: Market forces or state action?" mimeo.

Martínez Vázquez, J., Vulovic, V. y Dodson, B. (2012): “The Impact of Tax and Expenditure Policies on Income Distribution: Evidence from a Large Panel of Countries" Review of Public Economics, 200(4/2012): 95-130, Instituto de Estudios Fiscales.

Palma, G. (2011): "Homogeneous middles vs. heterogeneous tails, and the end of the 'Inverted-U': the share of the rich is what it's all about", Cambridge Working Papers in Economics 1111.

Perry, G., O. Arias, H. Lopez, W. Maloney y L. Serven (2006): "Poverty reduction and growth: virtuous and vicious circles", The World Bank.

Pessino, C. y Fenocchietto, R. (2010): “Determining Countries” Tax Effort” Revista de Economía Pública 195-4/2010, Instituto de Estudios Fiscales Hacienda Pública Española.

Piketty, T. (2003): 'Income Inequality in France, 1901-1998', JPE, 111(6).

Piketty, T. y Sáez, E. (2003): 'Income Inequality in the United States, 1913-1998', QJE, 118(1). (2013): “Optimal Labor Income Taxation” Working Paper 18521, National Bureau of Economic Research.

Piketty, T., Sáez, E. y Stantcheva, S. (2011): “Optimal Taxation of Top Labor Incomes: A Tale of Three Elasticities" Working Paper 17616, National Bureau of Economic Research.

Porporatto, P. (2013): "Estudio sobre el tratamiento tributario y el control de las instituciones financieras en América Latina", Documento GIZ-ITC-CIAT.

Rezende, F. y J. Afonso (2010), "Equidade fiscal no Brasil”, Equidad fiscal en Brasil, Chile, Paraguay y Uruguay, Banco Interamericano de Desarrollo (BID)/EUROsociAL.

Roca, J. (2009): “Tributación directa en Ecuador. Evasión, equidad y desafíos de diseño", CEPAL, Serie Macroeconomía del desarrollo $\mathrm{N}^{0} 85$.

(2010): "Equidad fiscal en Uruguay" BID-Eurosocial. 
Rodríguez Enríquez, C., Gherardi, N. y Rossignolo D. (2010): “Gender Equality and Taxation: The Argentine Case", en C. Grown, e I. Valodia. op. cit.

Romano, A. (2008); “La Reforma Tributaria en Uruguay. Un Proceso hacia la Equidad”, presentado en el XXI Seminario Regional de Política Fiscal, en Santiago de Chile, enero 2009.

Rossignolo, D. (2012): "Estimación de la recaudación potencial del Impuesto a la Renta en América Latina”, CEPAL, Serie Macroeconomía del Desarrollo $N^{\circ} 120$

Saez, E. (2013): "Striking it Richer: The Evolution of Top Incomes in the United States (Updated with 2011 estimates)", mimeo.

Santiere, J. J., Gómez Sabaíni, J. C. (2000): "Los impuestos y la distribución del ingreso en la Argentina”, PNUD, Eudeba.

Santiere, J. J., Gómez Sabaíni, J. C., Rossignolo, Darío A. (2000): "Impacto de los impuestos sobre la distribución del ingreso en Argentina en 1997”, Banco Mundial.

SEDLAC (2010): Socio-Economic Database for Latin America and the Caribbean.

Sepúlveda, C. y Martínez-Vázquez, J. (2010); "Explaining Property Tax Collections in Developing Countries: The Case of Latin America", CEPAL, Santiago de Chile.

Stotsky, J. y WoldeMariam, A. (1997): "Tax Effort in the Sub-Saharan Africa”, International Monetary Fund, Working Paper WP/97/107.

Stotsky, J. and A. WoldeMariam, A. (2002); “Central American Tax Reform: Trends and Possibilities," IMF Working Paper WP/02/227.

USAID (2011); “Collecting Taxes Database 2009-2010”, Fiscal Reform and Economic Governance Project.

Villela L., Lemgruber, A. y Jorrat, M. (2010): “Tax Expenditure Budgets Concepts and Challenges for Implementation", IDB Working Paper \# IDB-WP-179. 



\section{Anexo}


CUADRO A.1

EVOLUCIÓN DE LAS TASAS MARGINALES MÍNIMAS, PAÍSES Y AÑOS SELECCIONADOS DE AMÉRICA LATINA

(En porcentajes)

\begin{tabular}{|c|c|c|c|c|c|c|c|c|c|c|c|c|}
\hline \multirow{2}{*}{ América Latina } & \multicolumn{12}{|c|}{ Tasa marginal mínima } \\
\hline & 1991 & 1996 & 1997 & 1998 & 1999 & 2000 & 2006 & 2007 & 2008 & 2009 & 2010 & 2011 \\
\hline Argentina & 15,0 & 15,0 & 6,0 & 6,0 & 9,0 & 9,0 & 9,0 & 9,0 & 9,0 & 9,0 & 9,0 & 9,0 \\
\hline $\begin{array}{l}\text { Bolivia (Estado } \\
\text { Plurinacional de) }\end{array}$ & 10,0 & 10,0 & 13,0 & 13,0 & 13,0 & 13,0 & 13,0 & 13,0 & 13,0 & 13,0 & 13,0 & 13,0 \\
\hline Brasil & 10,0 & 10,0 & 15,0 & 15,0 & 15,0 & 15,0 & 15,0 & 15,0 & 15,0 & 15,0 & 7,5 & 7,5 \\
\hline Chile & 5,0 & 5,0 & 5,0 & 5,0 & 5,0 & 5,0 & 5,0 & 5,0 & 5,0 & 5,0 & 5,0 & 5,0 \\
\hline Colombia & 5,0 & 5,0 & 35,0 & 35,0 & 35,0 & 35,0 & 0,3 & 19,0 & 19,0 & 19,0 & 19,0 & 19,0 \\
\hline Costa Rica & 10,0 & 10,0 & 10,0 & 10,0 & 10,0 & 10,0 & 10,0 & 10,0 & 10,0 & 10,0 & 10,0 & 10,0 \\
\hline $\begin{array}{l}\text { República } \\
\text { Dominicana }\end{array}$ & 3,0 & 3,0 & 3,0 & 0,0 & 0,0 & 0,0 & 15,0 & 15,0 & 15,0 & 15,0 & 15,0 & 15,0 \\
\hline Ecuador & 10,0 & 10,0 & 10,0 & 10,0 & 0,0 & 0,0 & 5,0 & 5,0 & 5,0 & 5,0 & 5,0 & 5,0 \\
\hline EI Salvador & 10,0 & 10,0 & 10,0 & 10,0 & 10,0 & 10,0 & 10,0 & 10,0 & 10,0 & 10,0 & 10,0 & 10,0 \\
\hline Guatemala & 4,0 & 4,0 & 15,0 & 15,0 & 15,0 & 15,0 & 15,0 & 15,0 & 15,0 & 15,0 & 15,0 & 15,0 \\
\hline Honduras & 12,0 & 12,0 & 9,0 & 10,0 & 10,0 & 10,0 & 10,0 & 10,0 & 10,0 & 15,0 & 15,0 & 15,0 \\
\hline México & 3,0 & 3,0 & 3,0 & 3,0 & 3,0 & 3,0 & 3,0 & 3,0 & 3,0 & 1,9 & 1,9 & 1,9 \\
\hline Nicaragua & 8,0 & 8,0 & 10,0 & 10,0 & 10,0 & 10,0 & 10,0 & 10,0 & 10,0 & 10,0 & 10,0 & 10,0 \\
\hline Panamá & 4,0 & 4,0 & 4,0 & 4,0 & 2,0 & 2,0 & 4,0 & 4,0 & 4,0 & 4,0 & 4,0 & 4,0 \\
\hline Paraguay & 0,0 & 0,0 & 0,0 & 0,0 & 0,0 & 0,0 & 0,0 & 0,0 & 0,0 & 0,0 & 0,0 & 0,0 \\
\hline Perú & 6,0 & 6,0 & 15,0 & 15,0 & 15,0 & 15,0 & 15,0 & 15,0 & 15,0 & 15,0 & 15,0 & 15,0 \\
\hline Uruguay & 0,0 & 0,0 & 0,0 & 0,0 & 0,0 & 0,0 & 0,0 & 0,0 & 0,0 & 10,0 & 10,0 & 10,0 \\
\hline $\begin{array}{l}\text { Venezuela } \\
\text { (República } \\
\text { Bolivariana de) }\end{array}$ & 10,0 & 10,0 & 6,0 & 6,0 & 6,0 & 6,0 & 6,0 & 6,0 & 6,0 & 6,0 & 6,0 & 6,0 \\
\hline $\begin{array}{l}\text { Promedio no } \\
\text { ponderado }\end{array}$ & 6,9 & 6,9 & 9,4 & 9,3 & 8,8 & 8,8 & 8,1 & 9,1 & 9,1 & 9,9 & 9,5 & 9,5 \\
\hline
\end{tabular}

Fuente: Elaboración propia en base a CIAT y CEPALSTAT.

CUADRO A.2

EVOLUCIÓN DE LAS TASAS MARGINALES MÁXIMAS, PAÍSES Y AÑOS SELECCIONADOS DE AMÉRICA LATINA

(En porcentajes)

\begin{tabular}{lcccccccccccc}
\hline \multirow{2}{*}{ América Latina } & \multicolumn{10}{c}{ Tasa marginal máxima } \\
\cline { 2 - 12 } & 1991 & 1996 & 1997 & 1998 & 1999 & 2000 & 2006 & 2007 & 2008 & 2009 & 2010 & 2011 \\
\hline Argentina & 30,0 & 30,0 & 33,0 & 35,0 & 35,0 & 35,0 & 35,0 & 35,0 & 35,0 & 35,0 & 35,0 & 35,0 \\
Bolivia (Estado & 10,0 & 10,0 & 13,0 & 13,0 & 13,0 & 13,0 & 13,0 & 13,0 & 13,0 & 13,0 & 13,0 & 13,0 \\
Plurinacional de) & & & & & & & & & & & & \\
Brasil & 25,0 & 25,0 & 25,0 & 25,0 & 27,5 & 27,5 & 27,5 & 27,5 & 27,5 & 27,5 & 27,5 & 27,5 \\
Chile & 50,0 & 50,0 & 45,0 & 45,0 & 45,0 & 45,0 & 40,0 & 40,0 & 40,0 & 40,0 & 40,0 & 40,0 \\
Colombia & 30,0 & 30,0 & 35,0 & 35,0 & 35,0 & 35,0 & 22,1 & 33,0 & 33,0 & 33,0 & 33,0 & 33,0 \\
Costa Rica & 25,0 & 25,0 & 25,0 & 25,0 & 25,0 & 25,0 & 25,0 & 25,0 & 25,0 & 25,0 & 25,0 & 25,0 \\
República & 70,0 & 70,0 & 70,0 & 25,0 & 25,0 & 25,0 & 30,0 & 29,0 & 25,0 & 25,0 & 25,0 & 25,0 \\
Dominicana & 25,0 & 25,0 & 25,0 & 25,0 & 15,0 & 15,0 & 25,0 & 25,0 & 25,0 & 35,0 & 35,0 & 35,0 \\
Ecuador & 30,0 & 30,0 & 30,0 & 30,0 & 30,0 & 30,0 & 30,0 & 30,0 & 30,0 & 30,0 & 30,0 & 30,0 \\
El Salvador & & & & & & & & & & &
\end{tabular}




\begin{tabular}{|c|c|c|c|c|c|c|c|c|c|c|c|c|}
\hline \multicolumn{13}{|c|}{ Cuadro A.2 (conclusión) } \\
\hline \multirow{2}{*}{ América Latina } & \multicolumn{12}{|c|}{ Tasa marginal máxima } \\
\hline & 1991 & 1996 & 1997 & 1998 & 1999 & 2000 & 2006 & 2007 & 2008 & 2009 & 2010 & 2011 \\
\hline Guatemala & 34,0 & 34,0 & 30,0 & 25,0 & 25,0 & 25,0 & 31,0 & 31,0 & 31,0 & 31,0 & 31,0 & 31,0 \\
\hline Honduras & 40,0 & 40,0 & 40,0 & 30,0 & 25,0 & 25,0 & 25,0 & 25,0 & 25,0 & 25,0 & 25,0 & 25,0 \\
\hline México & 35,0 & 35,0 & 35,0 & 40,0 & 40,0 & 40,0 & 29,0 & 28,0 & 28,0 & 28,0 & 30,0 & 30,0 \\
\hline Nicaragua & 35,5 & 35,5 & 30,0 & 30,0 & 30,0 & 30,0 & 30,0 & 30,0 & 30,0 & 30,0 & 30,0 & 30,0 \\
\hline Panamá & 56,0 & 56,0 & 30,0 & 30,0 & 30,0 & 30,0 & 30,0 & 30,0 & 30,0 & 30,0 & 30,0 & 30,0 \\
\hline Paraguay & 0,0 & 0,0 & 0,0 & 0,0 & 0,0 & 0,0 & 0,0 & 0,0 & 0,0 & 0,0 & 0,0 & 0,0 \\
\hline Perú & 37,0 & 37,0 & 30,0 & 30,0 & 30,0 & 30,0 & 30,0 & 30,0 & 30,0 & 30,0 & 30,0 & 30,0 \\
\hline Uruguay & 0,0 & 0,0 & 0,0 & 0,0 & 0,0 & 0,0 & 0,0 & 0,0 & 0,0 & 25,0 & 25,0 & 25,0 \\
\hline $\begin{array}{l}\text { Venezuela } \\
\text { (República } \\
\text { Bolivariana de) }\end{array}$ & 30,0 & 30,0 & 34,0 & 34,0 & 34,0 & 34,0 & 34,0 & 34,0 & 34,0 & 34,0 & 34,0 & 34,0 \\
\hline $\begin{array}{l}\text { Promedio no } \\
\text { ponderado }\end{array}$ & 31,3 & 31,3 & 29,4 & 26,5 & 25,8 & 25,8 & 25,4 & 25,9 & 25,6 & 27,6 & 27,7 & 27,7 \\
\hline
\end{tabular}

Fuente: Elaboración propia en base a CIAT y CEPALSTAT.

\section{CUADRO A.3 \\ EVOLUCIÓN DE LOS NIVELES DE INGRESO GRAVABLE MÁXIMOS, AMÉRICA LATINA, PAÍSES Y PERÍODOS SELECCIONADOS}

(En múltiplos del ingreso per cápita)

\begin{tabular}{|c|c|c|c|c|c|c|c|c|c|c|c|}
\hline \multirow{2}{*}{ América Latina } & \multicolumn{11}{|c|}{ Ingreso gravable máximo } \\
\hline & 1991 & 1997 & 1998 & 1999 & 2000 & 2001 & 2007 & 2008 & 2009 & 2010 & 2011 \\
\hline Argentina & 13,70 & 14,50 & 14,40 & 25,50 & 15,50 & 16,50 & 8,74 & 4,55 & 4,52 & 4,21 & 3,37 \\
\hline $\begin{array}{l}\text { Bolivia (Estado } \\
\text { Plurinacional de) }\end{array}$ & 0,50 & & & & & & & & & & 0,76 \\
\hline Brasil & 2,80 & 4,20 & 4,10 & 3,70 & 3,30 & 3,10 & 3,03 & 2,17 & 3,28 & 2,58 & 2,26 \\
\hline Chile & 22,60 & 1,30 & 1,30 & 1,20 & 1,20 & 1,20 & 13,64 & 14,08 & 12,08 & 12,45 & 10,95 \\
\hline Colombia & 25,30 & 12,00 & 12,00 & 13,10 & 11,70 & 16,60 & 10,07 & 9,45 & 9,81 & 3,66 & 3,41 \\
\hline Costa Rica & 5,30 & 5,60 & 5,40 & 3,10 & 4,10 & 3,70 & 0,22 & 2,34 & 1,69 & 0,25 & 0,23 \\
\hline $\begin{array}{l}\text { República } \\
\text { Dominicana }\end{array}$ & 74,30 & 34,30 & 8,40 & 7,30 & 6,50 & 5,80 & 4,89 & 1,00 & 11,09 & 3,72 & 2,79 \\
\hline Ecuador & 35,80 & 22,70 & 34,40 & 23,40 & 11,30 & 8,30 & 23,47 & 23,99 & 22,23 & 25,44 & 23,16 \\
\hline EI Salvador & 32,50 & 12,70 & 12,20 & 11,80 & 11,40 & 11,00 & 10,44 & 7,34 & 5,94 & 6,31 & 6,32 \\
\hline Guatemala & 31,70 & 17,50 & 16,00 & 15,60 & 14,70 & 22,50 & 13,89 & 16,87 & 14,61 & 13,44 & 12,77 \\
\hline Honduras & 686,60 & 103,40 & 88,80 & & 39,10 & 36,00 & 22,85 & 16,00 & 14,55 & 13,94 & 13,82 \\
\hline México & 11,70 & 5,00 & 5,30 & 44,20 & 36,80 & 44,00 & 4,65 & 4,08 & 0,94 & 3,90 & 3,59 \\
\hline Nicaragua & 9,90 & 47,40 & 44,40 & 33,90 & 49,90 & 63,20 & 33,41 & 28,83 & 25,59 & 22,72 & 20,78 \\
\hline Panamá & 97,80 & 63,10 & 61,10 & 59,90 & 58,90 & 57,80 & 6,27 & 5,15 & 4,42 & 4,32 & 3,95 \\
\hline Paraguay & & & & & & & 15,25 & 12,79 & 13,78 & 12,76 & 10,88 \\
\hline Perú & & 20,10 & 20,90 & 21,80 & 21,80 & 22,30 & 19,28 & 14,90 & 16,41 & 14,80 & 13,22 \\
\hline Uruguay & & & & & & & & 10,11 & 10,11 & 10,08 & 8,85 \\
\hline $\begin{array}{l}\text { Venezuela } \\
\text { (República } \\
\text { Bolivariana de) }\end{array}$ & & & & & & & & 9,23 & 14,49 & 15,94 & 11,25 \\
\hline $\begin{array}{l}\text { Promedio no } \\
\text { ponderado }\end{array}$ & 75,04 & 25,99 & 23,48 & 20,35 & 20,44 & 22,29 & 12,67 & 10,76 & 10,91 & 10,03 & 8,46 \\
\hline
\end{tabular}

Fuente: Elaboración propia en base a Stotsky y Woldemariam (2002) y USAID Collecting Taxes Database. 


\section{CUADRO A.4 \\ EVOLUCIÓN DE LOS NIVELES DE INGRESO GRAVABLE MÍNIMOS, AMÉRICA LATINA, PAÍSES Y PERÍODOS SELECCIONADOS}

\begin{tabular}{|c|c|c|c|c|c|c|c|c|c|c|c|c|}
\hline \multirow{2}{*}{ América Latina } & \multicolumn{12}{|c|}{ Ingreso gravable mínimo } \\
\hline & 1986 & 1991 & 1997 & 1998 & 1999 & 2000 & 2001 & 2007 & 2008 & 2009 & 2010 & 2011 \\
\hline Argentina & 0,8 & 0,50 & 1,20 & 1,20 & 1,30 & 1,30 & 1,40 & 0,55 & 0,34 & 0,32 & 0,30 & 0,28 \\
\hline $\begin{array}{l}\text { Bolivia (Estado } \\
\text { Plurinacional de) }\end{array}$ & 1,0 & 0,50 & & & & & & & & & & 0,76 \\
\hline Brasil & 0,3 & 1,20 & 2,10 & 2,00 & 1,80 & 1,70 & 1,50 & 1,52 & 1,09 & 1,31 & 1,03 & 0,90 \\
\hline Chile & 0,2 & 0,10 & 0,10 & 0,10 & 0,10 & 0,10 & 0,10 & 1,23 & 1,27 & 1,09 & 1,12 & 0,99 \\
\hline Colombia & 0,0 & 0,40 & 2,70 & 4,90 & 5,00 & 4,40 & 4,10 & & 2,51 & 2,61 & 0,97 & 0,91 \\
\hline Costa Rica & 1,2 & 2,90 & 1,10 & 1,10 & 0,60 & 0,80 & 0,80 & 0,15 & 0,47 & 1,12 & 0,17 & 0,15 \\
\hline República Dominicana & 1,1 & 0,20 & 0,10 & 3,40 & 2,90 & 2,60 & 2,30 & 2,35 & 1,00 & 0,00 & 0,74 & 0,56 \\
\hline Ecuador & 0,4 & 2,90 & 1,80 & 2,80 & 1,90 & 0,90 & 2,40 & 2,71 & 2,35 & 2,00 & 2,50 & 2,27 \\
\hline El Salvador & & 2,30 & 1,40 & 1,00 & 1,30 & 1,20 & 1,20 & 1,15 & 1,22 & 0,99 & 0,69 & 0,69 \\
\hline Guatemala & 0,9 & 2,30 & 6,30 & 5,80 & 5,60 & 5,30 & 5,00 & 3,06 & 1,83 & 1,59 & 0,46 & 0,43 \\
\hline Honduras & 0,0 & 6,90 & 5,20 & 4,40 & & 3,90 & 3,60 & 3,20 & 2,24 & 2,04 & 3,07 & 3,04 \\
\hline México & 0,7 & 0,20 & 0,10 & 0,10 & 0,10 & 0,10 & 0,10 & 0,07 & 0,07 & 0,05 & 0,90 & 0,08 \\
\hline Nicaragua & 1,7 & & 6,60 & 6,20 & 4,70 & 8,30 & 7,70 & 3,34 & 2,88 & 2,56 & 2,27 & 2,08 \\
\hline Panamá & 0,3 & 0,50 & 0,90 & 0,90 & 0,90 & 0,90 & 0,90 & 1,88 & 1,54 & 1,40 & 1,44 & 1,32 \\
\hline Paraguay & 0,5 & & & & & & & 0,00 & 10,23 & 11,02 & 10,21 & 8,70 \\
\hline Perú & & & 2,60 & 2,70 & 2,80 & 2,80 & 2,90 & 2,50 & 2,02 & 1,88 & 0,76 & 0,68 \\
\hline Uruguay & & & & & & & & & 0,71 & 0,71 & 0,71 & 0,62 \\
\hline $\begin{array}{l}\text { Venezuela (República } \\
\text { Bolivariana de) }\end{array}$ & & & & & & & & & 1,54 & 2,90 & 2,66 & 1,87 \\
\hline $\begin{array}{l}\text { Promedio no } \\
\text { ponderado }\end{array}$ & 0,7 & 1,61 & 2,30 & 2,61 & 2,23 & 2,45 & 2,43 & 1,69 & 1,96 & 1,98 & 1,76 & 1,46 \\
\hline
\end{tabular}

Fuente: Elaboración propia en base a Stotsky y Woldemariam (2002) y USAID Collecting Taxes Database.

\section{CUADRO A.5}

CHILE: TRATAMIENTO TRIBUTARIO DE LOS INTERESES

\begin{tabular}{|c|c|c|c|}
\hline $\begin{array}{l}\text { Tipo de } \\
\text { contribuyente }\end{array}$ & Impuesto & Alícuota & Franquicias tributarias \\
\hline $\begin{array}{l}\text { Personas } \\
\text { jurídicas }\end{array}$ & $\begin{array}{l}\text { Los contribuyentes del } \\
\text { impuesto de primera } \\
\text { categoría se encuentran } \\
\text { afectos a este impuesto } \\
\text { por los intereses } \\
\text { percibidos o devengados }\end{array}$ & $\begin{array}{l}17 \% \text { entre } 2004 \text { y } \\
2010 ; 20 \% \text { en } \\
2011 ; 18,5 \% \text { en } 2 \\
2012 ; 17 \% \text { en } \\
2013 \text { y siguientes }\end{array}$ & $\begin{array}{l}\text { Se exime a los contribuyentes del impuesto de primera } \\
\text { categoría (explotación de bienes raíces o la obtención de } \\
\text { rentas de capitales mobiliarios) }\end{array}$ \\
\hline $\begin{array}{l}\text { Personas } \\
\text { naturales }\end{array}$ & $\begin{array}{l}\text { Afectas al impuesto } \\
\text { global complementario } \\
\text { por estas rentas } \\
\text { percibidas o devengadas }\end{array}$ & $\begin{array}{l}\text { Alícuota de } \\
\text { estructura } \\
\text { progresiva con un } \\
\text { rango de } 0 \% \\
\text { a } 40 \%\end{array}$ & $\begin{array}{l}\text { Los pequeños contribuyentes y/o asalariados se eximen de } \\
\text { pagar por el conjunto de rentas de capitales mobiliarios } \\
\text { cuando no exceden de un máximo. Beneficia a los } \\
\text { contribuyentes del impuesto global complementario y los } \\
\text { del impuesto único de segunda categoría, siempre que el } \\
\text { instrumento de inversión califique dentro de los } \\
\text { contemplados por ley. Depósitos a plazo fijo a un año o } \\
\text { más. Depósitos a plazo fijo renovables a un año o más. } \\
\text { Cuentas de ahorro a plazo }\end{array}$ \\
\hline $\begin{array}{l}\text { Contribuyentes } \\
\text { sin domicilio o } \\
\text { residencia }\end{array}$ & $\begin{array}{l}\text { Afectos al impuesto } \\
\text { adicional }\end{array}$ & $\begin{array}{l}4 \% \text { o } 35 \% \text { si opera } \\
\text { la norma de } \\
\text { exceso de } \\
\text { endeudamiento }\end{array}$ & $\begin{array}{l}\text { Se exime de impuesto a los intereses provenientes de } \\
\text { créditos a instituciones financieras constituidas en el país } \\
\text { cuando tales recursos son utilizados para otorgar un } \\
\text { crédito al exterior }\end{array}$ \\
\hline
\end{tabular}

Fuente: CIAT (2013). 


\section{CUADRO A.6}

CHILE: TRATAMIENTO TRIBUTARIO DE LOS DIVIDENDOS

\begin{tabular}{|c|c|c|c|}
\hline Tipo de contribuyente & Impuesto & Alícuota & Franquicias tributarias \\
\hline Personas jurídicas & $\begin{array}{l}\text { No pagan impuesto por los } \\
\text { dividendos percibidos de SA } \\
\text { constituidas en el país }\end{array}$ & $\begin{array}{l}17 \% \text { entre } 2004 \text { y } 2010 ; \\
20 \% \text { en } 2011 ; 18,5 \% \text { en } 2 \\
2012 ; 17 \% \text { en } 2013 \\
\text { y siguientes }\end{array}$ & $\begin{array}{l}\text { Crédito por los impuestos } \\
\text { pagados o retenidos en el } \\
\text { extranjero por dividendos } \\
\text { percibidos por el dominio, } \\
\text { posesión o tenencia a } \\
\text { cualquier título de } \\
\text { acciones de SA } \\
\text { constituidas en el } \\
\text { extranjero }\end{array}$ \\
\hline Personas naturales & $\begin{array}{l}\text { Afectas al impuesto global } \\
\text { complementario por las } \\
\text { cantidades distribuidas a } \\
\text { cualquier título por las SA }\end{array}$ & $\begin{array}{l}\text { Alícuota de estructura } \\
\text { progresiva con un rango de } \\
0 \% \text { a } 40 \%\end{array}$ & $\begin{array}{l}\text { Permite rebajar el } \\
\text { impuesto de primera } \\
\text { categoría pagado por } \\
\text { la SA }\end{array}$ \\
\hline $\begin{array}{l}\text { Contribuyentes sin } \\
\text { domicilio o residencia }\end{array}$ & $\begin{array}{l}\text { Afectos al impuesto } \\
\text { adicional por las cantidades } \\
\text { distribuidas a cualquier título } \\
\text { por las SA }\end{array}$ & $35 \%$ & $\begin{array}{l}\text { Permite rebajar el } \\
\text { impuesto de primera } \\
\text { categoría pagado por } \\
\text { la SA }\end{array}$ \\
\hline
\end{tabular}

Fuente: CIAT (2013).

\section{CUADRO A.7 \\ CHILE: TRATAMIENTO TRIBUTARIO DE LOS RENDIMIENTOS EN VEHÍCULOS DE INVERSIÓN COLECTIVA}

\begin{tabular}{|c|c|c|c|c|}
\hline $\begin{array}{l}\text { Tipo de vehículo } \\
\text { de inversión }\end{array}$ & Tipo de renta & Impuesto & Alícuota & $\begin{array}{l}\text { Franquicias tributarias } \\
\text { o rebajas }\end{array}$ \\
\hline \multirow[t]{3}{*}{$\begin{array}{l}\text { Fondos de } \\
\text { inversión }\end{array}$} & $\begin{array}{l}\text { Los beneficios } \\
\text { distribuidos a sus } \\
\text { aportantes tributan de } \\
\text { igual forma que los } \\
\text { dividendos de } \\
\text { sociedades anónimas }\end{array}$ & $\begin{array}{l}\text { Global Complementario o } \\
\text { Adicional dependiendo de si el } \\
\text { inversionista tiene domicilio o } \\
\text { residencia en Chile o no }\end{array}$ & $\begin{array}{l}\text { Alícuota de estructura } \\
\text { progresiva con un } \\
\text { rango de } 0 \% \text { a } 40 \% \\
\text { tratándose de } \\
\text { Impuesto Global } \\
\text { complementario o } \\
35 \% \text { si se trata del } \\
\text { impuesto adicional }\end{array}$ & $\begin{array}{l}\text { Pueden rebajar el } \\
\text { crédito del impuesto de } \\
\text { primera categoría } \\
\text { según la proporción de } \\
\text { los ingresos afectos a } \\
\text { nivel del fondo de } \\
\text { inversión a ese } \\
\text { impuesto en relación a } \\
\text { la totalidad de los } \\
\text { ingresos percibidos }\end{array}$ \\
\hline & $\begin{array}{l}\text { Gastos rechazados } \\
\text { siguen la misma } \\
\text { tributación que } \\
\text { en las SA }\end{array}$ & Impuesto Único & $35 \%$ & \\
\hline & $\begin{array}{l}\text { Ganancias de capital } \\
\text { por las cuotas de } \\
\text { participación en } \\
\text { el fondo }\end{array}$ & $\begin{array}{l}\text { Exentas de impuesto si son } \\
\text { enajenadas en una bolsa de } \\
\text { valores autorizada por la SVS } \\
\text { y el fondo de inversión tiene } \\
\text { presencia bursátil }\end{array}$ & & \\
\hline \multirow[t]{2}{*}{ Fondos mutuos } & $\begin{array}{l}\text { Los beneficios } \\
\text { distribuidos a sus } \\
\text { aportantes tributan de } \\
\text { igual forma que los } \\
\text { dividendos de } \\
\text { sociedades anónimas }\end{array}$ & $\begin{array}{l}\text { Global Complementario o } \\
\text { Adicional dependiendo de si el } \\
\text { inversionista tiene domicilio o } \\
\text { residencia en Chile o no }\end{array}$ & $\begin{array}{l}\text { Alícuota de estructura } \\
\text { progresiva con un } \\
\text { rango de } 0 \% \text { a } 40 \% \\
\text { tratándose de } \\
\text { Impuesto Global } \\
\text { complementario o } \\
35 \% \text { si se trata del } \\
\text { impuesto adicional }\end{array}$ & $\begin{array}{l}\text { Pueden rebajar el } \\
\text { crédito del impuesto de } \\
\text { primera categoría } \\
\text { según la proporción del } \\
\text { crédito puesto a } \\
\text { disposición del fondo } \\
\text { por los dividendos de } \\
\text { SA percibidos }\end{array}$ \\
\hline & $\begin{array}{l}\text { Ganancias de capital } \\
\text { por las cuotas de } \\
\text { participación } \\
\text { en el fondo }\end{array}$ & $\begin{array}{l}\text { Exento de impuesto el mayor } \\
\text { valor en la enajenación de } \\
\text { cuotas de fondos mutuos } \\
\text { cuyas inversiones } \\
\text { consistan en valores con } \\
\text { presencia bursátil }\end{array}$ & & \\
\hline
\end{tabular}

Fuente: CIAT (2013). 


\section{CUADRO A.8}

ARGENTINA: TRATAMIENTO DE LOS PRINCIPALES TIPOS DE RENTAS FINANCIERAS OBTENIDAS EN EL PAÍS SEGÚN EL SUJETO QUE LAS OBTIENE

\begin{tabular}{|c|c|c|c|c|}
\hline Inversión & Resultado & $\begin{array}{l}\text { Persona Física } \\
\text { Argentina }\end{array}$ & Sociedad Argentina & $\begin{array}{l}\text { Beneficiario del } \\
\text { exterior }\end{array}$ \\
\hline $\begin{array}{l}\text { Colocaciones en Bancos } \\
\text { argentinos }\end{array}$ & Interés & Exento & Gravado & $\begin{array}{l}\text { Exento (los intereses } \\
\text { están exentos en la } \\
\text { medida en que no } \\
\text { exista transferencia de } \\
\text { fondos a fiscos } \\
\text { extranjeros) }\end{array}$ \\
\hline \multirow{2}{*}{$\begin{array}{l}\text { Acciones de sociedades } \\
\text { argentinas }\end{array}$} & Dividendo & No computable & No computable & Exento \\
\hline & Resultado por la venta & Exento & Gravado & Exento \\
\hline \multirow{2}{*}{$\begin{array}{l}\text { Títulos Públicos } \\
\text { argentinos }\end{array}$} & Renta & Exenta & Gravada & Exenta \\
\hline & Resultado por la venta & Exento & Gravado & Exento \\
\hline \multirow{2}{*}{$\begin{array}{l}\text { Obligaciones } \\
\text { negociables de } \\
\text { sociedades argentinas } \\
\text { con oferta pública }\end{array}$} & Interés & Exento & Gravado & Exento \\
\hline & Resultado por la venta & Exento & Gravado & Exento \\
\hline \multirow{2}{*}{$\begin{array}{l}\mathrm{FCl} \text { abiertos - Cuotas } \\
\text { partes con oferta pública }\end{array}$} & Renta & Exenta & No computable & Exenta \\
\hline & Resultado por la venta & Exento & Gravado & Exento \\
\hline \multirow{2}{*}{$\begin{array}{l}\mathrm{FCl} \text { cerrados - Cuotas } \\
\text { partes con oferta pública }\end{array}$} & Renta & Exenta & Gravada & Exenta \\
\hline & Resultado por la venta & Exento & Gravado & Exento \\
\hline \multirow{2}{*}{$\begin{array}{l}\text { Fideicomiso Financiero - } \\
\text { Certificados de } \\
\text { participación con oferta } \\
\text { pública }\end{array}$} & Renta & Exento & No computable & Exento \\
\hline & Resultado por la venta & Exento & Gravado & Exento \\
\hline \multirow{2}{*}{$\begin{array}{l}\text { Fideicomiso } \\
\text { Financiamiento Títulos } \\
\text { de deuda }\end{array}$} & Interés & Exento & Gravada & Exento \\
\hline & Resultado por la venta & Exento & Gravado & Exento \\
\hline
\end{tabular}

Fuente: CIAT (2013).

Nota: A partir del 13 de septiembre del 2013, el Congreso aprobó una modificación de la ley del impuesto a la renta que grava con una tasa de $10 \%$ a la distribución de dividendos y con una alícuota del $15 \%$ al resultado de la compraventa de acciones no cotizantes. La ley aún no ha sido sancionada por el Poder Ejecutivo. 


\section{URUGUAY: TRATAMIENTO DE LOS PRINCIPALES TIPOS DE RENTAS DEL CAPITAL}

\begin{tabular}{|c|c|c|}
\hline Tipo de renta & Concepto específico & Alícuota \\
\hline \multirow[t]{3}{*}{ Intereses } & $\begin{array}{l}\text { Intereses correspondientes a depósitos en moneda nacional y en unidades } \\
\text { indexadas, a más de un año, en instituciones de intermediación financiera } \\
\text { de plaza. }\end{array}$ & $3 \%$ \\
\hline & $\begin{array}{l}\text { Intereses de obligaciones y otros títulos de deuda, emitidos por entidades } \\
\text { residentes a plazos mayores a tres años, mediante suscripción pública y } \\
\text { cotización bursátil en entidades nacionales. }\end{array}$ & $3 \%$ \\
\hline & $\begin{array}{l}\text { Intereses correspondientes a los depósitos en instituciones de plaza, a un año o } \\
\text { menos, constituidos en moneda nacional sin cláusula de reajuste. }\end{array}$ & $5 \%$ \\
\hline \multirow[t]{2}{*}{ Dividendos } & $\begin{array}{l}\text { Dividendos o utilidades pagados o acreditados por contribuyentes del IRAE } \\
\text { originados en los rendimientos comprendidos en el apartado ii) del literal C) del } \\
\text { artículo } 27 \text { de la Ley. }\end{array}$ & $12 \%$ \\
\hline & $\begin{array}{l}\text { Otros dividendos o utilidades pagados o acreditados por contribuyentes } \\
\text { del IRAE. }\end{array}$ & $7 \%$ \\
\hline \multirow[t]{3}{*}{ Otras rentas } & $\begin{array}{l}\text { Rendimientos derivados de derechos de autor sobre obras literarias, artísticas y } \\
\text { o Científicas } 7 \% \text {. }\end{array}$ & $7 \%$ \\
\hline & $\begin{array}{l}\text { Rentas de certificados de participación emitidos por fideicomisos financieros } \\
\text { mediante suscripción pública y cotización bursátil en entidades nacionales, a } \\
\text { plazos de más de } 3 \text { años. }\end{array}$ & $3 \%$ \\
\hline & Restantes rentas. & $12 \%$ \\
\hline \multirow[t]{3}{*}{ Exenciones } & $\begin{array}{l}\text { A. Los intereses de los títulos de deuda pública, así como cualquier otro } \\
\text { rendimiento de capital o incremento patrimonial, derivados de la tenencia o } \\
\text { transferencia de dichos instrumentos. }\end{array}$ & $0 \%$ \\
\hline & B. Los resultados obtenidos en los Fondos de Ahorro Previsional. & \\
\hline & $\begin{array}{l}\text { C. Los dividendos y utilidades distribuidos por entidades residentes y } \\
\text { establecimientos permanentes, derivados de la tenencia de participaciones de } \\
\text { capital, con excepción de los pagados o acreditados por los contribuyentes del } \\
\text { IRAE, ya sea por rentas gravadas por dicho tributo o por rendimientos del capital } \\
\text { mobiliario, originados en depósitos, préstamos, y en general en toda colocación } \\
\text { de capital o de crédito de cualquier naturaleza, en tanto tales rendimientos } \\
\text { provengan de entidades no residentes y constituyan rentas pasivas. }\end{array}$ & \\
\hline
\end{tabular}

Fuente: Elaboración propia en base a CIAT (2013). 


\section{TRATAMIENTO DE LOS PRINCIPALES TIPOS DE RENTAS FINANCIERAS SELECCIONADAS, LOS CASOS DE ECUADOR, MÉXICO Y PERÚ}

\begin{tabular}{|c|c|c|c|}
\hline \multirow{2}{*}{ Fuente de renta } & \multicolumn{3}{|c|}{ Países } \\
\hline & Ecuador & México & Perú \\
\hline $\begin{array}{l}\text { Intereses } \\
\text { percibidos }\end{array}$ & $\begin{array}{l}\text { Existe un tratamiento } \\
\text { diferenciado si los intereses } \\
\text { son percibidos en cuentas } \\
\text { corrientes o en cuentas de } \\
\text { ahorro y si el perceptor es una } \\
\text { persona natural o una } \\
\text { sociedad. Se consideran } \\
\text { rentas exentas los intereses } \\
\text { percibidos por personas } \\
\text { naturales por sus depósitos de } \\
\text { ahorro a la vista pagados por } \\
\text { entidades del sistema } \\
\text { financiero del país. Los } \\
\text { intereses en depósitos a plazo } \\
\text { fijo pagados por las } \\
\text { instituciones financieras } \\
\text { nacionales a personas } \\
\text { naturales y sociedades que } \\
\text { hayan sido emitidos a un } \\
\text { plazo de un año o más }\end{array}$ & $\begin{array}{l}\text { En el caso de las personas } \\
\text { morales son ingresos acumulables } \\
\text { los intereses nominales } \\
\text { devengados en el ejercicio a } \\
\text { través de instituciones del sistema } \\
\text { financiero. Estas tendrán la } \\
\text { obligación de realizar la retención } \\
\text { mensual del ISR calculando la } \\
\text { tasa del } 0,6 \% \text { al monto del capital } \\
\text { que dé lugar al pago de intereses. } \\
\text { En el caso de las personas físicas } \\
\text { las instituciones que paguen los } \\
\text { intereses están obligadas a } \\
\text { retener y enterar el impuesto } \\
\text { aplicando la tasa del } 0,6 \% \text { sobre } \\
\text { el monto del capital que dé lugar } \\
\text { al pago de intereses }\end{array}$ & $\begin{array}{l}\text { Los intereses que se } \\
\text { perciban de cuentas en el } \\
\text { Sistema Financiero están } \\
\text { exonerados del pago del } \\
\text { impuesto a la Renta excepto } \\
\text { cuando dichos ingresos. } \\
\text { Independientemente de la } \\
\text { condición de domicilio de } \\
\text { quién perciba los intereses, } \\
\text { la renta estará exonerada } \\
\text { siempre que quien la } \\
\text { percibe no desarrolle } \\
\text { actividad empresarial o } \\
\text { constituyen para su } \\
\text { perceptor renta de la } \\
\text { tercera categoría } \\
\text { (renta empresarial) }\end{array}$ \\
\hline Dividendos & $\begin{array}{l}\text { Están exentos de impuesto a } \\
\text { la renta los dividendos y } \\
\text { utilidades distribuidos o } \\
\text { sociedades nacionales o } \\
\text { extranjeras residentes en el } \\
\text { Ecuador, a favor de otras } \\
\text { sociedades nacionales o } \\
\text { extranjeras no domiciliadas en } \\
\text { paraísos fiscales o } \\
\text { jurisdicciones me menor } \\
\text { imposición o de personas } \\
\text { naturales no residentes } \\
\text { en Ecuador }\end{array}$ & $\begin{array}{l}\text { Las personas morales que } \\
\text { distribuyan dividendos calcularán } \\
\text { el impuesto sobre la renta } \\
\text { correspondiente, aplicando a la } \\
\text { suma del monto de los dividendos, } \\
\text { más el impuesto sobre la renta } \\
\text { que se deba pagar por los } \\
\text { mismos, la tasa del 30\%. Las } \\
\text { personas físicas deberán } \\
\text { acumular a sus demás ingresos } \\
\text { los percibidos por dividendos y } \\
\text { utilidades y aplicar sobre ellos la } \\
\text { tasa progresiva establecida por la } \\
\text { ley. Dichas personas físicas } \\
\text { podrán acreditar contra el } \\
\text { impuesto que se determine en su } \\
\text { declaración anual, el ISR pagado } \\
\text { por la sociedad que distribuyó los } \\
\text { dividendos o utilidades, siempre } \\
\text { que quien efectúe el } \\
\text { acreditamiento considere como } \\
\text { ingreso acumulable, además del } \\
\text { dividendo o utilidad percibido, el } \\
\text { monto del ISR pagado por dicha } \\
\text { sociedad correspondiente al } \\
\text { dividendo o utilidad percibido }\end{array}$ & $\begin{array}{l}\text { Los dividendos y cualquier } \\
\text { otra forma de distribución de } \\
\text { utilidades son considerados } \\
\text { renta de la segunda } \\
\text { categoría para efectos del } \\
\text { impuesto a la Renta y están } \\
\text { gravados con una tasa del } \\
4,1 \% \text {. Las personas } \\
\text { jurídicas que efectuarán la } \\
\text { distribución deben retener el } \\
4,1 \% \text { de los dividendos y } \\
\text { cualquier otra forma de } \\
\text { distribución de utilidades } \\
\text { excepto cuando la } \\
\text { distribución se efectúa a } \\
\text { favor de una persona } \\
\text { jurídica domiciliada. Cuando } \\
\text { la persona jurídica acuerda } \\
\text { la distribución de utilidades } \\
\text { en especie, el pago del } \\
4,1 \% \text { debe ser efectuado } \\
\text { por ella y reembolsado por } \\
\text { el beneficiario de } \\
\text { la distribución }\end{array}$ \\
\hline
\end{tabular}

Fuente: Elaboración propia en base a CIAT (2013). 


\section{CUADRO A.11 \\ PRINCIPALES REFORMAS DEL IMPUESTO SOBRE LA RENTA, PAÍSES DE AMÉRICA DEL SUR}

\begin{tabular}{|c|c|c|c|c|c|}
\hline $\begin{array}{l}\text { Países y años de } \\
\text { las reformas }\end{array}$ & $\begin{array}{l}\text { Cambio en } \\
\text { alícuotas }\end{array}$ & $\begin{array}{l}\text { Ampliación de la } \\
\text { base imponible }\end{array}$ & $\begin{array}{l}\text { Reducción de la } \\
\text { base imponible }\end{array}$ & Impuesto mínimo & $\begin{array}{l}\text { Tributación } \\
\text { internacional }\end{array}$ \\
\hline $\begin{array}{l}\text { Bolivia (Estado } \\
\text { Plurinacional de) } \\
2007\end{array}$ & $\begin{array}{l}\text { IRE: alícuota } \\
\text { adicional para la } \\
\text { minería }(12,5 \%)\end{array}$ & $\begin{array}{l}\text { La base imponible } \\
\text { se expresa en } \\
\text { Unidad de Fomento } \\
\text { de Vivienda (UFV), } \\
\text { no en dólares }\end{array}$ & $\begin{array}{l}\text { Regalía minera } \\
\text { acreditable al } \\
\text { impuesto sobre las } \\
\text { utilidades de las } \\
\text { empresas (si } \\
\text { precios bajos) }\end{array}$ & & \\
\hline Chile (2012) & $\begin{array}{l}\text { IRE: } 20 \% \text { (aumento } \\
\text { permanente) } \\
\text { IRP: rebaja de } \\
\text { tasas marginales, } \\
\text { excepto en } \\
\text { tramo superior }\end{array}$ & & $\begin{array}{l}\text { Crédito tributario } \\
\text { por gasto en } \\
\text { educación (hasta } \\
\text { cierto monto) }\end{array}$ & & $\begin{array}{l}\text { Adecuación de } \\
\text { normas de PT; } \\
\text { eliminación del } \\
\text { impuesto sobre la } \\
\text { renta de servicios } \\
\text { realizados en Chile } \\
\text { por chilenos que } \\
\text { viven en el } \\
\text { extranjero; } \\
\text { exención del } \\
\text { impuesto adicional } \\
\text { a pagos al exterior } \\
\text { por software }\end{array}$ \\
\hline Colombia (2012) & $\begin{array}{l}\text { IRE: del } 33 \% \text { al } \\
25 \% \text {, nuevo } \\
\text { impuesto (CREE) } \\
\text { con tasa del } 9 \% \\
\text { (del } 8 \% \text { desde } \\
2015 \text { ) }\end{array}$ & & & $\begin{array}{l}\text { Impuesto mínimo } \\
\text { alternativo } \\
\text { nacional e } \\
\text { impuesto mínimo } \\
\text { alternativo simple }\end{array}$ & $\begin{array}{l}\text { Adecuación de } \\
\text { normas de PT }\end{array}$ \\
\hline $\begin{array}{l}\text { Ecuador (2007, } \\
2010-2012)\end{array}$ & $\begin{array}{l}\text { IRP: del } 25 \% \text { al } \\
35 \% \text { (tasa máxima } \\
\text { y nuevos tramos) } \\
\text { IRE: del } 25 \% \text { al } \\
22 \% \text { (en } 2013 \text { ) }\end{array}$ & $\begin{array}{l}\text { Eliminación de } \\
\text { tarifa reducida a } \\
\text { instituciones } \\
\text { financieras }\end{array}$ & $\begin{array}{l}\text { Exoneración a } \\
\text { ciertas inversiones } \\
\text { nuevas; } \\
\text { deducciones } \\
\text { adicionales por } \\
\text { nuevos } \\
\text { trabajadores y por } \\
\text { adquisición } \\
\text { de vehículos }\end{array}$ & $\begin{array}{l}\text { Nuevo impuesto } \\
\text { único sobre la } \\
\text { renta para la } \\
\text { actividad } \\
\text { productiva del } \\
\text { banano (un } 2 \% \\
\text { sobre ventas } \\
\text { brutas) }\end{array}$ & \\
\hline Paraguay (2012) & & $\begin{array}{l}\text { Nuevo IRP: tasas } \\
\text { del } 10 \% \text { y el } 8 \%\end{array}$ & & & \\
\hline Perú $(2007,2012)$ & & $\begin{array}{l}\text { Eliminación de } \\
\text { exoneraciones a } \\
\text { intereses y } \\
\text { ganancias de } \\
\text { capital; ampliación } \\
\text { del gravamen } \\
\text { a dividendos }\end{array}$ & & & $\begin{array}{l}\text { Adecuación de } \\
\text { normas de PT; } \\
\text { nuevas normas } \\
\text { sobre sociedades } \\
\text { extranjeras } \\
\text { controladas }\end{array}$ \\
\hline $\begin{array}{l}\text { Uruguay } \\
(2007,2012)\end{array}$ & $\begin{array}{l}\text { IRP: del } 25 \% \text { al } \\
30 \% \text { (tasa máxima) }\end{array}$ & $\begin{array}{l}\text { Rentas del trabajo: } \\
\text { tasas progresivas; } \\
\text { rentas de capital: } \\
\text { tasa proporcional }\end{array}$ & & & \\
\hline $\begin{array}{l}\text { México (2007, } \\
2010-2012)\end{array}$ & $\begin{array}{l}\text { IRE: del } 28 \% \text { al } \\
30 \% \text { (de carácter } \\
\text { temporal, } \\
\text { disminuirá al } 28 \% \\
\text { entre } 2014 \text { y } 2015 \text { ) }\end{array}$ & & $\begin{array}{l}\text { En el impuesto a la } \\
\text { renta se permitió } \\
\text { deducir el gasto en } \\
\text { educación con un } \\
\text { monto máximo que } \\
\text { depende del } \\
\text { nivel educativo }\end{array}$ & $\begin{array}{l}\text { Impuesto } \\
\text { Empresarial a } \\
\text { Tasa Única } \\
(17,5 \%)\end{array}$ & \\
\hline
\end{tabular}

Fuente: CEPAL (2013). 


\section{CUADRO A.12}

\section{PRINCIPALES REFORMAS DEL IMPUESTO SOBRE LA RENTA, CENTROAMÉRICA Y REPÚBLICA DOMINICANA}

\begin{tabular}{|c|c|c|c|c|c|}
\hline $\begin{array}{l}\text { Países y años de } \\
\text { las reformas }\end{array}$ & $\begin{array}{l}\text { Cambio en } \\
\text { alícuotas }\end{array}$ & $\begin{array}{l}\text { Ampliación de la } \\
\text { base imponible }\end{array}$ & $\begin{array}{l}\text { Reducción de la } \\
\text { base imponible }\end{array}$ & Impuesto mínimo & $\begin{array}{l}\text { Tributación } \\
\text { internacional }\end{array}$ \\
\hline $\begin{array}{l}\text { El Salvador } \\
(2009,2011)\end{array}$ & $\begin{array}{l}\text { IRP: del } 25 \% \text { al } \\
30 \% \text { (tasa efectiva, } \\
\text { último tramo) } \\
\text { IRE: del } 25 \% \text { al } \\
30 \% \text { (tasa máxima) }\end{array}$ & $\begin{array}{l}\text { Límite a } \\
\text { exenciones de } \\
\text { intereses y } \\
\text { ganancias de } \\
\text { capital; eliminación } \\
\text { de exención de } \\
\text { títulos valores; } \\
\text { límite a } \\
\text { deducciones } \\
\text { personales; } \\
\text { distribución de } \\
\text { utilidades (5\%) }\end{array}$ & $\begin{array}{l}\text { IRP: aumento del } \\
\text { mínimo exento y } \\
\text { modificación } \\
\text { de tramos }\end{array}$ & $\begin{array}{l}\text { Nuevo impuesto } \\
\text { mínimo (un } 1 \% \\
\text { sobre renta bruta) }\end{array}$ & $\begin{array}{l}\text { Impuesto sobre la } \\
\text { renta de no } \\
\text { domiciliados (del } \\
25 \% \text { al } 30 \% \text { ); } \\
\text { adecuación de } \\
\text { normas de PT; } \\
\text { reglas de } \\
\text { subcapitalización }\end{array}$ \\
\hline $\begin{array}{l}\text { Guatemala } \\
(2009,2012)\end{array}$ & $\begin{array}{l}\text { IRE: del } 31 \% \text { al } \\
25 \% \\
\text { IRP: del } 15 \% \text { al } \\
31 \% \text { al } 5 \% \text { al } 7 \% \\
\text { (reducción en } \\
\text { tasas y tramos) }\end{array}$ & $\begin{array}{l}\text { Renta y ganancia } \\
\text { de capital (un } 10 \% \text {, } \\
\text { salvo dividendos al } \\
5 \% \text { ); eliminación } \\
\text { del crédito por IVA } \\
\text { a asalariados; } \\
\text { nueva normativa } \\
\text { para costos y } \\
\text { gastos deducibles }\end{array}$ & $\begin{array}{l}\text { IRP: aumento del } \\
\text { mínimo exento } \\
\text { asalariado }\end{array}$ & $\begin{array}{l}\text { Creación del } \\
\text { impuesto de } \\
\text { solidaridad }\end{array}$ & $\begin{array}{l}\text { Adecuación de } \\
\text { normas de } \mathrm{PT} \text {; } \\
\text { tasas para no } \\
\text { residentes (del } 3 \% \text {, } \\
\text { el } 5 \% \text {, el } 10 \% \text {, el } \\
15 \% \text { y el } 25 \% \text { ) }\end{array}$ \\
\hline $\begin{array}{l}\text { Honduras (2010, } \\
2011,2012)\end{array}$ & $\begin{array}{l}\text { Aportación } \\
\text { solidaria temporal: } \\
\text { del } 5 \% \text { al } 10 \% \\
\text { (hasta } 2015) ; \\
\text { ciertos rubros } \\
\text { (bienes muebles o } \\
\text { inmuebles, } \\
\text { minería, regalías): } \\
\text { del } 10 \% \text { al } 25 \%\end{array}$ & $\begin{array}{l}\text { Dividendos, } \\
\text { ganancias de } \\
\text { capital, alquileres y } \\
\text { excedentes de } \\
\text { instituciones } \\
\text { educativas: } 10 \% \text {; } \\
\text { condiciones para } \\
\text { deducciones }\end{array}$ & $\begin{array}{l}\text { IRP: aumento del } \\
\text { mínimo exento }\end{array}$ & & $\begin{array}{l}\text { Regulación de PT; } \\
\text { nivelación de tasas } \\
\text { de no domiciliados: } \\
10 \%\end{array}$ \\
\hline $\begin{array}{l}\text { Nicaragua } \\
(2010,2012)\end{array}$ & & $\begin{array}{l}\text { Dividendos e } \\
\text { intereses: } 10 \% \text {; } \\
\text { nueva clasificación } \\
\text { de rentas } \\
\text { gravables (trabajo, } \\
\text { actividades } \\
\text { económicas, } \\
\text { capital y demás) }\end{array}$ & $\begin{array}{l}\text { IRP: aumento del } \\
\text { mínimo exento }\end{array}$ & $\begin{array}{l}\text { Modificación de } \\
\text { base para } \\
\text { entidades } \\
\text { bancarias: } \\
\text { sustituye el total } \\
\text { de depósitos } \\
\text { por ingresos } \\
\text { brutos (1\%) }\end{array}$ & \\
\hline $\begin{array}{l}\text { Panamá (2009, } \\
2010,2012)\end{array}$ & $\begin{array}{l}\text { IRE: del } 27,5 \% \text { al } \\
25 \% \text { y del } 30 \% \text { al } \\
25 \% \text { para ciertos } \\
\text { sectores } \\
\text { IRP: del } 7 \% \text { al } 27 \% \\
\text { al } 15 \% \text { al } 25 \% \\
\text { (reducción en } \\
\text { tasas y tramos) }\end{array}$ & $\begin{array}{l}\text { Dividendos: } 10 \% \\
\text { (en regímenes } \\
\text { especiales: } 5 \% \text { ), } \\
\text { derogación de } \\
\text { gastos deducibles } \\
\text { y reducción de } \\
\text { deducciones } \\
\text { del IRP }\end{array}$ & $\begin{array}{l}\text { IRP: aumento } \\
\text { mínimo exento; } \\
\text { exoneración del } \\
\text { impuesto sobre la } \\
\text { renta para } \\
\text { actividades } \\
\text { agropecua-rias o } \\
\text { agroindus-triales } \\
\text { con cierto nivel de } \\
\text { ingreso }\end{array}$ & & \\
\hline $\begin{array}{l}\text { República } \\
\text { Dominicana } \\
(2012)\end{array}$ & $\begin{array}{l}\text { IRE: del } 29 \% \text { al } \\
27 \%(2013-2015)\end{array}$ & $\begin{array}{l}\text { Gravamen sobre } \\
\text { dividendos } \\
\text { (incluidas zonas } \\
\text { francas) e } \\
\text { intereses de } \\
\text { residentes: } 10 \% ; \\
\text { límite a deducción } \\
\text { de intereses y } \\
\text { gastos educativos }\end{array}$ & $\begin{array}{l}\text { IRP: aumento } \\
\text { mínimo exento }\end{array}$ & & \\
\hline
\end{tabular}

Fuente: CEPAL (2013). 


\title{
Serie
}

\section{¿ E P A L Estudios y Perspectivas - Montevideo}

\section{Números publicados}

\author{
Un listado completo así como los archivos pdf están disponibles en \\ www.cepal.org/publicaciones \\ www.cepal.org/uruguay
}

13. La tributación sobre las altas rentas en América Latina, Juan Carlos Gómez Sabaíni y Darío Rossignolo, (LC/L.3760; LC/MVD/L.43, 2014.

12. Negociación salarial colectiva: revisión de la literatura y de la experiencia en Uruguay 2005-2006, Verónica Amarante y Marisa Bucheli, (LC/L.3297-P; LC/MVD/L.42, N de venta: S.11.II.G.18 (U\$S 10), 2011.

11. Zonas Francas en Uruguay: actividad económica, comercio exterior y plataforma para la exportación de servicios, Marcel Vaillant y Álvaro Lalanne, (LC/L.3183-P; LC/MVD/L.41, N de venta: S.10.II.G.16 (U\$S 10), 2010.

10. El gasto en servicios de cuidado de los hogares uruguayos, Soledad Salvador y Gabriela Pradere, (LC/L.3182-P; LC/MVD/L.40, N de venta: S.10.II.G.15 (U\$S 10), 2010.

9. Reformas en Uruguay: una mirada desde la perspectiva de género, Sandra Rodríguez e Ivonne Perazzo, (LC/L.3181-P; LC/MVD/L39), $\mathrm{N}^{\circ}$ de venta: S.10.II.G.14 (U\$S 10), 2010.

8. El Tercer Sector en la promoción de las capacidades y emprendimientos productivos en Uruguay, Pascual Gerstenfeld y Álvaro Fuentes, (LC/L 2835-P; LC/MVD/L38), N de venta S.07.II.G.157 (U\$S 10), 2007.

7. El Tercer Sector en las políticas de formación de capital humano en Uruguay al 2005, Pascual Gerstenfeld y Álvaro Fuentes, (LC/L2834-P; LC/MVD/L37), º de venta S.03.II.G.156 (U\$S 10), 2007.

6. Mercado de trabajo juvenil: situación y políticas, Marisa Bucheli, (LC/L.2642-P; LC/MVD/L.36), $\mathrm{N}^{\circ}$ de venta S.06.II.G.168 (U\$S 10), 2006.

5. Los impactos del ALCA en el MERCOSUR: una revisión analítica de la literatura existente, Inés Terra, (LC/ 2494-P; LC/MVD/L.35), $\mathrm{N}^{\circ}$ de venta S.06.II.G.25 (US\$ 10), 2006.

4. El acceso a la jubilación o pensión en Uruguay: ¿cuántos y quiénes lo lograrían?, (LC/L.2487-P; LC/MVD/L.34), $\mathrm{N}^{\circ}$ de venta S.06.II.G.20 (US\$ 10), 2006.

3. Caracterización del Tercer Sector en las políticas de formación de capital humano en Uruguay, Pascual Gerstenfeld y Álvaro Fuentes, (LC/L.2415-P; LC/MVD/L.33), № de venta S.05.II.G.162 (US\$ 10), 2005.

2. Las políticas activas de mercado de trabajo: un panorama internacional de experiencias y evaluaciones, Marisa Bucheli, (LC/L2260-P; LC/MVD/L.32), Nº de venta S.05.II.G.50 (US\$ 10), 2005.

1. Uruguay 1998-2002: características de los cambios en el perfil de la distribución del ingreso, Marisa Bucheli y Magdalena Furtado, (LC/L.2162-P; LC/MVD/L.31), N de venta S.04.II.G.90 (US\$ 10), 2004. 


\section{3}
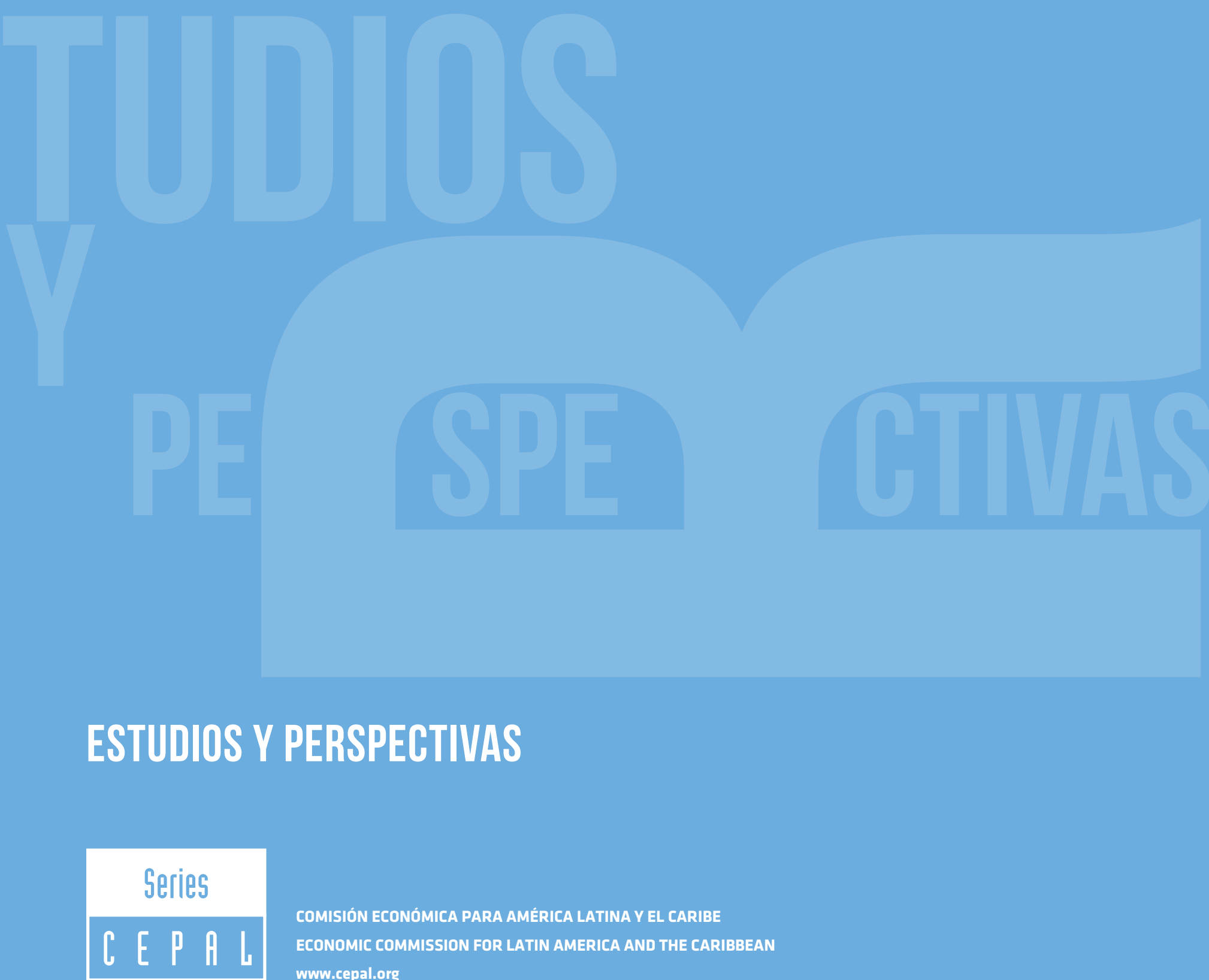

COMISIÓN ECONÓMICA PARA AMÉRICA LATINA Y EL CARIBE

ECONOMIC COMMISSION FOR LATIN AMERICA AND THE CARIBBEAN

www.cepal.org 